\title{
Sponge bioerosion and habitat degradation on Indonesian coral reefs
}

\author{
by
}

\author{
Joseph Marlow
}

A thesis submitted to Victoria University of Wellington in fulfilment of the requirements for the degree of Doctor of Philosophy

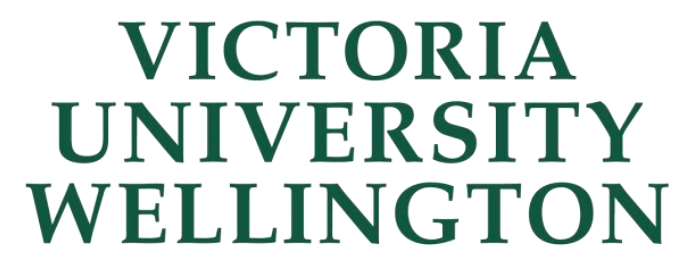

TE WHARE WĀNANGA

O TE ÜPOKO O TE IKA A MĀUI

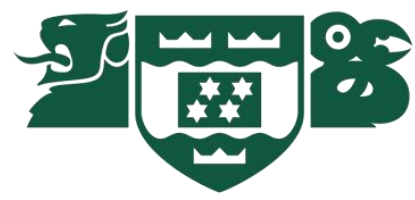




\section{Acknowledgments}

Firstly I would like to thank my primary supervisor, Associate Professor James Bell, for his unwavering support and advice these past three years. I feel very lucky to have had James as my supervisor, his help and guidance whether it was in the field, in the lab or in relation to the many many manuscript drafts I sent him has always been fantastic. I would also like to thank my secondary supervisor, Professor Simon Davy, in particular for his advice about Symbiodinium and photophysiology but also for his overall support and excellent feedback on manuscripts.

This research could not have happened without the funding and support from Operation Wallacea. I would like to thank in particular Pippa Mansell for her incredible management of the research station and thank both her and Chris Majors for all their support and help with my research. Thanks to all the Indonesian staff who kept me fed, in the water and made sure I always had a cold Bintang waiting for me at the end of the day.

I am incredibly grateful for the support and funding provided by VUW, without which I would not have been able to complete this $\mathrm{PhD}$. Thanks also to the PADI foundation which also provided research funding and Daniel LeDuc and Dennis Gordon at NIWA for their help and providing access to the SEM. Thank you to Hasanuddin University for facilitating this research.

I would like to thank Dr Christine Schönberg and Associate Professor Ken Ryan and Dr Clint Oakley for their time and help. Thank you Christine for revealing the world of spicules and sponge taxonomy to me and your incredibly helpful feedback for my manuscripts. Thank you Ken for your ever present open door so I could come and pick your brain about PAM flourometry. Thank you Clint for answering all my many questions on Symbiodinium.

Thanks to the amazing support group that is Sponge club, couldn't have done it without you guys. Special thanks to everyone who helped me survive Hoga; Andy Biggerstaff, Emily $\mathrm{M}^{\mathrm{C}}$ Grath, Charli Mortimer, Meg Shaffer (world's best RA), Tracey Bates and Holly Bennett.

Finally I would like to thank my friends and family without whose continuing support I could never have achieved any of this. 


\begin{abstract}
Coral reefs are among the most diverse ecosystems on the planet, yet they are also sensitive to anthropogenic disturbances that can degrade these systems. On many degraded reefs, large increases in bioeroding sponge abundance have occurred. On healthy reefs these sponges contribute to species diversity and habitat complexity, however there is growing concern that their proliferation on degraded reefs could lead to a state of net-erosion. In the Southeast Asian Indo-Pacific, the ecology of bioeroding sponges in relation to coral degradation has been poorly studied compared to other coral reef regions. This thesis aims to increase our understanding of the ecology of these sponges in the Wakatobi region of Indonesia, and their likely trajectory if reefs continue to degrade in the region.
\end{abstract}

My first research chapter aimed to identify the common bioeroding sponge species of the Wakatobi. This was achieved through in-water surveys, and subsequent spicule and phylogenetic analysis. This resulted in the identification of eight commonly occurring Wakatobi bioeroding sponge species, two of which are described for the first time. The assemblage composition was distinctly different from the only other bioeroding sponge study in Indonesian waters (Calcinai et al. 2005), highlighting the need for more clionaid taxonomic information from the region.

Having identified the common bioeroding sponge species in the region, my second chapter assessed the major environmental drivers of the abundance and assemblage composition of these sponges. Abundance surveys were conducted at 11 reef sites characterised by different environmental conditions and states of reef health. Bioeroding sponges occupied $8.9 \%$ of suitable substrate, and differences in abundance and assemblage composition were primarily attributed to differences in the availability of dead substrate. However, abundance was lowest at a sedimented and turbid reef, despite abundant dead substrate availability. This indicates a limited resilience in some species to conditions associated with terrestrial run-off and that not all forms of reef degradation are beneficial for bioeroding sponges. The capacity to increase spatial occupation of degraded reefs is also dependent upon larval recruitment and my third chapter was a two year recruitment study using in situ experimental calcareous blocks. Recruitment occurred rapidly and consistently with bioeroding sponges recruiting to approximately $70 \%$ of experimental blocks and exhibiting a preference for settlement on uncolonised dead calcareous substrates. The importance of substrate settlement cues and extent of larval dispersal appeared to 
differ between species, indicative of different recruitment mechanisms. Any significant increase in the availability of exposed calcareous substrate (e.g. following a mass coral bleaching event) is therefore likely to result in widespread increases in bioeroding sponge recruitment.

Surveys conducted in my second research chapter revealed that two of the three locally abundant zooxanthellate bioeroding species were absent from a highly turbid reef, Sampela. My fourth research chapter investigated whether this was due to light limitation by examining the photoacclimatory capabilities of the Symbiodinium photosymbionts of Cliona aff. viridis $\mathrm{n}$. sp. A. PAM chlorophyll fluorometry was employed in a 25 day shading experiment and Symbiodinium of $C$. aff. viridis n. sp. A demonstrated an ability to photoacclimate to extreme light reduction and recover quickly when conditions returned to normal. My results demonstrate that the absence of this species at Sampela is not due to light limitation but possibly due to other stressors associated with turbidity, e.g. suspended sediment.

My final chapter was an assessment of the environmental drivers of rates of bioerosion in Spheciospongia cf. vagabunda, a common species in the Wakatobi. Erosion rates were determined from changes in dry-weight of calcareous substrates with attached grafts of $S$. cf. vagabunda after a year deployment across seven reef sites. The average bioerosion rate was 12.0 $\mathrm{kg} \mathrm{m}^{-2}$ sponge tissue $\mathrm{yr}^{-1}( \pm 0.87 \mathrm{SE})$, but differed between sites and was negatively correlated with settled sediment depth. Bioerosion by this species can play a significant part in the carbonate budget on reefs where it is abundant (up to $20 \%$ of available substrate on some reefs in the Wakatobi) but is likely reduced on highly sedimented reefs.

In summary, the Wakatobi bioeroding sponge assemblage is diverse and overall, both adult abundance and recruitment are primarily driven by the availability of dead calcareous substrates. Therefore, further coral mortality and a subsequent rise in the availability of dead substrate in the region is likely to result in increased abundance of bioeroding sponges. However, not all forms of reef degradation will benefit these sponges; turbid and sedimented reefs will likely constitute stressful habitats for some bioeroding sponge species and assemblages in these environments will be comprised of fewer more resilient species. 


\section{Table of Contents}

Chapter 1: Introduction .................................................................................................................................... 17

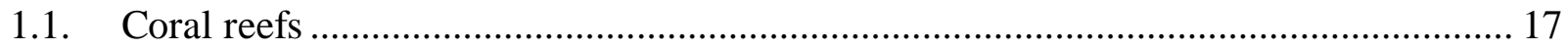

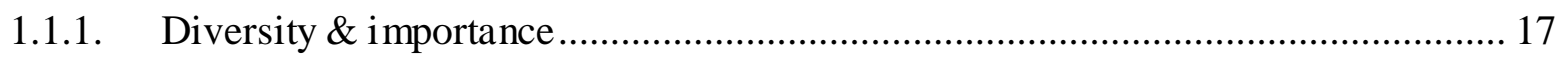

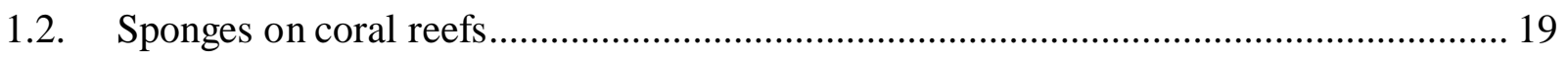

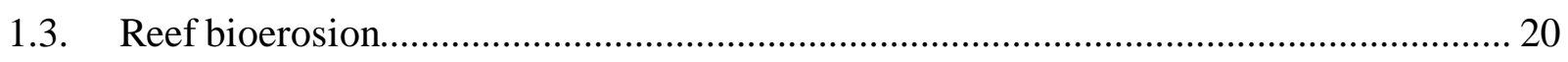

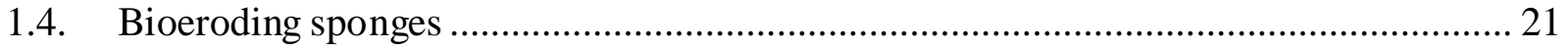

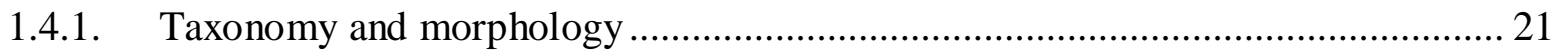

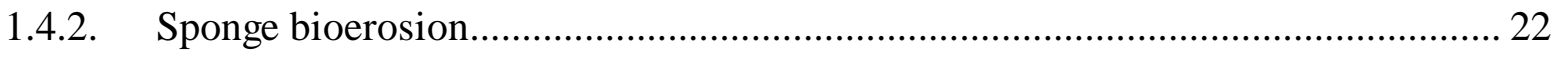

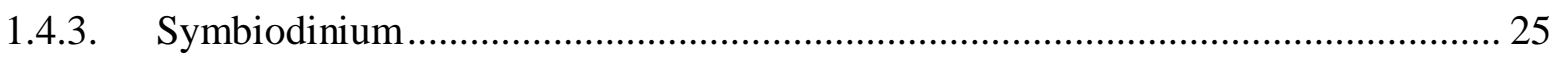

1.5. Bioeroding sponge abundance \& distribution ..................................................... 27

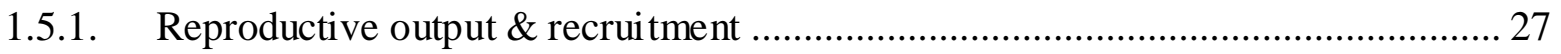

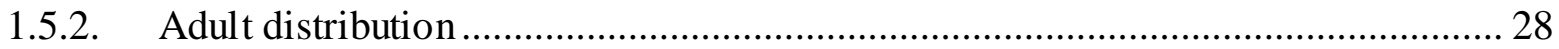

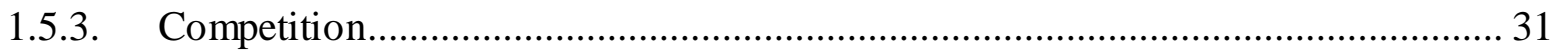

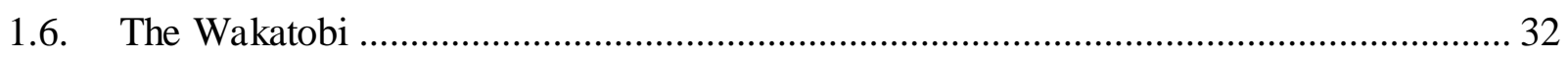

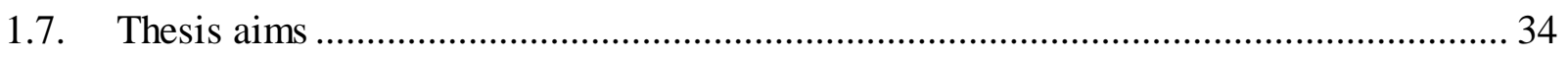

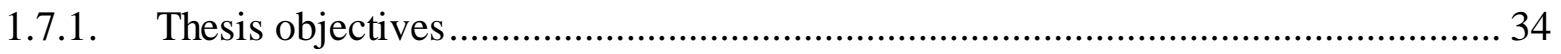

Chapter 2: Bioeroding Sponges from Wakatobi National Park, Southeast Sulawesi,

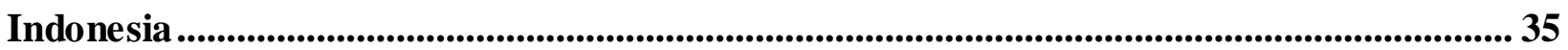

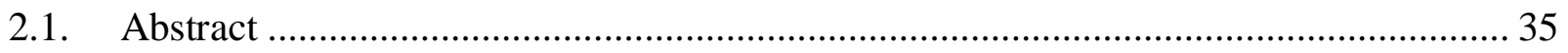

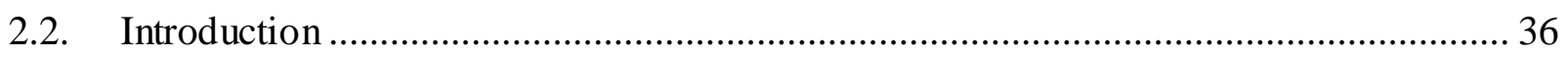

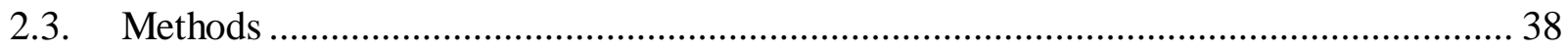

2.3.1. Sampling and morphological analysis ...................................................... 38

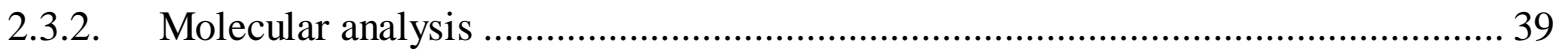

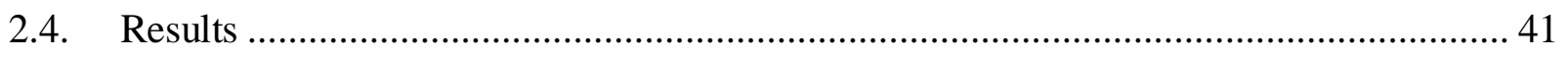

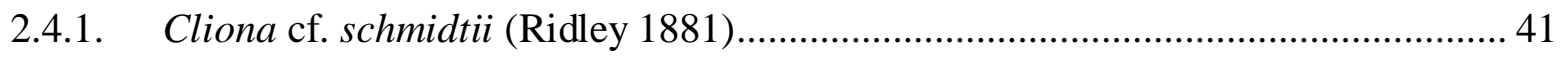

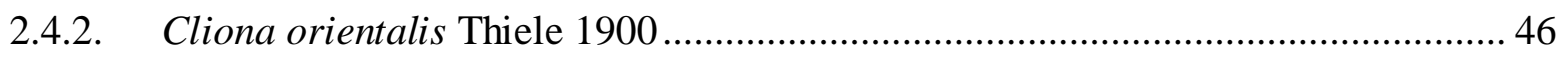

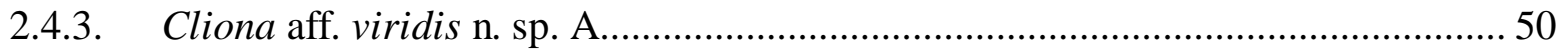

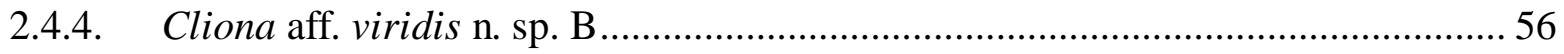

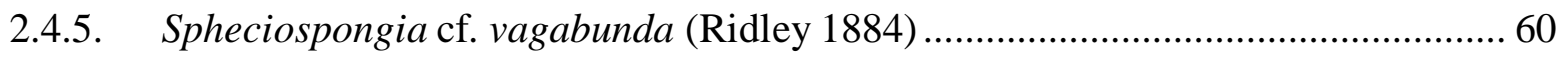

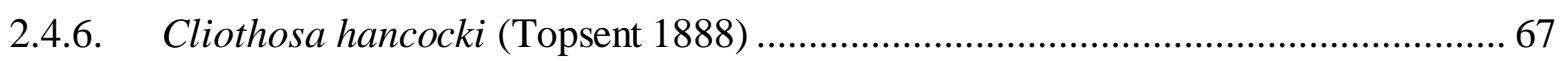




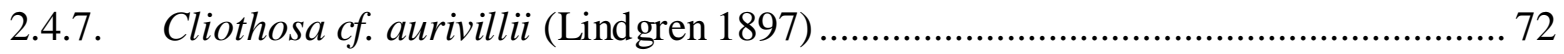

2.4.8. Zyzzya criceta Schönberg 2000a ……………………........................................... 76

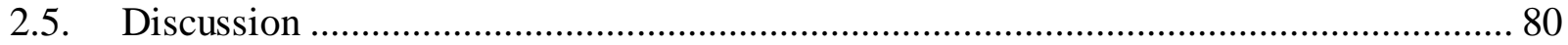

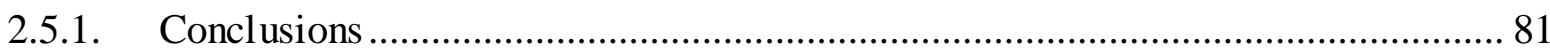

Chapter 3: Bioeroding sponge assemblage distribution: the importance of substrate availability and sedime nt........................................................................................................................ 82

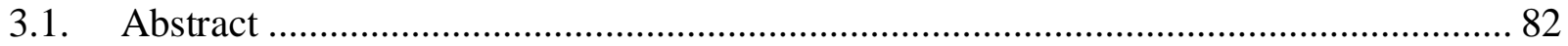

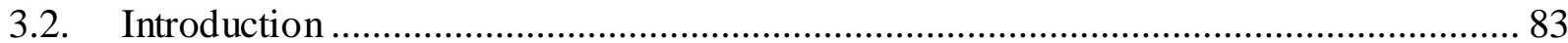

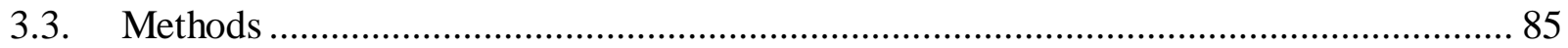

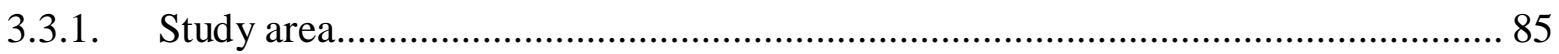

3.3.2. Bioeroding sponge abundance and benthic composition ....................................... 86

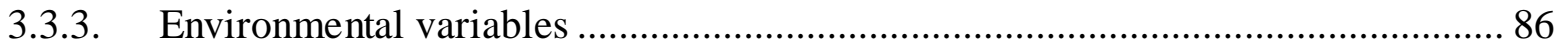

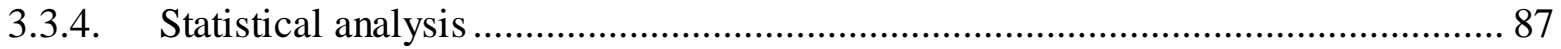

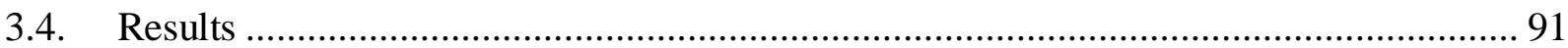

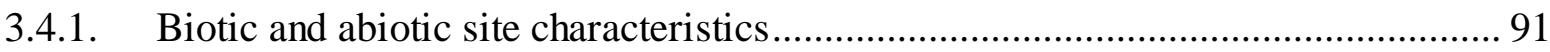

3.4.2. Sponge abundance, diversity and species composition ........................................ 93

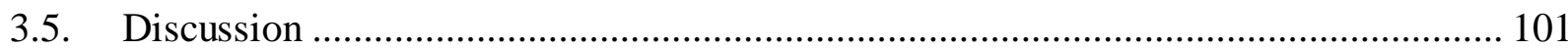

3.5.1. Abiotic and biotic influences on abundance, diversity and assemblage

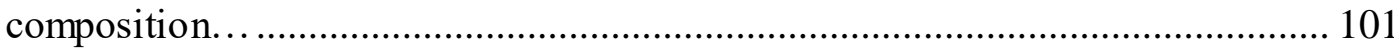

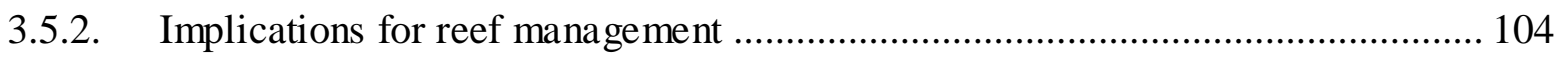

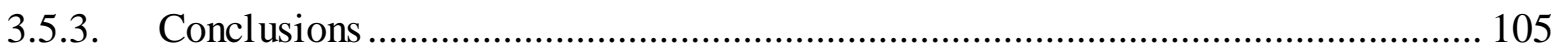

Chapter 4: Patterns of bioeroding sponge recruitment .................................................................. 106

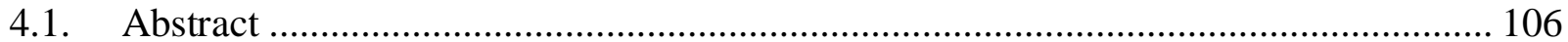

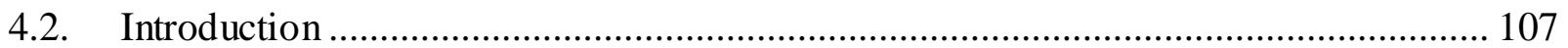

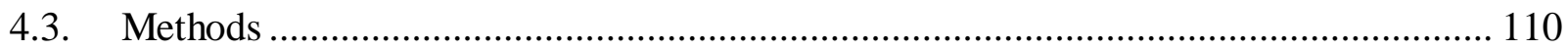

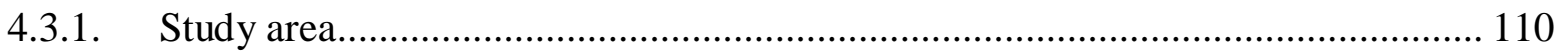

4.3.2. Bioeroding sponge recruitment ....................................................................... 110

4.3.3. Biotic and abiotic predicator variable data collection........................................... 111

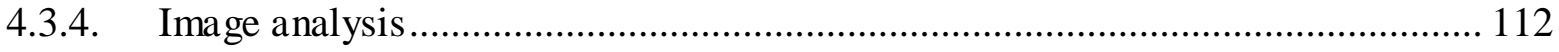

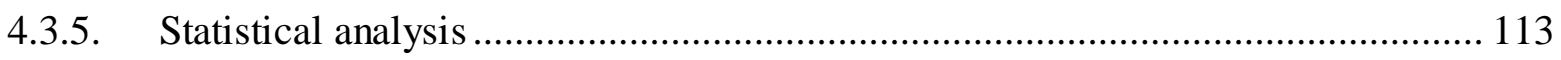

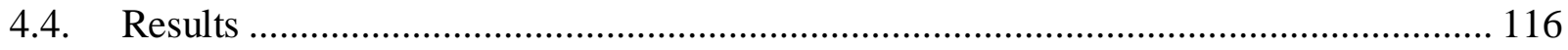

4.4.1. Localised substrate and block characteristics ....................................................... 116 


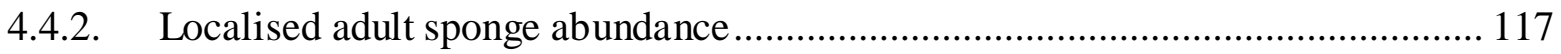

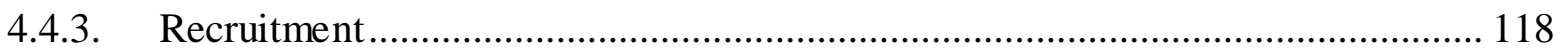

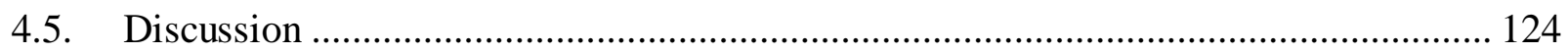

4.5.1. Biotic and abiotic factors affecting recruitment........................................... 124

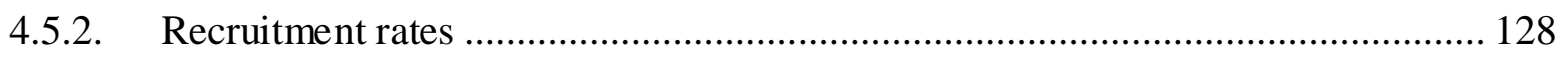

4.5.3. Bioroding sponge recruitment and reef degradation ......................................... 129

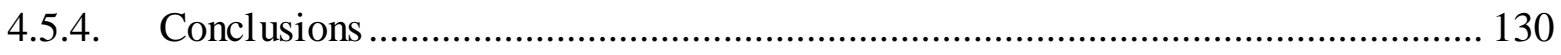

Chapter 5: Light limitation and Cliona aff. viridis n. sp. A, a photoadaptive response and

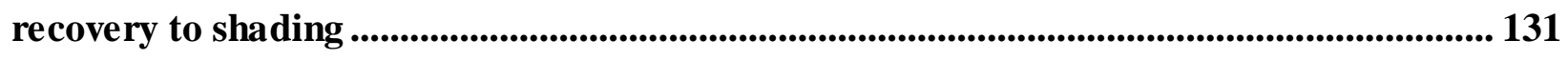

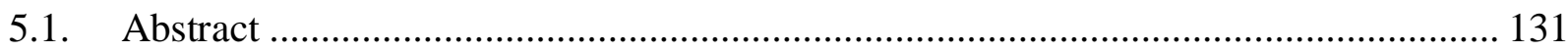

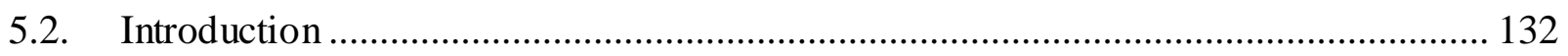

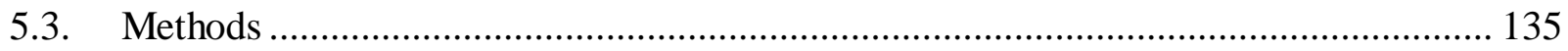

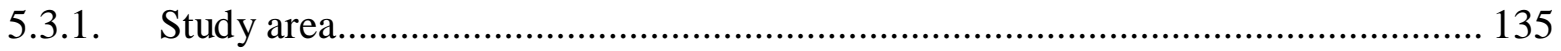

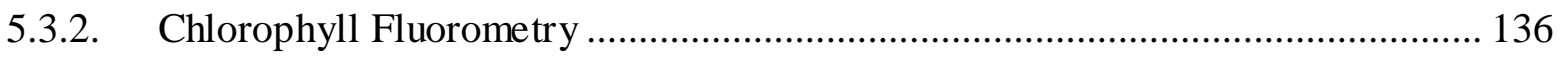

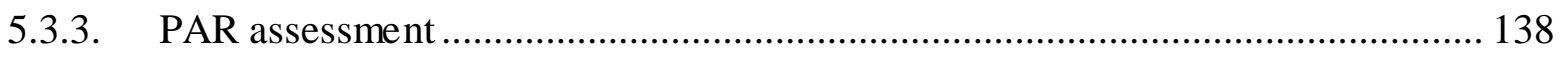

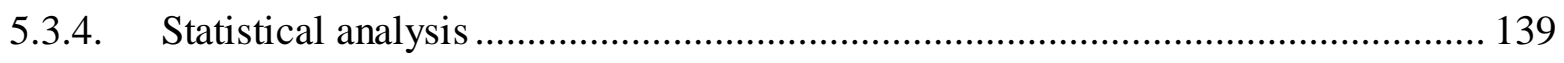

5.3.5. Molecular identification of symbiont cladal composition ................................ 139

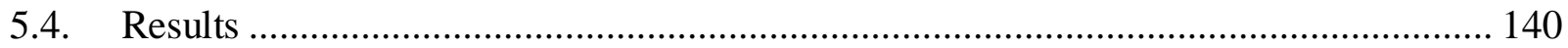

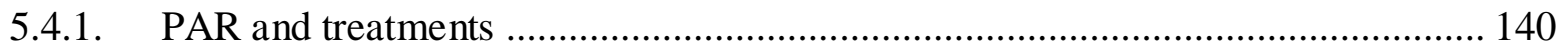

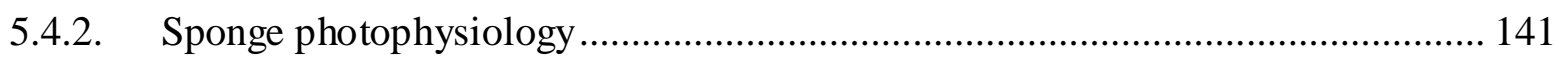

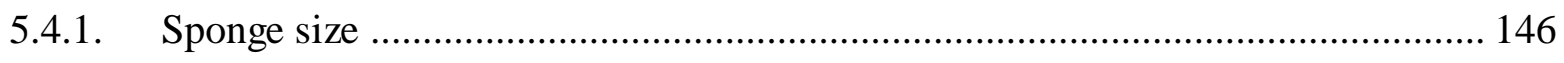

5.4.2. Symbiodinium cladal composition.............................................................. 146

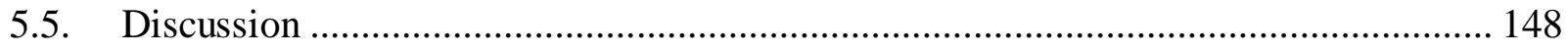

5.5.1. Photoacclimation of $C$. aff. viridis n. sp. A................................................. 148

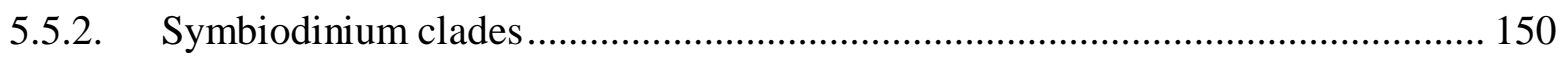

5.5.3. Reliance upon symbionts .................................................................... 151

5.5.4. Implications for survival on Sampela reef and other turbid Southeast Asian

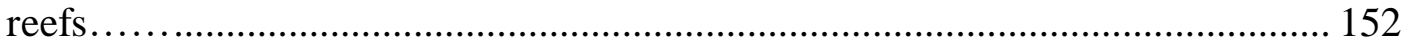

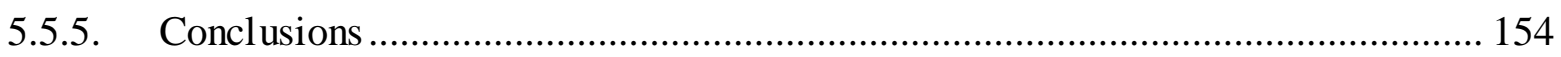

Chapter 6: Factors controlling the erosion rate of a Spheciospongia cf. vagabunda .......... 155

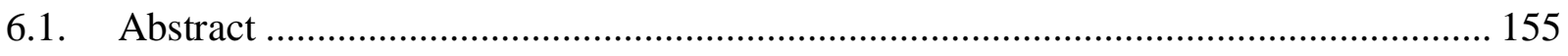

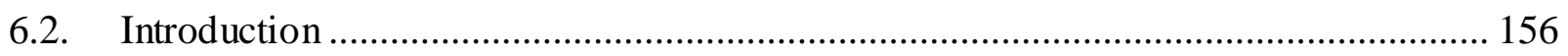




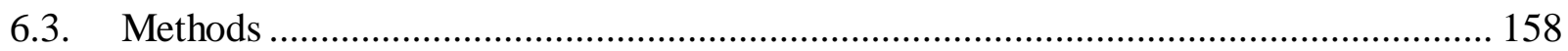

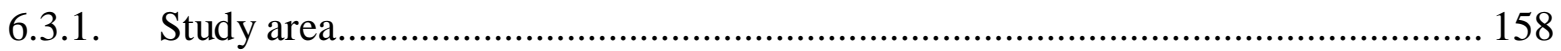

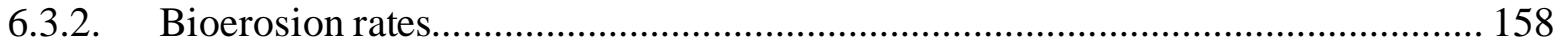

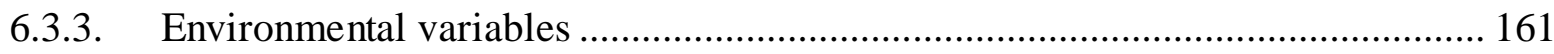

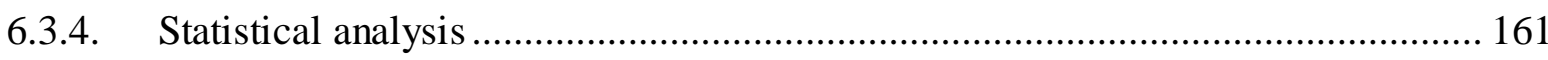

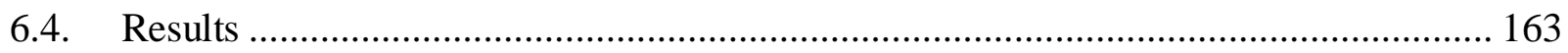

6.4.1. Site environmental characteristics ............................................................... 163

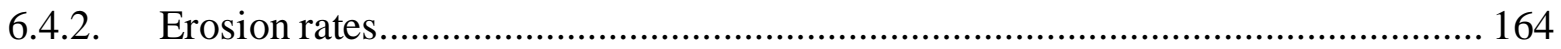

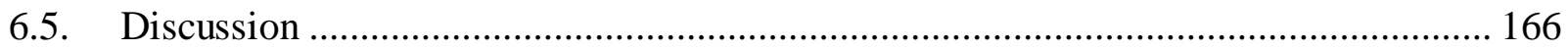

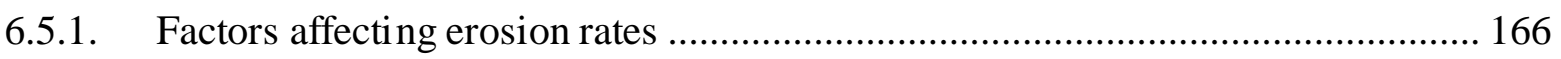

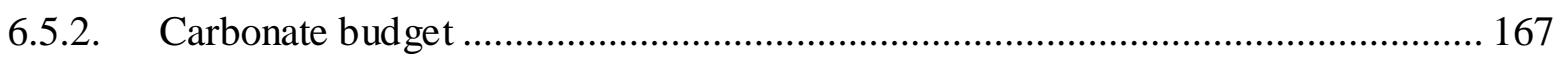

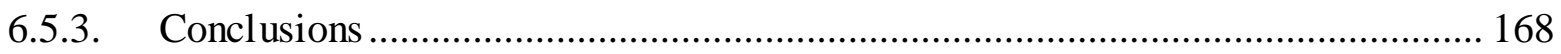

Chapter 7: General discussion ............................................................................................................ 169

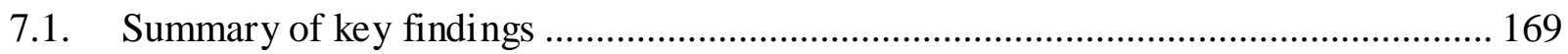

7.2. Global and local reef threats and bioerosion ........................................................ 170

7.3. Carbonate consequences of increased sponge bioerosion ......................................... 173

7.4. Indonesian sponge bioerosion in a global context................................................... 175

7.5. Implications for monitoring and management …………....................................... 176

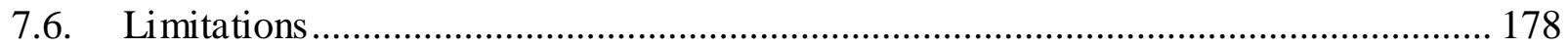

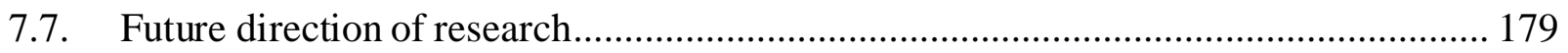

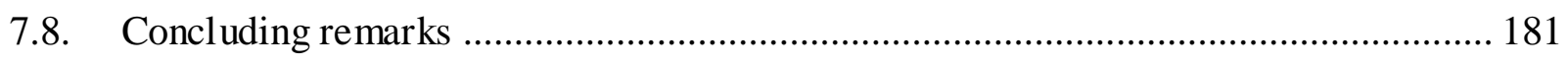

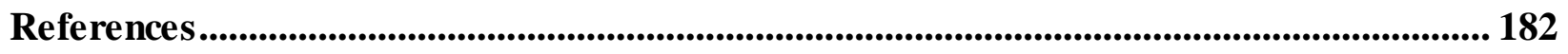

Appendices..................................................................................................................................................... 221

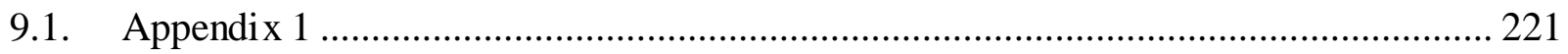

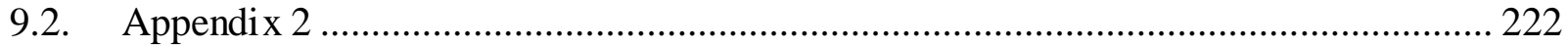




\section{List of Figures}

Figure 1.1. Map of the main study sites within the Wakatobi. Sites Buoy $1 \& 3$, Kaledupa 1 and Kaledupa Double Spur, Pak Kasim's, Ridge 1 and Sampela 1 are abbreviated as B1, B3, K1, KDS, PK, R1 and $\mathrm{S} 1$ respectively.

Figure 2.1. Map of sponge sampling locations within the Wakatobi National Park. Sites Buoy 1 \& 3, Kaledupa 1 and Kaledupa Double Spur, Pak Kasim's, Ridge 1 and Sampela 1 are abbreviated as B1, B3, K1, KDS, PK, R1 and S1 respectively.

Figure 2.2. Cliona cf. schmidtii. (A) Field image of papillae; (B) field image of merged papillae; (C) exposed erosion of carbonate rock; (D) tylostyle; (E \& F) "spindly" \& "stout" spirasters.

Figure 2.3. Cliona orientalis. (A) Field image of sponge; (B) close-up field image of exhalent papillae; (C) cross-section of erosion zone; (D) tylostyle; (E \& F) spirasters. 47

Figure 2.4. Cliona aff. viridis n. sp. A. (A) Field images of adult specimen; (B) field image of recruits/papillae; (C) field cross-section image showing sponge ectosome and extent of sponge erosion; (D) tylostyle; (E) c-shaped spiraster; (F) three-bend spiraster. 52

Figure 2.5. Phylogenetic tree analysis by Maximum Likelihood method based on the Kimura 2parameter model. The tree with the highest $\log$ likelihood is shown (-1018.61). The percentage of trees in which the associated taxa clustered together is shown next to the branches. Sequences are listed by GenBank accession number and taxon. S. coccinea is rooted as an outgroup.

Figure 2.6. Cliona aff. viridis n. sp. B. (A) Field images of inhalant and exhalent papillae (top right); (B) exposed erosion of carbonate rock; (C) straight tylostyle (spiraster also visible); (D) bent tylostyle; (E \& F) spirasters. 58

Figure 2.7. Spheciospongia cf. vagabunda. (A) Field images of adult specimen; (B) incision into sponge tissue revealing erosion zone; (C) tylostyle; (D \& E) amphiaster-like spirasters; (F) slender spiraster.

Figure 2.8. Cliothosa hancocki. (A) field image of exhalent (left \& centre) and inhalant papillae;

(B) field image of erosion chamber; (C) cluster of amphiasters around tyle; (D) tylostyle;

(E) amphiaster. 69 
Figure 2.9. Cliothosa cf. aurivillii. (A) field image of papillae, single exhalent papillae centre left; (B) field image of "bagpipe-like" erosion chamber; (C) tylostyles (smaller size class); (D \& E) spirasters

Figure 2.10. Zyzzya criceta. (A) field image of fistules protruding from coral rubble; (B) field image of erosion cavity; (C \& D) acanthostrongyles; (E) tylote; (F) microspined tylote head.

Figure 3.1. Site map of wider survey region in the Wakatobi (top left) and the core survey sites around the islands of Hoga and Kaledupa. 85

Figure 3.2. Principal coordinate analysis of site similarities with respect to their physical and water quality parameters. A) Comparison of all eleven study sites with regards to substrate composition and B) the seven core study sites regarding substrate composition and environmental factors. Overlaid vectors represent components that have a Pearson's correlation of greater than 0.4 with either of the PCO axes.

Figure 3.3. Bioeroding sponge distribution patterns per sample site and across all depths. A) Total sponge abundance (standardised to substrate). B) Species diversity. Standard errors shown 95

Figure 3.4. Average bioeroding sponge species abundance (standardised to substrate) at each core survey site. Standard errors shown. 96

Figure 3.5. Distance based redundancy analysis (dbRDA) ordinations of fitted models for assemblage composition. A) Seven core sites and both depth categories. B) Core sites and both depth categories with the omission of Sampela. 98

Figure 3.6. Distance based redundancy analysis (dbRDA) ordinations of fitted models for assemblage composition of the seven core sites (both depth categories), with the omission of Sampela 1. Overlapping 2D bubbles represent the abundance Cliothosa cf. aurivillii (top), Cliona aff. viridis n. sp. B (middle) and Spheciospongia cf. vagabunda (bottom). 100

Figure 4.1. Map of sponge recruitment study sites within the Wakatobi. 110

Figure 4.2. Example field images of recruitment block deployed to the reef in 2014 (A) and on retrieval in 2016 (B). 111 
Figure 4.3. Example screen shots of Vidana software. Left image depicting one side of recruitment block pre-measurement and the right image showing the same block after the recruits have been located and tagged.

Figure 4.4. Two dimensional representation (principal coordinate analysis, PCO) of recruitment block similarities with respect to their adjacent substrate composition. A \& B represent the same PCO but blocks are either designated by site (A) or depth (B). Overlaid vectors represent adjacent substrate components that have a Pearson's correlation of greater than 0.4 with either of the PCO axes. 116

Figure 4.6. Two dimensional representation (PCO) of recruitment block similarities with respect to their adjacent bioeroding sponge assemblage composition. Overlaid vectors represent Pearson's correlation of the same data with either of the PCO axes. Only Cliothosa cf. aurivillii, Cliona orientalis and Cliona aff. viridis n. sp A have correlation coefficients higher than 0.4 . 118

Figure 4.7. Average percent coverage of bioeroding sponge recruits (all species combined) across sites. Standard error bars shown.

Figure 4.8. Two dimensional representation (PCO) of site similarities with respect to recruited bioeroding sponge species assemblage

Figure 4.9. Distance based redundancy analysis (dbRDA) ordinations of fitted models for recruit assemblage composition. Overlaid vectors represent components that have a Pearson's correlation of greater than 0.4 .

Figure 5.1. Location of study area within the Wakatobi (inset black square) and position of reef sites Pak Kasim's and Sampela 1 in relation to the islands of Hoga and Kaledupa. Pak Kasim's and Sampela 1 abbreviated to PK and S1, respectively. 135

Figure 5.2. Example images of shade treatments showing $95 \%$ (left) and $70 \%$ (right) light reduction treatments suspended above individual Cliona aff. viridis n. sp. A individuals. 137

Figure 5.3. Mean rETRmax of controls (filled circles), procedural controls (open circles), 70\% light reduction (filled triangle), and 95\% light reduction (open triangle) treatments over time ( $n=5$ for each). Standard errors are shown and the vertical dashed line represents the time when shades were removed. 
Figure 5.4. Mean $\mathrm{E}_{\mathrm{k}}$ of controls (filled circles), procedural controls (open circles), 70\% light reduction (filled triangle) and 95\% light reduction (open triangle) treatments over time $(\mathrm{n}=$ 5 for each). Standard errors are shown and the vertical dashed line represents the time when shades were removed. 142

Figure 5.5. Mean $\alpha$ of controls (filled circles), procedural controls (open circles), 70\% light reduction (filled triangle), and 95\% light reduction (open triangle) treatments over time $(\mathrm{n}=$ 5 for each). Standard errors are shown and the vertical dashed line represents the time when shades were removed. 143

Figure 5.6. Mean $\Phi_{\mathrm{PSII}}$ of controls (filled circles), procedural controls (open circles), $70 \%$ light reduction (filled triangle), and 95\% light reduction (open triangle) treatments over time $(\mathrm{n}=$ 5 for each). Standard errors are shown and the vertical dashed line represents the time when shades were removed. 144

Figure 5.7. Mean F0 across time in different treatment groups ( $n=5$ for each). Standard errors shown 145

Figure 5.8. Mean rETR (RLCs) and mean $\mathrm{qP}$ for controls (filled circles), procedural controls (open circles), 70\% light reduction (filled triangle) and 95\% light reduction (open triangle) ( $\mathrm{n}=5$ for each) against PAR at day 0 (A\&B) and day 25 (C\&D), and after 14 days of recovery $(\mathrm{E} \& \mathrm{~F})$. Standard errors shown. 147

Figure 6.1. Map of Wakatobi region in southeast Sulawesi (top left) and the main study sites around the Islands of Hoga and Kaledupa. 158

Figure 6.2. Example images of treatment calcareous blocks in 2014; pre-deployment (A), and immediately after deployment in (B), and in 2015; on retrieving from the reef (C), measuring graft surface area (D), after $48 \mathrm{hrs}$ in bleach (E), and after excavation of erosion zone $(\mathrm{F})$. 160

Figure 6.3. Mean bioerosion rates of Spheciospongia cf. vagabunda and number of surviving individual grafts across the study sites. Standard error shown. 164

Figure 6.4. Pearson's correlations between erosion rates of Spheciospongia cf. vagabunda and water movement $\left(r^{2}=0.485, p=0.012\right.$, left $)$ and settled sediment $\left(r^{2}=-0.717, p<0.001\right.$, right). 
Figure 7.1. Partially bleached Cliona aff. viridis n. sp. A in July 2016 (left image) and after

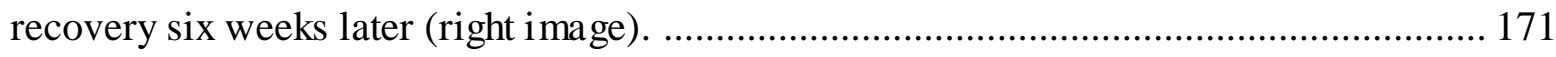




\section{List of Tables}

Table 2.1. Character list from previous descriptions of Spheciospongia vagabunda from around the Indo-Pacific. N/A indicates information not available.

Table 3.1. Substrate characteristics and environmental factors of each site. Each value represents a site mean and error values are standard errors of these means. 92

Table 3.2. Results of bivariate correlations comparing total sponge abundance and species diversity with substrate characteristics and environmental factors. Abundance tests using Pearson's and diversity tests using Spearman's Rank. Significant correlation probabilities in bold. Analyses conducted with and without Sampela data.

Table 4.1. Average percentage cover of bioeroding sponge recruits for individual species per site. Also shown is total average recruitment (all species combined) per site and average for species across all recruitment blocks. Not shown are species that did not recruit. Standard errors area shown

Table 5.1. Mean $\mathrm{qP}$ and standard error for all controls and treatments at days 0 and 25 , and after 14 days recovery. 145

Table 5.2. Mean sponge size and standard error for all controls and treatments at days 0 and 25 .

Table 6.1. Environmental characteristics of each site. Standard errors shown. 163 


\section{Chapter contributions and chapter manuscripts}

All surveys, experiments, analysis and writing of chapters were performed by Joseph Marlow with the guidance of Assoc. Prof. James Bell. Dr Christine Schönberg (University of Western Australia) provided additional guidance for the taxonomic anlaysis in Chapter 2. All chapters have been written into the following manuscripts:

\section{Chapter 2}

Marlow J, Jompa J, Schönberg C, Bell J (2017) Bioeroding sponges common to the Wakatobi region of southeast Sulawesi. In prep.

\section{Chapter 3}

Marlow J, Jompa J, Davy S, Schönberg C, Bell J (2017) Bioeroding sponge assemblage distribution: The importance of substrate availability and sediment. In prep.

\section{Chapter 4}

Marlow J, Jompa J, Bell J (2017) Rapid recruitment of Indonesian bioeroding sponges to experimental substrates: Implications for mass coral moraltality events. In prep.

\section{Chapter 5}

Marlow J, Jompa J, Davy S, Bell J (2017) Light limitation and a phototrophic bioeroding sponge, a photoadaptive response and recovery to shading. In prep.

\section{Chapter 6}

Marlow J, Werorilang S, Smith D, Bell J (2017) Sedimentation limits the erosion rates of a bioeroding sponge. Marine Ecology - under review. 


\section{Chapter 1: Introduction}

\subsection{Coral reefs}

\subsubsection{Diversity and importance}

Coral reefs are among the most biodiverse and resilient ecosystems on earth; they are host to an estimated 600,000 to 9 million species and have persisted for over 240 million years (Small et al. 1998; Bouchet \& Duarte 2006; Veron et al. 2009). They are the ubiquitous ecosystem in shallow tropical coastal environments across the globe and none more so than in the Indo-Pacific region, which harbours approximately $75 \%$ of the world's coral reefs (Roberts et al. 2002). This region is also home to the global centre of coral reef biodiversity, the Coral Triangle; this triangular area of tropical waters stretching from the Philippines in the north to Indonesia in the south and Papua New Guinea in the east, encompasses more species of corals, fish and other reef taxa than anywhere else on the planet (Briggs 2005; Veron et al. 2009). The benefits of healthy coral reefs extends far beyond merely the preservation of high levels of biodiversity and endemism, as coral reefs provide critical ecosystem goods and services for hundreds of millions of people (Moberg \& Folke 1999). More than 275 million people live within $30 \mathrm{~km}$ of a coral reef (Burke et al. 2011) and due to the equatorial distribution of coral reefs a significant proportion of these people live in developing nations where dependence on reef fish as a protein source (and also income) is high. For many tropical countries, in addition to the financial income from fishing, coral reefs are vital source of income through tourism activities such as diving. The non-market use value of diving in Indonesia, Malaysia and Thailand alone has been valued at US $\$ 4.5$ billion a year (Pascoe et al. 2014). As physical structures, the ability of coral reefs to dissipate wave energy also provide coastal countries with coastal protection (Villanoy et al. 2012).

\subsubsection{Threats and regime shifts}

Despite the well-known benefits that are derived from healthy functioning coral reefs, reefs worldwide have suffered from substantial anthropological induced declines in coral cover, habitat complexity, fish abundance and biodiversity (Gardner et al. 2003; Bruno \& Selig 2007; Burke et al. 2011). Human activities are negatively affecting coral reefs on a global scale; there are currently no reefs left on the planet that could be considered pristine; $19 \%$ of reefs have been lost permanently and 35\% are at a high risk of being lost in the next 40 years (Wilkinson 2008). 
It is unfortunate that the region with the highest biodiversity, the Indo-Pacific, is also highly threatened; the region has seen coral-cover declines of $20 \%$ since historical reference points (Bruno \& Selig 2007) and 95\% of reefs in the region are at risk from local threats (Burke et al. 2011). At the local scale reefs are over-fished, often with destructive fishing methods and dense coastal populations with poor coastal development management has led to increased watershedbased pollution, turbidity and sedimentation (Burke et al. 2011). On the global scale, anthropogenically introduced increases in atmospheric carbon dioxide are affecting reefs through two mechanisms - rising sea temperatures (global warming) and ocean acidification (HoeghGuldlberg et al. 2007). Rising water temperatures are increasingly causing the disintegration of scleractinina coral/symbiont endosymbiosis (bleaching), which often leads to permanent coral mortality (Hoegh-Guldberg 1999; Donner et al. 2005), and can occur across large geographic areas (Goreau et al. 2000; Normile 2016). Ocean acidification and the consequent increased disassociation of carbonic acid reduces the availability of carbonate to calcium carbonate accreting organisms such as scleractinian corals and is predicted to result in decreased growth rates and skeletal density of these critical reef builders (Hoegh-Gudlberg et al. 2007).

With the current and predicted declines in hard coral cover on tropical reefs, a lot of research has focused on those resilient benthic taxa that might benefit from increased substrate availability in what has traditionally been considered a spatially competitive system dominated by scleractinian corals. The majority of the literature has focused on shifts to macroalgal-dominated communities (e.g. Hughes 1994; Szmant 2002; McManus \& Polsenberg 2004; Cheal et al. 2010) and shifts in the Caribbean (e.g. Hughes 1994; Mumby 2009). Despite region wide declines in coral cover in the Indo-Pacific (Bruno \& Selig 2007), a subsequent shift to macroalgal dominance is not common; Bruno et al. (2009) found that amongst 963 sites across the Indo-Pacific region only $1 \%$ of sites were considered macroalgal-dominated ( $>50 \%$ cover) and that the regional average was $9-12 \%$ algal cover. Shifts to states dominated by other (non-algal) benthic taxa, have been reported to a lesser degree and help to highlight how other organisms may benefit from declines in coral cover. In their 2009 review, Norström et al. revealed a wide variety (taxonomically and geographically) of these incidences including soft corals (e.g. Fox et al. 2003; Stobart et al. 2005), corralimorphians (e.g. Kuguru et al. 2004; Loya 2004), ascidians (e.g. Bak et al. 1996) and sponges (e.g. Aronson et al. 2002; Rützler 2002a; Ward-Paige et al. 2005). Interestingly, the majority of literature on increases in sponge abundance on degraded reefs has shown increases of 
bioeroding sponges of the Clionaidae family (e.g. Ward-Paige et al. 2005; Schönberg \& Ortiz 2009; Carballo et al. 2013).

\subsection{Sponges on coral reefs}

Sponges are ancient organisms that have existed on reefs for millennia. During the Upper Carboniferous period ( 310 MYA) they were the major frame-building organisms on reefs (West 1988), and were responsible for other significant reef building events throughout the geological record (Brunton \& Dixon 1994; Wood 1999; Bell et al. 2013). The persistence of this group for over 500 million years has resulted in wide diversification of species and today sponges are among the most prominent groups of taxa on coral reefs with species diversity that equals and often exceeds that of corals in the same region. For example, over 420 species of sponges have been recorded from Indonesia and it is thought that there is probably up to 830

species (van Soest 1989; 1994) whereas the highest number of coral species recorded in the Indonesia (and the world) is 456 (McKenna et al. 2002). Similarly sponge abundance is often exceedingly high, occupying up to $24 \%$ of substrate on some Caribbean reefs (Diaz \& Rützler 2001) and up to $30 \%$ on some Indo-Pacific reefs (Bell \& Smith 2004).

Sponges are not only species diverse, but also functionally diverse and are a critical functional component of modern coral reefs. As obligate filter feeders, all sponges must pump water through their tissues in order to obtain food and nutrients, which can result in extremely high volumes of water exchange, for example Verongia lacunosa can pump up to $61 / \mathrm{h}$ per $500 \mathrm{ml}$ volume of sponge (Gerrodette \& Flechsig 1979). By removing carbon, nitrogen and other nutrients from the water column, sponges are a significant link between the pelagic environment and the benthos. The transfer of this dissolved organic matter to higher trophic levels can take place through activities such as predation (Wulff 2006) or by rapidly recycling and expelling filter cells as detritus. It has been hypothesised that this "sponge-loop" is critical for the existence of coral reef in oligotrophic seas (de Goeij et al. 2013). Sponges can also contain very high densities of photosynthetically active organisms such as cyanobacteria or the dinoflagellate Symbiodinium (Rützler 1990) and are important contributors to reef primary production (Wilkinson 1987). 
It is sponge impacts on the substrate that probably constitutes their most important functional roles on tropical reefs. These functional roles can be broadly broken down into the coralaccretion facilitating processes (consolidation and stabilisation) and the destructive process of bioerosion. In the Caribbean (Wulff 1984; 2001) some sponges are able to bind coral rubble together after disturbance events, which in turn creates a more stable platform for successive coral settlement (Biggs 2013). The antagonistic process to stabilisation and consolidation is bioerosion, where sponges are often the dominant agents of on coral reefs (Risk et al. 1995).

\subsection{Reef bioerosion}

Bioerosion is biological mediated erosion (rather than physical or due to oceanic chemistry) and on reefs includes any of the activities that cause the erosion or weakening of calcareous structures by a reef species (Neumann 1966). Bioerosion is the primary source of erosion on coral reefs as physical erosion is temporary and localised (e.g. storms and hurricanes) and chemical erosion is negligible due to the composition of ocean chemistry (Scoffin et al. 1980; Tribollet \& Golubic 2011). Bioerosion plays an important role in producing reef sediments (Hutchings 1986), in increasing reef biodiversity by creating microhabitats (Hutchings 1986; Moran \& Reaka 1988) and in reef biochemistry by recycling dissolved $\mathrm{Ca}^{2+}$ and $\mathrm{C}$ (Tribollet \& Golubic 2011). As the primary source of erosion on coral reefs, bioerosion is the key antagonistic process to calcium carbonate accretion by scleractinian corals and coralline algae, and hence an integral part of the reef carbonate budget. Coral reefs must maintain a positive balance between calcification and erosion if net reef growth is to occur (Glynn 1997; Perry et al. 2008) although this carbonate budget is often evenly balanced (Scoffin et al. 1980; Glynn 1988).

The organisms that are responsible for bioerosion are termed bioeroders and are comprised of a diverse range of taxa. These organisms can be broadly divided into two groups: 1) external bioeroders, which graze on benthic organisms and consequently abrade the substrate: and 2) internal bioeroders, which excavate carbonate substrates for shelter or nutritional purposes (Tribollet \& Golubic 2011). External bioeroders are a diverse group and range from small gastropods such as limpets (Radtke \& Campion-Alsumard 1996) to echinoderms (HerreraEscalante et al. 2005) and large fish species, such as Bolbometopon muricatum, (Bellwood et al. 2003). Internal bioeroders can be classed as either microborers $(<100 \mu \mathrm{m})$ or macroborers $(>100$ $\mu \mathrm{m})$ and are present in both live and dead carbonate substrates (Tribollet \& Golubic 2011). 
Microborers are either organotrophic (e.g. fungi and foraminfera) or phototrophic (e.g prokaryotic cyanobacteria and eukaryotic chlorophytes) microorganisms and penetrate carbonate substrates by dissolution (Tribollet 2008; Tribollet \& Golubic 2011). Macroborers are also a diverse group ranging from bryozoans (e.g. Smyth 1988) to polychaetes (e.g. Wielgus et al. 2006) and sponges (e.g. Rützler 2002b).

The extent to which these different bioeroders contribute towards bioerosion on different reefs is dependent on a range of biotic and abiotic conditions, including eutrophication (Sammarco \& Risk 1990; Risk et al. 1995; Tribollet \& Golubic 2005), grazing pressure (Golubic \& Schneider 1979; Kiene \& Hutchings 1994), substrate exposure time (Tribollet \& Golubic 2005; Kiene \& Hutchings 1994) and light availability (Magnusson et al. 2007). Whilst the compliment of bioeroders may differ with environmental and abiotic conditions, the majority of internal coral reef bioerosion is consistently attributed to demosponges, which frequently represent 60 to $90 \%$ of macroborer activity (Risk et al. 1995).

\subsection{Bioeroding sponges}

\subsubsection{Taxonomy and morphology}

Bioeroding sponges have been found in the geological record for a very long time, they were first documented in the lower Cambrian ( 525 MYA) (Kobluk \& Risk 1977) and with time increased in abundance in diversity so that by the Devonian ( 420 MYA) many were very similar to modern representatives (Wilson 2007). Today there are over 200 described and accepted bioeroding sponge species from the around the world, the majority of which belong to eight genera within the Clionaidae Family (Rützler 2002b), although they are not all restricted to this family or even the Hadromerida order (Rosell \& Uriz 1997).

Bioeroding sponges are unique amongst Porifera due to their endolithic life histories, the degree of which can vary and has been categorised as either papillate $\alpha$-form, encrusting $\beta$-form or freeliving Y-form. The $\alpha$-form is proportionally the most endolithic, with the majority of the sponge occupying the interior of the substrate and only separate inhalent ostial and exhalent oscular papillae penetrating the substrate surface. The $\beta$-form is encrusting, with a continuous tissue covering at the surface and an even penetration of the substrate below. The Y-form is restricted to a few species (e.g Cliona celata) and is entirely free living. These growth forms have 
previously been described as growth "phases", primarily due to the presence of all three stages in C. celata in the Atlantic (Xavier et al. 2010) and the postulation that this might also occur for some species within the Cliona viridis complex (Rosell \& Uriz 1991). Whilst Xavier et al. (2010) used phylogenetic reconstructions of mitochondrial and nuclear gene fragments to prove that this is indeed the case for C. celata, the case is not so clear for other species as often not all growth forms can be found in all habitats (e.g. Schönberg 2000a) and most bioeroding sponge species retain the $\alpha$-form (e.g. Hartman 1958).

Identification of species is primarily achieved through spicule analysis; comparisons of the size, shape and composition of the microscopic siliceous spicules that constitute the sponge skeleton (e.g. Schönberg 2000a: Rosell \& Uriz 2002; Calcinai et al. 2005). In the Clionaidae identification focuses on megascleres which are predominately composed of tylostyles, but may include oxeas and microscleres which, where present, include spirasters, amphiasters, microxeas, microrhabds, or raphides (Rützler 2002b). Spicule analysis has its drawbacks; spicule morphlogy can vary depending on environmental conditions, resulting in intraspecific variation that can outweigh interspecific variation in some closely related species (Rosell \& Uriz 1991; Bavestrello et al. 1993). Although molecular tools have only been applied in a handful of studies, phylogenetics is increasingly being incorporated into identification publications (e.g. Barucca et al. 2007; Escobar et al. 2012; Leal et al. 2016). Unfortunately there has been little overlap in terms of the regions of DNA used in the respective studies and consequently new studies are limited in their phylogenetic comparisons.

\subsubsection{Sponge bioerosion}

The reason these sponges have evolved to become obligate endoliths has been widely debated; bioerosion is metabolically costly activity and the benefits are not entirely understood. Ward \& Risk (1977) proposed that sponges may obtain some nutritional benefit from the eroded substrate, however Schönberg \& Wisshak (2012) point out that the sponges are efficient filter feeders and those of the $C$. viridis complex harbour symbiotic dinoflagellate zooxanthellae (Sammarco et al. 1987; Schönberg 2002), which would also compliment their energy intake. Other authors have hypothesised that an endolithic habitat provides a better refuge from grazers and predators (e.g. González-Rivero et al. 2011), which would support observations that these sponges have far lower spicule:tissue ratios than free living sponges (Schönberg \& Wisshak 
2012). An endolithic habitat may also allow the sponges to grow whilst minimizing competition with other benthic taxa, however many encrusting clionaids are extremely efficient spatial competitors (Rützler 2002b).

The process by which bioeroding sponges excavate the substrate is both mechanical and chemical and still not fully understood. The chemical component of erosion is accomplished by specialised etching cells that chemically carve out small chips (15-100 $\mu$ m diameter), which are then mechanically transported out of the sponge through the aquiferous system (Cobb 1969; Rützler \& Rieger 1973; Pomponi 1980). Several etching cells are involved in etching out each chip, combining to produce a web of filopods that form a basket around the chip (Rützler \& Rieger 1973). The exact chemical agent that is used to remove the chips remains elusive; Cobb (1969) reasoned that the process of dissolving calcium carbonate would necessarily involve acid and an additional enzyme but few studies have made progress beyond this hypothesis. Pomponi (1980) demonstrated that carbonic anhydrase activity was associated with etching cells. Sullivan \& Faulkner (1990) described a calcium chelator pathway in Aka coralliphaga in which the chelator molecule releases $\mathrm{H}^{+}$at the sponge-substrate interface and receives calcium ions in return. Schönberg (2008) used microsensors to measure $\mathrm{pH}$ and calcium concentrations within $C$. celata and found weak evidence that acid plays a role in chemical bioerosion. By measuring the width of sponge chips, Rützler and Rieger (1973) gauged the chemical component to be 2-3\% and the mechanical component 97-98\%. However, more recent studies suggest that chemical dissolution is a greater contributor than previously thought. Zundelevich et al. (2007) determined the chemical boring rates in Pione vastifica by measuring the changes in total alkalinity in sponge-containing chambers and concluded that $75 \%$ of erosion in P. vastifica was due to chemical dissolution. This same methodology was used by Nava and Carballo (2008) who also concluded that the amount of erosion due to chemical dissolution in Cliona vermifera and Cliona flavifodina was significant (27 and 10.2\%, respectively).

Rates of erosion are often measured in terms of mass of calcium carbonate per $\mathrm{m}^{2}$ of sponge tissue per year and can vary significantly between species e.g. $0.34 \mathrm{~kg} \mathrm{~m}^{-2}$ sponge $\mathrm{yr}^{-1}$ for $P$. vastifica and $23.8 \mathrm{~kg} \mathrm{~m}^{-2}$ sponge $\mathrm{yr}^{-1}$ for Cliona orientalis (Schönberg 2002; Zundelevich et al. 2007). However, this variability has to be considered in the context of the wide range of factors that can affect sponge erosion rates, which are not always controlled for in studies. Most studies 
that evaluate the influence of abiotic and environmental factors on sponge erosion do so by inferring differences in bioerosion rates from differences in in situ measurements of abundance and sponge size (e.g. Holmes et al. 2000). Due to the long experimental time periods required, fewer studies actually directly measure in situ rates of bioerosion in specific species. This is normally achieved by deploying experimental calcareous substrates with attached grafts of the target species and the additional deployment of control substrates (e.g. Holmes et al. 2009). Bioerosion rates are measured in terms of substrate weight loss over the period of the deployment and standardized using the control substrates to any other forms of weight change due to calcification or grazing etc.

One of the most studied variables to effect sponge erosion rates is differences in mineralogy and substrate density (e.g. Rose \& Risk 1985; Sammarco et al. 1987; Edinger \& Risk 1996; Schönberg 2002). Numerous studies have shown that erosion rates increase with substrate density (e.g. Neumann 1966; Schönberg 2002; Calcinai et al. 2008); it is proposed that sponges first occupy any porous material before beginning excavation, hence the lower erosion rates in less dense porous substrates (Schönberg 2002; Calcinai et al. 2008).

As filter feeders any mechanism that provides these sponges with increased food availability is also likely to result in increases in bioerosion rates. Most studies addressing this link have either focused on the relationship between erosion rates with eutrophication or with currents that deliver suspended matter (e.g. Hallock 1998). Numerous studies have demonstrated that sponge bioerosion rates correlate with natural or anthropogenic eutrophication gradients (e.g. Rose \& Risk 1985; Carballo et al. 1996; Ward-Paige et al. 2005; López-Victoria \& Zea 2005). For example, Holmes et al. (2000) found sponge bioerosion to be significantly higher on polluted reefs than control reefs in Indonesia, with the most dramatic differences occurring on Javan reefs with high concentrations of chlorophyll $\alpha$.

Sponges of the $C$. viridis complex harbour photosynthetic Symbiodinium symbionts that have been shown to enhance sponge bioerosion. Schönberg (2006) demonstrated that C. orientalis was able to erode through experimental substrate blocks 4.5 to 11 times faster in ambient light than when shaded and Hill (1996) found that Cliona varians erosion rates were $50 \%$ higher under ambient conditions than when shaded. However, not all species appear to rely as heavily on their 
symbionts as Zundelevich et al. (2007) found that the rates of chemical erosion by $P$. vastifica were constant during a diurnal cycle.

Recent research has focused on the effects of climate change on sponge erosion rates. It is believed that as a result of projected increases in atmospheric carbon dioxide, ocean acidification will facilitate bioerosion by weakening existing carbonate structures and reducing any $\mathrm{pH}$ gradient that needs to be overcome to enable chemical erosion (Duckworth \& Peterson 2013; Fang et al. 2013; Wisshak et al. 2012; 2013; Stubler et al. 2014). Experimental manipulations of

$p \mathrm{CO}_{2}$ and temperature with various sponge species have shown that increasing $p \mathrm{CO}_{2}$ amplifies a sponges bioerosion capacity but increasing temperature can have neutral to negative effects. Stubler et al. (2014) observed significant increases in the erosion efficiency of $C$. varians and Pione furcata when treated under $p \mathrm{CO}_{2}$ conditions replicating an end of the century scenario (SRES A2 scenario (IPCC 2007). Increases in temperature do not have the same effect. Wisshak et al. (2013) found a $17 \%$ increase in bioerosion rates of $C$. orientalis at moderately elevated levels of $\mathrm{pCO}_{2}$ and a $61 \%$ increase at strongly elevated levels but bioerosion rates actually slightly dropped at elevated temperatures.

\subsubsection{Symbiodinium}

Amongst Porifera, a significant number of bioeroding sponge species have associations with dinoflagellate Symbiodinium, the "zooxanthellae" that are usually associated with Cnidarian hosts. This association was first observed in C. viridis (Sarà \& Liaci 1964), but has since been observed in many other clionaid species (Schönberg 2000b; Schönberg \& Loh 2005; Calcinai et al. 2005; Granados et al. 2008; Cruz-Barraza et al. 2011; Zea \& López-Victoria 2016), which appear to be closely related and are grouped together in the C. viridis species complex (Rosell \& Uriz 1991, Schönberg 2000b). Similar to Cnidarian hosts, it is believed the members of the complex receive nutrients from the symbionts in the form of photosynthates (Rosell \& Uriz 1992; Hill 1996; Weisz et al. 2010) or by direct ingestion of the symbionts themselves (Sarà 1971). The benefits to the host have been observed in shading experiments where lateral growth and bioerosion rates were greater in ambient light conditions than shaded for $C$. orientalis (Schönberg 2006) and C. varians (Hill 1996). Members of this complex are also among the most efficient spatial competitors, often living adjacent to live coral colonies, some of which they are capable of overgrowing and eventually killing (Hill 1999; Schönberg \& Wilkinson 2001). The 
symbiotic relationship appears to be mutualistic with the symbionts receiving shelter from environmental stressors and predation (Schönberg \& Wilkinson 2001). However, it has been suggested that the nature of this relationship is flexible and under extreme light-limited conditions, Symbiodinium could survive through parasitism of the host sponge (Fang et al. 2017a). The three-dimensional nature of sponges also means that the symbionts are less susceptible to heat and light stress than in corals as the host is able to auto-shade them within deeper tissue layers. Evidence suggests that this shading effect might not be just passive. Schönberg \& Suwa (2007) observed a shifting of zooxanthellae to deeper tissues in C. orientalis after exposure to light stress, suggesting that the species is capable of mitigating potential bleaching events. This evidence supports observations that bleaching rarely occurs in $C$. viridis spp., even during disturbance events that have caused large scale bleaching in corals (Vicente 1990; Hill \& Wilcox 1998). However, recent evidence from the Caribbean demonstrates that elevated water temperature can cause large-scale bleaching in these sponges (Hill et al. 2016). Three studies have used phylogenetics to identify the Symbiodinium associated with $C$. viridis spp. (Schönberg \& Loh 2005; Granados et al. 2008; Hill et al. 2011). Identification of Sybiodinium is based upon lineages (Clades A-H) and to date symbionts of clades A,B,C and G have been detected in associations with clionaid sponges. The Clade G Symbiodinium found in many clionaid sponges appear to be from a sponge-specialist G2 sub-clade (Hill et al. 2011), which is evolutionary much older than many common Cnidarian associated clades (Pochon et al. 2006) and is believed to be more tolerant to external stressors. The mechanism of acquisition and transmission of symbionts is not still fully understood. Mariani et al. $(2000 ; 2001)$ observed vertical transmission (i.e. via gametes) in C. viridis in the Mediterranean and Schönberg \& Loh (2005) concluded the same type of transmission was occurring in $C$. orientalis in the Great Barrier Reef (GBR). However, the observation of different clade associations within different individuals of the same species of Cliona laticavicola, Cliona aprica and Cliona caribbaea (Granados et al. 2008) suggest that horizontal transmission (environmentally acquired) is also possible.

Currently there is very little information on the ability of Symbiondinium hosting sponges to photoacclimate to naturally or anthropogenically induced changes in light availability. Photoacclimation is the process by which either the photosymbiont or the host or both (the holobiont) change their photophysiological apparatus in order to maintain photosynthetic 
efficiency with changing light availability. In scleractininan corals this has been studied extensively and a high photoacclimatory capacity allows certain coral species to thrive in highly turbid conditions or occupy a broad depth range (e.g. Anthony \& Farbricius 2000; Hennige et al. 2010). The confinement of some zooxanthellate bioeroding sponge species to certain depth categories (e.g López-Victoria \& Zea 2005) suggests that potentially these species are unable to photoacclimate to less ideal light conditions. However the only in situ study for bioeroding sponges (Steindler et al. 2001) found that the usually deep and cryptic sponge, P. vastifica, was capable of photoacclimating to conditions of significantly increased light availability, suggesting that its depth preference is not a function of light availability. The effects of extreme reductions in light availability have been investigated in ex situ experiments on $C$. orientalis; prolonged exposure to complete darkness, caused a marked reduction in Symbiodinium density, maximum quantum yield and no change in heterotrophic uptake (Pineda et al. 2016; Fang et al. 2017a). Nevertheless, recovery was observed in sponges when ambient light conditions returned (Pineda et al. 2016)

\subsection{Bioeroding sponge abundance \& distribution}

\subsubsection{Reproductive output \& recruitment}

Sponges are capable of sexual and asexual reproduction. Sexual reproduction can be either gonochoristic or hermaphroditic and either oviparous or viviparous (Maldonado \& Riesgo 2008) and all these strategies have been observed in bioeroding sponges (e.g. Mariani et al. 2000; Maldonado \& Riesgo 2008; Piscitelli et al. 2011; González-Rivero et al. 2013; Bautista-Guerrero et al. 2014) although the majority of clionaid species are oviparous and gonochoristic. Gametogenesis is usually environmentally dependent and correlates with changes in water temperature; in most species (both temperate and tropical) oogenesis and fertilization occur during the warmer summer months (Mariani et al. 2000; Piscitelli et al. 2011; Bautista-Guerrero et al. 2014) although in the Caribbean species Cliona tenuis and C. caribbaea, reproduction is during the cooler winter months (Rützler 1974; González-Rivero et al. 2013). In tropical species, the reproduction appears to be iteroparous where the reproductive period often encompasses multiple pulses of reproductive output (González-Rivero et al. 2013; Bautista-Guerrero et al. 2014). As these sponges are not brooders, a lot of energy is invested in mass production of eggs 
(Piscitelli et al. 2011). Once the gametes are released, fertilization and embryogenesis of the negatively buoyant eggs usually occurs on the substrate (Maldonado 2006) and larval settlement occurs within days (Nassonov 1883; Mariani et al. 2001). In general sponge larvae are poor swimmers but clionaid larvae appear to be particularly poor; $C$. viridis displays crawling rather than swimming behaviour and as a result dispersal distance is extremely low (Mariani et al. 2000). Generally sponge population maintenance (not specifically bioeroders) is dependent upon sexual reproduction but asexual reproduction through gemmulation, budding or fragmentation can also play an important role (Maldonado \& Riesgo 2008). Transplantation experiments with C. tenuis and $C$. orientalis have shown that stable fragments of bioeroding sponges and spongebearing-rubble are able to colonise adjacent substrate and hard coral with very high rates of survival (Schönberg \& Wilkinson 2001; López-Victoria \& Zea 2004).

\subsubsection{Adult distribution}

Like any sessile benthic organism, the availability of suitable substrate for colonisation and growth is an important driving factor for bioeroding sponge abundance. This appears to be especially important for bioeroding sponges due to their obligate endolithic life history and inability to occupy non-calcareous substrates. Recent work by Schönberg (2015a) has found that the most important determinant of bioeroding sponge abundance in the GBR is the availability of suitable substrate and suggests that abundance monitoring should be standardised for substrate availability. Similar results were found at the Columbian island of Islas del Rosario in the Caribbean (López-Victoria \& Zea 2005), where C. aprica, C. caribbaea and C. tenuis were most abundant at sites with the greater availability of calcareous rock. The substratum occupation/availability ratios of these sponges were more positively associated with recently dead coral skeletons than older incrusted substratum. This tendency towards preferential establishments on "cleaner" substrates would explain observed increases in bioeroding sponge abundance following bleaching events e.g. an $81 \%$ increase in the Indian Ocean following the $1998 \mathrm{El}$ Nino event (Sheppard et al. 2002) and up to 150\% increase after two bleaching events in the GBR (Schönberg \& Ortiz 2009). Substrate preference is species-specific and not all bioeroding sponge species show a preference for recently dead coral skeletons. Carballo et al. (2008a) found that in the Mexican Pacific, C. vermifera and Cliona mucronata showed a preference for coral rubble whilst Aka cryptica and Cliothosa hancocki were commonly found in 
the vicinity of living coral. Substrate complexity can also be a limiting factor for the abundance of these species; in the same study at Islas de Rosario, López-Victoria \& Zea (2005) found that on reefs with high rugosity, the sponges were unable to spread laterally and therefore smaller in size than on the low relief reef terraces.

Whilst substrate availability is a crucial driver of bioeroding sponge abundance it may not always be the most important factor. Nava et al. (2014) found that on the Mexican Pacific coast, the preferred substrate type for bioeroding sponges was dead coral framework and coral rubble, but sites with the highest coverage of these substrates did not necessarily have highest sponge abundance. The highest abundances and diversity were actually found on reefs closest to tourist developments where the highest concentrations of $\delta^{15} \mathrm{~N}, \delta^{13} \mathrm{C}$ and cholorphyll existed, but not the highest substrate availability. Similar abundance patterns have been observed in the Caribbean where Ward-Paige et al. (2005) found the highest abundances of sponges at sites with the highest levels of total nitrogen, ammonium and $\delta^{15} \mathrm{~N}$. This relationship between abundance and eutrophication is due to the exact same mechanism, which results in higher erosion rates in these environments - increased food availability. However, the indirect effects of high nutrient input can also limit sponge abundance; an assessment of the abundance of Cliona delitrix and Cliona lampa along the Florida Reef Tract by Chaves-Fonnegra et al. (2007) found that the abundance of $C$. delitrix increased with proximity to sewage sources on a reef in the Columbian Caribbean, but dropped off adjacent to the sewage outlet presumably due to excessive sedimentation and turbidity. Nava and Carballo (2013) came to a similar conclusion when they found no relationship between the distribution of boring sponge assemblages and chlorophyll $\alpha$ concentrations on Pacific Mexican reefs.

Sedimentation can be another important regulator of bioeroding sponge abundance and there are large inter-specific differences in sedimentation tolerance. Some species, such as Siphonodictyon mucosum, have adapted to live in highly sedimented habitats; on the GBR S. mucosum is often found buried beneath sediment with only fistules protruding into the water column (Schönberg 2000a). Other important bioeroding sponge species such as C. celata and $C$. viridis have been shown to withstand very high sedimentation rates (Muricy 1991; Carballo et al. 1994) and this tolerance has allowed them to dominate some highly impacted sites (Carballo et al. 1996). However, many species are not so resilient to the adverse effects of sedimentation (smothering, 
turbidity, abrasion and clogging). Another study, also in the Mexican Pacific, found sediment disposition and water movement negatively correlated with bioeroding sponge abundance (Nava \& Carballo 2013). The combined effect of high water flow and high sediment loads is thought to limit sponge abundance through either clogging or abrasion (Nava \& Carballo 2013) or possibly through prevention of larval settlement (Bell \& Barnes 2000). Other studies have found similar negative impacts; an assessment of the bioeroding community in Discovery Bay, Jamaica, by Macdonald and Perry (2003) found that the community structure shifted from being dominated by sponges at clear water sites to being dominated by worms and bivalves and highly sedimented sites.

For those zooxanthelate species that comprise the $C$. viridis species complex, light availability appears to play an important role in determining their distribution. Light availability may be influenced by depth, turbidity and reef complexity (and interactions among these factors) and influence different species in different ways. For example in the Columbian Caribbean, three species in the $C$. viridis complex, $C$. aprica, $C$. caribbaea and $C$. tenuis, are all most abundant on well-lit surfaces, but restricted to different depth categories (López-Victoria \& Zea 2005). This depth distribution could be related to different tolerances for wave exposure but could also be a reflection of different photosynthetic requirements for each species. The zooxanthellate $C$. orientalis is most abundant in the very shallow waters just below the low tide mark around the Orpheus Island in the GBR (Schönberg 2001), however at Davies Reef (also in the GBR) the same species is most abundant between 3 and $8 \mathrm{~m}$ depth (Bergman 1983). This difference in distribution is attributed to the higher turbidity levels at Orpheus Island, forcing the sponge to seek shallower more optimal light conditions (Schönberg 2001). However as discussed earlier, the distribution of photosynthetic bioeroding sponges isn't always dependent upon light availability. When Steindler et al. (2001) showed that P. vastifica could photoacclimate to light levels far higher than in its natural habitat, the authors concluded that the distribution of $P$. vastifica was likely driven by factors controlling larval settlement or competition rather than photosynthetic requirements. 


\subsubsection{Competition}

Space is at a premium on coral reefs; suitable substrata is a limiting resource for the settlement, growth and reproduction of benthic organisms and competition is a major process that can govern distribution of abundance and diversity (Connell et al. 2004; Foster et al. 2008; Chadwick $\&$ Morrow 2011). The competitive abilities of bioeroding sponges are therefore an important biotic factor that can regulate the distribution of these organisms independently of environmental conditions. Reef sponges are important spatial competitors and are able to outcompete adjacent sessile invertebrates through a variety of means from physical overgrowth to producing an array of allelopathic chemicals (Porter \& Targett 1988; Aerts \& van Soest 1997; de Voogd et al. 2004). Encrusting bioeroding sponges ( $\beta$ form) are particularly aggressive spatial competitors. Their ability to erode the substrate beneath adjacent coral competitors allows them to avoid many of their defensive mechanisms and eventually displace it (Rützler 2002a; López-Victoria et al. 2003). Erosion beneath the coral polyps is accomplished by pioneering excavating tissue filaments, which precede the front of the sponge tissue (Schönberg \& Wilkinson 2001; LópezVictoria et al. 2003). This competitiveness allows species such as C. caribbaea to advance at rates of up to $9.2 \mathrm{~cm} \mathrm{yr}^{-1}$ into adjacent corals (Acker \& Risk 1984) and form large encrusting sheets (e.g. Calcinai et al. 2005; López-Victoria \& Zea 2005). Of course the outcome in any competitive interaction is also jointly determined by the competitive abilities of the sponges neighbor, Vicente (1978) found that $C$. varians on Puerto Rican reefs was competitively superior to 13 coral species but was unable to overgrow Mycetophyllia lamarckiana, one of the most aggressive Caribbean coral species (Lang 1973). Fang et al. (2017b) found similar competitive dominance by the Porites over $C$. orientalis using an ex situ experiment with sponge and coral cores. Competitive interactions are not limited to scleractinian corals, in the Caribbean there have been large increases in macroalgae abundance which are significant spatial competitors for bioeroding sponges. González-Rivero et al. (2011) found that the macroalgae Lobophora variegata was able to outcompete $C$. tenuis through a combination of allelopathy and physical shading. 


\subsection{The Wakatobi}

The Wakatobi Marine National Park (Wakatobi) in south-east Sulawesi, Indonesia, is an area of 1.4 million hectares encompassing the four major islands of the Tukang Besi Archipelago and the surrounding waters. It was gazetted a marine park in 1996 and a UNESCO Biosphere Reserve in 2012 due to its extremely high marine biodiversity; over 390 species of coral and 590 species of fish (Pet-Soede \& Erdmann 2003). The park is the third largest in Indonesia and while it includes approximately 50,000 hectares of coral reefs (Clifton et al. 2010), it is also home to over 90,000 local people who depend heavily on the local reefs for their protein intake and income (Cullen et al. 2007). The combination of heavy local reliance on the reefs, a history of poor resource management in the park (Cullen 2010) and regional/global stressors has resulted in declines in coral cover and fish abundance (Curtis-Quick 2013). As reef degradation within the Wakatobi is patchy (Powell et al. 2010), it represents a microcosm of the Southeast Asian IndoPacific region; some reefs are severely degraded while others have been less influenced by anthropogenic disturbance, and some are in near pristine condition. A classic example of a degraded reef is the fringing reef adjacent to the Bajo village of Sampela off the island of Kaledupa (Figure 1.1); the reef is heavily overfished, has experienced an $83 \%$ reduction in coral cover to below $10 \%$ in the last decade (Curtis-Quick 2013) and sedimentation levels are approximately four times higher than neighbouring reefs (Crabbe \& Smith 2005). The sediment is comprised of fine particles, which settle on the substrate, smothering benthic organisms, but also acts in suspension to dramatically increase turbidity (Crabbe \& Smith 2005). Healthier sites include an exposed part of the Hoga fringing reef called "Ridge 1", which has experienced a $51 \%$ decline in coral cover over the last decade and currently still has over $25 \%$ cover (Curtis-

Quick 2013; Fig 1.1). Some reefs around the lesser populated islands such as Tomia appear to be in near pristine condition with greater than $65 \%$ coral cover (J. Marlow pers obs.) which is comparative with historical baselines for the region (Bruno \& Selig 2007). 


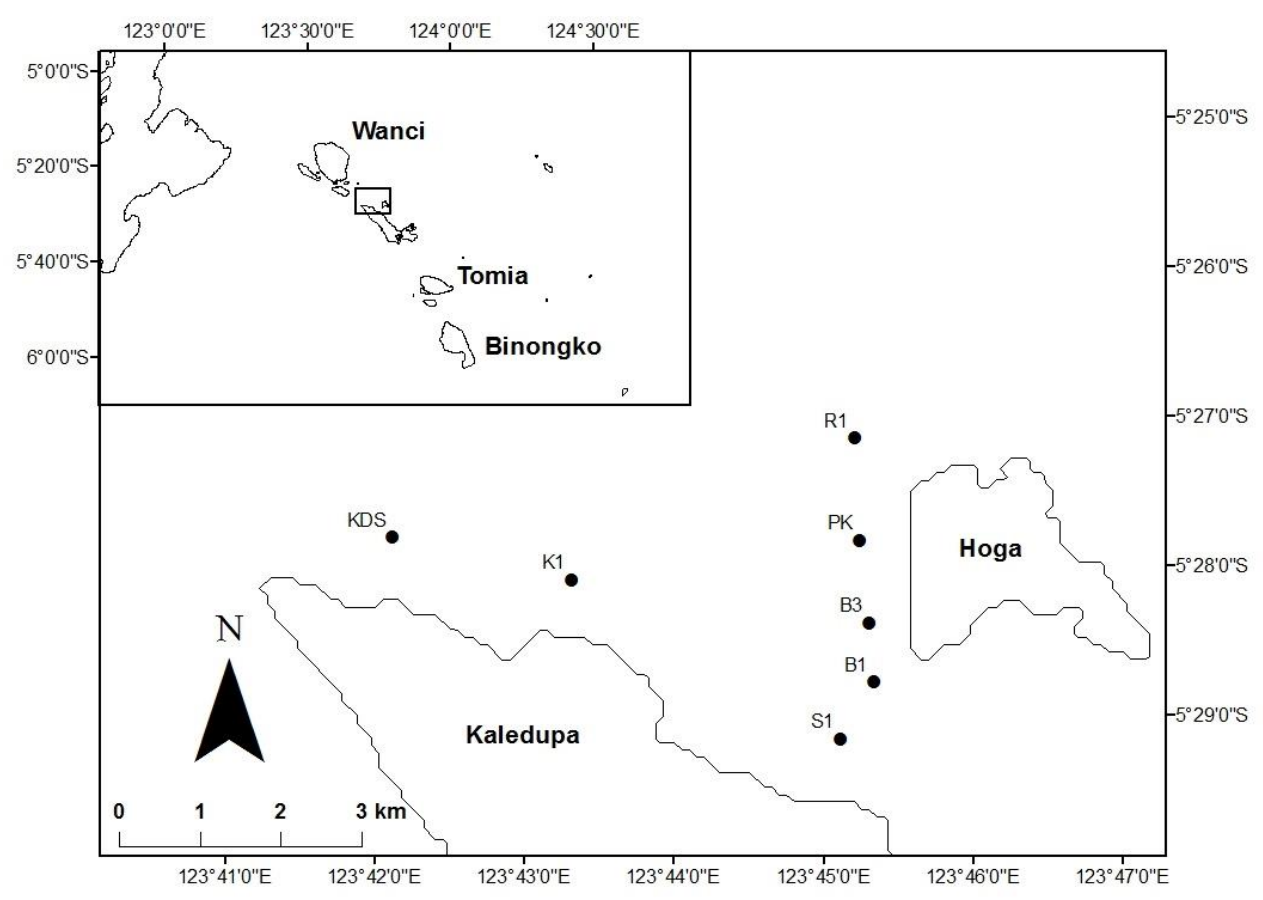

Figure 1.1. Map of the main study sites within the Wakatobi. Sites Buoy $1 \& 3$, Kaledupa 1 and Kaledupa Double Spur, Pak Kasim's, Ridge 1 and Sampela 1 are abbreviated as B1, B3, K1, KDS, PK, R1 and S1 respectively.

The ecology of the sponge assemblages within the Wakatobi is relatively well studied for the Indo-Pacific region (e.g. Bell et al. 2010; Powell et al. 2014) and to date over 100 species have been reported in the area (Bell \& Smith 2004). Bell \& Smith (2004) found sponge species richness to increase with depth and a significant difference in the sponge assemblage composition between the impacted site Sampela and another healthier site on the Hoga fringing reef. To date there has been no research into bioeroding sponges in the Wakatobi, although Bell \& Smith (2004) did report one unidentified clionaid sponge species in their assessment of the Hoga sponge assemblage. Within Indonesia there are only four published studies specifically addressing these organisms; two studies into erosion rates and eutrophication (Edinger et al. 2000; Holmes et al. 2000), one study identifying species of the bioeroding sponge community in North Sulawesi (Calcinai et al. 2005) and another addressing erosion rates and substrate composition (Calcinai et al. 2008).

Anthropogenic disturbances that have caused declines in coral cover in the Wakatobi have coincided with significant increases in abiotic substratum (Curtis-Quick, 2013). This increase in available substrate, potentially creates an opportunity for clionaid sponges to increase in 
abundance. It is therefore critical to understand the factors that control bioeroding sponge abundance and understand how the factors that constitute disturbance for corals, will affect the functioning and abundance of these sponges within the context of the reef system.

\subsection{Thesis aims}

The overall aim of this thesis is:

To obtain a greater understanding of how habitat degradation will affect the ecology and function of bioeroding sponges on Indonesian coral reefs

\subsubsection{Thesis objectives}

1. To use spicule characteristics and phylogenetics to identify the common bioeroding sponge species in the Wakatobi.

2. To assess current trends in the abundance, distribution and assemblage composition of bioeroding sponges in the Wakatobi and relating these trends to local environmental and abiotic conditions. Consequently, gaining a greater understanding of how changes in these factors, particularly those which co-vary with reef degradation, might drive abundance and assemblage composition on degraded reefs.

3. To assess the rates of bioeroding sponge recruitment and determine the relative importance of the abundance of local adult population and substrate settlement cues for this recruitment

4. To measure the capacity for zooxanthellate sponges to photoacclimate to conditions of reduced light availability associated highly turbid reefs.

5. To measure the bioerosion rates of Spheciospongia cf. vagabunda and determine how these vary in relation to environmental variables. 


\section{Chapter 2: Bioeroding Sponges from Wakatobi National Park, Southeast Sulawesi, Indonesia}

\subsection{Abstract}

Sponges that excavate and inhabit calcareous substrate, predominantly of the Clionaidae family, have a cosmopolitan distribution but are particularly diverse and abundant on coral reefs. Unfortunately, their cryptic habitat and difficult identification means their taxonomy is poorly understood and therefore they are rarely included in reef surveys. This is particularly true of the Southeast Asian Indo-Pacific, where compared to other coral reef regions, they are understudied. I conducted in situ surveys of the common bioeroding sponges in the Wakatobi region of Southeast Sulawesi, Indonesia, and samples were retained for spicule and molecular analysis. The Wakatobi bioeroding sponge fauna comprised 8 common species including two putative new species. Three species, Cliona orientalis, Spheciospongia $\mathrm{cf}$. vagabunda and Cliothosa $\mathrm{cf}$. aurivilli, have been previously described in Indonesian waters, while three species, Cliona cf. schmidtii, Cliothosa hancocki and Zyzzya criceta were new descriptions for Indonesia. Finally, two sponges belonging to the Cliona viridis species complex, Cliona aff. viridis n. sp. A \& B, were morphologically distinct from other species within the complex. A maximum likelihood analysis of ITS1 rDNA for these sponges found both to be monophyletic clades, phylogenetically closer to $C$. orientalis and Cliona varians than other species within the complex. Both species are described here for the first time. 


\subsection{Introduction}

Sponges are globally ubiquitous coral reef organisms that through a variety a mechanisms are major contributors to the functioning of reef ecosystems (Wulff 2001; Bell 2008). While some sponge species indirectly contribute towards reef building (Wulff \& Buss 1979), bioeroding sponges actively erode calcium carbonate. These sponges make a considerable contribution to reef bioerosion, frequently representing 60 to $90 \%$ of macroborer activity on coral reefs (Risk et al. 1995). Bioerosion influences coral reef structural complexity (Scott \& Risk 1988), produces significant amounts of sediment for framework accretion (Hubbard et al. 1990) and by counterbalancing calcification processes, affects the reef carbonate cycle (Perry et al. 2008). Bioeroding sponges have recently become the focus of numerous studies following reports of their apparent proliferation on many degraded reefs across the globe (e.g. Ward-Paige et al. 2005; Schönberg \& Ortiz 2009; Carballo et al. 2013). This rise in abundance is attributed to: 1) bioeroding sponge resilience to the anthropogenic disturbances that are stressors for hard corals (e.g. López-Victoria \& Zea 2004; Schönberg \& Suwa 2007; Schönberg \& Ortiz 2009; Wisshak et al. 2012); and 2) their close association with carbonate substrate which increases as a consequence of coral mortality (Chaves-Fonnegra et al. 2007; Nava \& Carballo 2013; Schönberg 2015a). Stressor resilience, endolithic dependency and bioerosion rates vary among species (e.g Schönberg 2001; Murphy et al. 2016) and bioeroding sponge assemblages on degraded reefs are often dominated by a few resilient species (e.g. Schönberg \& Ortiz 2009). Therefore, to better understand the trajectories of these sponges on future degraded reefs, relevant studies need to be undertaken at the species level. Regrettably this is often hampered by the lack of taxonomic knowledge.

Taxonomically, Mediterranean and Caribbean bioeroding sponges has traditionally been very well studied (e.g. Schmidt 1862; Carter 1882; Pang 1973; Vicente 1978; Carballo et al. 1994; Hill 1996; Rosell et al. 1999; Zea \& Weil 2003; Escobar et al. 2012; González-Rivero et al. 2013), and in the wider Caribbean bioeroding sponges are the subject of long-term monitoring programs (e.g. Atlantic and Gulf Rapid Reef Assessment (Lang et al. 2010) and Southeast Florida Coral Reef Evaluation and Monitoring Project (Gilliam 2010)). The situation is different for Indo-Pacific reefs and although bioeroding sponges in some areas such as the Great Barrier Reef (GBR) and the Mexican Pacific have received recent attention (e.g. Schönberg 2000a; 
Schönberg \& Ortiz 2009; Nava \& Carballo 2008; 2013; Cruz-Barraza et al. 2011), other important areas remained unstudied or only superficially studied. One such location is Indonesia; the 17,000 island archipelago nation is located centrally within the coral-triangle, the global epicentre of reef biodiversity (Briggs 2005; Veron et al. 2009), and is considered the largest and most important coral reef nation in the world (Spalding et al. 2001). To date, 314 sponge species have been recorded in Indonesian waters (World Porifera Database, (WPD; van Soest et al. 2017)) and it is estimated that the Indonesian sponge fauna could be comprised of up to 830 species (Van Soest 1989; 1994). However, very little is known about the Indonesian bioeroding sponge assemblage composition and only nine species are officially listed within the WPD. Despite this, Tomascik et al. (1997) tentatively reported the Indonesian bioeroding sponge fauna to consist of 33 species, of which 19 were provisionally identified to the species level; 17 species belonging to Clionaidae and 2 to Phloeodictyidae (van Soest, pers. comm.). Nevertheless, the only detailed assessment from this region is by Calcinai et al. (2005) who identified six clionaid species around the island of Bunaken in Northern Sulawesi.

Due to the lack of taxonomic information on Indonesian bioeroding sponges (and their cryptic habit), they are mostly excluded from surveys and monitoring work (e.g. de Voogd et al. 2006). Consequently, very little information exists on the status of these organisms on degraded Indonesian reefs (see Edinger et al. 2000; Holmes et al. 2000). The current gap in our knowledge of the Indonesian bioeroding sponge fauna needs to be addressed given the significant anthropogenic threats to these important reefs (Spalding 2001; Burke et al. 2011) and considerable potential negative impacts of proliferation of these sponges (e.g. Carballo et al. 2013). In this context, this chapter is an assessment and description of the eight most common bioeroding sponge species in the Wakatobi region of Southeast Sulawesi, Indonesia. 


\subsection{Methods}

\subsubsection{Sampling and morphological analysis}

Surveys were carried out at seven reef sites in the UNESCO Wakatobi Biosphere Reserve (here; Wakatobi) (Fig. 2.1) between the depths of 3 and $20 \mathrm{~m}$ during March-April and June-August 2014. Specimens were collected using a hammer and chisel or by rubble collection and preserved in 70 or $96 \%$ ethanol. In addition to the collection of specimen samples, comprehensive field notes and photographs were taken in situ detailing live colour, organism size, inhalant and exhalent structures and macroscopic characteristics of erosion. In addition, application of Pulse Amplitude Modulated Fluorometry (RED DIVING-PAM, Walz, Iffeltrich) to detect fluorescence yield in in situ light-adapted sponges, and subsequent tissue examination (using light microscopy) identified the presence of symbiotic Symbiodinium.

Spicule arrangement and composition within papillae/ecotosome and choanosome tissue was investigated using light microscopy (Leica DMLB, Wetzlar). Cross sections of papillae or ecotosome tissue were cut using a scalpel and choanosome tissue was removed from erosion chambers using forceps (pluck preparation; Schönberg 2000a). Tissue samples were fully dehydrated in $100 \%$ ethanol, cleared in Xylene and mounted on microscopy slides with DPX (Sigma-Aldrich, St Louis).

Spicule dimensions were studied with both light microscopy (Leica DMLB, Wetzlar) and scanning electron microscopy (SEM; Hitachi TM3000, Tokyo). For spicule preparation, portions of tissue from the choanosome and surface tissue were selected from each sample and separately heat dissolved in nitric acid, rinsed in distilled water and dehydrated in ethanol (procedure after Schönberg 2000a). Spicules were mounted on microscopy slides with DPX for light microscopy and placed on stubs before sputtering with gold for SEM. Spicule dimensions were measured using a micrometre eyepiece for light microscopy and the software package ImageJ for SEM images. Measurements were carried out along haphazardly selected transects across the slide or stub, disregarding broken, malformed and newly recruited spicules and using a minimum sample size of $n=25$ per spicule type. Megasclere dimensions were measured in terms of total length, shaft width (widest part) and tyle width, and microscleres were measured in terms of total length 
(including spines and branches), shaft width (widest part without spines) and number of bends for spirasters (see Schönberg 2000a).

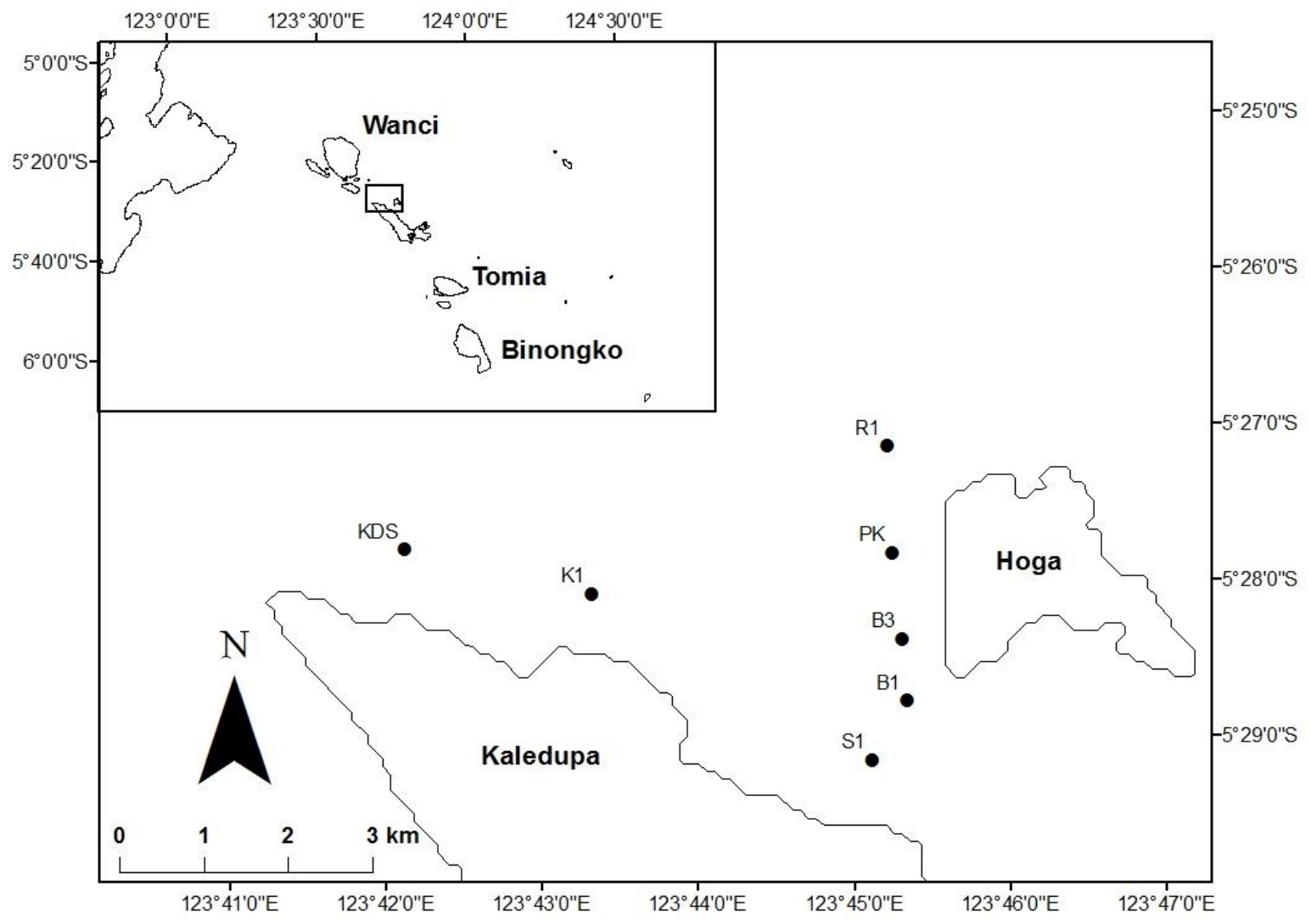

Figure 2.1. Map of sponge sampling locations within the Wakatobi National Park. Sites Buoy 1 \& 3, Kaledupa 1 and Kaledupa Double Spur, Pak Kasim's, Ridge 1 and Sampela 1 are abbreviated as B1, B3, $\mathrm{K} 1, \mathrm{KDS}, \mathrm{PK}, \mathrm{R} 1$ and S1 respectively.

\subsubsection{Molecular analysis}

DNA was extracted from two specimens of two $96 \%$ ethanol preserved zooxanthellate species, Cliona aff. viridis n. sp. A \& B (see below) using a Qiagen extraction kit. PCR amplifications of the ITS1 region were carried out according to the methodology outlined by Escobar et al. (2012), using the primers D-ITS1-F and D-ITS1-R and sequenced in both directions by a third party service (Macrogen, South Korea). Sequence alignment and phylogenetic tree construction were conducted in the software package MEGA v.7. Searches through the NCBI BLAST algorithm identified potential homologues for the sponges in question and were used with the Wakatobi sequences to generate a multiple sequence alignment using the MUSCLE method. The phylogenetic tree was constructed using the maximum likelihood method with the Kimura 2- 
parameter model (the best model selected by MEGA) and rapid bootstrap analysis with 1000 replicates.

Homologous sponges selected for the phylogenetic tree were Cliona aprica (JN011557.1, JN011558.1 \& JN011501.1), Cliona caribbaea (JN011500.1, JN011497.1 \& JN011555.1), Cliona tenuis (JN011499.1, JN011496.1, JN01149.1), Cliona orientalis (JN011482.1) and Cliona varians (JN011469.1, JN011474.1 \& JN011473.1). As per Escobar et al. (2012), Spirastrella coccinea (JN011577.1, JN011578.1 \& JN011579.1) was used as an outgroup. 


\subsection{Results}

\section{Order Clionaida Morrow \& Cárdenas 2015}

\section{Family Clionaidae d'Orbigny 1851}

\section{Genus Cliona Grant 1826}

\section{Diagnosis}

Heteroscleromorph clionaid genus with sponges in endolithic-papillate (alpha), endolithicencrusting (beta), free-living (gamma) and intermediate morphologies and with ability to erode calcareous materials. Silicate skeleton - monaxon megascleres, tylostyles, oxeas or modifications. If present, secondary or microscleres spirasterose spicules, amphiasters, oxeas, raphides and microrhabds. Arrangement of papillar tylostyles in palisade or as bouquets, tyles anchored in sponge tissue, points above tissue surface. Erosion traces largely camerate and small, but some species with large-camerate to cavernous erosion chambers. Symbiosis with Symbiodinium spp. common in sponges with tylostyles and spirasters.

\subsubsection{Cliona cf. schmidtii (Ridley 1881)}

Synonymised names

Thoosa istriaca Müller 1979

Vioa schmidtii Ridley 1881 (genus transfer)

Material examined

Wakatobi Material: B1-PA-01, B1-PA-02, B3-PA-01

Morphology and erosion

Exclusively in alpha form (Fig. 2.2A). Papillae and choanosome vivid purple in situ, and colour maintained after preservation in ethanol. Numerous circular papillae visible on substrate surface, usually up to $5 \mathrm{~mm}$ in diameter, but occasionally merging to form single papillae up to $10 \mathrm{~mm}$ in 
diameter (Fig. 2.2B). Inhalants level, fleshy patches with several small pores, while exhalants of similar or larger diameter slightly conical, with single oscular hole (Fig. 2.2B). Short papillar channels $(2-5 \mathrm{~mm})$ penetrate substrate and connect to small $\left(1.2 \mathrm{~mm}^{2} \pm 0.6 \mathrm{SD}\right)$ densely packed erosion chambers separated by irregularly shaped contiguous islands of substrate. Erosion overall shallow and rarely exceeding beyond $15 \mathrm{~mm}$ in depth (Fig. 2.2C).

\section{Tissue characteristics and Symbiodinium presence}

Papillae tylostyles densely packed in palisade form with tips pointing to the exterior. Tylostyles and abundant spirasters irregularly dispersed in papillar channels and choanosome. Low levels of fluorescence measured with DIVE-PAM but no Symbiodinium observed within tissue.

\section{Spicules}

Megascleres - Straight to slightly curved tylostyles (Fig. 2.2D), predominantly with spherical, but occasionally subterminal tyles or stylar modifications. Dimensions (min-max and mean): length 218 - $345 \mu \mathrm{m}(307.7 \mu \mathrm{m} \pm 27.2 \mathrm{SD})$; shaft width $5-9 \mu \mathrm{m}(6.5 \mu \mathrm{m} \pm 1.3 \mathrm{SD})$; and tyle width $5-12 \mu \mathrm{m}(8.4 \mu \mathrm{m} \pm 2.0 \mathrm{SD})$.

Microscleres - Spirasters morphologically very varied but broadly falling into two groups: 1) long and spindly spirasters with a maximum of 7 slight bends with fine, discrete spines in regular spiral distribution on convex side of shaft (Fig. 2.2E \& F): and 2) shorter, stout spirasters with up to three bends and large conical spines mostly concentrated at the ends of shafts (Fig. 2.2E \& F). Dimensions of spindly variety (min-max and mean): length $17.5-75 \mu \mathrm{m}(46.3 \mu \mathrm{m} \pm 15.6 \mathrm{SD})$; and width 1- $4 \mu \mathrm{m}(2.3 \mu \mathrm{m} \pm 0.6 \mathrm{SD})$. Dimensions of stout variety (min-max and mean): length 20 - $38 \mu \mathrm{m}(28.8 \pm 4.9 \mathrm{SD})$; and width 3 - $10 \mu \mathrm{m}(5.4 \mu \mathrm{m} \pm 1.5 \mathrm{SD})$.

\section{Habitat and occurrence}

Common; most frequently found in crevices on steep reef walls and often associated with crustose coralline algae (Fig. 2.2A). 

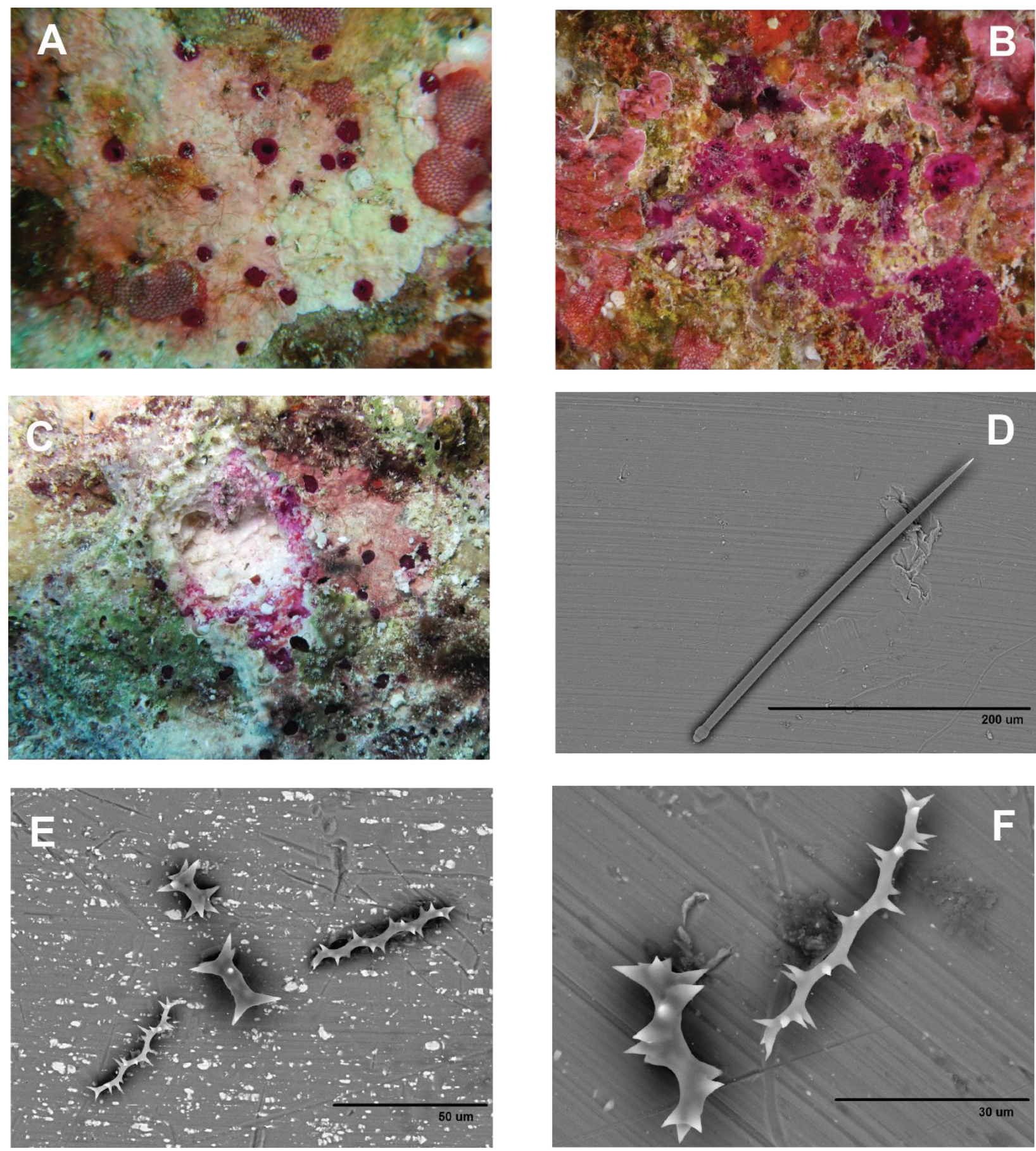

Figure 2.2. Cliona cf. schmidtii. (A) Field image of papillae; (B) field image of merged papillae; (C) exposed erosion of carbonate rock; (D) tylostyle; (E \& F) "spindly" \& "stout" spirasters. 


\section{Remarks}

Purple clionaid sponges stand out in the field and have been sampled from a wide range of sites, including

- the Mediterranean (C. schmidtii; Rosell and Uriz 2002),

- the Atlantic (C. schmidtii; Jamaica, Pang 1973)

- the Indo-Pacific (Cliona jullieni; Reunion, Kelly-Borges \& Vacelet 1998; C. schmidtii; Polynesia, Kirkpatrick 1900; Maldives, Calcinai et al. 2000; Indonesia, Hooper et al. 2000; Great Barrier Reef, Schönberg et al. 2006. Cliona tinctoria; Great Barrier Reef, Schönberg 2000a. Spheciospongia purpurea; East coast of Australia, Lamarck 1814).

Consequently, there are presently only four recognised species of purple clionaids, and due to their comparatively distinct spicule characters and growth form their identification is not generally considered difficult. Based on spicule dimensions C. jullieni and C. tinctoria were readily determined as not being conspecific with the Wakatobi material, even though these species have been described from the Indo-Pacific. Mean tylostyle dimensions of both $C$. jullieni (750 x 12 × $15 \mu \mathrm{m}$; Topsent 1891) and C. tinctoria (380 x 14 × $17 \mu \mathrm{m}$; Schönberg 2000a) are considerably larger than that those sampled from the Wakatobi sponge specimens. The spirasters of both $C$. jullieni and $C$. tinctoria species are also characteristically smaller $(17 \mathrm{x} 4 \mu \mathrm{m}$ and $30 \mathrm{x}$ $1.5 \mu \mathrm{m}$, respectively) than $C$. schmidtii. S. purpurea was equally readily ruled out due to its massive morphology which contrasts with the Wakatobi material that was exclusively found in papillae form.

The spicules of the purple clionaid in my study appear characteristic of $C$. schmidtii. Megasclere size is highly comparable to megascleres of other accounts (e.g. Ridley 1884; Carballo et al. 1994), and the size spectrum and appearance of microscleres are also in accordance with earlier publications, and within the typical size spectrum (e.g. Schmidt 1870). However, it should be noted that other published descriptions of the species report significantly larger spirasters, e.g. Ridley (1881) found two size classes $75 \times 2$ and $50 \times 6 \mu \mathrm{m}$.

The World Porifera Database (van Soest et al. 2017) currently does not accept other distributional areas than the Mediterranean and Eastern Atlantic as valid for C. schmidtii despite published records of occurrences listed above, which include Indonesia. The cautious approach 
by van Soest et al. (2017) is due to the attempt to separate Cliona carteri (Ridley, 1881) from $C$. schmidtii; the same publication by Ridley contains the full description of C. carteri and the first correct, but somewhat hidden, account of $C$. schmidtii. This is now accepted as the original description, but has led to the confusion of the two species that have occasionally been placed in synonymy (Schönberg pers. comm.). However, if it is accepted that C. schmidtii is a brightly purple sponge in alpha form with tylostyles and spirasters that display a continuum of lengths and widths, then based on the samples and accounts listed above its distribution is more widespread than stated by van Soest et al. (2017). Moreover, molecular phylogenetic work by Barucca et al. (2007) sequenced C. schmiditii specimens from the Mediterranean and the Celebes Sea (Indonesia) and found no evolutionary distance between the specimens, confirming the occurrence of $C$. schmidtii in Indonesia and providing good support for species identification of the Wakatobi material. Nevertheless, further molecular studies are required to fully confirm whether $C$. schmidtii is a circum-global species that can be found in temperate to tropical waters. Given this, this ambiguity is acknowledged and the identification of the Wakatobi material is limited to $C$. cf. schmidtii. 


\subsubsection{Cliona orientalis Thiele 1900}

Synonymised names

Anthosigmella orientalis (Thiele 1900) (reverted genus transfer)

Material examined

Wakatobi Material: KDS-BeA-01, KDS-BeA-02, PK-BeA-01

Morphology and erosion

Exclusively in alpha form (Fig. 2.3A). Circular to irregular-shaped papillae which frequently merge, $1-15 \mathrm{~mm}$ in diameter, dark brown with pale grey oscular rings that protrude $1 \mathrm{~mm}$ into water column (Fig. 2.3B). Short (2-6 mm) papillar canals leading to shallow, densely packed irregular-shaped erosion chambers $\left(0.8 \mathrm{~mm}^{2} \pm 0.2 \mathrm{SD}\right)$, separated by irregularly shaped contiguous islands of substrate (Fig. 2.3C). Choanosome yellow.

\section{Tissue characteristics and Symbiodinium presence}

Papillae tylostyles densely packed in palisade form with tips pointing to the exterior. Abundant spirasters irregularly dispersed beneath the palisade layer, in papillar channels and choanosome. Tylostyles irregularly dispersed and becoming rarer in the choanosome. High fluorescence measured with DIVE-PAM and Symbiodinium observed within ectosome tissue under light microscope.

\section{Spicules}

Megascleres - Straight to slightly curved, slender tylostyles with pronounced tyles (Fig. 2.3D). Dimensions (min-max and mean): length 250 - $385 \mu \mathrm{m}(316.7 \mu \mathrm{m} \pm 28.8 \mathrm{SD})$; shaft width 4 - 7 $\mu \mathrm{m}(5.4 \pm 0.6 \mathrm{SD})$ and tyle width $5-10 \mu \mathrm{m}(8.3 \pm 1.2 \mathrm{SD})$.

Microscleres - Spirasters (abundant), either straight, c-shaped or more often helical with three to four bends. Spines arranged in bouquets along both sides of spicule shaft and in terminal clusters (Fig. 2.3E \& F). Spiraster dimensions (min-max and mean): length 15 - $27 \mu \mathrm{m}(22.5 \mu \mathrm{m} \pm 3.2$ SD) and shaft width $0.7-1.5 \mu \mathrm{m}(1.0 \mu \mathrm{m} \pm 0.2 \mathrm{SD})$. 


\section{Habitat and occurrence}

Very rare, found on bare substrate, CCA and oyster shells in shallow waters (max $7 \mathrm{~m}$ depth) at low turbidity sites.
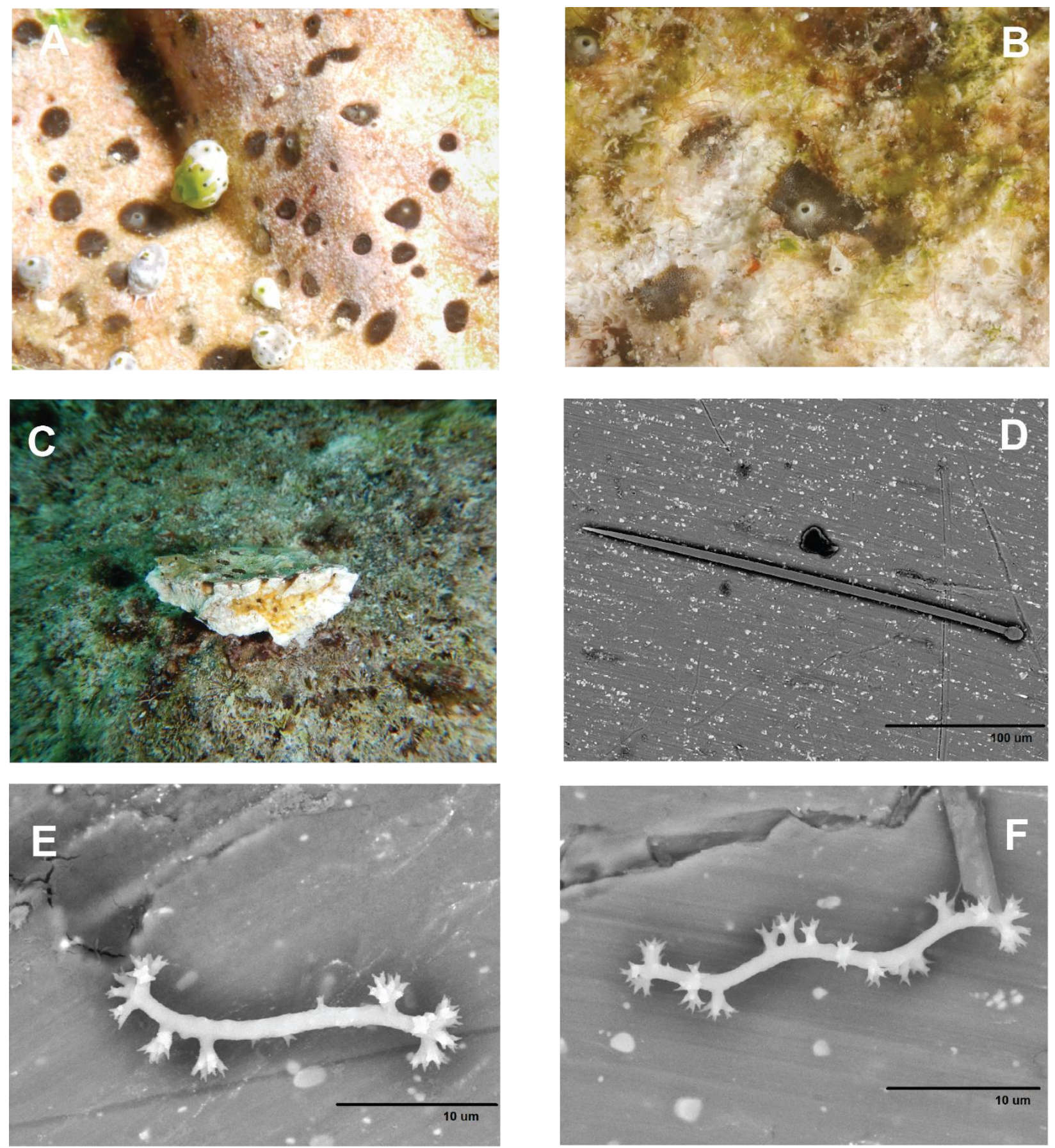

Figure 2.3. Cliona orientalis. (A) Field image of sponge; (B) close-up field image of exhalent papillae; (C) cross-section of erosion zone; (D) tylostyle; (E \& F) spirasters. 


\section{Remarks}

The spicule composition of tylostyles and delicate spirasters in combination with the presence of symbiotic Symbiodinium places the Wakatobi specimens within the "Cliona viridis species complex" (see Schönberg 2000b). Species within this complex found within the Indo-Pacific are C. orientalis (Thiele 1900), Cliona albimarginata (Calcinai et al. 2005), Cliona caesia (Schönberg 2000a) and in the east Pacific Cliona acephala (Zea \& López-Victoria 2016) and Cliona tropicalis (Cruz-Barraza et al. 2011). Based on the comparisons made below this species was identified as $C$. orientalis.

Wakatobi $C$. orientalis was only found in the alpha form, which distinguishes it from $C$. albimarginata and C. acephala which have only been found in the beta form. C. albirmarginata tylostyle dimensions are similar $(288.1 \times 4.6 \mu \mathrm{m})$, but the tyles are only subtly developed, the spirasters are smaller $(12.8 \times 1 \mu \mathrm{m})$, and microscleres are comprised of both amphiasters and spirasters (Calcinai et al. 2005). The differences for C. acephala also go beyond morphology as this species lacks spirasters altogether (Zea \& López-Victoria 2016).

The two exclusively papillate species in the region are C. caesia and C. tropicalis. C. caesia shares a similar raised central conical portion of the papillae, however the papillae are much smaller (0.5-2mm; Schönberg 2000a). Smaller tylostyles, oxeas and the absence of of spirasters further differentiate $C$. caesia from the Wakatobi specimens. Similarities between the Wakatobi specimens and C. tropicalis are limited to tylostyles, which are of a similar shape and size (193 x $5 \mu \mathrm{m}$ in C. tropicalis; Cruz-Barraza et al. 2011). However, C. tropicalis spirasters are predominantly straight and the sponge is morphologically quite dissimilar to the Wakatobi specimens; externally the papillae are yellow in colour and erosion chambers are large and well spaced (Cruz-Barraza et al. 2011).

C. orientalis was originally described in both the alpha and beta form from Ternate, Indonesia (Thiele 1900) and has since been described in Western Australia (Fromont et al. 2005), the Great Barrier Reef (Schönberg 2000a) and New Caledonia (Kelly-Borges \& Vacelet 1998). Schönberg (2000a) described the sponge surface as "beige-brown to mottled dark grayish brown" with oscula that are "slight elevated rings", which is very similar to the description by Fromont et al. (2005). Kelly-Borges \& Vacelet (1998) describe a broadly similar sponge but with distinctly 
large and raised yellow oscula. Although only found in the alpha form in the Wakatobi, the description fits, specifically the raised yellow oscules. Erosion characteristics are also similar; shallow erosion, small and irregularly shaped chambers, and rich-yellow choanosome colour.

Skeletal features of $C$. orientalis vary between descriptions. Tylostyles are generally described as straight/slightly curved with pronounced round to drop-shaped tyles but average sizes can range from 230 × $9 \mu \mathrm{m}$ (Thiele 1900) through $270 \times 7$ x $10 \mu \mathrm{m}$ (Schönberg, 2000a) and 336 × $9 \mu \mathrm{m}$ (Kelly-Borges \& Vacelet 1998) to 344 x $9 \mu \mathrm{m} \mu$ (Fromont et al. 2005). The tylostyles of the Wakatobi specimens are therefore similar in form and length but slightly narrower than previous descriptions. Microsclera composition of $C$. orientalis is similar between published descriptions; delicate spirasters with variable curvature width and length but averaging $23-25 \times 1-2 \mu \mathrm{m}, 3-4$ bends and bouquet spination on convex side of shaft (Thiele 1900; Borges \& Vacelet 1998; Schönberg, 2000a; Fromont et al. 2005).

Despite only occurring in alpha form, the external morphology, erosion characteristics and skeletal composition supports the identification Wakatobi specimens as $C$. orientalis. 


\title{
2.4.3. Cliona aff. viridis n. sp. A
}

\author{
Material examined
}

Wakatobi Material: PK-LBB-01, PK-LBB-02, KDS-LBB-01

\section{Morphology and erosion}

Sponge predominantly in beta form (Fig. 2.4A), but occasionally in alpha form (possibly only in recruits; Fig. 2.4B). Light brown or tan ectosome, yellow choanosome. Individual organisms usually small $\left(\sim 10 \mathrm{~cm}^{2}\right)$, but capable of reaching $75 \mathrm{~cm}^{2}$. Regularly distributed oscular openings 2-4 mm diameter and obvious small ostia. Surface tissue layer coating substrate $1 \mathrm{~mm}$ thick, and sponge evenly and densely pervading substrate beneath, to a depth of 5-7 mm (Fig. 2.4C). Erosion removing roughly $50 \%$ of material leaving irregularly shaped islands of substrate behind (visual assessment) and contiguous. Chambers with irregular outline and mean area of $2.0 \mathrm{~mm}^{2}$ $( \pm$ 1.1 SD) are densely crowded, with well-delineated erosion and not leaving a solid frame of substrate on the surface.

\section{Tissue characteristics and Symbiodinium presence}

Tylostyles in ectosome arranged in palisade pattern with tips pointing to the exterior. Choanosomal tissue comprised of irregularly dispersed tylostyles and numerous spirasters. Spirasters not visible in ectosome. High fluorescence yield measured with DIVE-PAM and Symbiodinium observed within ectosome tissue.

\section{Spicules}

Megascleres delicate straight tylostyles with considerable variation in tyle morphology and occasional subtylostyles (Fig. 2.4D). Dimensions (min-max and mean): length 225 - $375 \mu \mathrm{m}$ (310 $\mu \mathrm{m} \pm 34.7 \mathrm{SD})$; shaft width $3-7 \mu \mathrm{m}(4.9 \mu \mathrm{m} \pm 0.9 \mathrm{SD})$; and tyle width $4-10 \mu \mathrm{m}(7.4 \pm 1.4$ SD).

Microscleres slender spirasters with sparse supination along convex side of shafts, spines multisplit, ending in bouquets; additional bushy, amphiaster-like, terminal crowding of spines. Spirasters C-shaped with spines on convex side, or straight with no spines on central shaft or 
with two-three bends and spines along convex sides of shaft (Fig. 2.4E \& F). Dimensions (minmax and mean): length $13-23.8 \mu \mathrm{m}(19.1 \pm 2.8 \mathrm{SD})$ and shaft width $0.7-1.7 \mu \mathrm{m}(1.1 \pm 0.2 \mathrm{SD})$.

Molecular analysis

C. aff. viridis sp. A appears to be a monophyletic clade with high bootstrap values and a sister taxon to Cliona varians, C. orientalis and C. aff. viridis n. sp. B (Fig. 2.5).

Habitat and occurrence

Common in Wakatobi, most abundant at clear water sites and absent from highly sedimented sites. Spreading across bare substrate or massive coral colonies and often seen neighbouring live coral. 

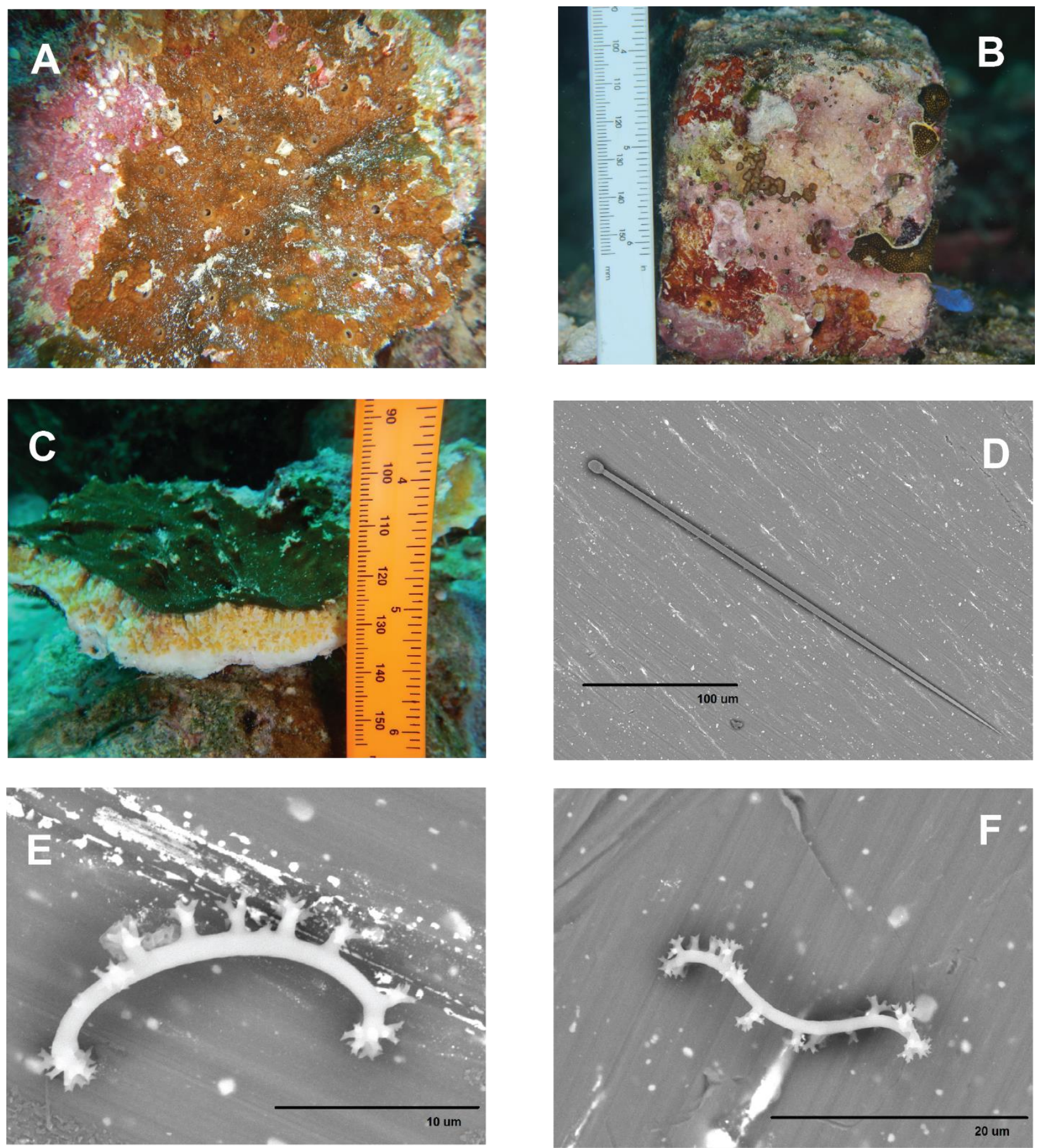

Figure 2.4. Cliona aff. viridis n. sp. A. (A) Field images of adult specimen; (B) field image of recruits/papillae; (C) field cross-section image showing sponge ectosome and extent of sponge erosion; (D) tylostyle; (E) c-shaped spiraster; (F) three-bend spiraster. 


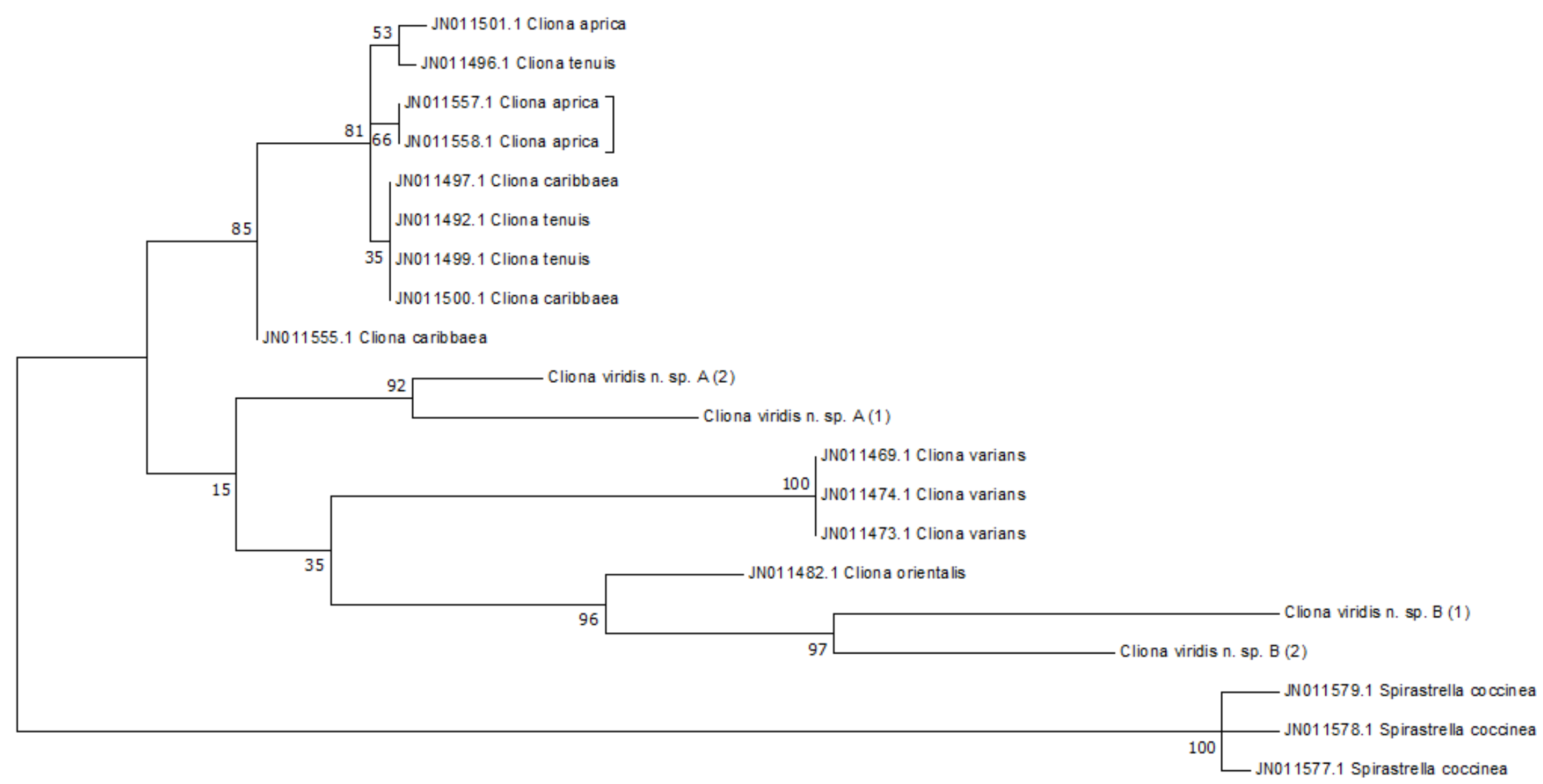

002

Figure 2.5. Phylogenetic tree analysis by Maximum Likelihood method based on the Kimura 2-parameter model. The tree with the highest log likelihood is shown (-1018.61). The percentage of trees in which the associated taxa clustered together is shown next to the branches. Sequences are listed by GenBank accession number and taxon. S. coccinea is rooted as an outgroup. 


\section{Remarks}

The spicule composition of tylostyles and delicate spirasters in combination with the presence of symbiotic Symbiodinium and position within the phylogenetic tree places the Wakatobi specimens within the "C. viridis species complex" (see Schönberg 2000b). Wakatobi specimens were compared to other species within the species complex that are either known to occur (or possibly occur) in the Indo-Pacific region or that bare close resemblance. The material reviewed below highlights the subtle yet important differences between the Wakatobi specimens and these species and leads to the conclusion that the Wakatobi specimens are likely a novel species.

C. albimarginata which is found in North Sulawesi is highly comparable with the Wakatobi specimens on the macro-morphological scale; dark-olive brown ectosome, yellow choanosome and irregular to spherical erosion chambers (Calcinai et al. 2005). However, these features are largely characteristic of all beta form $C$. viridis spp. and are not suitable for species comparison. Spicule composition does differ in two important ways: 1) while C. albimarginata tylostyle length is similar $(322-337 \mu \mathrm{m})$, subtylostyles are described as the norm rather than the exception as in the Wakatobi; and 2) C. albimarginata possesses spirasters (although smaller) but also small amphiasters that are absent in the Wakatobi material.

The molecular analysis inferred that $C$. aff. viridis n. sp. A was monophyletic clade distinct from the Caribbean species of $C$. caribbaea, $C$. aprica and $C$. tenuis and potentially a sister taxon to $C$. varians and $C$. orientalis. This inference is borne out by spicule similarities between the Wakatobi material and both $C$. varians and $C$. orientalis.

The distribution for $C$. varians is accepted for the Caribbean and West Atlantic (van Soest et al. 2017), and Pang (1973) suggested that it is endemic to the area, but the species has also been reported from the Indian and Pacific Oceans (e.g. Thomas 1979; Calcinai et al. 2000). The species displays high phenotypic plasticity with reported growth forms similar to the Wakatobi specimens; an endolithic papillate alpha form (Calcinai et al. 2000) and an endolithic encrusting beta form (Hill 1999). Tylostyle morphology is similar but often larger in C. varians, which can reach up to $465 \mu \mathrm{m}$ in length (Pang 1973; Thomas 1972; 1979) and $16 \mu \mathrm{m}$ in width (Pang 1973; Thomas 1972; 1979). However, it is the microscleres composition of $C$. varians that is diagnostic of the species as it is overwhelmingly dominated by $\mathrm{C}$-shaped spiraster and other forms are rare 
(e.g. Thomas 1972; Pang 1973; Calcinai et al. 2000). Conversely, while C-shaped spirasters are common in the Wakatobi specimens, they not overwhelmingly so and are half the width of those found in C. varians (Pang 1973, Hofman \& Kielman 1992; Calcinai et al. 2000).

Another comparable sponge within the species complex is $C$. orientalis, which is described previously. In the beta form, it's a similar brown sponge with yellow choanosome, shallow erosion and spicule composition of tylostyles of delicate spirasters (Schönberg 2000a) and has previously been confused with C. varians (e.g. Thomas 1972; 1979). The most distinct difference between the Wakatobi specimens and $C$. orientalis is the shape of the spirasters, which despite similar spination and size are considerably more "curvy" in C orientalis where an average of four bends is the norm. 


\subsubsection{Cliona aff. viridis n. sp. B}

Wakatobi Material: PK-B1A-01, PK-B1A-02, B3-B1A-01

\section{Morphology and erosion}

Exclusively in alpha form (Fig. 2.6A). Circular to irregular shaped papillae with brown outer edge and pale grey inner region. Papillae 2-13 mm diameter, frequently merged, and with obvious differences between inhalant and exhalant papillae. Exhalant papillae with slightly raised pale oscular ring (often closed in sampled material) and inhalant papillae dominated by sieve-like structure. Short papillar canals leading to shallow erosion zone (<20 mm depth), comprised of very small $\left(0.7 \mathrm{~mm}^{2} \pm 0.2 \mathrm{SD}\right)$ irregularly shaped erosion chambers separated by small islands of substrate Fig. 2.6B. Choanosome yellow in colour.

\section{Tissue characteristics and Symbiodinium presence}

Papillae tylostyles in ectosome arranged in dense palisade pattern with tips pointing to the exterior. Choanosomal tissue comprised of sparse and irregularly dispersed tylostyles and spirasters. High fluorescence measured with DIVE-PAM and Symbiodinium observed within ectosome tissue.

\section{Spicules}

Megascleres - Stout tylostyles; shaft shape can vary from straight to extensively bent, tyles predominantly spherical but occasionally elongated (Fig. 2.6C \& D). Dimensions (min-max and mean): length 290 - $376 \mu \mathrm{m}(340.0 \mu \mathrm{m} \pm 21.2 \mathrm{SD})$, shaft width $6-11.5 \mu \mathrm{m}(9.2 \mu \mathrm{m} \pm 1.3 \mathrm{SD})$ and tyle width $10-14.5 \mu \mathrm{m}(11.8 \mu \mathrm{m} \pm 1.1 \mathrm{SD})$.

Microscleres - Very rare, long, slender spirasters with long thin spines projecting from convex side of spicule shaft. Spiraster curvature varied, ranging from straight to up 7 bends (average 4; Fig. 2.6E \& F). Spiraster dimensions (min-max and mean): length 18 - $41 \mu \mathrm{m}(24.3 \mu \mathrm{m} \pm 7.2$ SD), shaft width $0.5-1 \mu \mathrm{m}(0.9 \mu \mathrm{m} \pm 0.1 \mathrm{SD})$. 


\section{Molecular analysis}

The phylogenetic tree (Fig. 2.5) infers that the specimens identified as C. aff. viridis n. sp. B occupied a monophyletic clade that is closely related to $C$. orientalis and relatively distantly related to C. caribbaea, C. aprica and C. tenuis (referred to as the Ct-complex by Escobar et al. (2012)).

\section{Habitat and occurrence}

Very common at all Wakatobi sites; usually on bare substrate or dead massive coral, but also on consolidated rubble. Most abundant between 7-12 m depth, except at highly turbid sites where absent below $7 \mathrm{~m}$. 

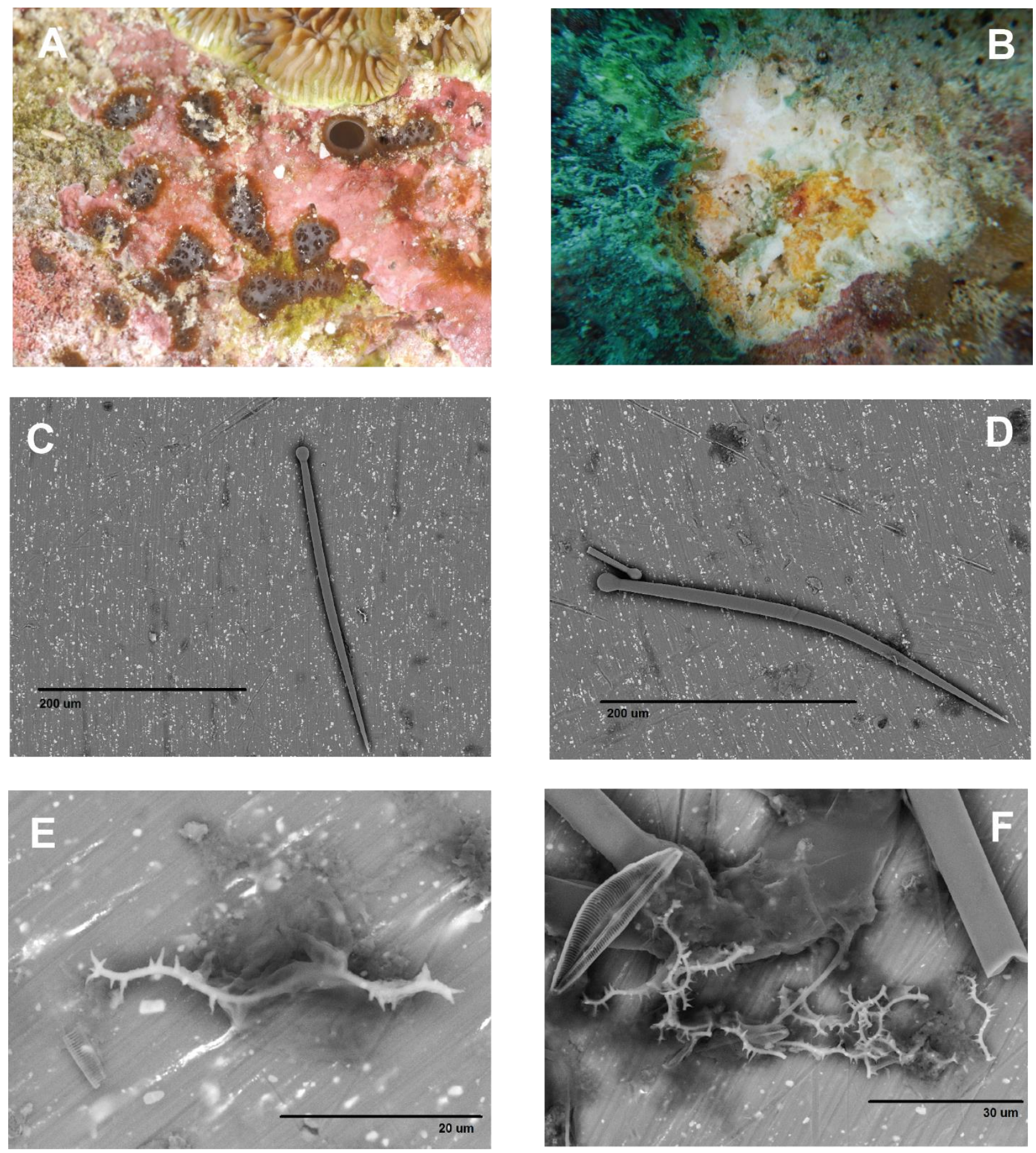

Figure 2.6. Cliona aff. viridis n. sp. B. (A) Field images of inhalant and exhalent papillae (top right); (B) exposed erosion of carbonate rock; (C) straight tylostyle (spiraster also visible); (D) bent tylostyle; (E \& F) spirasters. 


\section{Remarks}

The spicule composition of tylostyles and delicate spirasters in combination with symbiotic Symbiodinium and positioning within the phylogenetic tree places the Wakatobi specimens within the " $C$. viridis species complex" (see Schönberg 2000b). Nevertheless distinct elements of the sponge's morphology and spicule characteristics, as discussed below, appear unique to the Wakatobi samples and thus $C$. aff. viridis n. sp. B likely constitutes a new species.

Despite appearing to share a recent common ancestor with C. orientalis, two important characteristics of $C$. viridis sp. B are markedly different. The sieve-like inhalent papillae on the Wakatobi specimens are distinctive and quite different from $C$. orientalis where no such features have been described (Thiele 1900; Schönberg 2000a). Additionally, the spination of the spirasters is discrete and thorn-like, quite dissimilar to the multi-split, bouquet-like form found in C. orientalis (Thiele 1900; Schönberg 2000a).

The distinctive papillae and spirasters also excludes identification as C. albimarginata, C. caesia, C. acephala, C. varians or C. tropicalis. The only species within the complex to poses similar spiraster characteristics are the Caribbean sponges C. caribbaea and Cliona flavidona (Pang 1973; Rützler 1974; Zea \& Weil 2003). C. flavidona can be readily ruled out due to it's ovoid or droplet shaped tylostyle heads and the presence of amphiasters (Rützler 1974). C. caribbaea is considered a papillate or encrusting zooxanthellate sponge with tylostyles of rounded heads, spirasters with mostly unbranched spines and comparable spicule sizes to the Wakatobi specimens (Zea \& Weil 2003). However, papillate C. caribbaea are rare, considered juvenile and quickly fuse into the encrusting form (Zea \& Weil 2003), in contrast to C. aff. viridis sp. B, which is only encountered in papillae form and usually with less than twenty papillae. Phylogenetically the two are also quite distinct, with $C$. caribbaea grouped with other Caribbean species. 


\section{Genus Spheciospongia Marshall 1892}

\subsubsection{Spheciospongia cf. vagabunda (Ridley 1884)}

Synonymised names

Anthosigmella vagabunda (Ridley 1884) (genus transfer)

Spirastrella cylindrica Kieschnick 1896 (genus transfer and junior synonym)

Spirastrella vagabunda Ridley 1884 (genus transfer)

Spirastrella vagabunda var. fungoides Dendy 1905 (genus transfer and junior synonym)

Spirastrella vagabunda var. gallensis Dendy 1905 (genus transfer and junior synonym)

Spirastrella vagabunda var. tubulodigitata Dendy 1905 (genus transfer and junior synonym)

Material examined

Wakatobi Material: B3-OB-01, B3-OB-02, B1-OB-01

Morphology and erosion

Occurs in beta and gamma form. Ectosome tissue predominantly dark olive green in colour but occasionally brown and choanosome light brown or light olive green (Fig. 2.7A) Individual organisms large, with average surface area of $30 \mathrm{~cm}^{2}$, but occasionally up to $1.5 \mathrm{~m}^{2}$. Large oscular openings 2-7 cm diameter, dispersed across sponge surface, often merging and in larger individuals rising as conical projections up to $10 \mathrm{~cm}$ above sponge surface. Surface generally smooth, however forms lamello-digitate projections in more sedimented environments. No obvious ostia visible with unaided eye. High erosion activity; average erosion depth $5 \mathrm{~cm}$ into substrate, but occasionally penetrating down to $7 \mathrm{~cm}$ (Fig. 2.7B). Erosion chambers circular, small $\left(1.1 \mathrm{~mm}^{2} \pm 0.7 \mathrm{SD}\right)$ and distributed in honeycomb orientation with little calcareous material between chambers. 


\section{Tissue characteristics and Symbiodinium Presence}

Tylostyles organised bunched in palisade form in ecotosome with tips pointing towards exterior and abundant but irregularly dispersed in choanosome. Spirasters restricted to ectosome tissue. No evidence for photosymbionts, neither by surface fluorescence measured by PAM, nor through histology.

Spicules

Megascleres - Stout tylostyles (Fig. 2.7C), straight to slightly curved, highly variable in size and generally larger in the choanosome than in the ecotosome. Large variability in tyle development; generally subtylar and only subtly developed, with occasional stylar modifications. Ectosome tylostyle dimensions (min-max and mean): length $254-665 \mu \mathrm{m}(451.6 \mu \mathrm{m} \pm 116.3 \mathrm{SD})$, shaft width 7 - $11 \mu \mathrm{m}(6.8 \mu \mathrm{m} \pm 1.4 \mathrm{SD})$ and tyle width $5-9 \mu \mathrm{m}(7.1 \mu \mathrm{m} \pm 1.3 \mathrm{SD})$. Choanosome tylostyle dimensions (min-max and mean): length $304-703 \mu \mathrm{m}(541.7 \mu \mathrm{m} \pm 113.0 \mathrm{SD})$, shaft width $5-10 \mu \mathrm{m}(7.4 \mu \mathrm{m} \pm 1.4 \mathrm{SD})$ and tyle width $6-11 \mu \mathrm{m}(8.3 \mu \mathrm{m} \pm 1.4 \mathrm{SD})$.

Microscleres - Spirasters, very variable in morphology, but broadly falling into two categories: 1) short amphiaster-like spirasters (common) and; 2) more slender, contorted spirasters (very rare). Amphiaster-like spirasters with only terminal clusters of spines (Fig. 2.7D), or with spine bouquets aligned along convex side of spicule (Fig. 2.7E), or combinations thereof. Amphiasterlike spiraster dimensions (min-max and mean): length $7-11.4 \mu \mathrm{m}(9.0 \mu \mathrm{m} \pm 1.2 \mathrm{SD})$, central shaft width $1-3 \mu \mathrm{m}(2.1 \mu \mathrm{m} \pm 0.4 \mathrm{SD})$. Slender, helical spirasters with average of three bends and short spines in bouquets on convex side of spicule (Fig. 2.7F). Slender, helical spiraster dimensions (min-max and mean): length $10-22.5 \mu \mathrm{m}(12 \pm 6.0 \mathrm{SD})$, central shaft width $2-2.5$ $\mu \mathrm{m}(2.1 \pm 0.3 \mathrm{SD})$.

\section{Habitat and occurrence}

Very common sponge; most abundant on steep drop-offs and overhangs, less abundant at high rugosity sites dominated by complex corals, and absent from highly sedimented site. Growing across bare substrate and often in apparent competition with live corals and other benthic taxa. 

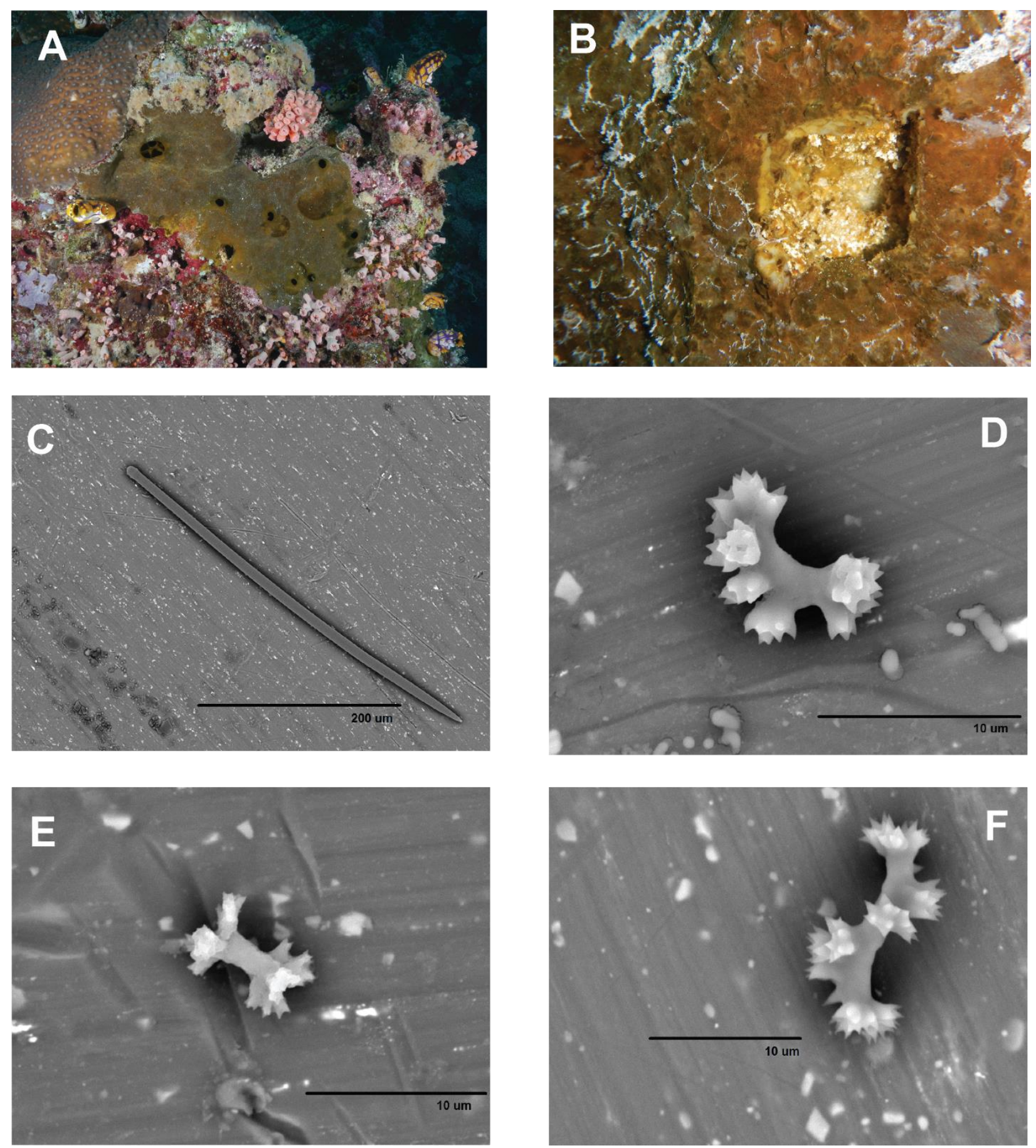

Figure 2.7. Spheciospongia cf. vagabunda. (A) Field images of adult specimen; (B) incision into sponge tissue revealing erosion zone; (C) tylostyle; (D \& E) amphiaster-like spirasters; (F) slender spiraster. 


\section{Remarks}

The spicule compliment of robust tylostyles, slender spirasters and amphiasterose derivatives is diagnostic of sponges belonging to the genus Spheciospongia (Rützler 2002b) and the present samples were identified as S. cf. vagabunda (Ridley 1884), which has a wide distribution across the Indo-Pacific.

The WPD lists five other Spheciospongia species in Indonesian waters; S. carnosa (Topsent 1897), S. lacunosa (Kieschnick 1898), S. semilunaris (Lindgren 1897), S. solida (Ridley \& Dendy 1886) and S. spiculifera (Kieschnick 1898). These were eliminated as possible conspecifics with Wakatobi material due to morphological, colour or spicular differences: $S$. carnosa is described as "cauliflower-shaped, expanding upwards from a narrow base" (Kirkpatrick 1900); S. lacunose has a blue-grey ectosome covered in many tine pores; $S$. semilunaris has a yellow ectosome with no obvious oscula; S. solida is yellow and lobate with pronounced tylostyle tyles; and S. spiculifera is tall and club-like, grey, and with no oscula but abundant ostia.

When looking at the wider Indo-Pacific region, this list expands to include six other Spheciospongia species: S. alcyonoides (Hallmann 1912), S. congenera (Ridley 1884), S. inconstans (Dendy 1887), S. montiformis (Hallman 1912), S. poculoides (Hallmann 1912), S. purpurea (Lamark 1814). All of which are sufficiently dissimilar in either morphology (e.g. $S$. poculoides), colour (e.g. S. purpurea) and or spicule composition (e.g. S. solida \& S. congenera) to be ruled out as concordant with the Wakatobi specimens.

The original description of S. vagabunda by Ridley (1884) is similar to those found in the Wakatobi; "massive, attached by broad base" and "tending to grow up into large nodular elevations, which may bear one or more vents" and olive greenish in colour. However other publications demonstrate a far more varied morphology (see Table 2.1). For example KellyBorges \& Bergquist (1988) describe coral encrusting individuals following the contours of corals, juveniles and endopsammic individuals forming steep sided conical projections and individuals on dead substrate forming mounds. Unlike previous studies (see Table 2.1) endopsammic (sediment buried) individuals were not observed in the Wakatobi, but those 
located in more sedimented environments formed lamello-digitate projections as described by Kelly-Borges \& Bergquist (1988).

Spicule compliment and size in $S$. vagabunda appears very varied, with early authors (e.g. Ridley 1884; Dendy 1905) describing tylostyles with well-developed tyles and later authors (de Laubenfels 1954 onwards) describing tyle variation and subtylar tylostyles. Wakatobi tylostyles are more comparable to the latter forms and are of comparable length but generally smaller in shaft width (see Table 2.1). The existence of two tylostyle size classes also concurs with the most recent work by Kelly-Borges \& Bergquist (1988) and Sutcliffe et al. (2010). Two classes of ectosome restricted spirasters also concurs with previous studies and although the extent to which these size classes dominate varies from study to study, dominance by amphiaster-like spirasters (as in the Wakatobi) has been found in most. It should be noted that the Wakatobi spirasters are a little smaller than in previous descriptions but well within the variation seen between descriptions.

The allocation of this species as $S$. cf. vagabunda acknowledges that there are some morphological and skeletal differences between the Wakatobi specimens and some other descriptions of the species. However, previous descriptions are unusually varied and it is probable that $S$. vagabunda represents a species complex, to which the Wakatobi specimensbelongs. Clarification on this point will likely only come from further phylogenetic research. 
Table 2.1. Character list from previous descriptions of Spheciospongia vagabunda from around the Indo-Pacific. N/A indicates information not available.

\begin{tabular}{|c|c|c|c|c|c|c|}
\hline \multirow[t]{2}{*}{ Characters } & \multicolumn{6}{|l|}{ Publication } \\
\hline & Riddley 1884 & Dendy 1905 & $\begin{array}{l}\text { de Laubenfels } \\
1954\end{array}$ & Bergquist 1965 & $\begin{array}{l}\text { Kelly-Borges \& } \\
\text { Bergquist } 1988\end{array}$ & Sutcliffe et al. 2010 \\
\hline Location & $\begin{array}{l}\text { Torres Strait, } \\
\text { Australia }\end{array}$ & $\begin{array}{l}\text { Sri Lanka \& Java, } \\
\text { Indonesia }\end{array}$ & $\begin{array}{l}\text { West-Central } \\
\text { Pacific }\end{array}$ & Palau & Papua New Guinea & GBR, Australia \\
\hline Habitat & $\mathrm{N} / \mathrm{A}$ & $\begin{array}{l}\text { Deep water \& lagoon. } \\
\text { Sand \& rubble. }\end{array}$ & $\begin{array}{l}\text { Lagoons \& } \\
\text { seagrass. Sand } \\
\text { and rubble. } \leq 35 \\
\text { m depth }\end{array}$ & Sand & $\begin{array}{l}\text { Shallow lagoons } \\
\text { and seagrass }\end{array}$ & $\begin{array}{l}\text { Sandy substrate } 14 \text { - } \\
92 \mathrm{~m} \text { depth }\end{array}$ \\
\hline Morphology & $\begin{array}{l}\text { Massive with } \\
\text { large nodular } \\
\text { elevations. }\end{array}$ & $\begin{array}{l}\text { Four growth forms: } \\
\text { Massive base \& } \\
\text { digitate projections; } \\
\text { fistular; massive; } \\
\text { cylindrical }\end{array}$ & $\begin{array}{l}\text { Basal } \\
\text { "ramifying } \\
\text { mass". } \\
\text { Endopsammic \& } \\
\text { fistular. }\end{array}$ & $\begin{array}{l}\text { Massive \& } \\
\text { digitate with } \\
\text { prominent } \\
\text { oscules }\end{array}$ & $\begin{array}{l}\text { Varied: encrusting } \\
\& \text { excavating; } \\
\text { endopsammic \& } \\
\text { fistular; massive }\end{array}$ & $\begin{array}{l}\text { Massive and fistular } \\
\text { with apical oscules }\end{array}$ \\
\hline In situ Colour & Olive green & N/A & Brown & $\mathrm{N} / \mathrm{A}$ & $\begin{array}{l}\text { Dark olive; olive } \\
\text { brown; dark } \\
\text { reddish brown }\end{array}$ & N/A \\
\hline
\end{tabular}




\begin{tabular}{|c|c|c|c|c|c|c|}
\hline \multirow[t]{2}{*}{ Characters } & \multicolumn{6}{|l|}{ Publication } \\
\hline & Riddley 1884 & Dendy 1905 & $\begin{array}{l}\text { de Laubenfels } \\
1954\end{array}$ & Bergquist 1965 & $\begin{array}{l}\text { Kelly-Borges \& } \\
\text { Bergquist } 1988\end{array}$ & Sutcliffe et al. 2010 \\
\hline \multicolumn{7}{|c|}{ Spicules ( average (unless max stated) size in $\mu \mathrm{m}$ ) } \\
\hline \multirow[t]{5}{*}{ Megascleres } & Tylostyles: & Tylostyles: & Tylostyles; & Tylostyles: & Tylostyles: & Tylostyles: \\
\hline & $\begin{array}{l}\text { strong, slight } \\
\text { curved shaft and } \\
\text { oblong to oval } \\
\text { head }\end{array}$ & $\begin{array}{l}\text { curved, stout } \\
\text { fusiform shafts with } \\
\text { well developed } \\
\text { heads. }\end{array}$ & $\begin{array}{l}\text { some morph. } \\
\text { variation \& } \\
\text { occasional style }\end{array}$ & $\begin{array}{l}\text { large morph. } \\
\text { variation from } \\
\text { styles to tylostyles. } \\
\text { Smaller variety in } \\
\text { cortex }\end{array}$ & $\begin{array}{l}\text { slightly curved with } \\
\text { subterminal head }\end{array}$ & $\begin{array}{l}\text { large morph. } \\
\text { variation. Straight } \\
\text { to slightly curved } \\
\text { shafts. Tyles: } \\
\text { subtylar to well } \\
\text { rounded. }\end{array}$ \\
\hline & One size class: & One size class: & One size class: & One size class: & Two size classes: & Two size classes: \\
\hline & $600 \times 20(\max )$ & $500-600 \times 9-19$ & $500-600 \times 8-27$ & $454 \times 12.5$ & $551 \times 13$ & $483 \times 10$ \\
\hline & & & & & $316 \times 11$ & $268 \times 6$ \\
\hline \multirow[t]{4}{*}{ Microscleres } & Spirasters: & Spirasters: & Spirasters: & Spirasters: & Spirasters: & Spirasters: \\
\hline & $\begin{array}{l}\text { delicate with } \\
\text { three bends and } 4 \\
-8 \text { blunt spines. }\end{array}$ & $\begin{array}{l}\text { not numerous and } \\
\text { varied from only } \\
\text { blunt c-shape to } \\
\text { only slender spiral } \\
\text { form. }\end{array}$ & $\begin{array}{l}\text { not numerous, } \\
\text { most "typical" i.e. } \\
\text { spiral. Many c- } \\
\text { shaped with plunt } \\
\text { projections }\end{array}$ & $\begin{array}{l}\text { found in "dermal } \\
\text { crust" and only of } \\
\text { one type - lacking } \\
\text { slender spiral form }\end{array}$ & $\begin{array}{l}\text { abundant in cortex. } \\
\text { Pred. c-shaped with } \\
\text { 5-7 spined tufts. } \\
\text { Less common long } \\
\text { spiral spirasters }\end{array}$ & $\begin{array}{l}\text { pred. thick curved } \\
\text { shafts }+ \text { spination } \\
\text { on curved side. } \\
\text { Less common thin } \\
\text { spiraster } \leq 4 \text { bends }\end{array}$ \\
\hline & $32 \times 16(\max )$ & $\begin{array}{l}\text { Two size classes: } \\
12 \text { x N/A }\end{array}$ & $13-20 \times \mathrm{N} / \mathrm{A}$ & $16 \times \mathrm{N} / \mathrm{A}$ & $\begin{array}{l}\text { Two size classes: } \\
10 \text { x } 5\end{array}$ & $\begin{array}{l}\text { Two size classes: } \\
11 \times 5\end{array}$ \\
\hline & & $\leq 48 \mathrm{x} \leq 2$ & & & $26 \times 4$ & $14 \times 2$ \\
\hline
\end{tabular}




\section{Genus Cliothosa Topsent 1905}

\section{Diagnosis}

Heteroscleromorph clionaid genus with sponges in endolithic-papillate (alpha) morphology and only one species reported to have free-living forms (gamma). With ability to erode calcareous materials. Silicate skeleton. Monaxon megascleres, robust tylostyles with round tyles. Microscleres spirasterose to amphiasterose forms with spines that commonly have multisplit tips. Arrangement of papillar tylostyles in palisade or as bouquets, tyles anchored in sponge tissue, points above tissue surface. Erosion traces commonly large-camerate or even single, cavernous erosion chambers.

\subsubsection{Cliothosa hancocki (Topsent 1888)}

Synonymised names

Cliona seurati (Topsent 1905) (genus transfer and junior synonym)

Cliothosa ramosa (Lendenfeld 1898) (junior synonym)

Cliothosa seurati Topsent 1905 (junior synonym)

Papillella quadrata (Hancock 1849)

Thoosa hancocci Topsent 1888 (genus transfer and spelling correction)

Thoosa hancocki Topsent 1888 (genus transfer)

Vioa ramosa Lendenfeld 1898 (genus transfer and junior synonym)

Material examined

Wakatobi Material: R1-OA-01, B1-OA-01, PK-OA-01

Morphology and erosion

Exclusively in alpha form (Fig. 2.8A). Papillae light orange to dark yellow, circular and 1-5 mm in diameter. Choanosomal tissue of slightly darker yellow-orange colour than papillae. Inhalant and exhalant papillae noticeably different; inhalant papillae more or less flush with substrate 
surface, with villar papillar wall slightly extending as ring above, and central, meshed area covering papillar lumen slightly below substrate surface. Exhalant papillae rising as stubby, conical projections $2-5 \mathrm{~mm}$ above substrate, becoming more delicate towards minutely scalloped apical edge. Papillar canals lead to sub-ovoid large irregular erosion chambers $\left(5.1 \mathrm{~cm}^{2} \pm 6.5 \mathrm{SD}\right.$; Fig. 2.8B) up to $5 \mathrm{~cm}$ depth, with multiple canals often merging into one chamber, creating a bagpipe appearance.

\section{Tissue characteristics and Symbiodinium presence}

Papillar tissue consists of tylostyles densely packed in a palisade orientation with no microscleres present. Tylostyles and amphiasters are irregularly diffused throughout the choanosome with amphiasters often clustered around tylostyles (Fig. 2.8C). No evidence for photosymbionts, neither by surface fluorescence measured by PAM nor through histology.

\section{Spicules}

Megascleres - Straight to slightly curved, stout tylostyles predominantly with pronounced spherical tyles (Fig. 2.8D). Dimensions (min-max and mean): length $300-481 \mu \mathrm{m}(368.4 \mu \mathrm{m} \pm$ 48.6 SD), shaft width $7-14 \mu \mathrm{m}(11.1 \mu \mathrm{m} \pm 2.0 \mathrm{SD})$ and tyle width $8-16 \mu \mathrm{m}(12.2 \mu \mathrm{m} \pm 1.9$ $\mathrm{SD})$.

Microscleres - Characteristic, very abundant amphiasters, with 3-4 branches at either end of central shaft (Fig. 2.8E). Branches terminating in groups of curved spines. Amphiaster dimensions (min-max and mean): length $18-28 \mu \mathrm{m}(22.3 \mu \mathrm{m} \pm 3.2 \mathrm{SD})$ and central shaft width $1.5-3.7 \mu \mathrm{m}(2.4 \mu \mathrm{m} \pm 0.6 \mathrm{SD})$.

\section{Habitat and occurrence}

Found in low abundances in shallow water ( $<7 \mathrm{~m}$ depth) at most sites in the Wakatobi. Occurs on bare calcareous substrate and often found in dead massive Porites coral skeletons. 

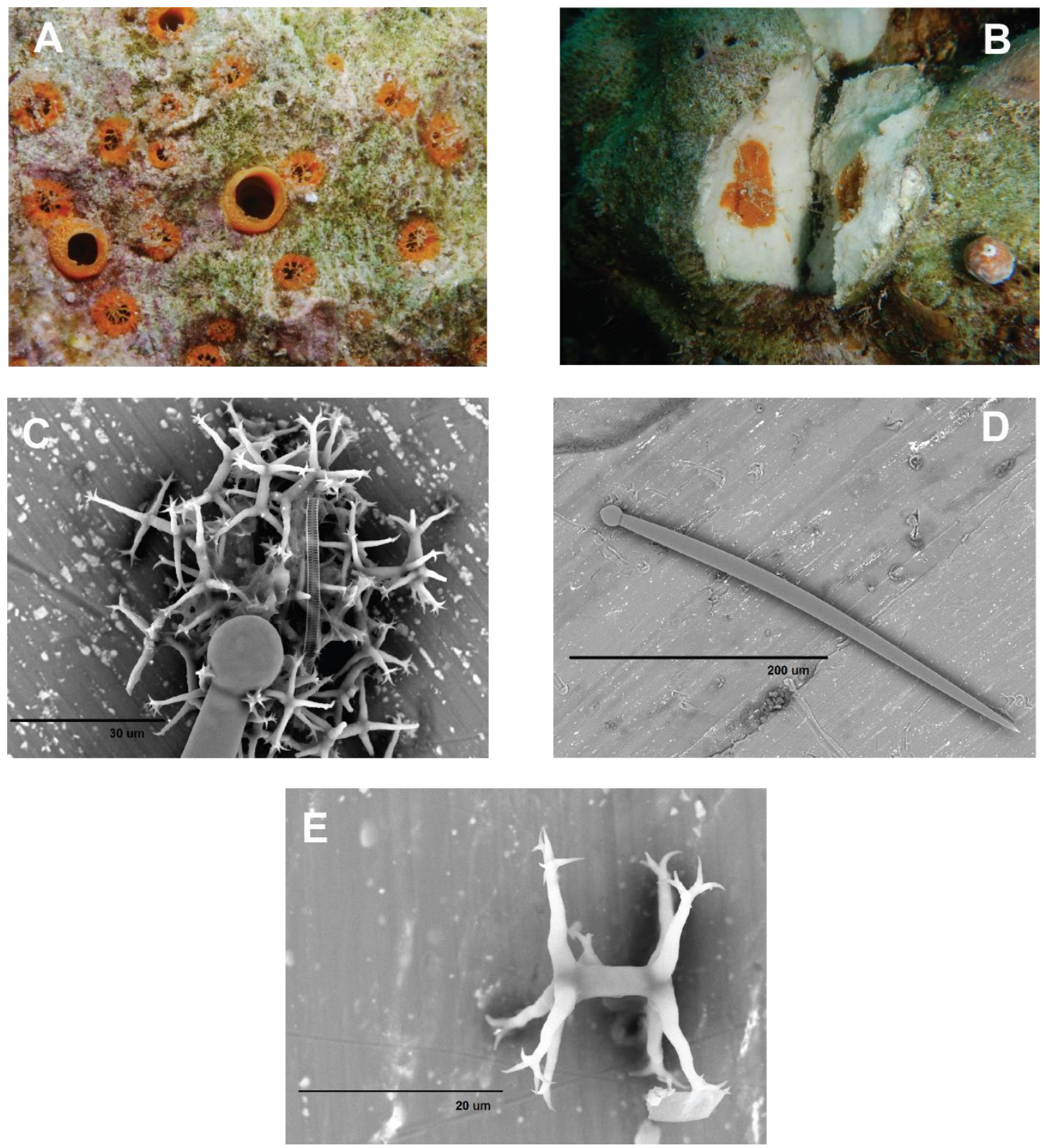

Figure 2.8. Cliothosa hancocki. (A) field image of exhalent (left \& centre) and inhalant papillae; (B) field image of erosion chamber; (C) cluster of amphiasters around tyle; (D) tylostyle; (E) amphiaster. 


\section{Remarks}

This genus has caused some confusion over time and Van Soest et al. (2017) presently accept six Cliothosa species as valid. They are yellow or orange to red or even dull pink, are not known for photosynthetic symbioses and occur in papillate alpha form without papillar fusion, with the exception of Cliothosa aurivillii. Cliothosa erosion chambers are often considerably larger than in Cliona and where respective observations are available, the endolithic tissue in Cliothosa spp. is exceedingly soft and fragile (Annandale 1915 for Cliothosa investigatoris; Cruz-Barraza et al. 2011 for Cliothosa tylostrongylata). The tylostyles are comparatively robust, and have been described as ensiform for a number of species (e.g. Calcinai et al. 2000 for Cliothosa dichotoma). Tyles are spherical as a rule and usually clearly set off from the shaft by a sharp edge, however, they can be subterminal (Annandale 1915; Rützler \& Stone 1986; Cruz-Barraza et al. 2011). Importantly, finding amphiasters resembling "matchstick men" is a clear indicator for Cliothosa. These amphiasters can be less characteristic in some species, but the pattern is displayed in form of a short central axis with terminal branches that can in some species branch again into spines that recurve in the typical form. This pattern is again interrupted in $C l$. aurivillii, in which long spirasters occur, but even these have terminally split spines. Nodulous forms of amphiasters exist, but cannot be found in every specimen, and Annandale (1915) published an observation that these stubby microscleres are patchily distributed.

In the regard to the Wakatobi material, the shape and dimensions of the tylostyles, as well as amphiasterose microscleres readily led to the conclusion that the material belonged into the genus Cliothosa. Of the presently six accepted Cliothosa spp. (van Soest et al. 2017), four have similar amphiasters: Cl. dichotoma (Calcinai et al. 2000), Cl. investigatoris (Annandale 1915), Cl. quadrata (Hancock 1849) and Cl. tylostrongylata (Cruz-Barraza et al. 2011). Cl. dichotoma from the Maldives has significantly shorter tylostyles than the Wakatobi specimens, and they have ensiform shafts, which are also not analogous (Calcinai et al. 2000). Cl. dichotoma amphiasters have conical branches with rare and irregular branching, while the Wakatobi specimens have amphiasters with slender branches that apically split into a few spines. Moreover, unlike the large chambers in the Wakatobi material, erosion traces of $\mathrm{Cl}$. dichotoma were described as small-porous (Calcinai et al. 2000). 
Identification of $\mathrm{Cl}$. hancocki is usually largely determined by the presence of two distinctive groups of amphiasters; the ramose amphiasters described above \& smaller nodulose amphiasters with bulbous branches (e.g. Rosell and Uriz 1997). The latter group of amphiasters were not identified in the studied specimens, however this is not unusual as they are significantly less abundant and can occur in clusters, which can be missed in sampling (Schönberg 2000a). All other skeletal characteristics of the Wakatobi specimens correspond with published descriptions (e.g. Rützler 1973; Schönberg 2000a) as is the cavernous erosion and the presence of little villi on the edges of the inhalant papillae (Schönberg 2000a).

The species has a cosmopolitan distribution spanning from the Mediterranean (e.g. PulitzerFinali 1983), to the East African Coast (Thomas 1979), to Vietnam (Calcinai et al. 2006) and the Australian Great Barrier Reef (Schönberg 2000a). 


\subsubsection{Cliothosa cf. aurivillii (Lindgren 1897)}

Synonymised Names

Spirastrella aurivillii Lindgren 1897

Spirastrella aurivillii excavans Lindgren 1897

\section{Material examined}

Wakatobi Material: B1-RA-01, K1-RA-01, K1-RA-02

\section{Morphology and erosion}

Exclusively in alpha form (Fig. 2.9A). Papillae vivid red/orange, circular, 2 (inhalants) to $10 \mathrm{~mm}$ in diameter (exhalants). Inhalant and exhalant papillae of noticeably different shape when extended. Inhalant papillae shallow rings of villar tissue not extending far above substrate surface and centrally covered by horizontal sieve-like mesh. Exhalant papillae smooth chimneylike, wide open conical projections, rising 2-7 mm above substrate, with finely scalloped, more translucent apical edge. Long papillar canals leading to large $\left(4.5 \mathrm{~cm}^{2} \pm 3.2 \mathrm{SD}\right)$, irregularly shaped erosion chambers, with multiple canals often merging into one chamber, creating "bagpipe" appearance (Fig. 2.9B). Choanosomal tissue paler than papillae and yellow/orange.

\section{Tissue characteristics and Symbiodinium presence}

Papillae tissue consisting of tylostyles in dense palisade with tips pointing to the exterior. Choanosome tissue comprised of irregularly dispersed tylostyles and very rare spirasters. No evidence for photosymbionts, neither by surface fluorescence measured by PAM, nor through histology.

\section{Spicules}

Megascleres - Straight to slightly curved tylostyles with large variability in shaft width, but overall appearing comparatively robust (Fig. 2.9C), predominantly with pronounced spherical tyles and clear crease between tyle and shaft, occasional subterminal tyles. Two size classes. Larger class dimensions (min-max and mean): length $280-515 \mu \mathrm{m}(451.2 \mu \mathrm{m} \pm 33.8 \mathrm{SD})$, shaft width 9 - $16 \mu \mathrm{m}(11.4 \mu \mathrm{m} \pm 1.7 \mathrm{SD})$ and tyle width $12-20 \mu \mathrm{m}(16.1 \mu \mathrm{m} \pm 2.1 \mathrm{SD})$. Small class 
dimensions (min-max and mean): length 250 - $390 \mu \mathrm{m}(331 \mu \mathrm{m} \pm 34.4$ SD), shaft width 6 - 13 $\mu \mathrm{m}(9.4 \mu \mathrm{m} \pm 2.0 \mathrm{SD})$ and tyle width $7-15 \mu \mathrm{m}(11.4 \mu \mathrm{m} \pm 2.6 \mathrm{SD})$.

Microscleres - Helical slender spirasters (rare) with average of 2.5 bends (Fig. 2.9D \& E). Conical spines radiate out along the spiraster length often ending in branched tips. Spiraster dimensions (min-max and mean): length 45 - $80 \mu \mathrm{m}(64.8 \mu \mathrm{m} \pm 9.4 \mathrm{SD})$ and shaft width 2 - 2.5 $\mu \mathrm{m}(2.2 \mu \mathrm{m} \pm 0.3 \mathrm{SD})$.

\section{Habitat and occurrence}

Very common sponge found at all sites and depths studied in the Wakatobi. Highest abundances in shallower water ( $5 \mathrm{~m}$ depth) on bare calcareous rock, dead coral or CCA. 

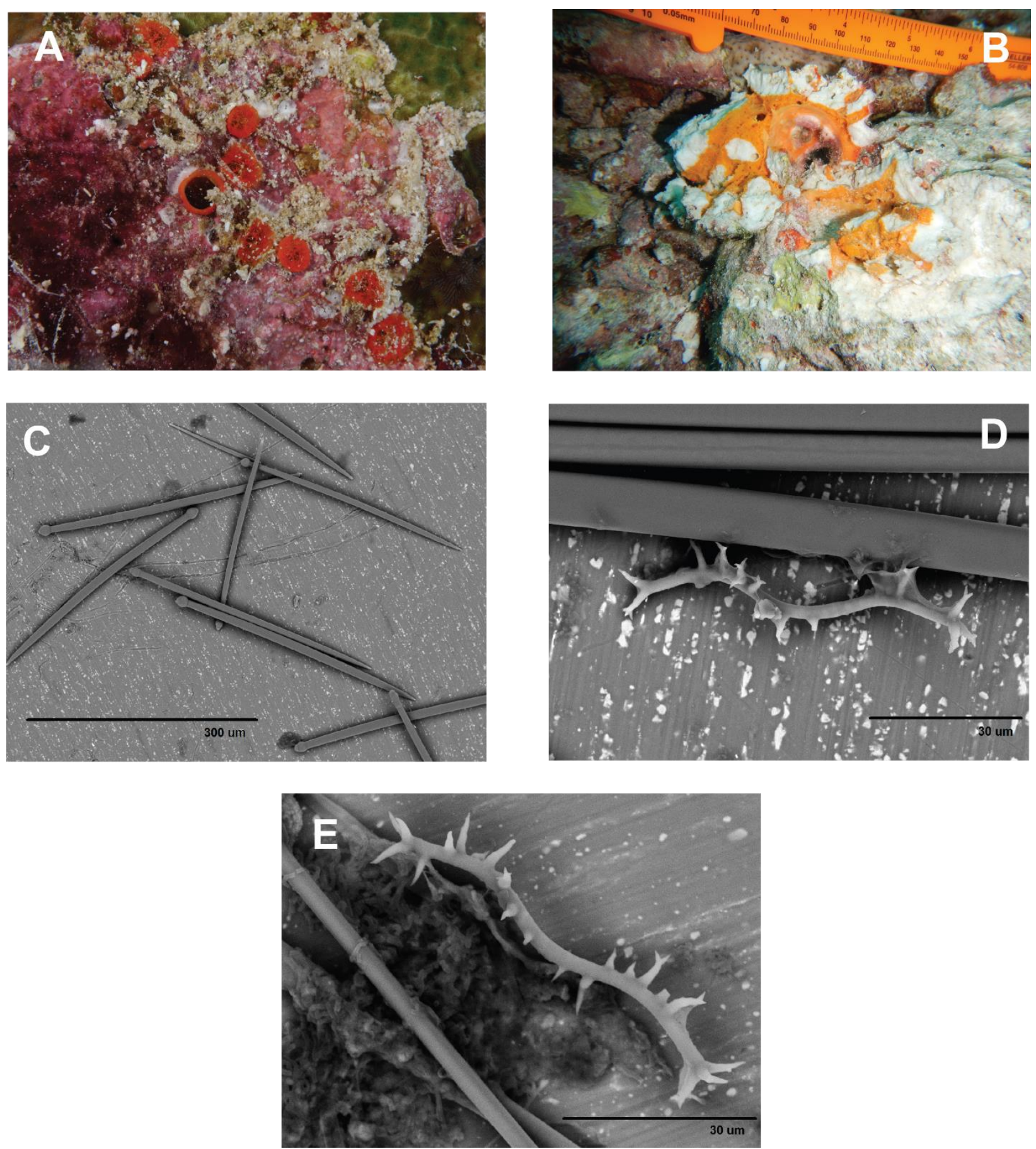

Figure 2.9. Cliothosa cf. aurivillii. (A) field image of papillae, single exhalent papillae centre left; (B) field image of "bagpipe-like" erosion chamber; (C) tylostyles (smaller size class); (D \& E) spirasters. 


\section{Remarks}

The present samples were identified as $\mathrm{Cl}$. cf. aurivillii. The villi on the inhalant papillae, the shape of the tylostyles, the split tips of the spines on the spirasters and the erosion traces all very much resembled characteristics of Cliothosa (see above). Cl. aurivillii, and its original description is based on material from the Java Sea (Lindgren 1897) and thus close to the present sample site, and is known from other places in the Pacific (Bergquist 1965: Calcinai et al. 2006: Schönberg \& Wisshak 2014).

Nevertheless, the identification of this sponge as $\mathrm{Cl}$. cf. aurivillii acknowledges some room for identification error, as there are some differences between the measured spicule dimensions and those in published literature. The original description by Lindgren (1897) describes two size classes of tylostyles $(672 \times 36 \mu \mathrm{m} \& 540 \times 12 \mu \mathrm{m})$, which is similar to descriptions by other authors (e.g. Topsent 1928; Rosell \& Uriz 1997). While two apparent size classes of tylostyles were found in this study, the tylostyles from these specimens are significantly shorter and thinner than previous descriptions. The spirasters are also slightly larger than those previously described (e.g. $40 \times 4 \mu \mathrm{m}$, Lindgren 1897), although in this original description there appears to be some variation in spiraster shape and size (Lindgren 1897, Fig. 22c.). Despite the size differences, the helical axis of the spirasters and the conical spines, which often end in branched tips is characteristic of $\mathrm{Cl}$. aurivillii (Lindgren 1897; Bergquist 1965; Rosell \& Uriz 1997; Calcinai et al. 2006). 


\section{Family Acarnidae Dendy 1922}

\section{Genus Zyzzya de Laubenfels 1936}

\section{Diagnosis}

Heteroscleromorph poecilosclerid genus with sponges in endolithic-papillate (alpha) morphology and one species known to have free-living forms (gamma). Silicate skeleton. Monaxon megascleres, robust tylostyles with round tyles. Microscleres spirasterose to amphiasterose forms with spines that commonly have multisplit tips. Arrangement of papillar tylostyles in palisade or as bouquets, tyles anchored in sponge tissue, points above tissue surface. Erosion traces commonly large-camerate or even single, cavernous erosion chambers.

\subsubsection{Zyzzya criceta Schönberg 2000a}

\section{Material examined}

Wakatobi Material: KDS-BF-01, KDS-BF-02, K1-BF-01

\section{Morphology and erosion}

Very dark green (appear black underwater) fistules, $1 \mathrm{~mm}$ in diameter and rising 2-4 mm above coral rubble surface (Fig. 2.10A). Erosion in form of numerous small and irregularly sized (4.2 $\mathrm{mm}^{2} \pm 2.3 \mathrm{SD}$ ) chambers, interconnected to often occupy entirety of rubble interior (Fig. 2.10B). Choanosomal tissue dark green/grey.

\section{Tissue characteristics and Symbiodinium presence}

Fistular tylotes arranged criss-crossing parallel to surface in ectosome, irregularly in choanosome and acanthostrongyles rarely and irregularly dispersed throughout fistule. Acanthostrongyles far more abundant in erosion chamber choanosome, outnumbering tylotes and dispersed irregularly as per tylotes. No evidence for photosymbionts, neither by surface fluorescence measured by PAM, nor through histology. 


\section{Spicules}

Megascleres - Comprised of numerous acanthostrongyles and terminally microspined tylotes. Acanthostrongyles softly curved, with regularly spaced spines orientated towards the middle of the spicule. Spine distribution varied from covering the entire spicule (Fig. 2.10C) to concentrated at the peripheries (Fig. 2.10D). Acanthostrongyle dimensions (min-max and mean): length $181-250 \mu \mathrm{m}(222.2 \mu \mathrm{m} \pm 13.4 \mathrm{SD})$ and shaft width $8-16 \mu \mathrm{m}(13.1 \mu \mathrm{m} \pm 2.0 \mathrm{SD})$. Tylotes long and slender, with microspined heads (Fig. 2.10E \& F). Predominantly straight but occasionally slightly bent (Fig. 2.10E). Tylote dimensions (min-max and mean): length $182-262$ $(221.8 \mu \mathrm{m} \pm 22.5 \mathrm{SD})$, shaft width $4-7 \mu \mathrm{m}(5.0 \mu \mathrm{m} \pm 0.8 \mathrm{SD})$ and head width $4-8 \mu \mathrm{m}(5.5 \mu \mathrm{m}$ $\pm 1.1 \mathrm{SD})$.

No microscleres found.

\section{Habitat and occurrence}

Very rare in the Wakatobi; only found in rubble at shallow depth $(5-7 \mathrm{~m})$ at two low turbidity/high flow sites. 

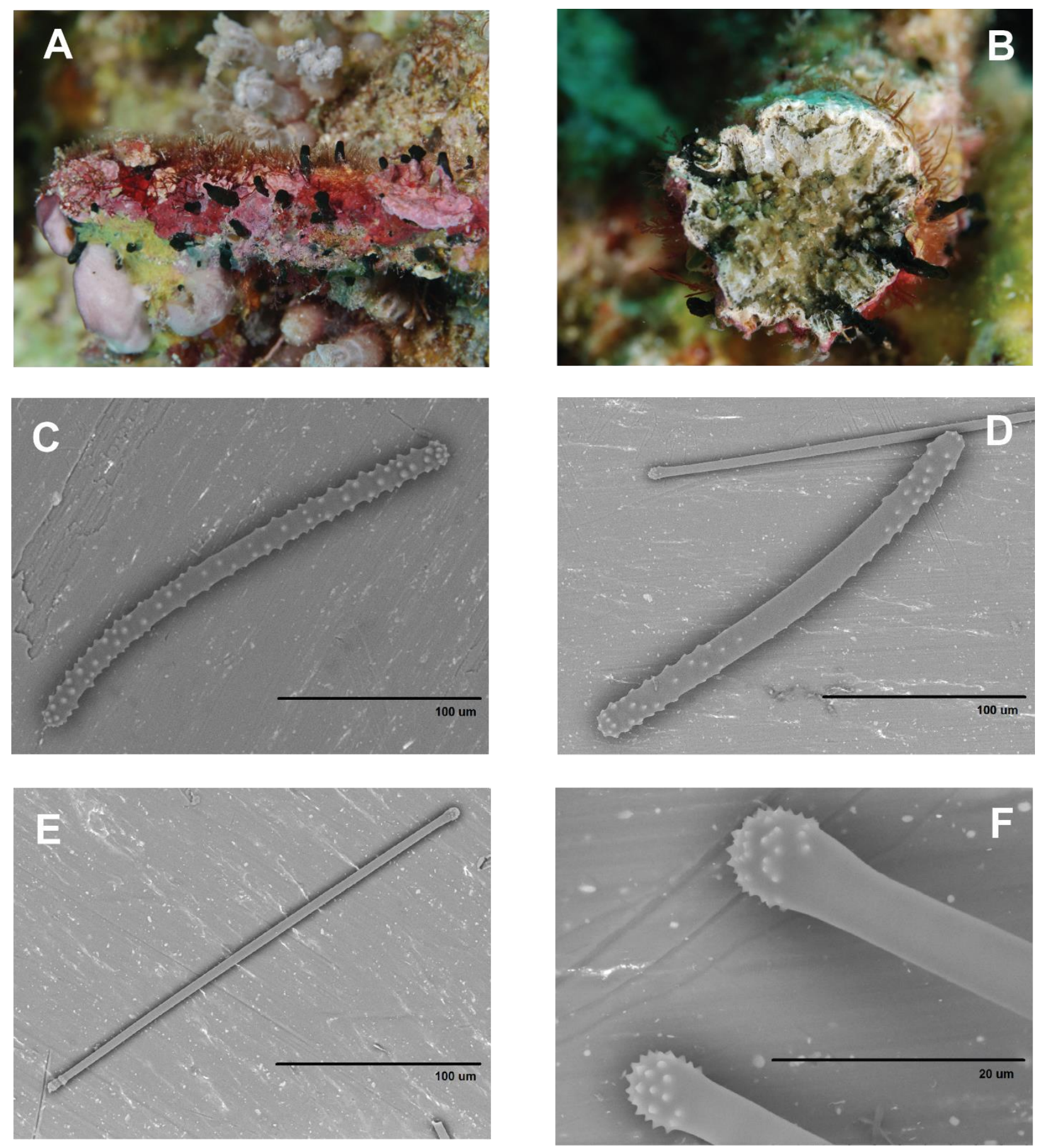

Figure 2.10. Zyzzya criceta. (A) field image of fistules protruding from coral rubble; (B) field image of erosion cavity; (C \& D) acanthostrongyles; (E) tylote; (F) microspined tylote head. 


\section{Remarks}

The World Porifera Database presently accepts five valid species of Zyzzya (van Soest et al. 2017): Z. coriacea (Lundbeck 1910), Z. criceta (Schönberg 2000a), Z. fuliginosa (Carter 1879), Z. invemar (van Soest et al. 1994), and Z. papillata (Thomas 1968). Comparing these to my samples, four species were discounted as not analogous and the Wakatobi material was identified as Z. criceta.

Judging from the morphology and older synonyms, Lundbeck's North Atlantic Z. coriacea appears to be an endopsammic species, not an endolithic one. Unlike the Wakatobi material, alcohol-preserved specimens of $Z$. coriacea are pale-violet, and the acanthotylotes are considerably longer than in the Wakatobi samples and strongly size variable. The Thomas (1968) species Z. papillata is endolithic-fistulate, but yellow, while the Wakatobi specimens were blackish green. In Z. papillata the acanthostrongyles are only about half as long as the microspined tylotes, while they are of similar length in the Wakatobi samples. Z. invemar is similar to the Wakatobi material in fistule size however it can be excluded due to spicule differences. The Wakatobi material does not have the regular verticils of spination on the acanthostrongyles nor the large size difference between acanthostrongyles and tylotes or the microscleres found in $Z$. invemar. Microspined tylotes that are significantly longer than acanthostrongyles is also a feature of Z. fuliginosa. Spicule dimensions provided for Z. fuliginosa spicules vary widely in the literature (Carter 1879; Dendy 1922; Hooper \& Krasochin 1989; Schönberg 2000a), but the size difference between the two spicule types has been uniformly reported, and precludes the identification of Wakatobi sponges as Z. fuliginosa.

Z. criceta is a Pacific sponge, with characteristic dark green (almost black) fistules (Schönberg 2000a), but unlike the Wakatobi material they are bulbous rather than small-fistulate. As in the present samples, the two megascleres in Z. criceta are of similar length, but those in the Wakatobi sponges are about $30 \mu \mathrm{m}$ shorter. Acanthostrongyles in Z. criceta are straight or slightly curved and spines are alike in shape and distribution as in the Wakatobi material. Tylotes are also similar in form in Z. cricteta, they are predominantly straight (or occasionally slightly bent) with microspined heads. 


\subsection{Discussion}

This study provides information on the bioeroding sponge fauna in the Wakatobi Marine National Park and advances our knowledge of the species composition of this critical functional group in Indonesian waters. Of the known species, the distribution of $C$. schmidtii, Cl. hancocki and Z. criceta is currently not listed as extending to Indonesian waters (WPD), although Hooper et al. (2000) suggest that $C$. schmidtii and Cl. hancocki could be. Regardless, this study provides the first description of $Z$. criceta outside of the GBR and describes two potential new species belonging to the $C$. viridis species complex.

The only other study to specifically address Indonesian bioeroding sponge taxonomy was by Calcinai et al. (2005) who focused on the reefs around the Island of Bunaken, in North Sulawesi, a site that is comparatively near the Wakatobi. Interestingly, the present study found no species in common with those identified by Calcinai et al. (2005) and both studies identified novel species. High variability in sponge assemblage composition between different geographic locations has been observed before in Indonesia (e.g. Amir 1992) and is likely to be due to a combination of environmental factors and dispersal ability (Zea 1993; Mariani et al. 2000). Larval dispersal ability is generally limited in sponges, dependent on a combination of larval behaviour, larval life-span and hydrographic regimes (Maldonado 2006; Mariani et al. 2006), and in the case of bioeroding sponges is highly limited (Mariani et al. 2000). Therefore differences in dispersal capacity may structure Wakatobi species diversity between a combination of more region-wide distributed species (e.g. Cl. hancocki and S. cf. vagabunda) and locally endemic species with limited dispersal capabilities.

The systematics of bioeroding sponges is particularly obscure and has had several recent revisions (Rosell \& Uriz 1997; Rützler \& Hooper 2000; Rützler 2002b). Many original descriptions are based on a single microscope slide, however spicule types (and sponge colour/morphology) can vary intraspecifically depending on environmental conditions (Rosell \& Uriz 1991; Bavestrello et al. 1993). This plasticity means that intraspecific variation can sometimes outweigh interspecific variation, making some species particularly hard to identify. Indeed some authors have for example merely classified them as in the $C$. viridis spp. complex (e.g. Sammarco et al. 1987; Sammarco 1996). The difficulty in relying on observable morphological and spicule characteristics for identification purposes has led to the 
experimentation in different identification diagnoses. One feature that is unique to bioeroding sponges is the erosion scars (pits) that are left on substrate. These pits have been used to identify sponge bioerosion in the fossil record (e.g. Perry \& Bertling 2000) and more recently have been

investigated as tool to aid speciation (Calcinai et al. 2003; 2004; 2007). However, while there were early indications that the macroscopic patterns of erosion pits differed between genera (Schönberg 2000a; Calcinai et al. 2004), the eroded substrate type appears to be an equally important determinant for these characteristics (Calcinai et al. 2007). Therefore the use of erosion pits requires caution and is not a solution to the potential inadequacies of traditional identification. Phylogenetic analysis offers the best resolution to these problems but has had particularly limited application in bioeroding sponges. Early work used a few nominal Cliona species to aid understanding of the relationship between families of the Hadromerida (KellyBorges et al. 1991; Borchiellini et al. 2000), but more recent Clionaidae-focused research is limited to the $C$. viridis spp. complex (Escobar et al. 2012; Leal et al. 2016) and a few other species (Barucca et al. 2007). For a fuller understanding of the systematics of this group, molecular analysis needs to be expanded to the less well studied species and genera of Clionaidae (such as Spheciospongia and Pione), some of which have received little attention since their original description.

\subsubsection{Conclusions}

Regardless of our understanding of the systematic positioning of a species, the ability to differentiate between species in the field is critical to understanding how assemblages differ spatially and temporally. This chapter not only furthers our understanding of species composition on Indonesian reefs but provides the foundation for research into the environmental drivers that will potentially structure these assemblages on future degraded coral reefs. 


\section{Chapter 3: Bioeroding sponge assemblage distribution: the importance of substrate availability and sediment}

\subsection{Abstract}

Despite coral reef health deteriorating globally, not all reef-associated organisms are in decline. Bioeroding sponges are a comparatively resilient group to the factors that stress and kill corals, and are increasing in abundance at many locations. However, there is a paucity of information on how environmental factors influence temporal and spatial variation in the abundance and diversity of these sponges, and how they might be affected by different stressors. I aimed to identify factors that explain differences in bioeroding sponge abundance and assemblage composition, and to determine whether bioeroding sponges benefit from dead substrate availability and from environmental conditions that contribute towards coral mortality. Abundance surveys were conducted in the Wakatobi region in Indonesia at reef sites characterised by different biotic and abiotic conditions. Bioeroding sponges occupied an average of $8.9 \%$ of suitable substrate with both abundance and assemblage composition differing significantly between sites, primarily attributed to differences in the availability of dead substrate. However, despite abundant dead substrate, sponge abundance was lowest at a highly sedimented and turbid site. My results suggest that if availability of dead substrate increases as a consequence of coral mortality, then bioeroding sponge abundance is also likely to increase. Conversely, these results also indicate that sedimentation mediated coral mortality, despite resulting in increased dead substrate, may not favour bioeroding sponges. Overall I demonstrate the importance of understanding the drivers of bioeroding sponge abundance and assemblage composition in order to predict possible impacts of different stressors on reefs communities. 


\subsection{Introduction}

Coral reefs are among the most diverse ecosystems on Earth and harbour up to an estimated 9 million species (e.g. Small et al. 1998). They also provide critical ecosystem goods and services, with hundreds of millions of people reliant on them globally (Moberg \& Folke 1999; Bouchet \& Duarte 2006). Despite their importance, coral reefs worldwide are increasingly threatened by anthropogenic activities and have suffered from substantial declines in coral cover, habitat complexity and biodiversity over the past 50 years (e.g. Bruno \& Selig 2007; Burke et al. 2011). In some locations, coral cover has already been reduced by $50 \%$ since the 1980 's (Bruno \& Selig 2007; De'ath et al. 2012). Such declines in spatially competitive scleractinian corals have the potential to provide less competitive benthic taxa with an opportunity to expand, and there are increasing reports of substantial reef community shifts (e.g. McManus \& Polsenberg 2004; Norström et al. 2009). While the majority of the literature has focused on shifts from coral to macroalgal-dominated communities, many other groups of benthic taxa can potentially benefit from coral declines (Mumby 2009; Norström et al. 2009; Cheal et al. 2010; Bell et al. 2013). Bioeroding sponges are one such group, and are reportedly becoming more abundant on some degraded reefs in the Caribbean (e.g. Rützler 2002a; López-Victoria \& Zea 2004), the eastern Pacific (Carballo et al. 2013), and on the Great Barrier Reef (GBR) (Schönberg \& Ortiz 2009). Many bioeroding sponge species appear to be resilient to some of the stressors that are detrimental to corals (e.g. Schönberg \& Suwa 2007; Enochs et al. 2015; Stubler et al. 2015), and some species are aggressive spatial competitors (e.g. López-Victoria \& Zea 2005; ChavesFonnegra \& Zea 2007; González-Rivero et al. 2011).

While a wide range of organisms contribute to bioerosion (e.g. Glynn 1997; Wisshak \& Tapanila 2008), sponges regularly generate the majority of internal bioerosion on a reef and often represent 60-90\% of macroborer activity (e.g. Risk et al. 1995; Mallela \& Perry 2007). Rates of erosion can be very high, with some species capable of removing over $20 \mathrm{~kg}$ of calcareous substrate per $\mathrm{m}^{2}$ sponge area per year (Schönberg 2002; Calcinai et al. 2008). Furthermore, under certain environmental conditions that favour high abundances of bioeroding sponges, and in combination with reduced coral cover/calcification, the balance between calcification and reef erosion can be altered by sponge bioerosion, resulting in net carbonate erosion (e.g. Nava \& Carballo 2008; Perry et al. 2008; Kennedy et al. 2013). Moreover, bioerosion has been identified 
as a principal driver of the loss of structurally complexity (Alvarez-Filip et al. 2011). This is important, as the three-dimensional structure of coral reefs provides critical habitat and maintains densities and biomass of other common reef organisms, as well as being central to ecosystem services that support tourism and shoreline protection (e.g. Enochs \& Manzello 2012; Graham \& Nash 2012).

Given the potentially negative consequences of increases in bioeroding sponge abundance on reefs, it is important to understand the factors that influence their abundance and assemblage composition. As bioeroding sponges can only inhabit calcareous substrates, the availability of suitable substrate has been identified as a key factor influencing their abundance (ChavesFonnegra et al. 2007; Carballo et al. 2008a; Schönberg \& Ortiz 2009; Schönberg 2015a). Other important environmental and abiotic factors that have been previously shown to regulate bioeroding sponge abundance include eutrophication (e.g. Holmes et al. 2000; Chavez-Fonnegra et al. 2007; Nava et al. 2014), light availability (e.g. López-Victoria \& Zea 2005), and sedimentation and turbidity (Muricy 1991; Nava \& Carballo 2013; see summary in Schönberg 2008). Many of these environmental parameters can be associated with reef degradation: polluted reefs are often eutrophic and have elevated chlorophyll $a$ concentrations (chl $a$ ), and reefs that are subject to excessive terrestrial run-off are typically characterised by highly turbid water with high sedimentation rates, and may experience large fluctuations in salinity (Burke et al. 2011).

In this Chapter, I hypothesised that coral mortality, resulting in increased dead substrate availability, and the environmental conditions that contribute towards this mortality or reduce the severity of spatial competition, are beneficial for bioeroding sponges. To test this hypothesis I determined how different biotic and abiotic factors influenced the abundance and assemblage composition of bioeroding sponges on Indonesian reefs. Understanding these patterns will provide an increased understanding of how reef degradation may affect bioeroding sponge abundance and how future reefs might function if degradation continues. 


\subsection{Methods}

\subsubsection{Study area}

The research for this chapter was conducted within the Wakatobi region of southeast Sulawesi, Indonesia. The Wakatobi supports a high diversity of marine species and was gazetted as a Biosphere Reserve by UNESCO in 2012 (UNESCO 2012). The region is also home to over 90,000 people who depend on the local reefs for food and other resources (Cullen et al. 2007).

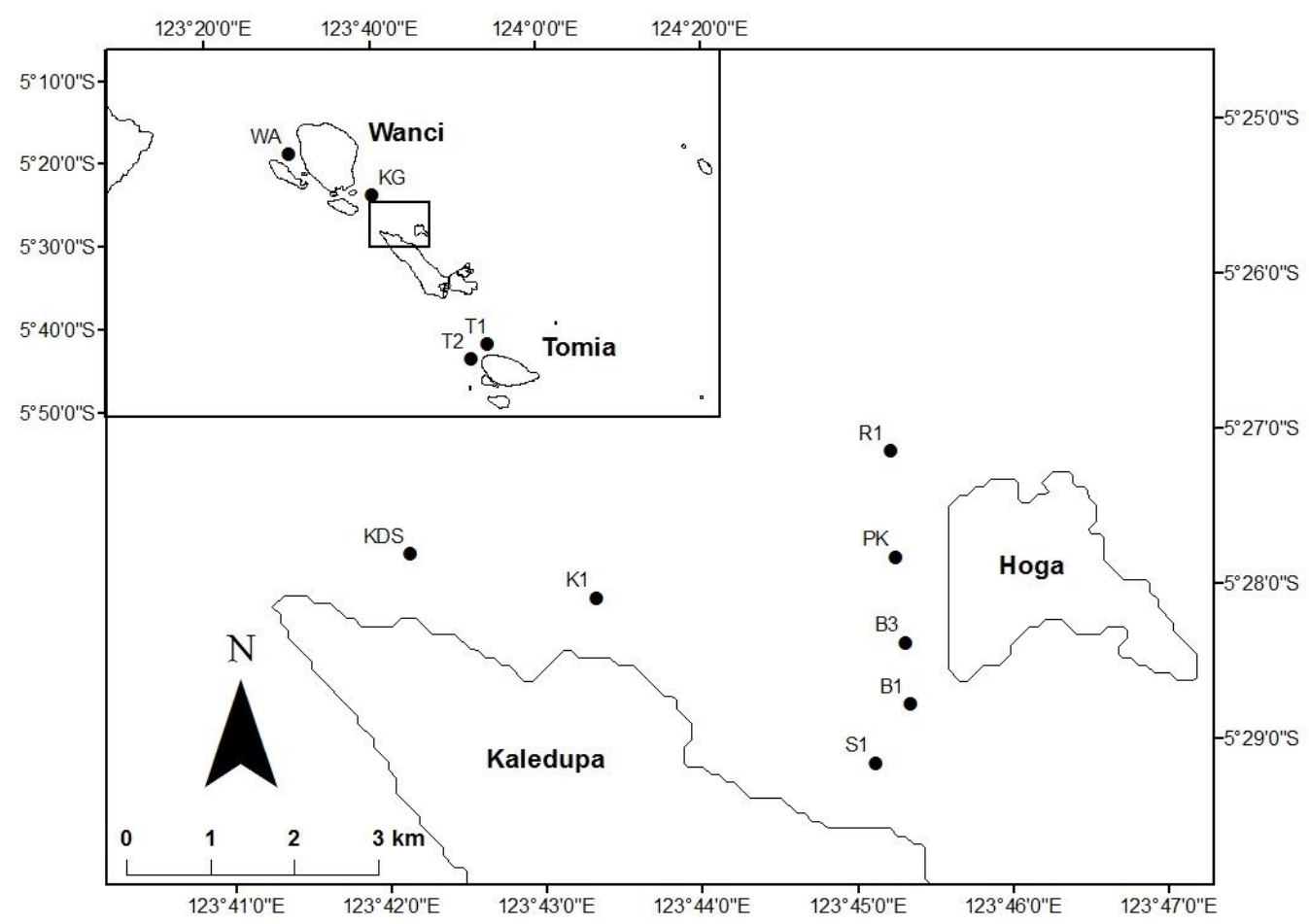

Figure 3.1. Site map of wider survey region in the Wakatobi (top left) and the core survey sites around the islands of Hoga and Kaledupa.

Surveys were conducted at seven sites on the fringing reefs around the islands of Hoga and Kaledupa in March-April 2014 and then continued in June 2014 to include another four sites around the islands of Wanci and Tomia (Fig. 3.1). Survey sites were chosen to represent a variety of reef types, environmental conditions and levels of reef degradation. The initial core seven sites included three steep-wall reefs: Buoy 1 and 3, and Ridge 1; three sloping reefs: Kaledupa 1, Kaledupa Double Spur and Pak Kasim's; and Sampela 1, which is adjacent to a 
stilted Bajo village and is considered to be highly degraded (McMellor \& Smith 2010). The additional four sites were: Karang Gurita, a coral atoll located off the island of Wanci; Tomia 1

and 2, sloping reefs off the island coast of Tomia, which appear relatively healthy with high branching coral cover; and Wanci Harbour, a turbid and sedimented sloping reef within Wanci Harbour. Sites Buoy 1 \& 3, Kaledupa 1 and Kaledupa Double Spur, Karang Gurita, Pak Kasim’s, Ridge 1, Sampela 1, Tomia 1 \& 2, and Wanci Harbour are abbreviated in figures as B1, B3, K1, KDS, KG, PK, R1, S1, T1, T2 and WA, respectively.

\subsubsection{Bioeroding sponge abundance and benthic composition}

Bioeroding sponge abundance and substrate characteristics were assessed in situ using line intercept transects at 5 and $10 \mathrm{~m}$ depth for the initial seven core survey sites in March-April 2014, and at just $10 \mathrm{~m}$ depth (due to logistical constraints) for the four additional sites surveyed in June 2014. At each site and depth, six $10 \mathrm{~m}$ transects were haphazardly deployed running parallel to the reef contours with a minimum separation of $10 \mathrm{~m}$ between replicate surveys. Sponge abundances and substrate composition were recorded by visually inspecting ten $1 \mathrm{~m}$ subsamples on each transect and recording the linear distance of each sponge species and substrate type that intercepted the measuring tape (after English et al. 1994; Schönberg 2015a). Schönberg (2015a) found linear distance to be proportional to areal extent, therefore linear distributions were treated as a proxy for percentage benthic cover. Substrate types were listed as 'live coral', 'live other' (excluding algal turf on dead substrate, which was counted as dead substrate), 'dead substrate' and 'sand'.

\subsubsection{Environmental variables}

Throughout March-August 2014 and May-June 2015, a XR-420 CTD data logger (RBR, Ottawa) was deployed at the seven core sites on haphazardly selected dates to measure turbidity and chl $a$. The CTD was set to record every minute with no averaging. Each deployment was for a minimum of 24 hours, with a minimum of three separate deployments at each site. This data collection methodology was identical (including same equipment and sites) to a previous study by Powell et al. (2014) in 2010. Given this, the data were combined to create average values for each environmental parameter for each site. Averages were based on each $24 \mathrm{~h}$ deployment with 
minutes considered as subsamples within each $24 \mathrm{~h}$ period. Due to time constraints, no CTD data were collected from the four additional sites around Tomia and Wanci.

Sediment deposition and retention were indirectly evaluated by measuring depth of settled sediment on horizontal and $30-60^{\circ}$ inclined surfaces without live cover. Measurements were taken at $3 \mathrm{~m}$ intervals along two haphazardly placed $30 \mathrm{~m}$ transects at each depth and site, and hence were limited to just $10 \mathrm{~m}$ depth at the four additional sites. The horizontal and inclined measurements were combined to create a mean measure of depth of settled sediment for each site.

Mean proportional current velocity for the seven core sites was quantified using plaster of Paris casts, commonly referred to as "clods" (e.g. Jokiel \& Morrisey 1993). Clods were prepared in rubber moulds according to the manufacturer's mixing instructions, to produce $5 \mathrm{~cm}$ diameter hemispherical casts with stainless steel nails embedded and passing through the centre. The plaster was allowed to air-dry for $24 \mathrm{~h}$ before being dried to constant weight in a $100{ }^{\circ} \mathrm{C}$ oven. The dry weight was recorded for each clod before deployment (mean weight $=59.3 \mathrm{~g} \pm 0.54 \mathrm{SE}$ ). Three clods were gently nailed into bare substrate at each site at 10 and $5 \mathrm{~m}$ depth for three $24 \mathrm{hr}$ periods, before recovering and repeating dry weight measurements. For each $24 \mathrm{~h}$ deployment, three control clods were placed on the reef within an anchored 401 perforated bucket; this excluded water currents experienced by the freely deployed clods, but allowed limited water exchange and exposed the clods in the buckets to the same water temperature and salinity (which also affect clod dissolution; Jokiel \& Morrisey 1993). Assessment of proportional differences in water movement between sites was achieved by converting dry weight lost by each clod into the percentage of initial clod weight lost, and subtracting mean control percentage losses (Doty 1971).

\subsubsection{Statistical analysis}

All univariate statistical analyses were performed in SPSS (version 21; IBM, Auckland, New Zealand) and multivariate analysis using the PRIMER-E v6 software package with the permutational multivariate analysis of variance (PERMANOVA) add on (Clarke \& Gorley 2006). 
Abundance of each bioeroding species for each transect was calculated using the mean linear extent across the ten subsamples on each transect and used as a proportional indicator for areal cover (see Schönberg 2015a). Previous studies have consistently found that bioeroding sponge abundance correlates with the abundance of calcareous substrate and therefore used substratestandardised abundance data when analysing environmental drivers (Chaves-Fonnegra et al. 2007; Carballo et al. 2008a; Schönberg \& Ortiz 2009; Schönberg 2015a). After finding similar correlations in the Wakatobi (see below), total bioeroding sponge abundance and individual species abundances were standardised to available dead substrate (including that which the sponges already occupy).

The absence of data from $5 \mathrm{~m}$ depth at the four additional survey locations meant that, where differences were found between depths, the analysis was separated into two sections: all eleven sites were evaluated for $10 \mathrm{~m}$ depth; and the seven core sites at both 5 and $10 \mathrm{~m}$ depth. In addition, the lack of CTD deployment at these four additional sites meant that the analysis of interactions between environmental variables and bioeroding sponges only incorporated data from the core sites. Due to the considerable differences in environmental conditions between Sampela 1 and the other sites, and the tendency for this site to drive collinearity amongst variables, the analysis of the core sites was conducted twice, once including Sampela 1 and once without.

\section{Bioeroding sponge abundance and diversity}

Differences in total bioeroding sponge abundance and species diversity (Shannon's index; H') between sites and depths were tested using a two factorial general linear model (GLM). Where differences occurred, Tukey's or Gabriel's (in the case of unequal sample sizes) post hoc procedures were used to identify where the differences occurred. Correlations between individual environmental/benthic factors and bioeroding sponge abundance and diversity were assessed with Pearson's product-moment correlation coefficients. Data were square-root or $\log$ transformed to meet the necessary assumptions of variance and generate normality for both tests. For any data that failed to meet these assumptions despite transformation, non-parametric tests were used; namely a Kruskal-Wallis or Spearman's Rank test. 


\section{Environmental characterisation}

Environmental characterisation of each site was achieved using a multivariate analysis within PRIMER. All analyses were based on resemblance matrices calculated from normalised data using Euclidean-Distance similarity coefficients. Draftman's plots of all pairwise correlations were checked for collinearity and skewness in the abiotic and biotic data; these suggested that fourth-root transformation was appropriate for an increase in normality for all the variables. Biotic and abiotic differences between sites and depths were examined using one and two-factor PERMANOVAs (site and depth as factors with 7 levels or site as factor with 11 levels), and results were graphically displayed through principal coordinate analysis (PCO). The inter-site differences in abiotic and biotic variables were characterised with Pearson's correlations $(>0.4)$ between PCO axes and the individual abiotic/biotic components.

\section{Bioeroding sponge assemblage patterns}

All biological assemblage data analyses were based on resemblance matrices calculated from square-root transformed data using Bray-Curtis similarity coefficients. The Bray-Curtis similarity index was chosen due to the large number of zeros in the data set, which this index ignores, and abundance data were transformed to preserve information on relative abundance, while reducing the effect of overly abundant or rare species (Clarke 1993). Due to the general sparseness or patchiness of bioeroding sponge abundances and the complete absence on one transect, a dummy species with the abundance value of 0.5 was added to each transect in order to diminish the erratic behaviour of the Bray-Curtis coefficient (Clarke et al. 2006). Differences in sponge assemblage compositions between sites were assessed using one- and two-factor PERMANOVAs of the same design as for the abiotic/biotic data. To identify those species that were contributing towards any assemblage dissimilarity between sites or depths, a SIMPER analysis was performed. Associations between bioeroding sponge assemblage structure and abiotic/biotic variables were investigated in a distance-based multiple linear regression model (DISTLM), which is a non-parametric permutation-based procedure that enables significance testing of explanatory variables against multivariate response variables (Anderson et al. 2007). In order to find the most parsimonious model, Akaike's Information Criterion (AIC), a step-wise procedure, adjusted for small sample sizes (AICc) was used (Burnham \& Anderson 2004). As with univariate correlations, the DISTLMs were repeated twice; once with the outlier site 
Sampela 1 and once without. DISTLM outputs were represented graphically with a distancebased redundancy ordination (dbRDA), including a 2D scatterplot to illustrate differences between sites and 2D bubble plots to illustrate differences in species abundance. The influence of the predictor variables selected by the DISTLM on the abundance of the individual species that were contributing the greatest difference between sites were tested using Spearman's Rank correlations. 


\subsection{Results}

\subsubsection{Biotic and abiotic site characteristics}

Substrate composition of the core sites did not differ significantly with depth (PERMANOVA, Pseudo-F $=1.7118, \mathrm{p}=0.143$; Table 3.1). Therefore, analyses referring to substrate composition across all 11 sites were performed including both depth categories. Substrate composition differed significantly between the sites (PERMANOVA, Pseudo-F $=9.1056, p=0.001$ ), with $59.2 \%$ of the variation being explained by the principal coordinate analysis (PCO; Fig. 3.2A). Tomia 1 and Buoy 3 were characterised by hard corals; Kaledupa Double Spur and Kaledupa 1 by dead substrate; Karang Gurita, Sampela 1 and Wanci Harbour by sand; and the other four sites were more heterogeneous in their substrate composition. The environmental conditions also varied significantly between the core sites where the CTD and clods were deployed (PERMANOVA, Pseudo-F $=26.572, p=0.001$ ), but not between depths. The two axes of the PCO together explained $63.4 \%$ of the variation (Fig. 3.2B), further characterising the sites: elevated chl $a$ concentration, comparatively high settled sediment and turbidity at Sampela 1; low flow rates at Buoys 1 and 3; high flow rates at Kaledupa 1, Kaledupa Double Spur and Ridge 1; and comparatively heterogeneous environmental conditions at Pak Kasim's.
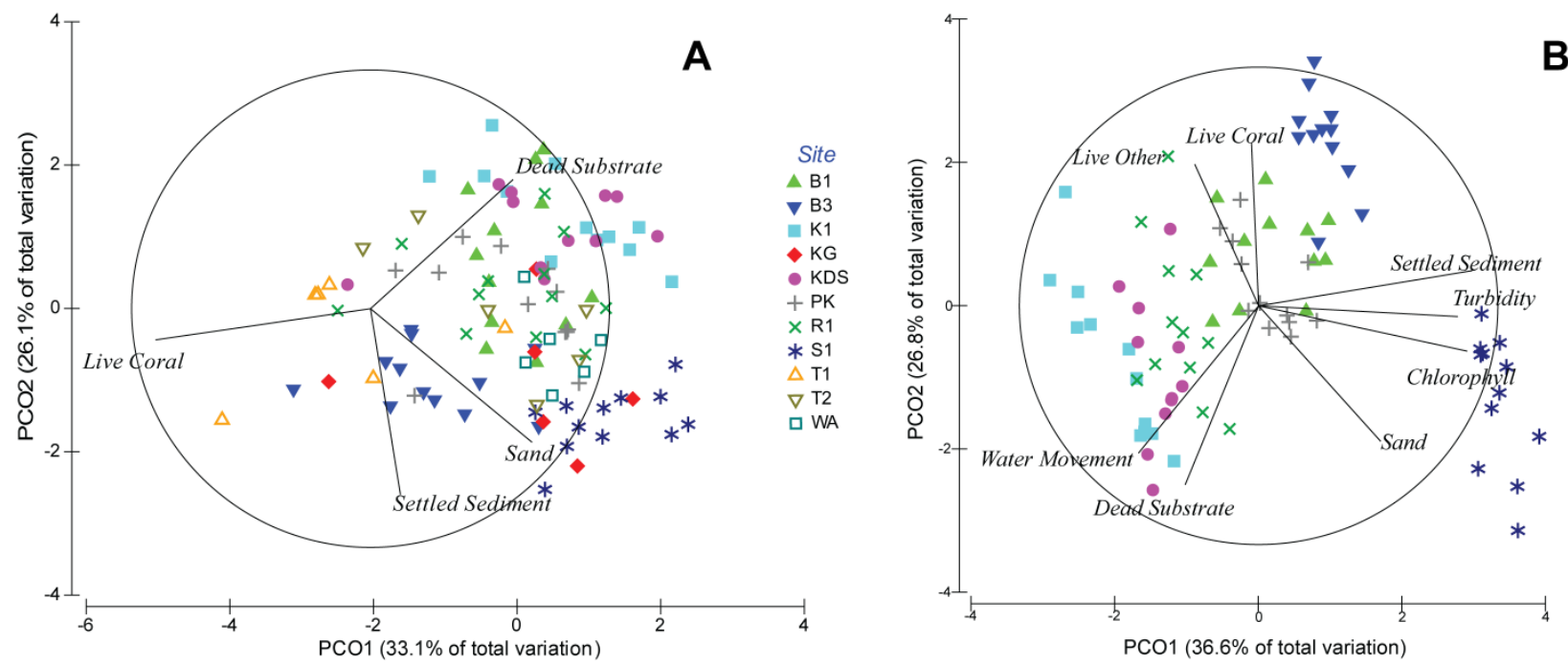

Figure 3.2. Principal coordinate analysis of site similarities with respect to their physical and water quality parameters. A) Comparison of all eleven study sites with regards to substrate composition and B) the seven core study sites regarding substrate composition and environmental factors. Overlaid vectors represent components that have a Pearson's correlation of greater than 0.4 with either of the PCO axes. 
Table 3.1. Substrate characteristics and environmental factors of each site. Each value represents a site mean and error values are standard errors of these means.

\begin{tabular}{|c|c|c|c|c|c|c|c|c|c|c|c|c|}
\hline Factor & Unit & & & & & & Site & & & & & \\
\hline & & B1 & B3 & K1 & KDS & KG & PK & $\mathbf{R 1}$ & S1 & T1 & T2 & WA \\
\hline Live coral & $\%$ cover & $\begin{array}{c}19.29 \\
( \pm 2.57)\end{array}$ & $\begin{array}{c}33.88 \\
( \pm 4.20)\end{array}$ & $\begin{array}{c}11 \\
( \pm 1.79)\end{array}$ & $\begin{array}{c}15.04 \\
( \pm 4.06)\end{array}$ & $\begin{array}{c}19.25 \\
( \pm 8.91)\end{array}$ & $\begin{array}{c}23.75 \\
( \pm 4.30)\end{array}$ & $\begin{array}{c}27.98 \\
( \pm 4.55)\end{array}$ & $\begin{array}{c}11.58 \\
( \pm 2.27)\end{array}$ & $\begin{array}{c}64.58 \\
( \pm 7.05)\end{array}$ & $\begin{array}{c}27.58 \\
( \pm 8.11)\end{array}$ & $\begin{array}{c}18.0 \\
( \pm 2.55)\end{array}$ \\
\hline $\begin{array}{c}\text { Dead } \\
\text { substrate }\end{array}$ & $\%$ cover & $\begin{array}{c}37.96 \\
( \pm 3.80)\end{array}$ & $\begin{array}{c}16.17 \\
( \pm 1.80)\end{array}$ & $\begin{array}{c}39.98 \\
( \pm 4.07)\end{array}$ & $\begin{array}{c}46.04 \\
( \pm 4.94)\end{array}$ & $\begin{array}{c}24.33 \\
( \pm 4.53)\end{array}$ & $\begin{array}{c}33.63 \\
( \pm 2.16)\end{array}$ & $\begin{array}{c}41.17 \\
( \pm 4.05)\end{array}$ & $\begin{array}{c}34.08 \\
( \pm 3.04)\end{array}$ & $\begin{array}{c}20.33 \\
( \pm 4.96)\end{array}$ & $\begin{array}{c}28.42 \\
( \pm 4.58)\end{array}$ & $\begin{array}{c}41.92 \\
( \pm 2.41)\end{array}$ \\
\hline Live other & $\%$ cover & $\begin{array}{c}38.04 \\
( \pm 3.22)\end{array}$ & $\begin{array}{c}45.12 \\
( \pm 3.35)\end{array}$ & $\begin{array}{c}35.13 \\
( \pm 4.82)\end{array}$ & $\begin{array}{c}35.38 \\
( \pm 4.50)\end{array}$ & $\begin{array}{c}36.33 \\
( \pm 7.64)\end{array}$ & $\begin{array}{c}33.91 \\
( \pm 3.76)\end{array}$ & $\begin{array}{c}24.92 \\
( \pm 2.61)\end{array}$ & $\begin{array}{c}23.25 \\
( \pm 4.84)\end{array}$ & $\begin{array}{c}10.75 \\
( \pm 3.17)\end{array}$ & $\begin{array}{c}14.42 \\
( \pm 1.93)\end{array}$ & $\begin{array}{c}31.92 \\
( \pm 3.57)\end{array}$ \\
\hline Sand & $\%$ cover & $\begin{array}{c}4.52 \\
( \pm 1.46)\end{array}$ & $\begin{array}{c}4.21 \\
( \pm 1.92)\end{array}$ & $\begin{array}{c}7.67 \\
( \pm 2.18)\end{array}$ & $\begin{array}{c}3.88 \\
( \pm 1.48)\end{array}$ & $\begin{array}{c}20.08 \\
(( \pm 9.34)\end{array}$ & $\begin{array}{c}8.29 \\
( \pm 2.94)\end{array}$ & $\begin{array}{c}8.39 \\
( \pm 3.39)\end{array}$ & $\begin{array}{c}30.38 \\
( \pm 3.54)\end{array}$ & $\begin{array}{c}4.42 \\
( \pm 3.05)\end{array}$ & $\begin{array}{c}29.42 \\
( \pm 11.84)\end{array}$ & $\begin{array}{c}7.67 \\
( \pm 2.66)\end{array}$ \\
\hline $\begin{array}{l}\text { Sediment } \\
\text { thickness }\end{array}$ & $\mathrm{mm}$ & $\begin{array}{c}0.78 \\
( \pm 0.18)\end{array}$ & $\begin{array}{c}1.95 \\
( \pm 0.37)\end{array}$ & $\begin{array}{c}0.25 \\
( \pm 0.12)\end{array}$ & $\begin{array}{c}0.5 \\
( \pm 0.10)\end{array}$ & $\begin{array}{c}2.23 \\
( \pm 0.54)\end{array}$ & $\begin{array}{c}1.06 \\
( \pm 0.13)\end{array}$ & $\begin{array}{c}0.85 \\
( \pm 0.16)\end{array}$ & $\begin{array}{c}2.94 \\
( \pm 0.28)\end{array}$ & $\begin{array}{c}0.5 \\
( \pm 0.17)\end{array}$ & $\begin{array}{c}0.4 \\
( \pm 0.12)\end{array}$ & $\begin{array}{c}2.45 \\
( \pm 0.86)\end{array}$ \\
\hline $\begin{array}{c}\text { Water } \\
\text { movement }\end{array}$ & $\begin{array}{c}\% \text { clod } \\
\text { weight loss }\end{array}$ & $\begin{array}{c}8.36 \\
( \pm 0.84)\end{array}$ & $\begin{array}{c}8.79 \\
( \pm 0.75)\end{array}$ & $\begin{array}{c}18.73 \\
( \pm 0.67)\end{array}$ & $\begin{array}{c}24.42 \\
( \pm 1.81)\end{array}$ & $\mathrm{n} / \mathrm{a}$ & $\begin{array}{c}12.78 \\
( \pm 2.60)\end{array}$ & $\begin{array}{c}16.93 \\
( \pm 1.62)\end{array}$ & $\begin{array}{c}13.88 \\
( \pm 0.81)\end{array}$ & $\mathrm{n} / \mathrm{a}$ & $\mathrm{n} / \mathrm{a}$ & $\mathrm{n} / \mathrm{a}$ \\
\hline Turbidity & $\begin{array}{c}\text { Standard } \\
\text { turbidity } \\
\text { units }\end{array}$ & $\begin{array}{c}2.66 \\
( \pm 1.22)\end{array}$ & $\begin{array}{c}2.06 \\
( \pm 0.70)\end{array}$ & $\begin{array}{c}1.69 \\
( \pm 0.50)\end{array}$ & $\begin{array}{c}2.07 \\
( \pm 0.40)\end{array}$ & $\mathrm{n} / \mathrm{a}$ & $\begin{array}{c}1.75 \\
( \pm 0.20)\end{array}$ & $\begin{array}{c}1.32 \\
( \pm 0.60)\end{array}$ & $\begin{array}{c}4.10 \\
( \pm 1.04)\end{array}$ & $\mathrm{n} / \mathrm{a}$ & $\mathrm{n} / \mathrm{a}$ & $\mathrm{n} / \mathrm{a}$ \\
\hline Chl a & $\mu \mathrm{g} / \mathrm{l}$ & $\begin{array}{c}0.36 \\
( \pm 0.12)\end{array}$ & $\begin{array}{c}0.36 \\
( \pm 0.02)\end{array}$ & $\begin{array}{c}0.12 \\
( \pm 0.10)\end{array}$ & $\begin{array}{c}0.31 \\
( \pm 0.08)\end{array}$ & $\mathrm{n} / \mathrm{a}$ & $\begin{array}{c}0.94 \\
( \pm 0.14)\end{array}$ & $\begin{array}{c}0.33 \\
( \pm 0.03)\end{array}$ & $\begin{array}{c}2.54 \\
( \pm 0.05)\end{array}$ & $\mathrm{n} / \mathrm{a}$ & $\mathrm{n} / \mathrm{a}$ & $\mathrm{n} / \mathrm{a}$ \\
\hline
\end{tabular}




\subsubsection{Sponge abundance, diversity and species composition}

Bioeroding sponges occupied an average of $3.1 \%( \pm 0.21 \mathrm{SE})$ of total reef area, and total abundance varied significantly between sites $\left(\mathrm{GLM}, \mathrm{F}_{(10,108)}=5.721, \mathrm{p}<0.001\right)$, but not between depths $\left(\mathrm{GLM}, \mathrm{F}_{(1,108)}=0.242, \mathrm{p}=0.624\right)$. Abundance was highest at Wanci Harbour $(4.9 \% \pm$ $0.63 \mathrm{SE})$ and lowest at Tomia $1(1.3 \% \pm 0.31 \mathrm{SE})$. Overall, bioeroding sponge abundance was positively correlated with availability of dead calcareous substrate (Pearson's, $\mathrm{r}^{2}=0.345, \mathrm{p}<$ 0.001), thus justifying the standardisation of abundance data to the availability of dead substrate (\%cover). Abundance was also negatively correlated with the abundance of sandy substrate (Pearson's, $\mathrm{r}^{2}=-0.199, \mathrm{p}<0.039$ ), but showed no significant correlation with either live coral or other live cover (Table 3.2). Following standardisation to dead substrate, bioeroding sponges were found to occupy an average of $8.9 \% \operatorname{cover}( \pm 0.7 \mathrm{SE})$ of suitable habitat across all sites, up to $21.9 \%$ cover $( \pm 2.7 \mathrm{SE})$ at Buoy 3 and as low as $3.5 \%$ cover ( $\pm 0.8 \mathrm{SE})$ at Sampela 1 (Fig. 3.3A). There was again a significant difference among sites and between depths (GLM, $\mathrm{F}_{(10,108)}=$ 17.366, $\mathrm{p}<0.001$ and $\mathrm{F}_{(10,108)}=10.445, \mathrm{p}=0.002$, respectively). Across the core sites, \%cover decreased on higher water movement reefs and on those with high chl $a$ concentrations (Table 3.2). Omitting Sampela 1, data still showed that within the remaining core sites, water movement limited \%cover, but greater depth of settled sediment and turbidity were positively correlated with \%cover and chl $a$ concentration had no influence (Table 3.2). The abundance of different substrate types (with the exception of dead substrate) also had no effect on the \%cover of these sponges (Table 3.2).

Species diversity of the bioeroding sponges differed significantly between the 11 sites, but not between depths (Kruskal-Wallis, $\mathrm{p}=0.003$ and $\mathrm{p}=0.986$, respectively). Species diversity was highest at Wanci Harbour and Buoys $1 \& 3\left(\mathrm{H}^{\prime}=1.173,1.098\right.$ and 1.102, respectively), and lowest at Karang Gurita and Tomia 1 ( $\mathrm{H}^{\prime}=0.380$ and 0.385, respectively; Fig. 3.3B). Sponge species diversity increased with increasing cover of "other live" benthos, regardless of whether or not Sampela 1 was included in the analysis. However, a significant negative correlation with chl $a$ concentration only occurred when Sampela 1 was included in the analysis, and a significant negative correlation with turbidity only when Sampela 1 was omitted (Table 3.2). 
Table 3.2. Results of bivariate correlations comparing total sponge abundance and species diversity with substrate characteristics and environmental factors. Abundance tests using Pearson's and diversity tests using Spearman's Rank. Significant correlation probabilities in bold. Analyses conducted with and without Sampela data.

\begin{tabular}{|c|c|c|c|c|c|}
\hline \multirow[t]{2}{*}{ Factor } & \multirow[t]{2}{*}{ Dependent variable } & \multirow{2}{*}{$\begin{array}{c}\text { Sampela } \\
\text { included } \\
\mathbf{r}\end{array}$} & \multicolumn{3}{|c|}{$\begin{array}{l}\text { Sampela } \\
\text { excluded }\end{array}$} \\
\hline & & & $\mathbf{p}$ & $\mathbf{r}$ & $\mathbf{p}$ \\
\hline \multirow[t]{3}{*}{ Live coral } & Total abundance & -0.159 & 0.099 & -0.287 & 0.005 \\
\hline & Standardised Total Abundance & 0.186 & 0.054 & 0.031 & 0.765 \\
\hline & Species Diversity & 0.048 & 0.622 & -0.033 & 0.750 \\
\hline \multirow[t]{3}{*}{ Live other } & Total abundance & 0.055 & 0.571 & 0.080 & 0.436 \\
\hline & Standardised Total Abundance & 0.164 & 0.090 & 0.219 & 0.032 \\
\hline & Species Diversity & 0.206 & 0.032 & 0.236 & 0.021 \\
\hline \multirow[t]{3}{*}{ Dead substrate } & Total abundance & 0.345 & $>0.001$ & 0.344 & 0.001 \\
\hline & Standardised Total Abundance & - & - & - & - \\
\hline & Species Diversity & 0.152 & 0.117 & 0.134 & 0.194 \\
\hline \multirow[t]{3}{*}{ Sand } & Total abundance & -0.199 & 0.039 & -0.077 & 0.455 \\
\hline & Standardised Total Abundance & -0.126 & 0.1944 & 0.062 & 0.547 \\
\hline & Species Diversity & -0.073 & 0.451 & 0.019 & 0.855 \\
\hline \multirow[t]{3}{*}{ Settled sediment } & Total abundance & -0.110 & 0.256 & 0.176 & 0.087 \\
\hline & Standardised Total Abundance & -0.950 & 0.388 & 0.483 & $<0.001$ \\
\hline & Species Diversity & -0.036 & 0.712 & 0.081 & 0.432 \\
\hline \multirow[t]{3}{*}{ Turbidity } & Total abundance & -0.364 & 0.001 & 0.306 & 0.009 \\
\hline & Standardised Total Abundance & -0.177 & 0.107 & 0.471 & $<0.001$ \\
\hline & Species Diversity & 0.070 & -0.527 & 0.309 & 0.008 \\
\hline \multirow[t]{3}{*}{ Chl $a$} & Total abundance & -0.400 & $>0.001$ & -0.222 & 0.061 \\
\hline & Standardised Total Abundance & -0.440 & $<0.001$ & -0.159 & 0.183 \\
\hline & Species Diversity & -0.277 & 0.011 & -0.161 & 0.177 \\
\hline \multirow[t]{3}{*}{ Water movement } & Total abundance & -0.191 & 0.082 & -0.189 & 0.111 \\
\hline & Standardised Total Abundance & -0.328 & 0.002 & -0.435 & $<0.001$ \\
\hline & Species Diversity & -0.061 & 0.583 & -0.097 & 0.415 \\
\hline
\end{tabular}



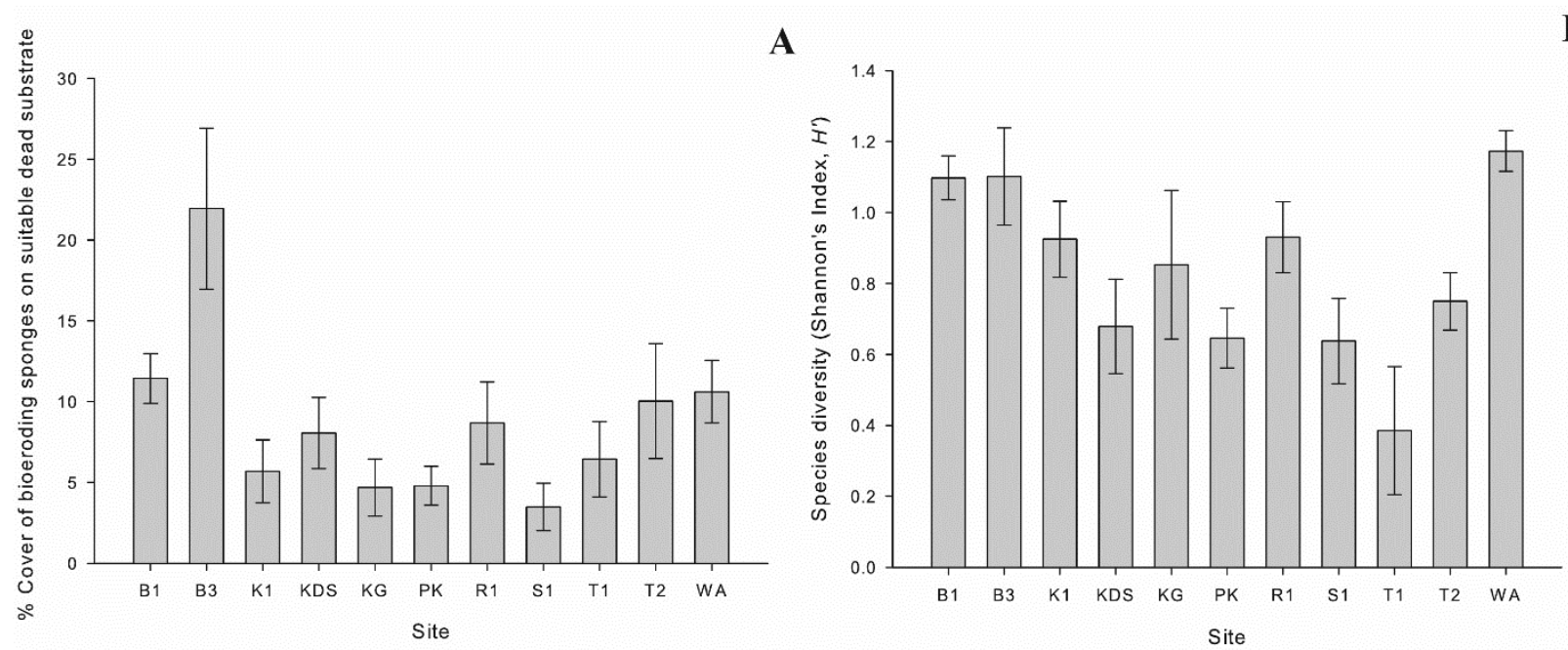

Figure 3.3. Bioeroding sponge distribution patterns per sample site and across all depths. A) Total sponge abundance (standardised to substrate). B) Species diversity. Standard errors shown.

Although the field surveys recognised eight bioeroding sponge species as being dominant within the assemblage (Chapter 2), and rare species were not considered, $81.8 \%$ of the abundance of the sponges was represented by only three species - Cliona aff. viridis n. sp. B (39.1\%), Cliothosa cf. aurivillii (23.2\%) and Spheciospongia cf. vagabunda (19.5\%). Species assemblage composition was significantly different among the 11 sites (PERMANOVA, Pseudo-F $=5.1843$, $\mathrm{p}=0.001$; Fig. 3.4), and between 5 and $10 \mathrm{~m}$ depth (PERMANOVA, Pseudo-F $=6.3, \mathrm{p}=0.001$ ). Given the influence of depth on assemblage composition, the multivariate analysis with regards to species composition was split into two analyses: the seven core sites including all depths (and CTD and clod data), and the full 11 sites with just $10 \mathrm{~m}$ depth surveys. 

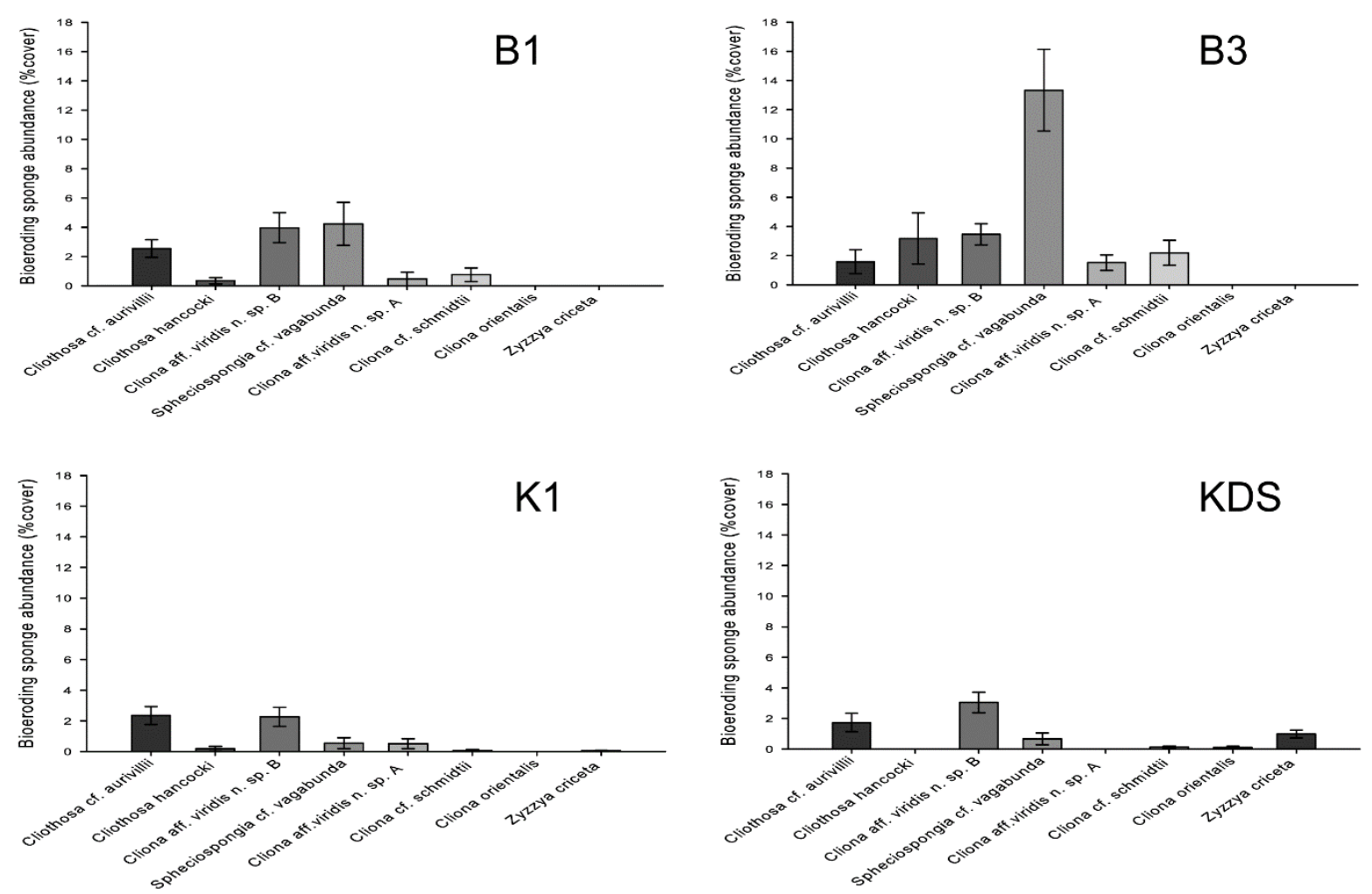

PK
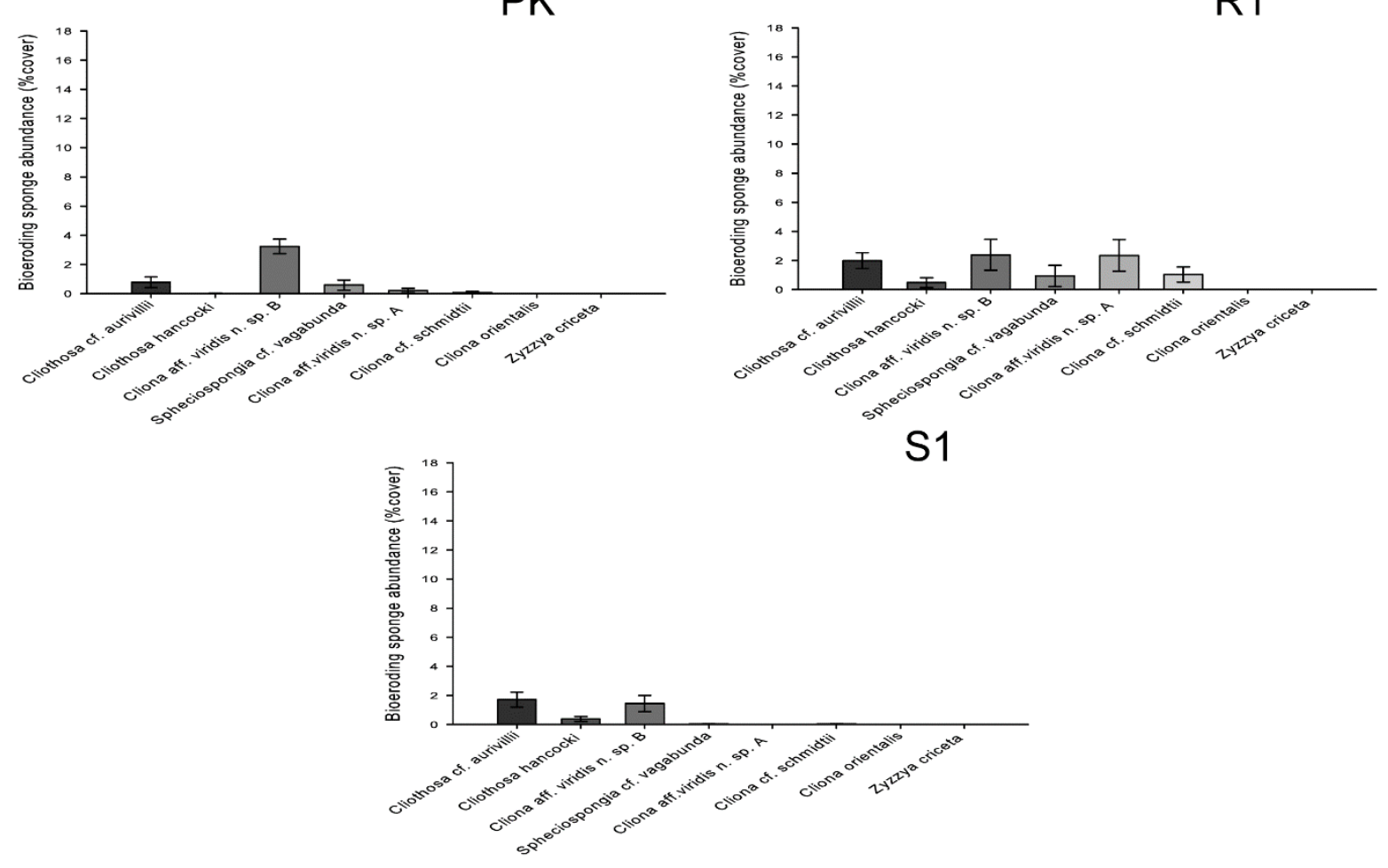

Figure 3.4. Average bioeroding sponge species abundance (standardised to substrate) at each core survey site. Standard errors shown. 
Species composition at all eleven sites combined and for $10 \mathrm{~m}$ depth

At $10 \mathrm{~m}$ depth, species composition significantly differed among the 11 sites (PERMANOVA, Pseudo-F $=3.5829, \mathrm{p}=0.001$ ), which had an average dissimilarity of $61.1 \%$. The largest differences existed between Sampela 1 and either Buoy 3, Karang Gurita or Tomia 1 (86.0, 82.0 and $82.3 \%$, respectively). The common S. cf. vagabunda at Buoy 3 had an average abundance of $19.3 \%$ cover, but at Sampela only an average cover of $<0.1 \%$ cover, representing $45.6 \%$ of the site's assemblage difference. The abundance of another dominant species, C. aff. viridis n. sp. B, was the primary reason for the assemblage differences between Sampela $1(0.9 \%$ cover) and both Karang Gurita (5.3\%cover) and Tomia 1 (3.9 \%cover), which contributed $45.0 \%$ and $39.8 \%$ towards the dissimilarities, respectively. The best sponge assemblage model in DISTLM found dead substrate to be the only benthic variable with a significant correlation with the biotic data before they were standardised to availability of dead substrate, explaining just $5.4 \%$ of the variation. Following standardisation to dead substrate, the best and only predictor of assemblage composition was live coral cover, accounting for just $3.7 \%$ of assemblage variation.

\section{Species composition at the seven core sites}

As above, $68.1 \%$ of the $52.6 \%$ difference in species composition between depths was attributed to the three most common species, $C$. aff. viridis n. sp. B, Cl. cf. aurivillii and $S$. cf. vagabunda. Variation in $\mathrm{Cl}$. cf. aurivillii abundance contributed $25.7 \%$ of the difference; the species was more common in shallower water and had an average abundance of $2.6 \%$ cover on the $5 \mathrm{~m}$ surveys, but only $1.1 \%$ cover on the $10 \mathrm{~m}$ surveys. The reverse was true for $S$. cf. vagabunda, which at $5 \mathrm{~m}$ had an average abundance of $1.5 \%$ cover, but $4.3 \%$ cover at $10 \mathrm{~m}$, accounting for $19.1 \%$ of variation between depths. Abundances of $C$. aff. viridis n. sp. B accounted for $23.4 \%$ of variation, and although average abundance was similar at 5 and $10 \mathrm{~m}$ depth $(2.6 \%$ and $3.1 \%$ cover, respectively), there was high within-group variation.

The three largest inter-site differences in assemblage composition occurred with Buoy 3 versus Sampela 1, Kaledupa Double Spur and Kaledupa 1 (80.0\%, 70.1\% and 68.6\%, respectively), and were largely driven by differences in the abundance of $S$. cf. vagabunda. This species was relatively abundant at Buoy 3 (average abundance of 13.3\%cover and within-site assemblage similarity contribution of 58.0\%), but had low abundance at Sampela $1(<0.1 \%$ cover $)$, Kaledupa 
Double Spur (0.7\%cover) and Kaledupa 1 (0.5\%cover), contributing 40.7\%, 35.3\% and 37.8\% towards inter-site dissimilarity, respectively. The best sponge assemblage model in DISTLM explained $30.1 \%$ of variation in assemblage structure based on non-substrate-standardised abundance: dead substrate (14.0\%), chl $a$ concentration $(6.4 \%)$, water movement $(4.9 \%)$ and the proxy for sedimentation, sediment thickness (4.9\%) (Fig. 3.5A).

Removal of the Sampela 1 data increased the total explanation value slightly to $33.0 \%$. The explanatory power of dead substrate $(16.1 \%)$ water movement $(5.2 \%)$ and settled sediment (4.0\%) changed little, there was no explanatory value for chl $a$ concentration, and changes in turbidity (4.2\%) and live coral cover (3.5\%) were found to be slightly influential (Fig. 3.5B).
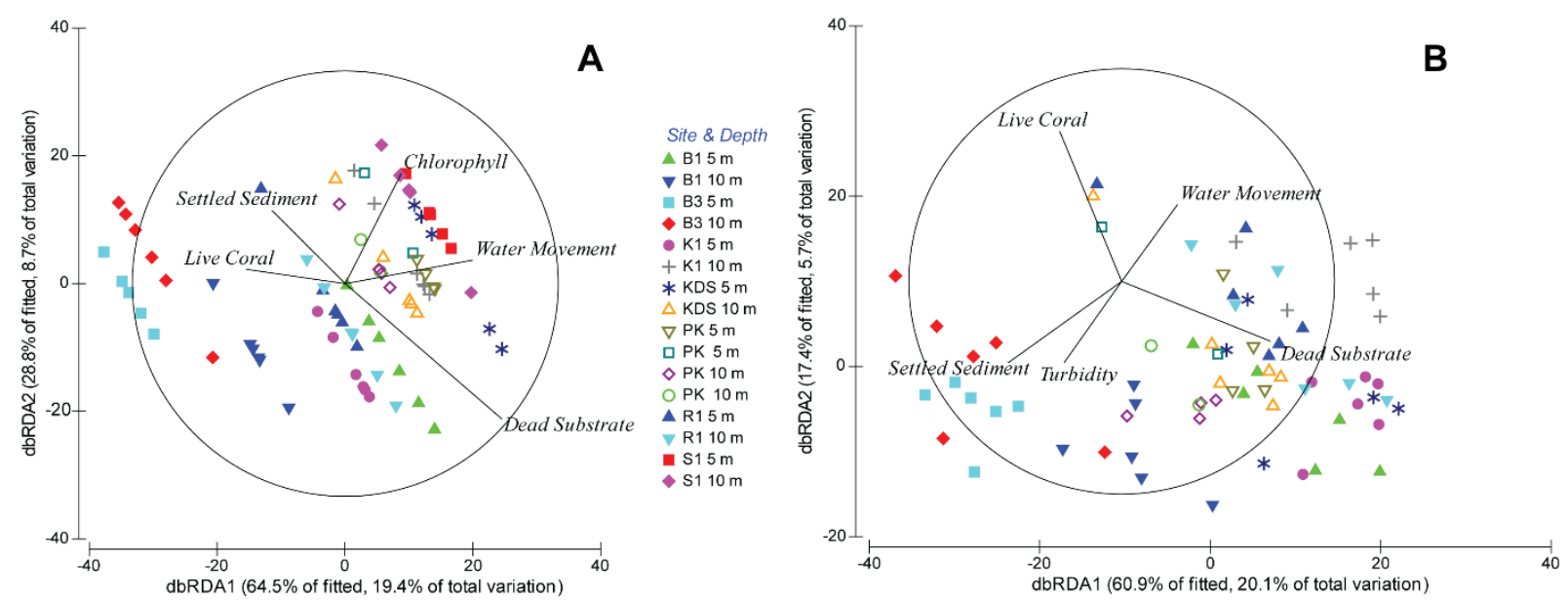

Figure 3.5. Distance based redundancy analysis (dbRDA) ordinations of fitted models for assemblage composition. A) Seven core sites and both depth categories. B) Core sites and both depth categories with the omission of Sampela.

When abundance was standardised to dead substrate availability, 23.9\% of assemblage structure variation was explained by environmental variables including water movement $(9.3 \%)$, settled sediment (8.2\%) and chl $a$ concentration (6.4\%). The removal of Sampela 1 from this analysis explained a similar amount of variation (24.4\%), but the explanatory value of settled sediment was greater (14.8\%), water movement became less important $(4.4 \%)$, chl a concentration no longer had an effect, and turbidity was found to be more important (5.2\%). 


\section{Individual species}

Greater abundance of dead substrate resulted in higher abundance by two of the three dominant boring sponge species: $C$. aff. viridis $\mathrm{n}$. sp. B and $C l$. cf. aurivillii (Spearman's Rank, $\mathrm{r}_{\mathrm{s}}=0.245$, $\mathrm{p}=0.011$ and $\mathrm{r}_{\mathrm{s}}=0.552, \mathrm{p}<0.001$, respectively). However, $S$. cf. vagabunda had an inverse relationship with dead substrate (Spearman's Rank, $r_{s}=-0.299, p=0.002$ ) (Fig. 3.6). Substratestandardising the abundance of these species and investigating their individual relationships with the explanatory variables identified by the DISTLM revealed that the abundance of $C$. aff. viridis n. sp. B correlated with none of these variables, increasing settled sediment limited the abundance of $\mathrm{Cl}$. cf. aurivillii but positively influenced $\mathrm{S}$. cf. vagabunda, and the abundance of Spheciospongia cf. vagabunda was limited by high water movement. (Appendix 1). Omitting Sampela 1 changed these relationships very little, but revealed a stronger relationship between

Spheciospongia cf. vagabunda and settled sediment; it was also found that higher turbidity increased the abundance of this species (Appendix 1). 

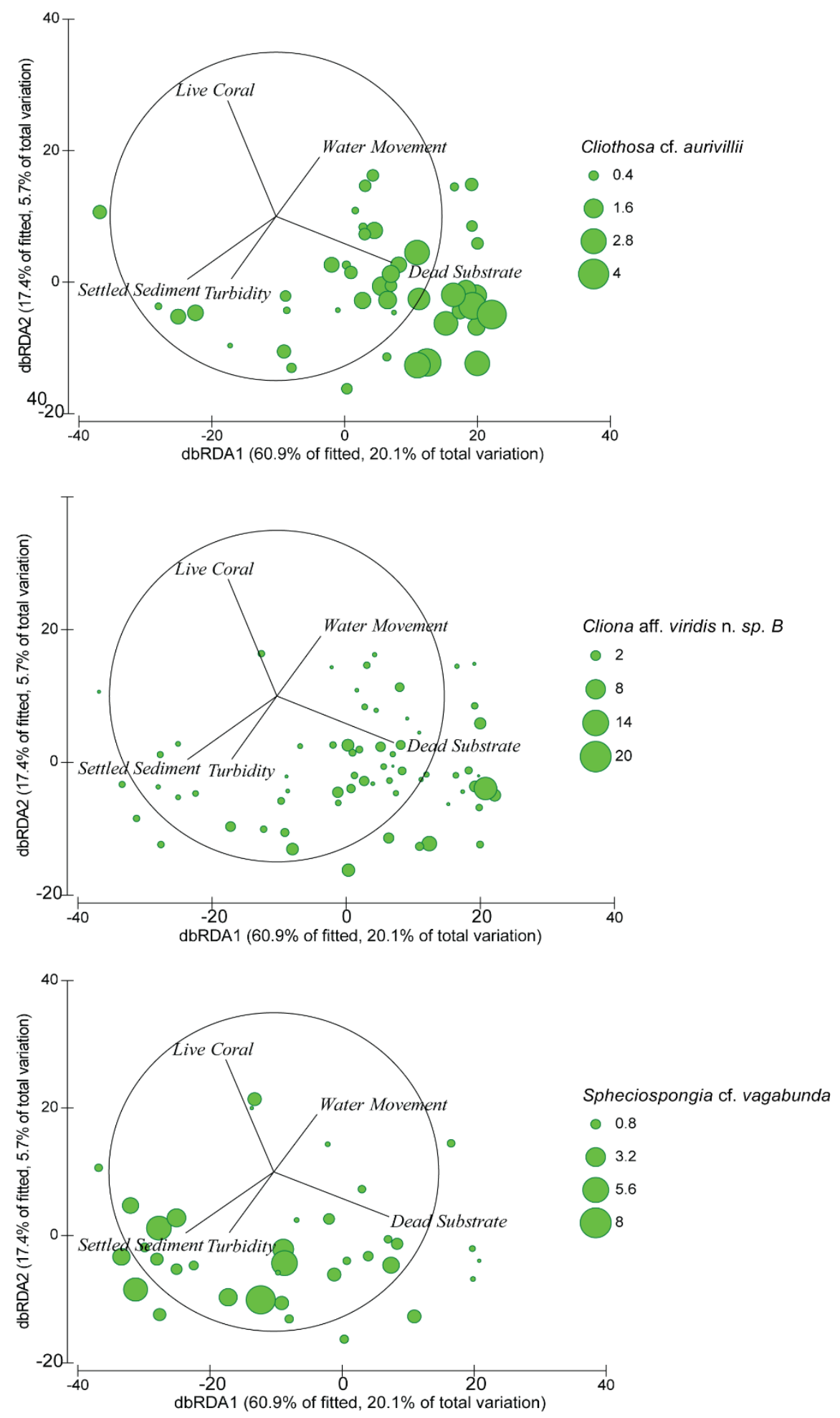

Figure 3.6. Distance based redundancy analysis (dbRDA) ordinations of fitted models for assemblage composition of the seven core sites (both depth categories), with the omission of Sampela 1. Overlapping 2D bubbles represent the abundance Cliothosa cf. aurivillii (top), Cliona aff. viridis n. sp. B (middle) and Spheciospongia cf. vagabunda (bottom). 


\subsection{Discussion}

By identifying putative environmental drivers of bioeroding sponge abundances this chapter provides an opportunity to assess how different bioeroding sponges respond to environmental variability using a model reef system in the world's most biodiverse coral reef region. This is the first such study in the central Indo-Pacific. I hypothesised that factors leading to coral stress and mortality, resulting in decreased spatial competition and increased availability of dead substrate, are beneficial for bioeroding sponges. While I found that the availability of suitable dead substrate was consistently positively correlated with the overall abundance of bioeroding sponges and was the best predictor of differences in assemblage composition, I also found negative impacts of high levels of sedimentation on bioeroding sponges. This suggests that while coral health and abundance can decline as a result of intensifying sedimentation (e.g. Fabricius 2005; Erftemeier et al. 2012), promoting the availability of dead substrate, sedimentation will not necessarily also result in higher bioeroding sponge abundance. Furthermore, while dead substrate was the key predictor for differences in bioeroding sponge abundance and assemblage composition, at best it only explained $15.1 \%$ of biotic variation, indicating that while bioeroding sponges depend on dead substrate, they do not settle or survive on it uniformly (Driscoll 1967; Callahan 2005). Finally, inter-species variation in abundance with respect to environmental factors illustrated how largely ubiquitous patterns should not readily be generalised across the entire taxon, but that species-specific requirements apply (as they do for other bioeroders: Schönberg et al. 2017).

\subsubsection{Abiotic and biotic influences on abundance, diversity and assemblage composition}

A number of abiotic and biotic factors were evaluated as possible drivers of bioeroding sponge distribution patterns, but none of them explained more than $33 \%$ of the total variability. Among these factors, availability of dead substrate was consistently one of the most important factors causing differences in bioeroding sponge abundance and assemblage composition in Indonesia (present data; Holmes et al. 2000). This is consistent with earlier studies on the Australian GBR (Schönberg 2001; 2015a; Schönberg \& Ortiz 2009), the Mexican Pacific (Nava \& Carballo 2013), and in the Caribbean (Callahan 2005; Chaves-Fonnegra et al. 2007). This observation is a consequence of the sponges' endolithic habit that creates a dependency on calcium carbonate structures (see Schönberg 2008). Nevertheless, this relationship could not uniformly be shown 
across all species studied, and differences were primarily driven by the abundances of the papillate $C$. cf. aurivillii and $C$. aff. viridis n. sp. B. Both species dominated at three sites with a high occurrence of dead substrate and little live coral. Conversely, S. cf. vagabunda became more common where dead substrate availability was low, but coral cover was relatively high. This suggests that biological requirements vary between these species and could be due to different levels of dependency on endolithic life style. Some Spheciospongia spp. are facultative endoliths, known to develop into fleshy or massive morphologies that are independent of the endolithic habit (Rützler 2002b). Cl. cf. aurivillii was originally described as occurring in a freeliving, as well as in an endolithic form (Lindgren 1897), but the species is more typically associated with the endolithic form. Not enough is known about $C$. aff. viridis n. sp. B to assess how tightly it is associated with the substrate, but in Wakatobi it was only observed in endolithic form. Furthermore, dispersal capabilities of bioeroding sponges are thought to vary significantly, from the extremely limited $(<10 \mathrm{~m})$ to the extensive $(>10 \mathrm{~km})$ (Mariani et al. 2000; ChavesFonnegra et al. 2015; Bautista-Guerrero et al. 2010; 2016). Thus, depending on species-specific traits, distribution patterns can be further decoupled from substrate availability, as some recruits may settle close to the parent sponge rather than evenly spreading out across all available substrate (Callahan 2005).

Bioeroding sponges have repeatedly been shown to react strongly to gradients of eutrophication, with the abundance of a number of species, and resulting damage by bioerosion, increasing with increasing nutrient levels (e.g. Rose \& Risk 1985; Holmes et al. 2000; Ward-Paige et al. 2005). However, my proxy for nutrient enrichment (chl $a$ concentration) only correlated with boring sponge abundance and assemblage composition when data from Sampela 1 were included in the analysis. The otherwise lack of a clear nutrient stimulus may be explained by the generally low and similar chl $a$ concentrations at most sites and interactions with other factors that can mask the effects of nutrient enrichment, leading to different net responses (e.g. Chaves-Fonnegra et al. 2007; Holmes et al. 2000; Reis \& Leão 2000; Holmes at al. 2009; Nava et al. 2014). When including Sampela 1, chl a concentration was negatively correlated with sponge abundance, which appears inconsistent with the concept of nutrient enrichment being beneficial to these sponges. However, Sampela 1 was not only characterised by high chl $a$ levels, but it was also the most turbid and sedimented of the surveyed sites. Low abundances of bioeroding sponges in eutrophic environments that experience excessive sedimentation or suspended particle 
concentrations have also been found in other studies. For example, Edinger et al. (2000) noted that bioeroding sponges were rare on reefs in the highly eutrophic Jakarta Bay, which the authors attributed to high sedimentation levels. Nava and Carballo (2013) came to a similar conclusion when they observed no relationship between the distribution of boring sponges and chl $a$ concentration on Pacific Mexican reefs.

Sedimentation can influence sponge distribution patterns by preventing settlement, by impeding vital physiological functions or by controlling survival and therefore selecting for adapted species over others (Bell et al. 2015; Schönberg 2016). Some bioeroding sponges can tolerate high levels of sedimentation, being covered by a thin layer of sand or are even adapted to live mostly buried in sediments (endopsammic; Holmes et al. 2000; Schönberg 2016). However even these tolerant species are thought to require a patch of free substrate for larval settlement and need to establish elevated, emerging structures before their main bulk becomes sediment covered. In the Wakatobi, up to $15 \%$ of the observed variance was explained by variation in the depth of settled sediment covering otherwise suitable substrate. The low total sponge abundance at Sampela 1 and the difference including or omitting this site's data has in regards to the importance of settled sediment implies that sedimentation resilience of the some bioeroding sponges has it's limits. In this Chapter, sedimentation effects on individual species primarily emerged as a positive correlation of $S$. cf. vagabunda abundance with settled sediment depth, when excluding Sampela data. Several species within this genus are known to benefit from living embedded in sediments and are adapted to tolerate sediment deposition on their surfaces (e.g. Schönberg 2016). However, no endopsammic individuals were observed in this study, and it should be noted that the sites with high $S$. cf. vagabunda abundance and high levels of settled sediment were also wall sites (primarily Buoys $1 \& 3$ ). The presence of vertical surfaces represents sediment-free substrate and can decouple the impacts of sedimentation from horizontal substrates at the same site (Bell \& Barnes 2000). This situation offers a refuge for less sediment-tolerant species (in the Wakatobi: Bell \& Smith 2004). The almost entire absence of $S$. cf. vagabunda from Sampela 1, implies either a limitation in settled sediment tolerance or a vulnerability to the high concentrations of suspended material also associated with the site. The latter is potentially the case for $S$. cf. vagabunda, given that the species has been associated with sandy habitats in other studies (e.g. Bergquist 1965; Sutcliffe et al. 2010). However, as discussed 
in Chapter 2, S. cf. vagabunda is potentially part of an unresolved species complex of which Wakatobi specimens represent a sediment intolerant species.

Holmes et al. (2000) found that the concentration of suspended material and turbidity were proportional to sponge bioerosion and explained this with collinearity to nutrient availability. Depending on the quality of the suspended materials, however, turbidity can counteract or be independent from the positive influence of nutrient enrichment (this Chapter; Holmes 2000). Whilst low levels of particle suspension in the water column were beneficial for the Wakatobi bioeroding sponges, evidence from Sampela 1 suggested that excessive turbidity may have limited bioeroding sponge abundance, a similar finding to that of Chaves-Fonnegra et al. (2007) in the Caribbean. Sponges have the capacity to be affected by suspended particles either by direct impairment of the pumping and filtration apparatus or indirectly through shading (Bell et al. 2015). If suspended particle concentration is limiting the abundance of S. cf. vagabunda at Sampela 1 it is likely due to direct impairment of vital functions rather than shading, as no photosymbionts were found in the species. However, turbidity induced shading may have contributed to the absence of two of the three locally abundant zooxanthellate species at Sampela 1. By altering the quality and quantity of photosynthetically active radiation, turbidity can regulate distribution patterns of phototrophic sponges (Caballero et al. 2009). For example, the zooxanthellate Cliona orientalis is most abundant near or below $5 \mathrm{~m}$ depth on clear-water reefs on the GBR, but at more turbid sample sites it dominates in the upper subtidal and intertidal regions (Bergman 1983, as Cliona viridis; Schönberg 2001). However, light requirements are likely species specific, as other zooxanthellate clionaids appear capable of persisting in conditions of greatly reduced light availability (Rosell \& Uriz 1991).

\subsubsection{Implications for reef management}

Globally increasing abundances of bioeroding sponges on degraded coral reefs are primarily attributed to the sponges' ability to exploit newly available calcareous habitat released by coral mortality (e.g. López-Victoria \& Zea 2005; Schönberg \& Ortiz 2009). The spatial patterns of bioeroding sponge assemblages in this study could not be conclusively associated with coral mortality. Low overall values of sponge occurrence made spatial comparisons difficult, and the absence of baseline data prevented the recognition of a temporal sequence of events related to reef degradation. The Wakatobi bioeroding sponge occupation levels of $8.9 \%$ of the dead reef 
substrate were somewhat lower than found on other reefs; e.g. 20 - $81 \%$ in the Mexican Pacific and $15 \%$ of dead substrate on the GBR (Schönberg \& Ortiz 2009; Nava \& Carballo 2013). However, the positive correlation between dead substrate availability and total bioeroding sponge abundance supports the hypothesis that further increases in the abundance of bioeroding sponges may occur if coral mortality increases in the region. Furthermore, the importance of dead substrate availability differed with species and had no overall association with sponge diversity, indicating that assemblages on degraded reefs are likely to be dominated by a few resilient species, a trend already observed by Schönberg and Ortiz (2009) on the GBR. Importantly, most of the local species had an apparent low resilience to sediment deposition and turbidity. This suggests that on reefs degraded by terrestrial run-off, which can cause declines in coral health and cover (Edinger et al. 1998; Fabricius 2005; Burke et al. 2011), bioeroding sponges may be prevented from exploiting increases in substrate availability.

\subsubsection{Conclusions}

In conclusion, not all factors that negatively affect corals are of benefit to bioeroding sponges. It is therefore vital to obtain a better understanding of the biological traits not just of calcifying, but also of bioeroding organisms, and of how they sustain or reduce the ecosystem health when reef function will be impacted by stress and degradation. 


\section{Chapter 4: Patterns of bioeroding sponge recruitment}

\subsection{Abstract}

As coral bleaching events increase in severity and regularity on coral reefs across the globe, the ensuing mass mortality of hard corals is resulting in increased availability of dead calcareous substrates. Benthic taxa that exclusively inhabit calcareous substrates, such as bioeroding sponges, are consequently likely to increase their colonisation of these substrates through either lateral expansion or larval recruitment. However, very little is currently known about rates of recruitment in bioeroding sponges or the influence of factors such as local adult abundance or substrate cues. Rates and drivers of bioeroding sponge recruitment were investigated using the two year deployment of experimental calcareous substrates across seven reefs in the Wakatobi region of Indonesia. After two years, five of the eight locally abundant species had recruited, and recruits were present on $69 \%$ of the experimental substrates. Recruitment only occurred on coralline algae, encrusting bryozoans and dead calcareous substrate, with a preference for the latter. Differences in assemblage structure of recruits was primarily driven by local adult abundance and current flow, predominantly due to large recruitment events of Cliona orientalis at two sites where local abundance was high. However, phylopatric recruitment was not observed in all species, with cues from the adjacent substrate appearing more important for species such as Cliothosa cf. aurivillii. Overall, the results from my study suggest that coral mortality, and subsequent increases in dead substrate availability, is likely to result in rapid and widespread recruitment of bioeroding sponges in the region. Assemblage composition of recruits is likely to differ depending upon local adult abundance and local substrate cues. 


\subsection{Introduction}

Coral reefs are in a global state of decline as sources of anthropogenic stress increase (Bellwood et al. 2004; Bruno \& Selig 2007; De'ath et al. 2012; Jackson et al. 2014). In recent years, a large extent of these declines have been attributed to man-made climate change and mass coral bleaching with associated die-offs (e.g. Eakin et al. 2010; Hughes et al. 2003; 2017; DeCarlo et al. 2017). As the key-stone taxa on tropical reefs, historically corals have dominated substrate composition through competitive interactions with less-competitive taxa. However, increased coral die-offs, associated with bleaching events (e.g. Glynn 1984; Normile 2016) or other stressors (e.g. Aronson \& Precht 2001; Kayal et al. 2012), is increasingly exposing new areas of bare calcareous substrate. Historically, on healthy reefs, space previously occupied by a coral could be colonised by any benthic taxa, but would predominantly follow a successional transition to eventual hard coral reoccupation (Endean 1976). However, on degraded and stressed reefs, where coral recruitment can be low (Kuffner et al. 2006; Hoey et al. 2011) and spatialcompetitive ability reduced (e.g. Aerts 2000; Vermeiji et al. 2010), other taxa can colonise and competitively maintain this substrate. The classic example of this is in the Caribbean where coral disease, coral bleaching, and a die-off of a keystone herbivore Diadema antillarum, led to a dramatic region-wide coral cover decline and a regime shift to macroalgal dominance (Lessios et al. 1984; Aronson \& Precht 2001; Gardner et al. 2003; Eakin et al. 2010; Mumby 2009; Jackson et al. 2014). The situation appears to be different in the Indo-Pacific, where despite large declines in coral cover (Bruno \& Selig 2007), macroalgal dominated reefs are rare (Bruno et al. 2009). This has led to some authors (e.g. Norström et al. 2009; Bell et al. 2013) to question what other benthic taxa might occupy the space left by coral mortality and potentially dominate some degraded reefs. Recent bleaching events (and subsequent coral mortality) on the Australian Great Barrier Reef (GBR), in the east Pacific and in the Indian Ocean have been associated with large increases in bioeroding sponge abundance (Sheppard et al. 2002; Schönberg \& Ortiz 2009; Carballo et al. 2013). These increases, and the resilience demonstrated by some bioeroding sponges to elevated water temperature and reduced $\mathrm{pH}$, have led authors to propose that bioeroding sponges are likely to be among the "winners" on degraded coral reefs (Schönberg \& Ortiz 2009).

The ability for bioeroding sponges to occupy newly available substrate following coral mortality is likely to happen through lateral encroachment, fragmentation, larval recruitment or a 
combination of these processes (López-Victoria \& Zea 2004; 2005; Zillberberg et al. 2006; Chaves-Fonnegra \& Zea 2011). Broadly defined, recruitment is the addition of new individuals to populations (Caley et al. 1996). As with all animals, the supply of new individuals is vital for population maintenance in sponges (Pineda et al. 2009, 2010; McMurray et al. 2010; Knapp et al. 2016) but is also important for regulating distribution (Uriz et al. 1998) and likely the expansion of a population into novel habitats (as in formifera; Alve 1999). Recruitment rates in sponges are generally low (Zea 1993) and appear to be particularly low in bioeroding sponges from the few studies that indirectly assessed recruitment for this group (Kiene \& Hutchings 1994; Pari et al. 1998; 2002). Recruitment of internal bioeroders has been studied in French Polynesia and the GBR and revealed a successional pattern from initial colonisation by polychaetes and sipunculans to an increasing abundance of boring molluscs and sponges over time (Kiene \& Hutchings 1994; Pari et al. 1998; 2002; Tribollet et al. 2002).

Although sponges are capable of asexual reproduction and dispersal (e.g. López-Victoria \& Zea 2004), the prevailing reproductive mode is sexual and dispersal relies on a free-living larval stage (Uriz et al. 2008). As such, recruitment is limited by larval production (e.g, Mariani et al. 2001; Piscitelli et al. 2011), survival (e.g. Uriz et al. 1996), dispersal (e.g. Maldonado 2006), habitat selection and settlement (e.g. Maldonado \& Uriz 1998), and post settlement survival (e.g. Maldonado \& Young 1996; de Caralt et al. 2007).

The pre-settlement lifespan of sponge larvae is short, normally only remaining in the water column for a matter of minutes to days and usually less than two weeks (Maldonado 2006). During this period, dispersal is thought to be largely passive and is a function of hydrodynamics that operate on a scale of tens of meters to kilometres (Pawlik 1992). Once larvae contact the sea bed dispersal transitions into active substratum exploration that occurs at a much finer scale of centimetres to meters, and can last longer than the planktonic phase (Maldonado 2006). Little is known about the mechanisms that govern the final selection of settlement location; it has long been hypothesised that chemical signals produced by conspecifics, competitors, or substrates etc play a role (as is the case for other invertebrate larva (e.g. Pawlik 1992)), but evidence for this is only beginning to emerge (e.g. Whalan et al. 2008; 2012; Wahab et al. 2011).

Our understanding of embryonic development and larval dispersal in bioeroding sponges is patchy and predominantly attributable to work by Mariani et al. $(2000 ; 2001 ; 2005 ; 2006)$ on 
Cliona viridis although Cliona celata and Cliona tenuis have also been studied (e.g. Piscitelli et al 2011; González-Rivero et al. 2013). From the few available studies it appears that oviparous embryonic development is the most widespread in bioeroding sponges (although potentially with internal fertilisation) (Rosell 1993; Mariani et al. 2000; Maldonado \& Riesgo 2008; GonzálezRivero et al. 2013). Gamete development occurs on an annual cycle and release is a highly synchronised event that is related to water temperature (Mariani et al. 2000; Piscitelli et al 2011; González-Rivero et al. 2013). Clionaidae larvae, unlike the majority of sponges which produce parenchymella larvae, are clavabastula ((Maldonado 2006; Maldonado \& Riesgo 2008) and particularly week swimmers, often demonstrating predominantly crawling rather than swimming behaviour (Mariani et al. 2000; 2001; 2006). Dispersal as a consequence is considered to be low and phylopatric (Mariani et al. 2006). As bioeroding sponges can only erode calcareous substrates it was assumed that larval settlement is limited to these substrates (Hartman 1958); however, settlement non-specificity has been also been observed in C. celata (Warburton 1966). Therefore it has been suggested that while bioeroding sponges are able to settle on a variety of substrates, post settlement development is reliant upon excavation on calcareous substrates (Rosell \& Uriz 1992). The only available measure of post settlement survival (13\% after 15 days in $C$. viridis) is unreliable as the experimental substrate was a plastic petri-dish (Mariani et al. 2000).

Despite some studies indirectly studying bioeroding sponge recruitment within the Indo-Pacific, (Kiene \& Hutchings 1994; Tribollet et al. 2002), our knowledge of the drivers of recruit abundance and diversity and the timescales over which recruitment occurs is still very limited. Understanding these factors is important given the increase in potential habitat availability due to regional decreases in coral cover (Bruno \& Selig 2007). This chapter therefore will focus on the recruitment on bioeroding sponges in the Wakatobi region of Indonesia. Through the use of a two year deployment of carbonate recruitment blocks, recruitment was analysed in relation to local environmental conditions, substrate composition and adult sponge abundance. 


\subsection{Methods}

\subsubsection{Study area}

The research for this chapter was conducted within the Wakatobi UNESCO Biosphere Reserve (Wakatobi) in southeast Sulawesi, Indonesia. Bioeroding sponge recruitment was studied at seven reef sites fringing the islands of Hoga and Kaledupa, which were chosen to represent a variety of reef types, environmental conditions and levels of reef degradation (Fig. 4.1). The same sites constituted the "core" sites in Chapter 3; three steep-wall reefs; Buoy 1 and 3, and Ridge 1; three sloping reefs: Kaledupa 1, Kaledupa Double Spur and Pak Kasims; and Sampela 1, which is highly sedimented and considered to be highly degraded (McMellor \& Smith 2010). Sites Buoy 1 \& 3, Kaledupa 1 and Kaledupa Double Spur, Pak Kasim's, Ridge 1 and Sampela 1 are abbreviated in the results and figures as B1, B3, K1, KDS, PK, R1 and S1 respectively.

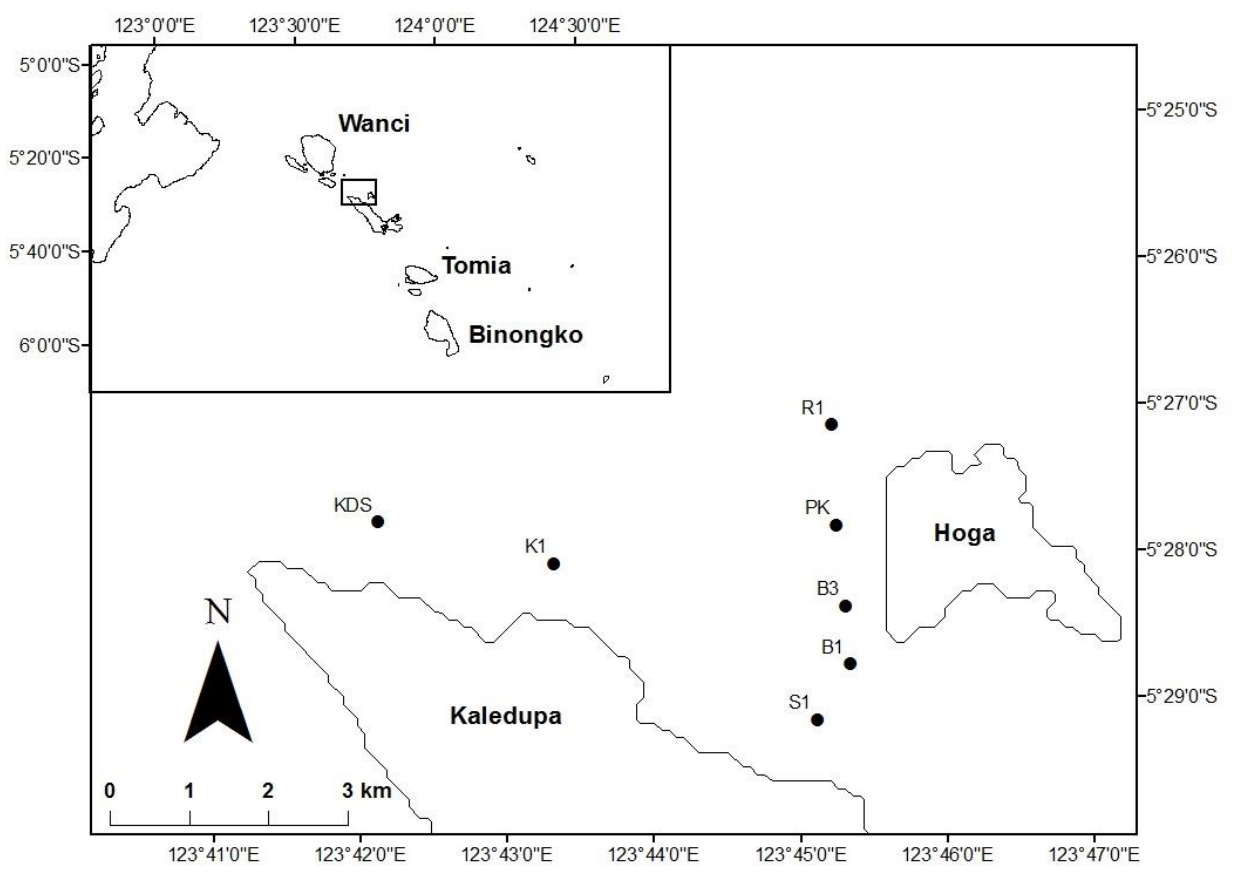

Figure 4.1. Map of sponge recruitment study sites within the Wakatobi.

\subsubsection{Bioeroding sponge recruitment}

Bioeroding sponge recruitment was studied using a two year deployment of experimental calcareous substrates. The calcareous blocks $\left(10 \times 10 \times 10 \mathrm{~cm}^{3}\right)$ of cemented reef rock were obtained from a mine on the local coralline island of Wanci and deployed to reef sites in July and 
August 2014. At each of the seven sites five blocks were attached $15 \mathrm{~m}$ apart to suitable patches of dead substrate at 10 and $5 \mathrm{~m}$ depth $(\mathrm{n}=70)$ using marine epoxy (Fig 4.2A). Each block was then photographed in reference to notable reef features to aid future recovery.
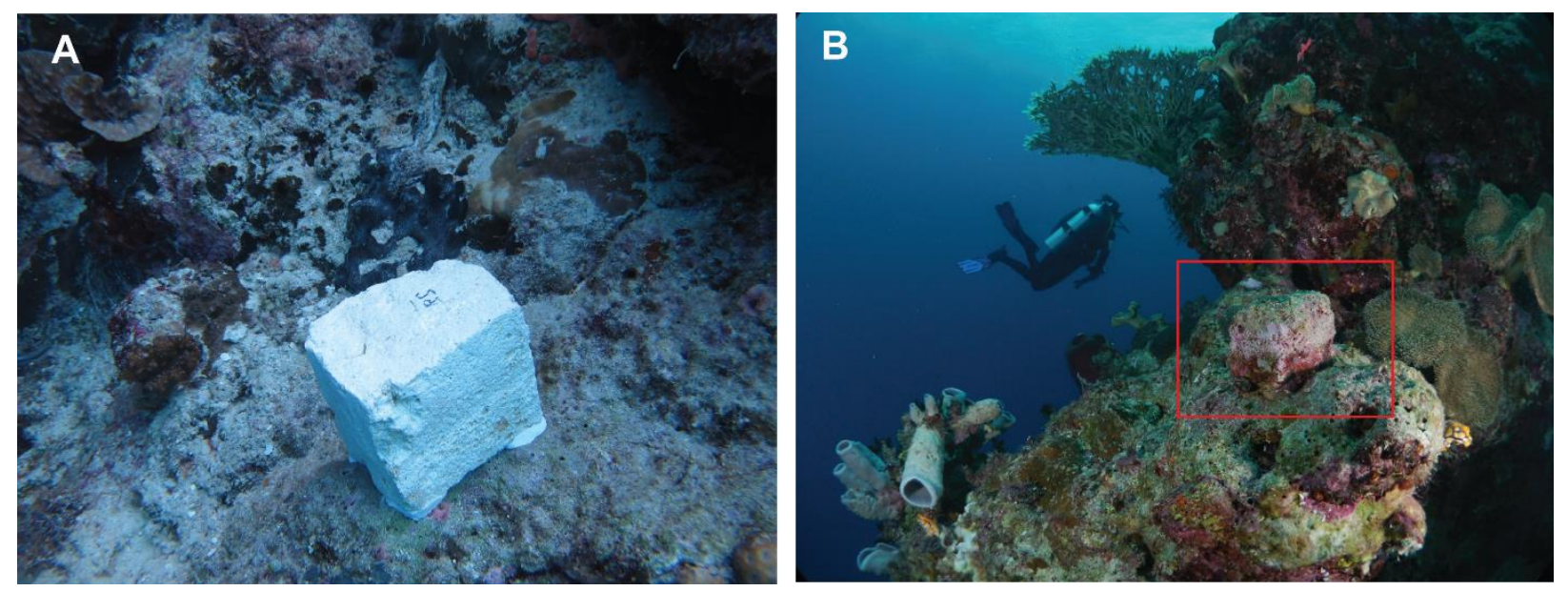

Figure 4.2. Example field images of recruitment block deployed to the reef in 2014 (A) and on retrieval in 2016 (B).

Through the course of July and August 2016 the recruitment blocks were located (Fig. 4.2B) and retrieved from the relevant reef sites. Upon locating each block, the block was removed from substrate with a hammer and chisel and examined. Each exposed side of the block was examined for any bioeroding sponges, noting species present, sponge location on the block and the presence of any taxa that may be mistaken for sponges during image analysis. Blocks were then photographed in situ (every exposed side) and removed from the reef. In the lab each block was subsequently split open using a hammer and chisel to either confirm in-water observations or locate previously unobserved sponges.

\subsubsection{Biotic and abiotic predicator variable data collection}

The following data was collected to determine the degree to which bioeroding sponge recruitment is driven by the local adult population, substrate cues or environmental conditions.

The local adult sponge population and substrate composition was assessed using $1 \mathrm{~m}^{2}$ photoquadrats that were taken of the benthos surrounding each recruitment block during block deployment in 2014. Each quadrat was divided into sixteen subdivisions and in addition to taking 
photos of each subdivision, field notes were taken of observations of any bioeroding sponges within each subdivision.

In order to augment environmental data already collected for Chapter 3 the XR-420 CTD (RBR, Ottawa) data logger was further deployed at the seven sites on randomly selected dates in June August 2016 to measure turbidity and chl $a$. As per Chapter 3, each deployment took place for a minimum of 24 hours and the CTD set to record every minute with no averaging. The data was combined to create average values for each environmental parameter for each site, based on each 24 hour deployment with minutes considered as subsamples within each 24 hour period. In addition the clod data from Chapter 3 was used for estimations of site differences in current flow. A snapshot estimation of settled sediment for each block was obtained after deployment in 2014 and before retrieval in 2016 by measuring the depth of settled sediment on the top each block (mean of each corner and the centre) using callipers.

\subsubsection{Image analysis}
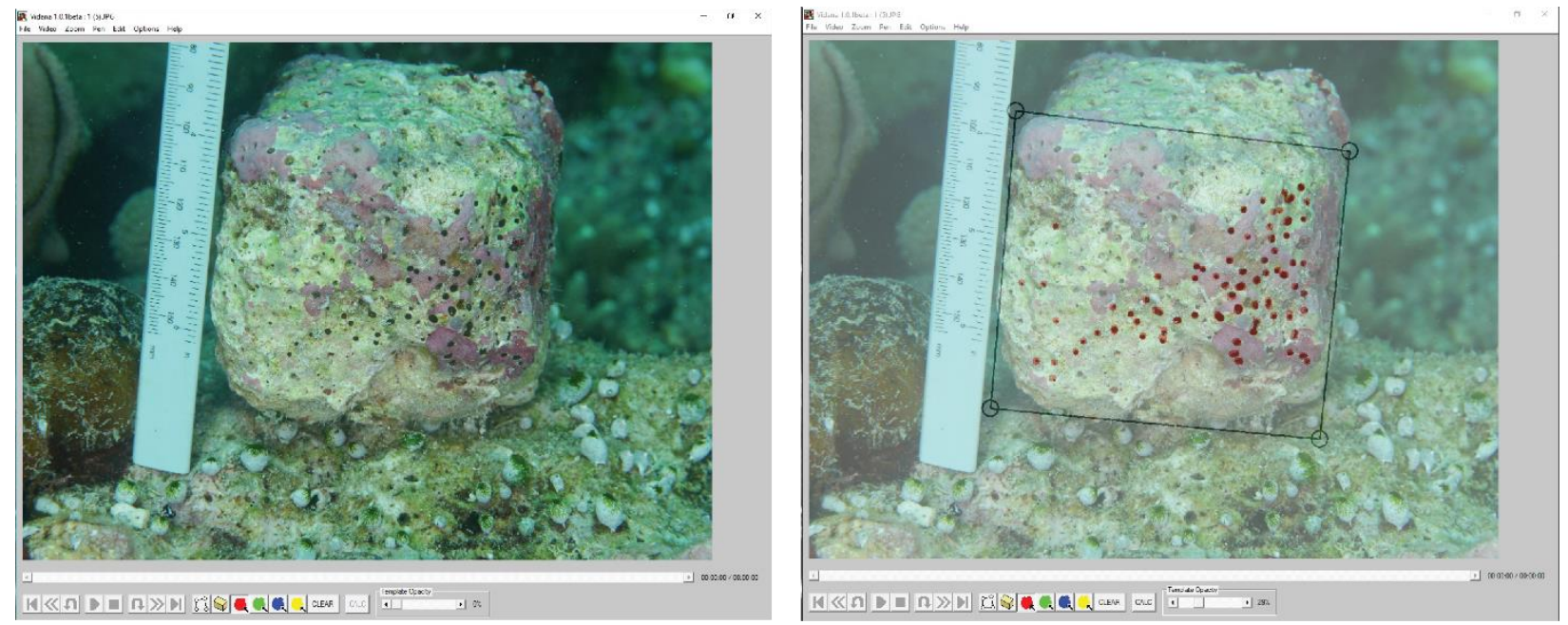

Figure 4.3. Example screen shots of Vidana software. Left image depicting one side of recruitment block pre-measurement and the right image showing the same block after the recruits have been located and tagged.

Recruitment was analysed using the in situ images and imaging software Vidana (freely available at marinespatialecologylab.org/resources/vidana). On each side of the block, recruits were located (with the aid of field notes) and marked (Fig. 4.3). Recruitment was then measured in terms of percentage cover of sponge recruits (per species) in relation to the total area of the 
recruitment block side. Each side of the recruitment block was considered a subsample and data was averaged over all five sides of the block.

The 2014 abundance of bioeroding sponges adjacent to each block was also analysed using the Vidana software. The images of each subdivision of the photo-quadrat (and in combination with field notes) were examined for bioeroding sponge presence. As per the recruitment blocks, sponge cover was measured in terms of percentage cover of each subdivision. Sponge cover data for each photo-quadrat subdivisions were treated as subsamples and were averaged to create mean values for the entire square meter.

Benthic composition of both the substrate adjacent to each block and of each block surface was measured using Coral Point Count (CPC) software. CPC analysis of the photo-quadrat data involved the random allocation of 15 points per subdivision image $(n=240$ per photo-quadrat). The substrate beneath each point was then allocated to one of the following categories; macro algae, coralline algae (CCA), hard coral, sponge, soft coral, dead coral + algae, rubble, dead platform, recently dead coral (bleached), sand, silt, sediment on rock or "other". Data from all 16 subdivisions were then averaged across the photo-quadrat. The sponge recruitment images were used for CPC analysis of 2016 benthic composition of recruitment blocks. Percentage cover of ascidians, encrusting bryozoans, macroalgae, coralline algae, hard coral, soft coral, sponges, dead carbonate, settled sediment and "other" were measured. Twenty points were randomly allocated to each block side image $(n=100$ per block) and the benthic taxa beneath each point identified as one of the categories above. Data from each side of the block was taken as a subsample and averaged to create mean block benthic composition.

The image analysis of the precise substrate beneath each recruit was judged by eye; the adjacent substrate around each recruit was inspected and allocated a substrate type (same categories as for the block the analysis). If more than one substrate type was present then the most contiguous was chosen.

\subsubsection{Statistical analysis}

The statistical analysis focused on site and depth based differences in bioeroding sponge recruit assemblages and abundance and the degree to which these were influenced by biological and environmental factors. In this context, biological factors constituted localised bioeroding sponge 
abundance (adjacent photo-quadrat data) and reef-scale abundance (survey data from Chapter 3). Environmental data constituted recruitment block benthos, photo-quadrat benthos, CTD data, sediment and flow.

Multivariate analysis was performed using the PRIMER-E v6 software package with the permutational multivariate analysis of variance (PERMANOVA) add on (Clarke \& Gorley 2006).

Differences in the benthic composition of the recruitment blocks and adjacent substrate was analysed using PERMANOVAs, constructed from normalised data and resemblance matrices constructed using Euclidean distance. Differences were further characterised graphically using principal coordinate analysis (PCO) with overlaying Pearson's correlation vectors.

Sponge recruitment was highly varied; recruit assemblage data (average percentage cover per species per recruitment block) ranged from the very small (e.g. a single papillae) to quite large (e.g. a large encrustation) and contained many zeros. Therefore the data was square-root transformed and resemblance matrices constructed using Bray-Curtis similarity coefficients. The transformation helping to preserve information on relative abundance, while reducing the effect of the overly abundant species and the Bray-Curtis similarity index ignores the large number of zeros in the data set (Clarke 1993). Due to the absence of bioeroding sponge recruits on many recruitment blocks, a dummy species with the abundance value of 0.5 was added to each recruitment block in order to construct the resemblance matrix and diminish the erratic behaviour of the Bray-Curtis coefficient (Clarke et al. 2006). Differences in recruit assemblages between site and depth (and any interactions) were assessed using a two-factor PERMANOVA and results were graphically displayed using PCO. The species of recruits that contributed most towards any site or depth differences were investigated using a SIMPER analysis. Differences in bioeroding sponge recruit assemblages were also analysed in relation to differences in explanatory biological and environmental data. These explanatory variables were either squareroot transformed (biological data) or normalised (environmental data). Possible associations were investigated in a distance-based multiple linear regression model (DISTLM), which is a non-parametric permutation-based procedure that enables significance testing of explanatory variables against multivariate response variables (Anderson et al. 2007). In order to find the most parsimonious model, Akaike's Information Criterion (AIC), a step-wise procedure, 
adjusted for small sample sizes (AICc) was used (Burnham \& Anderson 2004). Biological and non-biological influences on recruitment were tested separately and DISTLM outputs were represented graphically with a distance-based redundancy ordination (dbRDA).

All univariate statistical analyses were performed in SPSS (version 23; IBM, Auckland, New Zealand). The large number of zeros in the data set meant that the data was inherently not normally distributed and variance high, therefore where data failed to meet the assumptions of the parametric tests data was square-root, fourth-root or log transformed. In the event that transformations failed to meet these assumptions non-parametric Kruskal-Wallis or Spearman's Rank tests were used.

Differences in total average recruit abundance (all species combined) between sites and depth (and interactions) were tested using a GLM on fourth-root transformed data. Correlations between recruit abundance (species combined and individual species) were tested against all biological and environmental data. As the data set contained a large amount of zeros, the correlation analysis for individual species was split into two analyses; 1) all data (Spearman's Rank, untransformed) and 2) positive abundance data (only using data from blocks that recruited bioeroding sponges; Pearson's correlation, fourth-root transformed). For correlations involving recruit data for individual species, only species that recruited to minimum of 10 recruitment blocks were included in the analysis.

Recruit substrate settlement choice was analysed using a means comparison (Kruskal-Wallis, untransformed) between the percentage of recruits (total) settling on a substrate type and the percentage of that substrate type on the block. 


\subsection{Results}

\subsubsection{Localised substrate and block characteristics}

The local substrate composition in 2014 adjacent to each block differed significantly between sites (PERMANOVA, Pseuedo-F $=5.6117, \mathrm{p}=0.001$ ). The substrate composition was characterised by sand and rubble around blocks at KDS and S1; by soft coral, dead substrate, recently dead coral and macroalgae around blocks at $\mathrm{K} 1$ and $\mathrm{PK}$; by sponges, coralline algae and settled sediment around blocks at B3; and a more heterogeneous composition around blocks at B1 and R1 (Fig. 4.4A). The local substrate composition adjacent to each block also differed significantly between depths (PERMANOVA, Pseuedo-F $=3.8435, \mathrm{p}=0.001$ ), which appears to be primarily driven by high cover of sponges, coralline algae and settled sediment around many $10 \mathrm{~m}$ recruitments blocks Fig. 4.4B).
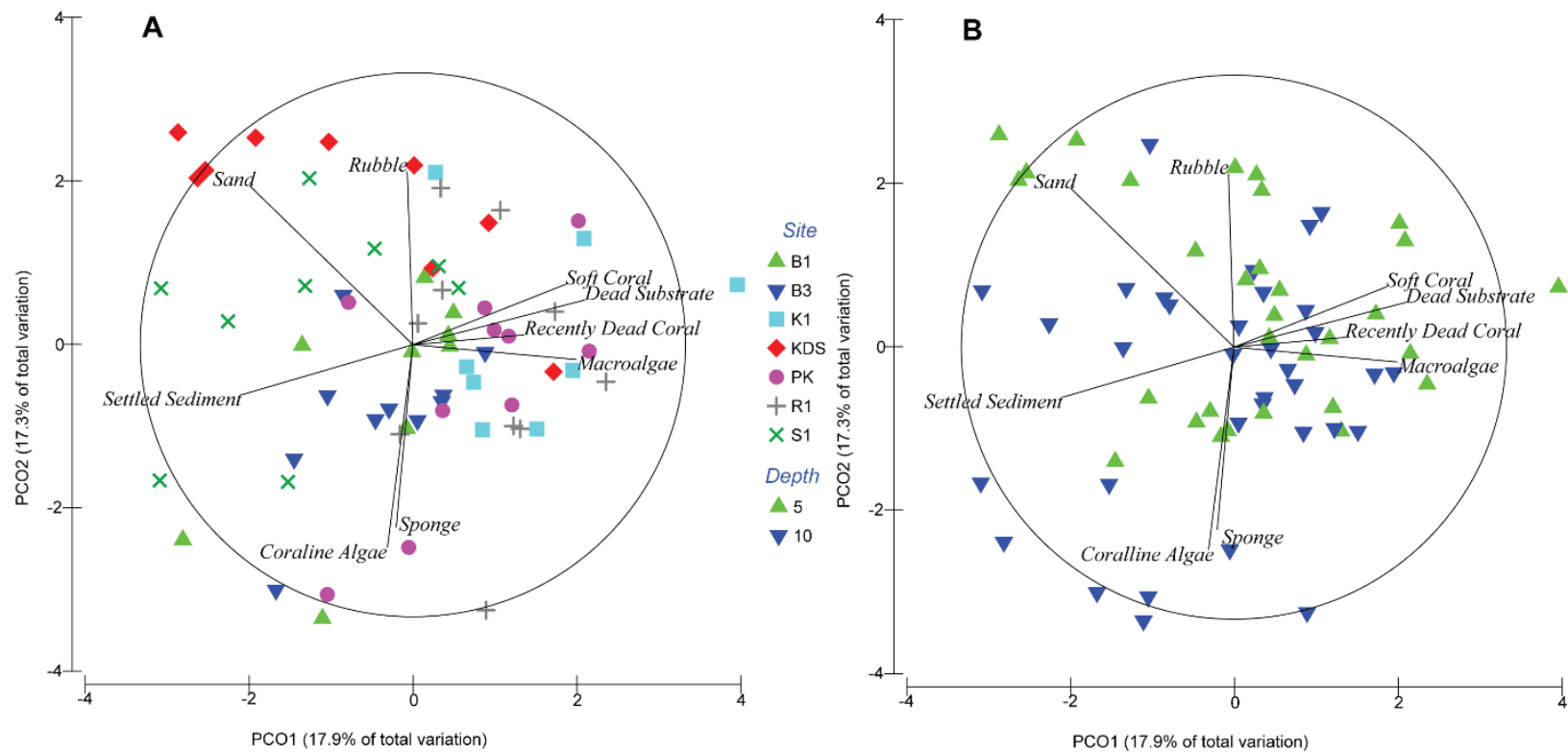

Figure 4.4. Two dimensional representation (principal coordinate analysis, PCO) of recruitment block similarities with respect to their adjacent substrate composition. A \& B represent the same PCO but blocks are either designated by site (A) or depth (B). Overlaid vectors represent adjacent substrate components that have a Pearson's correlation of greater than 0.4 with either of the PCO axes. 
Recruitment block benthos in 2016 was significantly different between sites (PERMANOVA, Pseuedo-F $=1.772, \mathrm{p}=0.002$ ) but not between depths. Recruitment blocks at KDS, R1 and S1 were predominantly characterised by coralline algae and "other", while blocks at all other sites showed a more heterogeneous composition of coralline algae, macroalgae, sponges, dead substrate and "other". Three blocks at B3 and one at R1 showed notably high ascidian cover (Fig. 4.5).

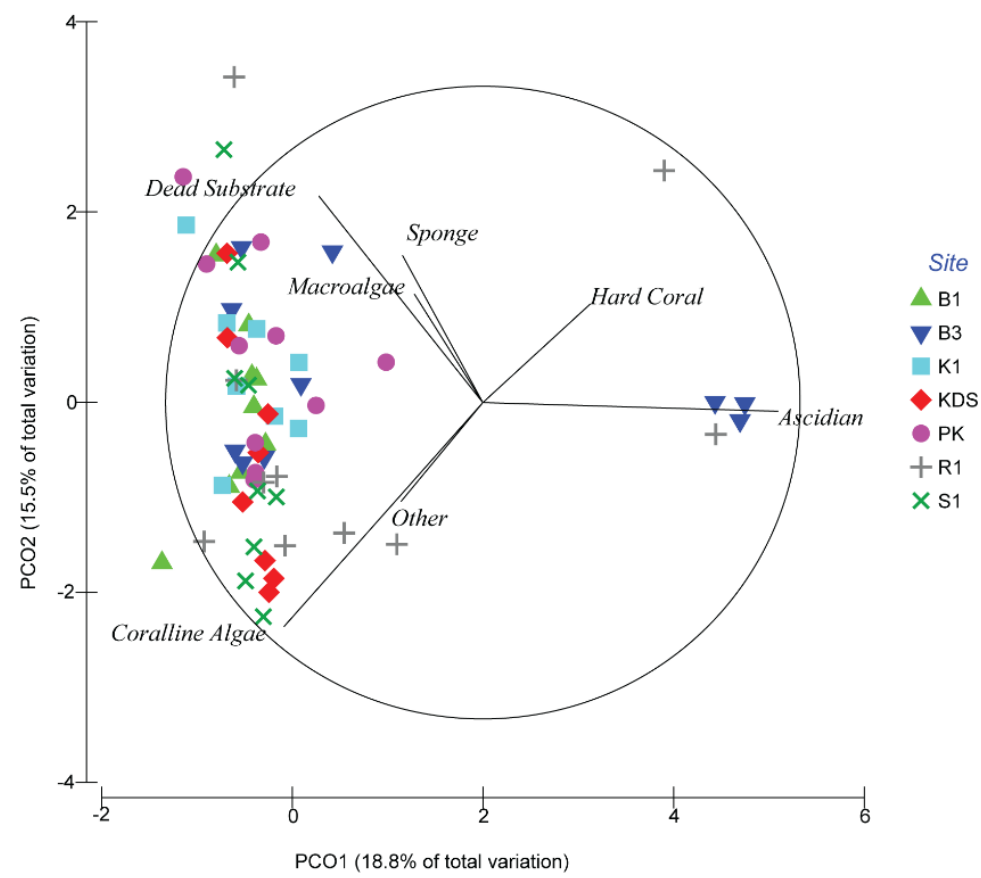

Figure 4.5. Two dimensional representation (PCO) of recruitment block similarities with respect to their benthic composition. Overlaid vectors represent recruit block benthic components that have a Pearson's correlation of greater than 0.4 with either of the PCO axes.

\subsubsection{Localised adult sponge abundance}

All eight locally abundant species were identified in the photo-quadrats adjacent to the recruitment blocks with significant differences in assemblage composition occurring between sites $($ PERMANOVA, Pseudo-F $=3.3053, \mathrm{p}=0.001)$ and depths (PERMANOVA, Pseudo-F $=$ 2.2846, $\mathrm{p}=0.047)$. When assessing differences in these assemblages but not including those species that did not recruit (see below) local bioeroding sponge assemblage composition was still significantly different among the sites (PERMANOVA, Pseudo-F $=3.5373, \mathrm{p}=0.001$ ) and depths (PERMANOVA, Pseudo-F = 2.9823, $\mathrm{p}=0.030$ ). The majority of sites were associated 
with assemblages that were dominated by Cliothosa cf. aurivillii, however KDS was more characterised by the presence of Cliona orientalis and a number of blocks at K1, KDS and R1 were adjacent to assemblages characterised by the presence of Cliona aff. viridis n. sp. A. Although present in the local bioeroding sponge assemblage, neither Cliothosa hancocki nor Cliona aff. viridis n. sp. B were strongly associated with any particular site (Fig. 4.6)

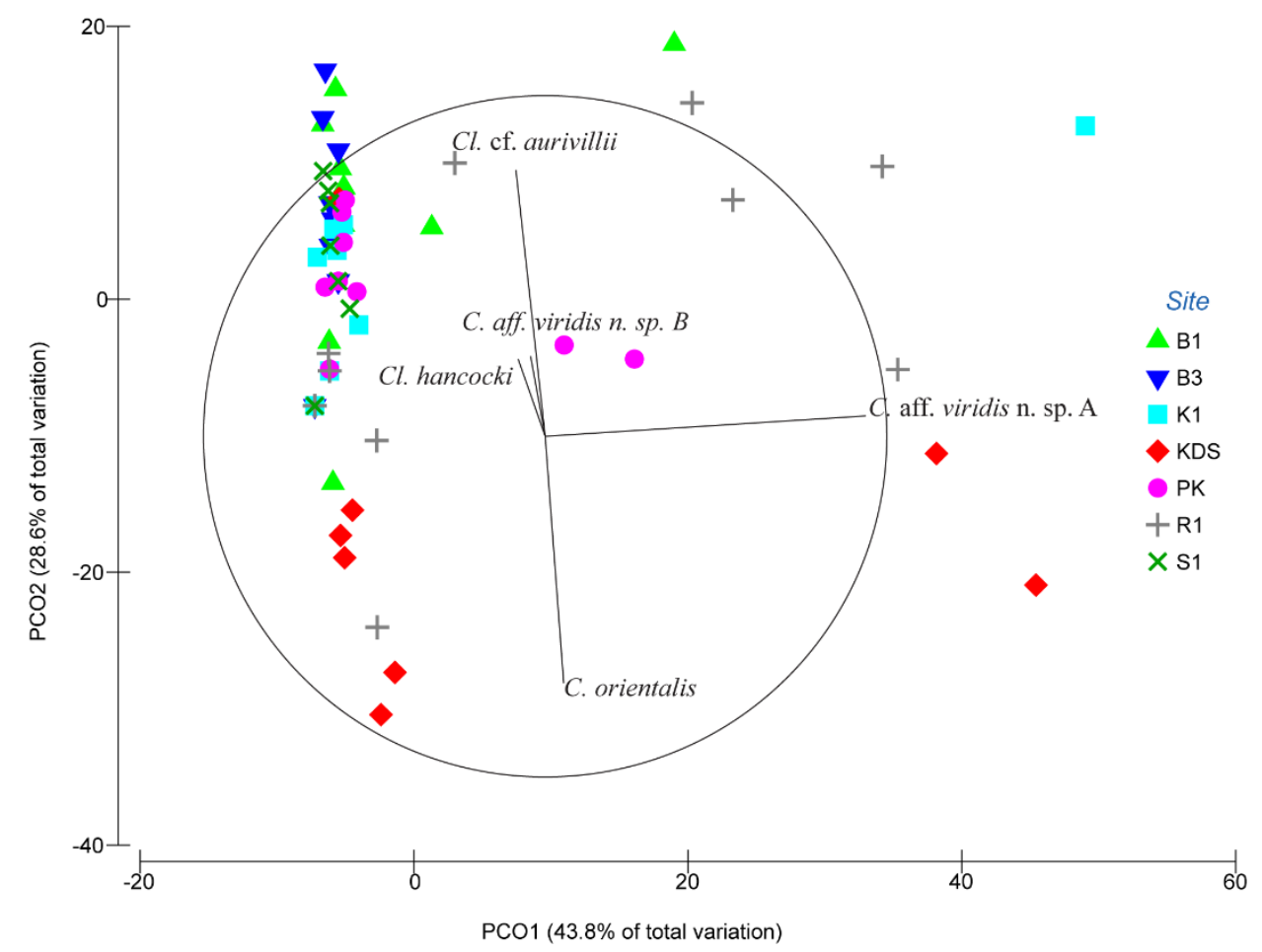

Figure 4.6. Two dimensional representation (PCO) of recruitment block similarities with respect to their adjacent bioeroding sponge assemblage composition. Overlaid vectors represent Pearson's correlation of the same data with either of the PCO axes. Only Cliothosa cf. aurivillii, Cliona orientalis and Cliona aff. viridis $\mathrm{n}$. sp A have correlation coefficients higher than 0.4 .

\subsubsection{Recruitment}

Of the 70 recruitment blocks deployed across the seven reef sites, 65 were recovered. Of the 65 recovered, $45(69.1 \%)$ had at least one sponge recruit, however average cover was generally low $(0.42 \% \pm 0.13 \mathrm{SE})$ and of those blocks to which sponges recruited, species richness was also low (average of 1.2 species per block $\pm 0.06 \mathrm{SE})$. Average recruit cover was highest at KDS $(1.3 \% \pm$ $0.8 \mathrm{SE})$ and lowest at B1 $(0.1 \% \pm 0.05 \mathrm{SE})$, and higher at $5 \mathrm{~m}(0.6 \% \pm 0.3 \mathrm{SE})$ than at $10 \mathrm{~m}$ depth $(0.2 \% \pm 0.05 \mathrm{SE})$. These differences were not significant (Fig. 4.7). Recruits only settled 
on CCA $(60.4 \% \pm 3.2 \mathrm{SE})$, dead substrate $(38.8 \% \pm 3.2 \mathrm{SE})$ and encrusting bryozoans $(0.8 \% \pm$ $0.5 \mathrm{SE})$. The respective percentage of recruits settling on each of those substrates was significantly higher than the average cover of dead substrate on those blocks $(26.4 \% \pm 2.0 \mathrm{SE}, \mathrm{p}$ $=0.017)$, significantly lower than the average cover of encrusting bryozoans $(1.4 \% \pm 0.4 \mathrm{SE}, \mathrm{p}=$ $0.049)$ and similar (not significantly different) to the average cover of CCA $(57.5 \% \pm 2.3 \mathrm{SE})$.

Average total recruit cover correlated positively with local bioeroding sponge abundance $\left(r_{s}=\right.$ $0.338, \mathrm{p}=0.006)$, flow $\left(\mathrm{r}_{\mathrm{s}}=0.333, \mathrm{p}=0.007\right)$ and negatively with the abundance of algaecovered dead coral in the adjacent substrate $\left(r_{s}=-0.318, \mathrm{p}=0.010\right)$.

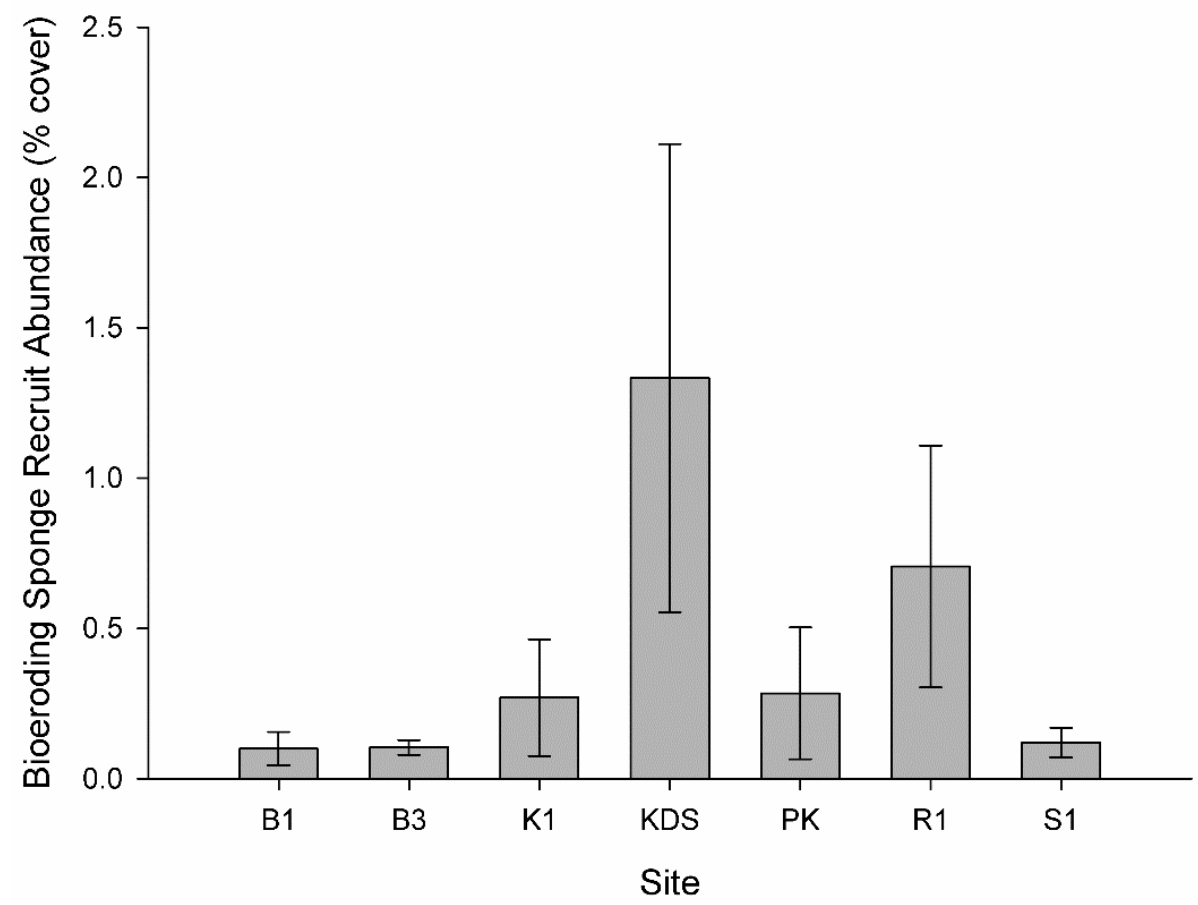

Figure 4.7. Average percent coverage of bioeroding sponge recruits (all species combined) across sites. Standard error bars shown.

Of the eight bioeroding sponge species identified in Chapter 2, five were present on the recruitment blocks. These species were $C l$. cf. aurivillii (11 blocks), $C l$. hancocki (1 block), $C$. orientalis (11 blocks), C. aff. viridis n. sp. A (3 blocks) and C. aff. viridis n. sp. B (28 blocks). Absent were Cliona cf. schmidtii, Spheciospongia cf. vagabunda and Zyzzya criceta. Despite recruiting the most regularly, $C$. aff. viridis n. sp. B was not as abundant overall as $C$. orientalis (see Table 4.1), predominantly due large recruitment events for the latter species at KDS at R1. 
Table 4.1. Average percentage cover of bioeroding sponge recruits for individual species per site. Also shown is total average recruitment (all species combined) per site and average for recruitment for each species across all recruitment blocks. Not shown are species that did not recruit. Standard errors area shown.

\begin{tabular}{|c|c|c|c|c|c|c|}
\hline \multirow[t]{2}{*}{ Site } & \multicolumn{5}{|c|}{ Species } & \multirow[t]{2}{*}{ Total } \\
\hline & $\begin{array}{c}C l . \text { cf. } \\
\text { aurivillii }\end{array}$ & $\begin{array}{c}C l . \\
h a n c o c k i\end{array}$ & $\begin{array}{c}C . \\
\text { orientalis }\end{array}$ & $\begin{array}{c}\text { C. aff. } \\
\text { viridis } \mathrm{n} . \mathrm{sp} \text {. } \\
\text { A }\end{array}$ & $\begin{array}{c}\text { C. aff. } \\
\text { viridis } \mathrm{n} . \mathrm{sp} \text {. } \\
\mathrm{B}\end{array}$ & \\
\hline B1 & 0 & 0 & 0 & 0 & $\begin{array}{c}0.100 \pm \\
0.060\end{array}$ & $\begin{array}{c}0.100 \pm \\
0.060\end{array}$ \\
\hline B3 & $\begin{array}{c}0.004 \pm \\
0.003\end{array}$ & $\begin{array}{c}0.008 \pm \\
0.008\end{array}$ & 0 & 0 & $\begin{array}{c}0.092 \pm \\
0.030\end{array}$ & $\begin{array}{c}0.104 \pm \\
0.025\end{array}$ \\
\hline K1 & 0 & 0 & 0 & $\begin{array}{c}0.213 \pm \\
0.140\end{array}$ & $\begin{array}{c}0.058 \pm \\
0.016\end{array}$ & $\begin{array}{c}0.270 \pm \\
0.194\end{array}$ \\
\hline KDS & $\begin{array}{c}0.036 \pm \\
0.017\end{array}$ & 0 & $\begin{array}{c}1.297 \pm \\
0.500\end{array}$ & 0 & 0 & $\begin{array}{c}1.333 \pm \\
0.778\end{array}$ \\
\hline PK & $\begin{array}{c}0.218 \pm \\
0.211\end{array}$ & 0 & 0 & $\begin{array}{c}0.040 \pm \\
0.040\end{array}$ & $\begin{array}{c}0.026 \pm \\
0.024\end{array}$ & $\begin{array}{c}0.284 \pm \\
0.220\end{array}$ \\
\hline R1 & $\begin{array}{c}0.040 \pm \\
0.040\end{array}$ & 0 & $\begin{array}{c}0.364 \pm \\
0.342\end{array}$ & $\begin{array}{c}0.012 \pm \\
0.012\end{array}$ & $\begin{array}{c}0.290 \pm \\
0.240\end{array}$ & $\begin{array}{c}0.706 \pm \\
0.402\end{array}$ \\
\hline S1 & $\begin{array}{c}0.056 \pm \\
0.030\end{array}$ & 0 & $\begin{array}{c}0.007 \pm \\
0.005\end{array}$ & 0 & $\begin{array}{c}0.058 \pm \\
0.013\end{array}$ & $\begin{array}{c}0.120 \pm \\
0.049\end{array}$ \\
\hline Average & $\begin{array}{c}0.052 \pm \\
0.033\end{array}$ & $\begin{array}{c}0.001 \pm \\
0.001\end{array}$ & $\begin{array}{c}0.237 \pm \\
0.125\end{array}$ & $\begin{array}{c}0.034 \pm \\
0.027\end{array}$ & $\begin{array}{c}0.092 \pm \\
0.038\end{array}$ & $\begin{array}{c}0.417 \pm \\
0.134\end{array}$ \\
\hline
\end{tabular}

Recruitment of the species, $C l$. cf. aurivillii, $C$. orientalis and $C$. aff. viridis n. sp. B was high enough to warrant individual correlation analysis. Correlations are split into those using positive abundance data (only using blocks which the species recruited to) and all data. Correlation analysis (positive abundance) of $\mathrm{Cl}$. cf. aurivillii recruits found their abundance to be only correlated with the cover of encrusting bryozoan on the recruitment blocks $\left(\mathrm{r}^{2}=0.649, \mathrm{p}=\right.$ 0.031). When including all data, the recruitment correlated with the cover of algae-covered dead coral and rubble in the adjacent substrate $\left(r_{\mathrm{s}}=-0.381, \mathrm{p}=0.002\right.$ and $\mathrm{r}_{\mathrm{s}}=-0.247, \mathrm{p} 0.048$, 
respectively) and the cover of dead substrate on the recruitment blocks $\left(\mathrm{r}_{\mathrm{s}}=0.318, \mathrm{p}=0.010\right)$. Positive abundance correlations found $C$. orientalis to be positively correlated with the cover of dead substrate on the recruitment blocks $\left(\mathrm{r}^{2}=0.603, \mathrm{p}=0.049\right)$ and settled sediment on the adjacent dead substrate $\left(r^{2}=0.648, p=0.031\right)$, but negatively correlated with the cover of CCA on the recruitment blocks $\left(\mathrm{r}^{2}=-0.640, \mathrm{p}=0.034\right)$. When including all data, $C$. orientalis recruit abundance correlated with flow $\left(\mathrm{r}_{\mathrm{s}}=0.546, \mathrm{p}<0.001\right)$, the local cover of CCA and sand $\left(\mathrm{r}_{\mathrm{s}}=-\right.$ 0.329, $\mathrm{p}=0.007$ and $\mathrm{r}_{\mathrm{s}}=0.397, \mathrm{p}=0.001$, respectively), the cover of macroalgae and CCA on the blocks $\left(\mathrm{r}_{\mathrm{s}}=-0.269, \mathrm{p}=0.030\right.$ and $\mathrm{r}_{\mathrm{s}}=0.276, \mathrm{p}=0.026$, respectively) and both the local and reef-scale abundance of adult $C$. orientalis $\left(\mathrm{r}_{\mathrm{s}}=0.586, \mathrm{p}<0.001\right.$ and $\mathrm{r}_{\mathrm{s}}=0.506, \mathrm{p}<0.001$, respectively). Positive abundance of $C$. aff. viridis n. sp. B recruits only correlated with characteristics of the adjacent substrate; bleached coral $\left(r^{2}=0.474, p=0.011\right)$, settled sediment on dead substrate $\left(r^{2}=-0.386, p=0.042\right)$ and "other" $\left(r^{2}=0.419, p=0.026\right)$. When including all data, $C$. aff. viridis n. sp. B recruit abundance negatively correlated with the species abundance at the reef-scale $\left(r_{s}=-0.311, p=0.012\right)$, as well as positively with turbidity $\left(r_{s}=0.247, p=0.047\right)$, adjacent cover of CCA $\left(r_{\mathrm{s}}=0.279, \mathrm{p}=0.024\right)$ and cover of encrusting bryozoans on the recruitment blocks $\left(\mathrm{r}_{\mathrm{s}}=0.246, \mathrm{p}=0.048\right)$.

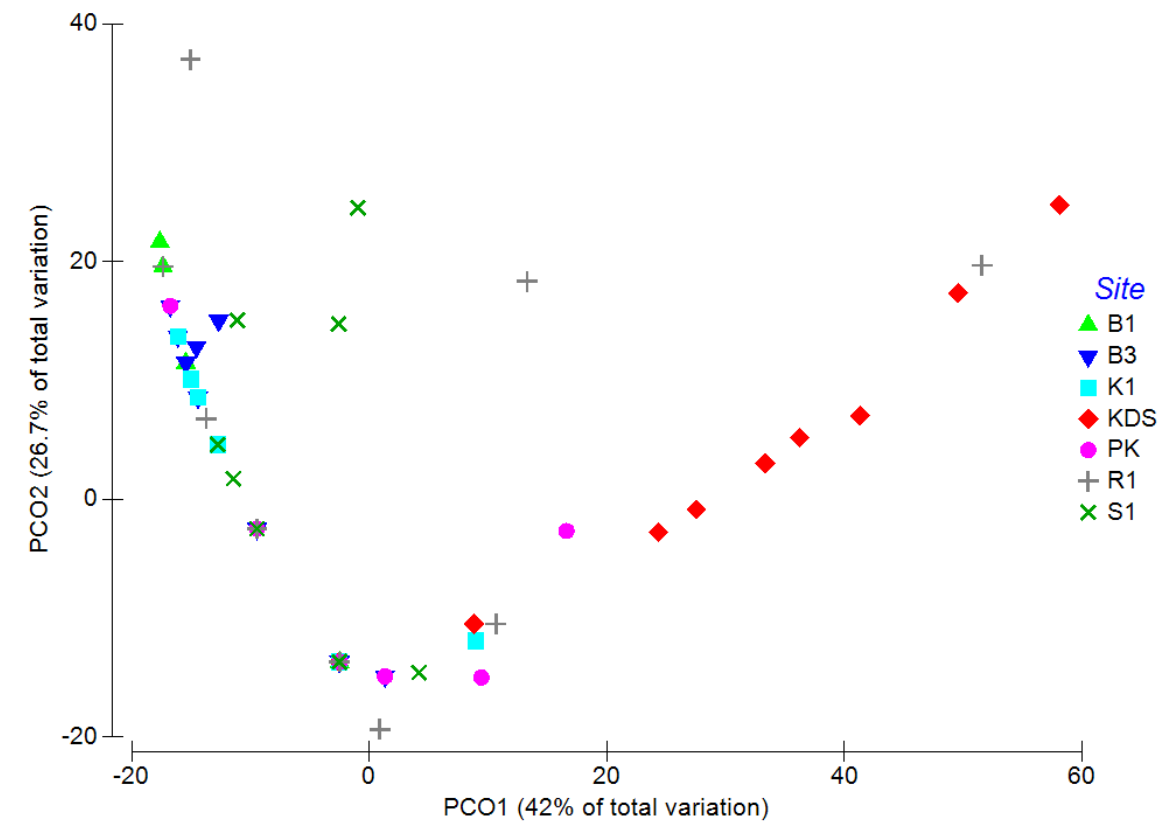

Figure 4.8. Two dimensional representation (PCO) of site similarities with respect to recruited bioeroding sponge species assemblage. 
The assemblage composition of the recruits differed significantly between the sites (PERMANOVA, Pseudo-F = 3.876, $\mathrm{p}=0.001$ ), but not between depths (Fig. 4.8). The highest differences occurred between KDS and K1 and B1 (both 100\% dissimilarity), driven by the dominance of $C$. orientalis in the KDS assemblage, which was absent at K1 and B1. The smallest differences were between B3 and S1 (63.98\% dissimilarity), K1 and S1 (72.4\% dissimilarity), and B3 and $\mathrm{K} 1$ (70.52\% dissimilarity). At these sites $C$. aff. viridis n. sp. B was abundant, but the relative importance of other species, such as $C$. aff. viridis n. sp. A and $C l$. cf. aurivillii differed (Table 4.1).

$26.6 \%$ of the variation in the recruit species assemblage composition was explained (DISTLM) by variations in the local adult population of $C$. orientalis $(14.8 \%)$, C. aff. viridis n. sp. A (6.6\%) and $\mathrm{Cl}$. cf. aurivillii (5.2\%) (Fig. 4.9). Using the abundance data from the whole reef surveys (Chapter 3 data) the best model from the DSTLM explained only $14.8 \%$ of the variation in the recruit assemblage, predominantly due to differences in the adult abundance of $C$. orientalis (11\%) but also in $\mathrm{Cl}$. hancocki $(3.8 \%)$.

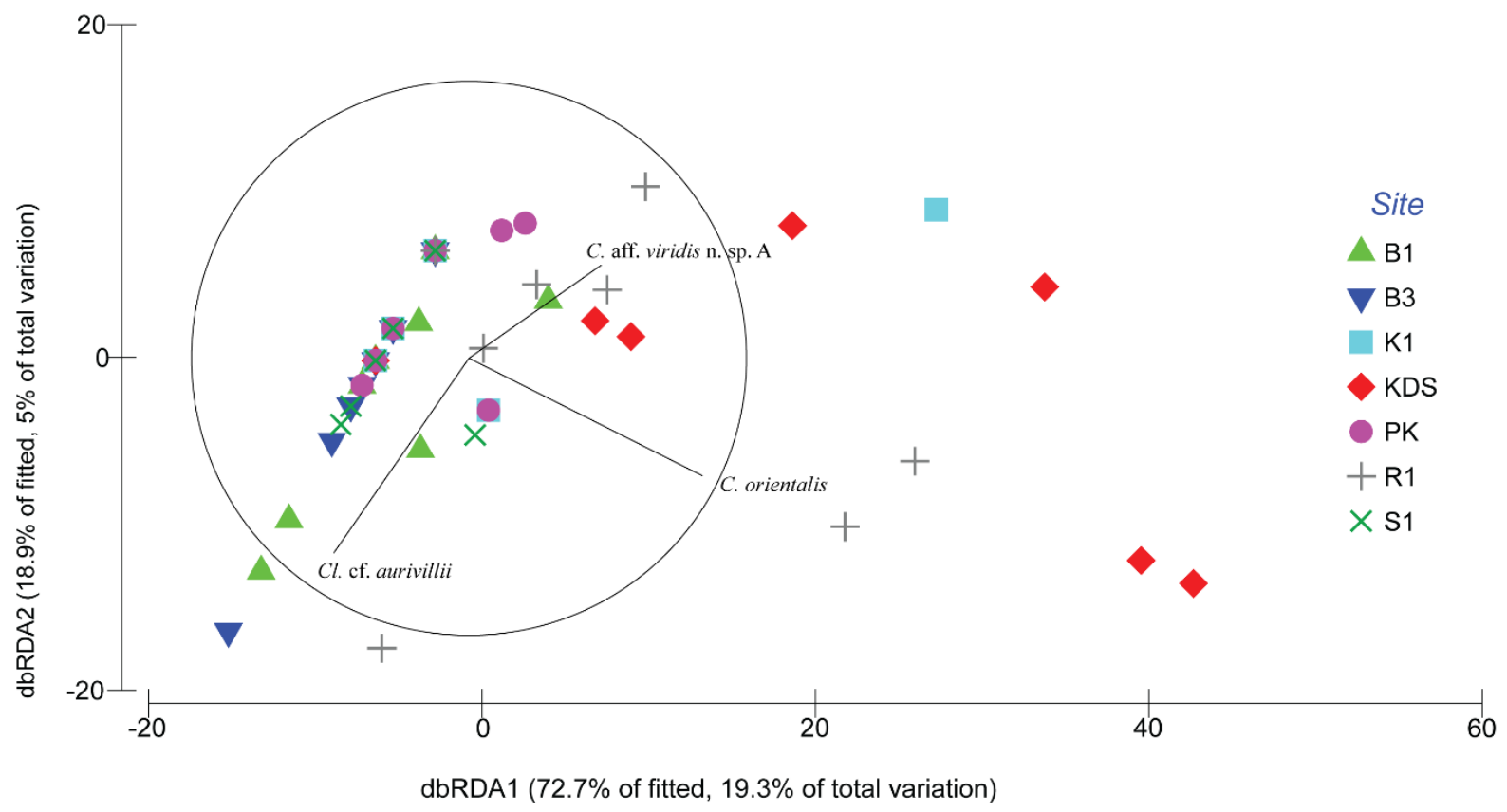

Figure 4.9. Distance based redundancy analysis (dbRDA) ordinations of fitted models for recruit assemblage composition. Overlaid vectors represent components that have a Pearson's correlation of greater than 0.4 . 
The best DISTLM models for substrate composition (both the local benthos and the block) and environmental predictors all only selected one variable; sand (9\%) for the local benthos, dead substrate $(3.7 \%)$ for the blocks and flow (16\%) for the environmental variables. 


\subsection{Discussion}

Over the course of the two year deployment, five species of bioeroding sponges recruited to the majority of deployed recruitment blocks and were present at every site and depth category. Generally low levels of recruitment and species richness made analysis problematic, however some clear trends did emerge. Bioeroding sponges only recruited to dead calcareous substrate, coralline algae or occasionally encrusting bryozoans and showed a preference for settling onto dead substrate. Recruitment, particularly in C. orientalis, showed signs of phylopatry and was potentially influenced by differences in hydrodynamic regime and substrate cues. Finally, although recruitment was low in terms of recruitment block coverage, relative to other studies (e.g. Kiene \& Hutchings 1994; Pari et al. 1998; 2002), the proportion of blocks that exhibited bioeroding sponge recruitment was very high for this length of study.

\subsubsection{Biotic and abiotic factors affecting recruitment}

The local abundance of adult sponge species was one of the most important factors governing overall sponge recruitment and assemblage composition, largely driven by high recruitment of $C$. orientalis at KDS and R1 where the species was also locally abundant. This finding supports work on the Mediterranean zooxanthellate bioeroding sponge C. viridis by Mariani et al. (2000) who found that the abundance of adults and larvae were highly correlated. These authors attributed this correlation to the adherence of clusters of eggs to the substratum adjacent to mother sponges, the predominantly crawling (rather than swimming) behaviour of larvae and rapid larval settlement (<24 hours) (Mariani et al. 2000; 2001; 2006). The significant correlation between $C$. orientalis recruitment and flow rate appears to counter to this hypothesis, suggesting that recruits accumulate at R1 and KDS due to hydrodynamics. However, this may not be the case if the larvae are predominantly crawling; at the boundary layer these larvae are subject to significantly less flow speed and turbulence than midwater larvae and should be able to manoeuvre and explore the substratum for settlement cues (Maldonado 2006). Limited dispersal and phylopatric aggregated recruitment is a strategy that facilitates fertilisation by proximity (e.g. Levitan 1991), settlement in favourable habitats (Pawlik 1992) and reduce the risk of mortality due to predators or being washed to unsuitable environments (Maldonado et al. 2006). Aggregated phylopatric recruitment might be particularly important for zooxanthellate bioeroding sponges, such as $C$. orientalis given their requirements for well-lit calcareous habitat 
(López-Victoria \& Zea 2005), which may be in a higher abundance close to adults than elsewhere. Not all bioeroding sponges in the Wakatobi assemblage showed a similar dispersal pattern. $C$. aff. viridis n. sp. B and $C l$. cf. aurivillii were among the most consistent and abundant recruiters but recruitment was not correlated with local adult abundance. In the case of $C$. aff. viridis $\mathrm{n}$. $\mathrm{sp}$. B, recruitment actually showed a slight negative correlation with adult abundance at the reef scale. Not all bioeroding sponge larval dispersal is as limited as $C$. orientalis (current data) and C. viridis (Mariani et al. 2006), in fact larvae of Thoosa and Alectona are often found in offshore plankton (Karawaiew 1896; Trégouboff 1942). When Uriz et al. (1998) investigated the relationship between recruitment and adult spatial patterns in Crambe crambe and Scopalina lophyropoda, they found that the distribution of $C$. crambe was much less aggregated and phylopatric than S. lophryopoda. The authors suggested that the comparatively active swimming and late crawling phase of the $C$. crambe larvae accounted for the differing patterns of recruitment (Uriz et al. 1998). While a wider dispersal and longer planktonic phase is likely to incur greater pre-settlement mortality, the advantages include higher chances of encountering optimal settlement cues and sites, the avoidance of localised extinctions and increased adaptation to a wider variety of environments (Uriz et al. 1998; Maldonado 2006).

Recruitment of bioeroding sponges was restricted to calcareous substrates. Despite some previous observations of larval settlement on non-calcareous substrates (Warburton 1966), these sponges are only able to erode and inhabit calcareous substrates (Rosell \& Uriz 1992). Therefore while some larvae may have settled on non-calcareous substrates, it is unlikely that metamorphosis occured. Adult substrate occupation patterns have demonstrated interspecies differences in substrate preferences, varying from mollusc shells, to dead massive or branched coral colonies to coral rubble (Hartman 1958; López-Victoria \& Zea 2005; Calcinai et al. 2008; Chaves-Fonnegra \& Zea 2011). My data suggests that overall, bioeroding sponges settled uniformly on CCA, tended to avoid bryozoans (but could settle on them) and preferred uncolonised dead substrate. A preference for clean, un-colonised substrate supports earlier studies by López-Victoria \& Zea (2005) in the Columbian Caribbean who found that bioeroding sponges were more positively associated with recently dead coral skeletons than older incrusted substratum. Settlement on CCA, a ubiquitous calcareous substrate on coral reefs, is unsurprising given the evidence that it acts as a cue for settlement in hard corals (e.g. Ritson-Williams et al. 2010) as well as some sponges (Jackson et al. 2002; Whalan et al. 2012). In hard corals, settling 
larvae exhibit a high degree of selectivity in regard to the CCA species on which they settle (Harrington et al. 2004). If bioeroding sponges also show some degree of preference between CCA species, then this is an important element to be incorporated into future recruitment studies. There is little available information about sponge recruitment to encrusting bryozoans. In scleractinians, bryozoans are generally thought to inhibit larval settlement (Birkeland 1977; Dunstan \& Johnson 1998; Glassom et al. 2004) except on older substrates where CCA or dead substrate is rare (Arnold \& Steneck 2011). It should be noted that these observations of settlement are based on the assumption that sponge recruitment occurred after the recruitment of CCA and bryozoans. This assumption is based on recruitment studies from other locations within the Indo-Pacific, where CCA and bryozoans are among the earliest colonisers of newly available substrate, often appearing on recruitment tiles within a few months of deployment (Fairfull \& Harriott 1999; Field et al. 2007). Conversely, bioeroding sponges are often not present at all after a year or two of deployment (e.g. Pari et al. 1998; Tribollet et al. 2002). If the majority of sponge recruitment happened before the colonisation by CCA and bryozoans, then the interpretation of the observed bioeroding sponge occurrence is different. It would suggest that bioeroding sponges are slightly competitively inferior to CCA and more so to encrusting bryozoans. Unfortunately, it was logistically impossible to visit the blocks at more regular intervals, which could have provided a better timescale for recruitment and resolve the issue.

The relationship between recruitment and local substrate composition (both of the blocks and the adjacent $1 \mathrm{~m}^{2}$ of substrate), varied greatly between species, making patterns in substrate cues for total bioeroding sponge recruitment difficult to infer. Many significant correlations also had low coefficients, casting doubt on their biological relevance. Nevertheless there were some stronger correlations that warrant discussion. For $\mathrm{Cl}$. cf. aurivillii the strongest evidence for settlement cues was a moderately high correlation with the cover of encrusting bryozoans on the recruitment blocks. This is reflected in the settlement of this species, which was the only species to settle on bryozoans. As discussed previously there is little information on sponges recruiting to bryozoans but they could constitute an alternative substrate option for some sponge species when more preferable substrates are unavailable. If this is the case for $\mathrm{Cl}$. cf. aurivillii then the species was potentially a late recruiter, consistent with evidence from other Cliothosa species (Pari et al. 1998; 2002). Settlement cues from the adjacent $1 \mathrm{~m}^{2}$ indicate an aversion to rubble and algae-covered dead coral, which is also reflected in $\mathrm{Cl}$. cf. aurivillii's habitat choice on the 
reef as the species is predominantly found in clean calcareous rock and dead massive corals. $C$. orientalis recruits exhibited a preference for blocks with high cover of dead substrate over blocks dominated by CCA. This is consistent with observations by López-Victoria \& Zea (2005) on the substrate occupation preferences of the Caribbean zooxanthelate bioeroding sponges Cliona aprica and Cliona caribbaea. The positive correlation with cover of settled sediment on the adjacent substrate is perplexing as most sponges cannot colonise sediment, especially when it is moving (Schönberg 2016), which is likely at a high flow sites like KDS and R1. It's perhaps prudent to treat this correlation more cautiously; the snapshot nature of the data collection and the mobile dynamics of settled sediment mean that it is highly possible that the cover of settled sediment was very different during the time of larval settlement. This is especially the case where larval settlement is likely to occur over a very short period in a single annual recruitment (Mariani et al. 2000; 2001). The strongest and most notable correlation of $C$. aff. viridis n. sp. B recruitment was with the cover the recently dead (bleached) coral in the adjacent substrate. This positive relationship appears to strengthen the suggestion that recruitment on un-colonised and clean calcareous substrate is favoured among exploratory bioeroding sponge larvae (LópezVictoria \& Zea 2005).

Of the eight species identified in Chapter 2, three species, C. cf. schmidtii, S. cf. vagabunda and Z. criceta did not recruit at all and one species, $C l$. hancocki, recruited to only one block. Interspecies differences in recruitment rates could be due to number of pre and post settlement factors and or due to interspecies differences in fecundity. Species that produce more offspring are likely to have a larger adult population (Uriz 1998), as has been postulated for the reason behind the population size differences in $C$. viridis and C. celata in the Western Mediterranean (Piscitelli et al 2011). Additionally, reproductive output can vary not only between species but within species over time. If I assume that the species in this study reproduce with the same frequency as many other bioeroding sponges, i.e. once annually (e.g. Mariani et al. 2000; Rosell \& Uriz 2002; Piscitelli et al. 2011; González-Rivero et al. 2013), then a maximum of two recruitment events could have occurred during the duration of the block deployment. However, recruitment in sponges often varies with time, with "pulses" occurring some years and not others (e.g. McMurray et al. 2010). Therefore the timescale of this study could well be over- or underestimating the recruitment rates of some species depending upon the success of that species in those two recruitment events, and complete absence of a species being the ultimate example of 
this. This could possibly be the case for S. cf. vagabunda; in Papua New Guinea the species is thought to recruit in pulses every three to nine years with lower reproductive output in the intervening years (Kelly 1986). The low numbers of small individuals of this species (J. Marlow pers. obs.) in the Wakatobi would support this. This could possibly also account for singular occurrence of $\mathrm{Cl}$. hancocki on the recruitment blocks. In a five year study of bioerosion in French Polynesia by Pari et al $(1998 ; 2002)$ Cl. hancocki was not found on experimental substrates after 24 months of exposure but was found after 60 months. Another possible explanation for the lack of recruitment of some species may be the unsuitability of experimental substrate. In this regard, Z. criceta is only found on coral rubble in the Wakatobi, a substrate that other sponge species have also shown a preference for (Jackson et al. 2002). Therefore the recruitment blocks may not have represented an ideal substrate for explorative Z. criceta larvae, especially if there was an abundance of preferable coral rubble in the vicinity. The sides of the blocks were also all equally exposed which could possibly deter settlement by sponges with a preference for cryptic habitats. Numerous studies have found large differences in sponge abundance between cryptic and exposed surfaces (e.g. Maldonado \& Young 1996; Stubler et al. 2016), which is thought to be a function of negative phototaxis in settlement, reduced exposure to predators and or settled sediment (Maldonado \& Young 1996). Species such as C. cf. schmidtii that are more common in cryptic habitats (J. Marlow pers. obs.) may require more cryptic substrate for recruitment then offered by the recruitment blocks.

\subsubsection{Recruitment rates}

The timescale of bioeroding sponge recruitment in the Wakatobi was very quick relative to other comparable studies. A deployment of experimental substrates by Tribollet et al. (2002) in the GBR found no bioeroding sponge presence after twelve months of deployment. A similar absence of bioeroding sponges was found after 15 months deployment on Palmyra Atoll in the central Pacific (Elmer 2016) and after 24 months in French Polynesia where only 5\% of experimental substrates were colonised by bioeroding sponges (Pari et al. 1998). Kiene and Hutchings (1994) who found a similar trend around Lizard Island in the GBR, suggested that bioeroding sponges may take four or more years to appear after substrate becomes available. They also hypothesise that after new substrate becomes available, the macroboring community changes with increasing age of the substrate; following a successional path from small, shortlived polychaete species, to longer-lived, larger polychaetes, sipunculans, molluscs and sponges. 
However, this hypothesis not only contradicts the results from the Wakatobi but also observations from other studies. As previously mentioned, López-Victoria \& Zea (2005) found a positive tendency of $C$. aprica to occupy recently dead coral and a neutral (for $C$. caribbaea) to slightly negative tendency to occupy encrusted calcareous rock in the Columbian Caribbean. MacGeachy (1977) also found that bioeroding sponges were less abundant on heavily encrusted dead coral and hypothesised that "fouling" prevented larval settlement. These different recruitment timescales could be due to differences in substrate preferences of the individual species in the respective assemblages (this study; Hartman 1958; López-Victoria \& Zea 2005; Calcinai et al. 2008; Chaves-Fonnegra and Zea 2011) or (as discussed earlier) differences in timing of reproductive output (Kelly 1986; McMurray et al. 2010).

\subsubsection{Bioroding sponge recruitment and reef degradation}

The results from this chapter further the suggestion that these sponges will benefit from reef perturbation. Recruitment was very quick relative to other studies (e.g. Kiene \& Hutchings 1994; Pari et al. 1998; 2002), suggesting that newly available substrate could be rapidly colonised before other benthic taxa that may be unsuitable for recruitment. Indeed bioeroding sponges preferred to recruit to dead substrate over other live calcareous substrates, indicating that recruitment would be higher on recently dead substrate than more encrusted substrates. Nevertheless settlement does not appear to be inhibited by coralline algae, indicating recruitment would be successful even CCA were the earliest coloniser of newly available substrate. The degree of recruitment success following coral mortality therefore appears likely to be a product of timing. Successful species are likely to have reproductive modes that annually allocate considerable amounts of energy to egg production (e.g. C. viridis; Mariani et al. 2001; Piscitelli et al. 2011), have multiple spawning events (e.g. Cliona delitrix; Chaves-Fonnegra et al. 2016), display constant recruitment (e.g. C. tenuis; González-Rivero et al. 2013) or just fortuitous timing in the cases of those species that recruit at more irregular intervals (e.g. S. vagabunda; Kelly 1986). Finally, a mixture of dispersal strategies was observed; species that have a more restricted dispersion (e.g. C. orientalis) are potentially able to proliferate on more local scales (Uriz et al. 1998) while wider larval dispersal (e.g. $C l$. cf. aurivillii and $C$. aff. viridis n. sp. B) is generally considered a more opportunistic strategy (Mariani et al. 2006). When taken into consideration the adult persistence of $C l$. cf. aurivillii and $C$. aff. viridis n. sp. B at the degraded 
Sampela (Chapter 3), the widespread and early recruitment of these two species, further indicates that they are likely to benefit from reef degradation in the region.

\subsubsection{Conclusions}

In conclusion, increased availability of calcareous substrate due to coral mortality is likely to result in increases in bioeroding sponge abundance through larval recruitment. However, interspecies differences in reproductive output, larval dispersal and larval settlement preferences will likely mean that some species will profit from reef degradation more than others. Species that recruit continuously or at least annually are expected to be particularly successful given the increased chances of larval settlement on clean substrates. While species with wider larval dispersal might benefit from more regional scales of coral mortality (given the right settlement cues), more limited dispersal strategies could result in localised proliferation and even dominance on some degraded reefs. 


\section{Chapter 5: Light limitation and Cliona aff. viridis n. sp. A, a photoacclimation response and recovery to shading}

\subsection{Abstract}

Normally associated with coral hosts, photosynthetic Symbiodinium symbionts have an important function in many bioeroding sponges; enhancing growth, bioerosion and spatial competitiveness. In the Wakatobi, three such species have been identified as locally abundant, however two are absent from a turbid reef at Sampela. Increasingly a feature of coral reefs degraded by watershed-based pollution, high turbidity has the potential to negatively affect sponges through direct clogging of the filtering apparatus or shading of photosynthetic symbionts. In this chapter, I addressed the latter impact by examining the photoacclimatory capacity of Cliona aff. viridis $\mathrm{n}$. sp. A in response to reduced light availability using in situ PAM fluorometry (rapid light curves; RLCs). Light availability was artificially reduced for individuals of $C$. aff. viridis n. sp. A at a clear-water reef using shades (70 \& 95\% reduction) for a period of 25 days, with a subsequent 14 day recovery period. Changes in $\mathrm{ETR}_{\max }, \mathrm{E}_{\mathrm{k}}$ and $\mathrm{qP}$ in $C$. aff. viridis $\mathrm{n}$. sp. A demonstrated an ability to photoacclimate to levels of extreme light reduction and recover within a relatively short period of time. A lack of corresponding tissue loss or evidence of necrosis during this period suggests that either photoacclimation resulted in sufficient nutritional provision for the host or that $C$. aff. viridis n. sp. A may not be an obligative phototroph. The abundance of $C$. aff. viridis n. sp. A is therefore unlikely to be limited by light availability on turbid reefs but its distribution may be restricted due to the other associated impacts of high sediment loading. 


\subsection{Introduction}

Coral reefs are generally accepted as being one of the most stressed and threatened ecosystems in the marine environment (e.g. Hoegh-Guldberg \& Bruno 2010; Frieler et al. 2013). In addition to climate change associated stressors (Hoegh-Guldberg et al. 2007; Normile 2016), reefs are at risk from local disturbances, which can further exacerbate the negative impacts of climate change (Ateweberhan et al. 2013; Ban et al. 2014; McClanahan et al. 2014). Of growing concern is watershed-based pollution that is increasing due to anthropogenic changes in land usage such as deforestation, agricultural intensification and coastal urbanisation (e.g. Munday 2004; Bartley et al. 2014; Stender et al. 2014). Watershed-based pollution can expose coral reefs to excessive levels of sedimentation, turbidity, eutrophication and pollutants (see Fabricius 2005 for review), and is responsible for reef degradation across the globe (e.g. Crabbe \& Smith 2005; Wolanski et al. 2009; Golbuu et al. 2011). In some locations the negative impacts of terrestrial-runoff alone could outweigh those of climate change (Maina et al. 2013). In the case of increased turbidity, associated reductions in ambient light availability can have serious negative consequences for scleractinian corals, as they are reliant on endosymbiotic photosynthetic Symbiodinium algae for their nutritional needs. Corals in turbid environments can display reduced growth rates (Crabbe \& Smith 2005), reduced diversity (e.g. De'ath \& Fabricius 2010) and increased disease prevalence (Pollock et al. 2014).

While the impacts of turbidity are relatively well understood for scleractinian corals, few studies have considered how other photosynthetic reef taxa might be affected in these environments. The need for such information is increasing given the trend for regime shifts away from coral dominance towards dominance by other benthic taxa on degraded reefs (McManus \& Polsenberg 2004; Norström et al. 2009). One such benthic group is bioeroding sponges, which in addition to increasing in abundance on many degraded reefs (see López-Victoria \& Zea 2005; Schönberg \& Ortiz 2009; Carballo et al. 2013), are also often hosts to photosynthetic endosymbiotic Symbiodinium (Rützler 1990). This symbiotic association is normally associated with cnidarian hosts, but unusually among sponges is common in Clionaidae (Rützler 1990). As in cnidarians, the relationship is generally assumed to be mutualistic; translocated carbon from symbiont to host enhances bioerosion and growth rates (Hill 1996; Schönberg 2006; Weisz et al. 2010). These zooxanthellate clionaids are also some of the most aggressive spatial competitors on coral reefs (Vicente 1978; Schönberg \& Wilkinson 2001) and among bioeroding sponges are often the 
primary species to opportunistically occupy recently dead substrate following coral mortality (Rützler 2002a; López-Victoria \& Zea 2005; Ward-Paige et al. 2005). Abundance surveys of zooxanthellate clionaids regularly show a preferential occupation of well-lit substrate (e.g. López-Victoria \& Zea 2005) and it is presently unclear what acclimatory mechanisms they have (if any) for prolonged exposure to turbid environments.

Coping with changes in ambient light availability for Symbiodinium-hosting holobionts has predominantly been studied in cnidarians. Some scleractinian corals have a capacity to modify their photophysiology and trophic mode that allows these animals to live and thrive in highly turbid environments and occupy a broad depth range (e.g. Anthony \& Farbricius 2000; Hennige et al. 2008a; Morgan et al. 2016). Photoacclimation to low light is possible by adjusting pigmentation within Symbiodinium cells (Falkowski \& Dubinski 1981), by increasing Symbiodinium density (Titlyanov et al. 2001), and by changing holobiont morphology (Einbinder et al. 2009). In the past, this information was derived from destructive sampling and ex situ respirometry analysis in the form of photosynthesis-irradiance curves (MacIntyre et al. 2002). However, the development of portable underwater pulse amplitude-modulated (PAM) fluorometry devices (DIVING-PAM) has allowed for non-destructive in situ assessments of photoacclimation by providing rapid collection of a suite of photophysiological data (Maxwell \& Johnson 2000; Ralph \& Gademann 2005). PAMs measure chlorophyll a fluorescence of photosystem (PS) II, providing information on the electron transport rate (ETR; equivalent to photosynthetic activity (Beer et al. 1998)), as well as photochemical and non-photochemical quenching (qP and NPQ, respectively) (Ralph \& Gademann 2005). By plotting ETR (or relative ETR; rETR) against irradiance (PAR), rapid light curves (RLCs) can be constructed that allow for not only the determination of current photosynthetic capacity but also their responses over a broad range of ambient light conditions (Ralph \& Gademann 2005), i.e. photoacclimatory capability. Of specific interest for investigating photoacclimatory potential is the minimum saturating irradiance $\left(\mathrm{E}_{\mathrm{k}}\right)$ and maximum photosynthetic capacity $\left(\mathrm{ETR}_{\max }\right)$ (Sakshaug et al. 1997; Schreiber 2004; Ralph \& Gademann 2005). PAM fluorometry has had limited use in in situ sponge photophysiological studies but has been used to demonstrate photoacclimation in the zooxanthellate Pione vastifica and in cyanobacteria-hosting Theonella swinhoei and Lamellodysidea herbacea (Beer \& Ilan 1998; Steindler et al. 2001; Biggerstaff et al. 2015). 
This study was conducted in the UNESCO Wakatobi Biosphere Reserve (here: Wakatobi) in Southeast Sulawesi Indonesia. The surveys conducted in Chapter 3 found Cliona aff. viridis n. sp. A to be locally abundant and common around 10-14 $\mathrm{m}$ depth on patches of dead substrate. Notably this species is absent from a turbid and sedimented site, Sampela 1, despite abundant substrate availability. This absence suggests that the species is either unable to acclimate and survive in light-limited conditions or directly physiologically impacted by high levels of sedimentation, or a combination of both. The aim of this chapter was to address the first of these hypotheses: to determine whether $C$. aff. viridis n. sp. A is light limited at Sampela or capable of photoacclimating to similar and even more extreme levels of ambient light limitation. I artificially shaded individuals of $C$. aff. viridis n. sp. A for prolonged periods at a clear water reef and used in situ PAM fluorometry measurements to detect photoacclimatory changes in PSII. In addition, photographic analysis was used to analyse changes in holobiont health. Reductions in sponge size or signs of necrosis inferring that either photoacclimation failed to meet the host's nutritional requirements or in the absence of photoacclimation the same observation would indicate an inability to regulate heterotrophic feeding to compensate. 


\subsection{Methods}

\subsubsection{Study area}

This study was conducted within the Wakatobi in July-August 2015. The photophysiological acclimatory capabilities of $C$. aff. viridis $n$. sp. A were assessed in situ at a reef site known locally as Pak Kasim's (Fig 5.1). Pak Kasim's is a section of the sloping fringing reef on the western side of Hoga Island and a location where $C$. aff. viridis n. sp. A is abundant. At this site (and within the wider Wakatobi), C. aff. viridis n. sp. A occupies dead calcareous substrate, predominantly in encrusting form, and is most abundant at 10-14 m depth.

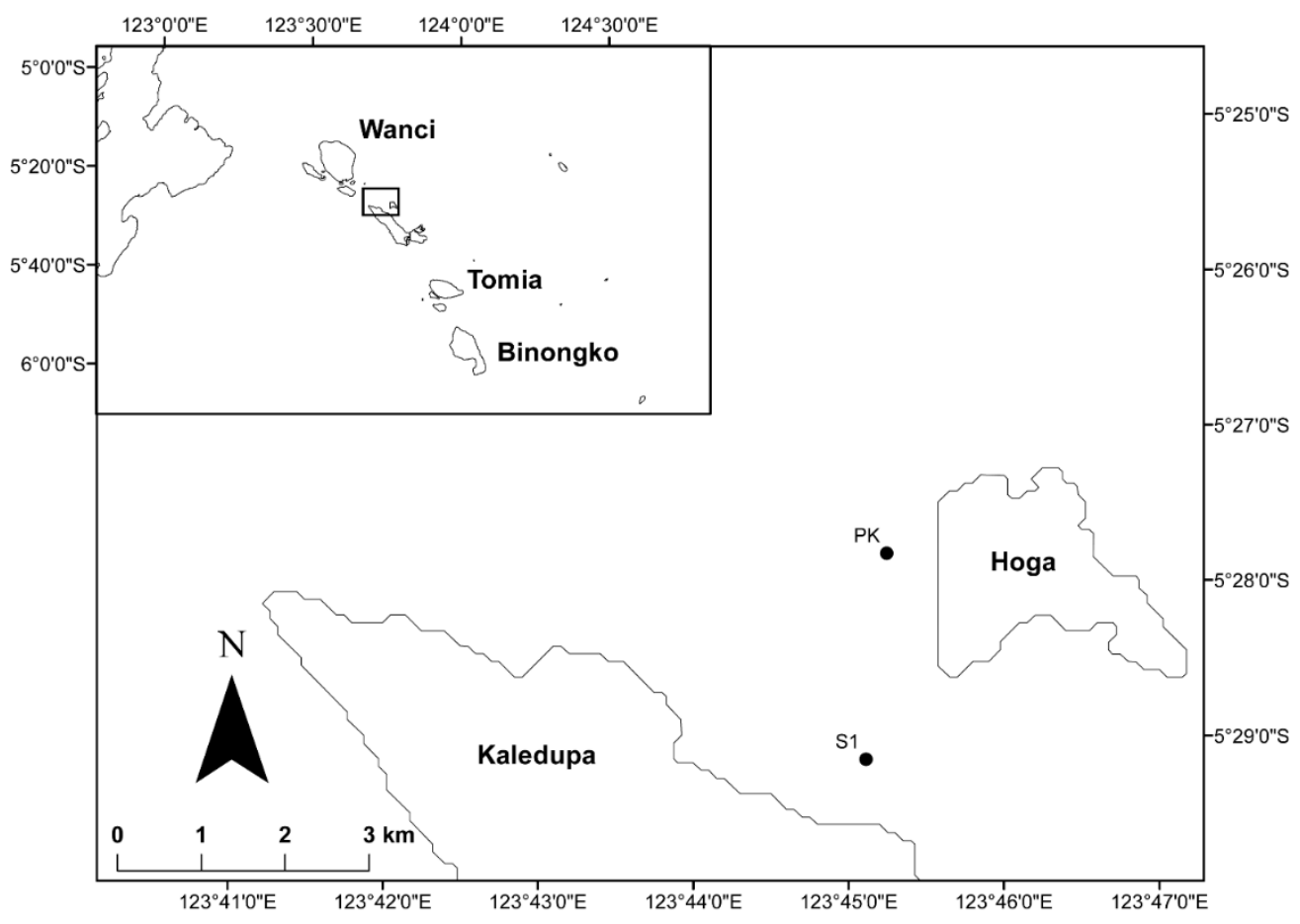

Figure 5.1. Location of study area within the Wakatobi (inset black square) and position of reef sites Pak Kasim's and Sampela 1 in relation to the islands of Hoga and Kaledupa. Pak Kasim's and Sampela 1 abbreviated to PK and S1, respectively.

Ambient photosynthetically active radiation (PAR) was measured at Pak Kasims's and at the turbid site Sampela 1 (Fig 5.1). Sampela 1 is considered a degraded reef site; adjacent to the Bajau village of Sampela it is subject to destructive fishing, coral mining, and excessive sedimentation and turbidity thought to be due to mangrove removal, untreated sewage discharge and seasonal changes in currents (Crabbe \& Smith 2005; Hennige et al. 2010; Salinas de Leon et 
al. 2013). Bioeroding sponge abundance surveys in 2014 (see Chapter 3) found C. aff. viridis n. sp. A to be absent on the Sampela reef.

\subsubsection{Chlorophyll fluorometry}

All chlorophyll fluorometry was conducted using a Pulse Amplitude Modulated (PAM) flourometer (RED DIVING-PAM, Walz, Iffeltrich Germany) and rapid light curves (RLCs). Prior to sponges being exposed to treatments, trial RLCs were performed on randomly selected sponges at $10 \mathrm{~m}$ depth at Pak Kasim's to identify a suitable dark adaption period, and RLC-PAR width and intensities. Full dark adaption took approximately $30 \mathrm{~min}$, which was logistically unachievable when collecting data from multiple sponges on a single dive. Instead the initial fluorescence measurement (in the absence of actinic light) was collected after period of $10 \mathrm{~s}$ of quasi-darkness was applied (Ralph \& Gademann 2005). This was followed by increasing actinic light steps of 270, 382, 510, 724, 954, 1399, 1957 and $2762 \mu \mathrm{mol}$ photons $\mathrm{m}^{-2} \mathrm{~s}^{-1}$, each for a duration of $10 \mathrm{~s}$. For all fluorometry measurements, the fibre optic cable was placed in the centre

of the sponge, taking care to avoid patches of necrosis or algal growth. To maintain consistency in the distance to the sponge surface, a $1 \mathrm{~cm}$ spacer was attached to the end of fibre optic cable.

Maximum electron transport rates $\left(\mathrm{ETR}_{\max }\right)$, light saturation coefficients and $\mathrm{E}_{\mathrm{k}}$, light-limited photosynthetic efficiency $(\alpha)$, effective quantum yield $\left(\Phi_{\mathrm{PSII}}\right)$ and photochemical quenching (qP) were calculated in the software package WinControl (version 3.25). An absorption coefficient of 0.84 was assumed (Schreiber et al. 1994), but as absorption was not directly measured for these sponges, ETR and ETR $_{\max }$ are considered relative (rETR \& $\left.\mathrm{rETR}_{\max }\right)$.

\section{Shading experiment}

Twenty individuals of $C$. aff. viridis n. sp. A were located and tagged at $10 \mathrm{~m}$ depth at Pak Kasim's. Sponges were selected based on organism size $\left(5-10 \mathrm{~cm}^{2}\right)$, upwards orientation (to minimise self-shading) and minimal shading by other reef topographical features. Tagged sponges were randomly allocated treatments of control, procedural control, 70\% light reduction and $95 \%$ light reduction $(n=5)$. Control sponges were left uncovered for the duration of the experiment, while procedural controls had the same transparent polymethyl methacrylate (Plexiglas GS Clear 0F00, Evonik Industries, Morrinsville NZ) suspended above the sponge as were used in the $70 \%$ and $90 \%$ shading experiments (Fig. 5.2). The Plexiglass was tested for 
PAR attenuation using a spectrophotometer (USB4000, Ocean Optics Inc, Dunedin USA); approximately $10 \%$ attenuation at $380 \mathrm{~nm}$ and dropping to $0 \%$ at approximately $550 \mathrm{~nm}$ through to $750 \mathrm{~nm}$ (Biggerstaff et al. 2015). A light reduction of $70 \%$ was achieved by attaching shadecloth (Redpath, Palmerston North NZ) to the underside of the Plexiglass and a $95 \%$ reduction was achieved by painting both sides of the Plexiglass with marine paint. Shade and procedural control cover dimensions were $15 \times 15$ x $0.3 \mathrm{~cm}$, and were suspended approximately $5 \mathrm{~cm}$ above sponges using cable ties and masonry nails embedded into adjacent dead substrate. Shades and procedural controls were cleaned every other day to clear algal growth and settled sediment. RLCs were applied on days 0 (just prior to treatment application) 5,11, 18 and 25, after which the treatments were removed. Final RLCs were applied to each sponge 14 days post treatment removal (recovery). All RLCs were performed between 11 am and $12 \mathrm{pm}$ to minimise inconsistency in the influence of circadian control.

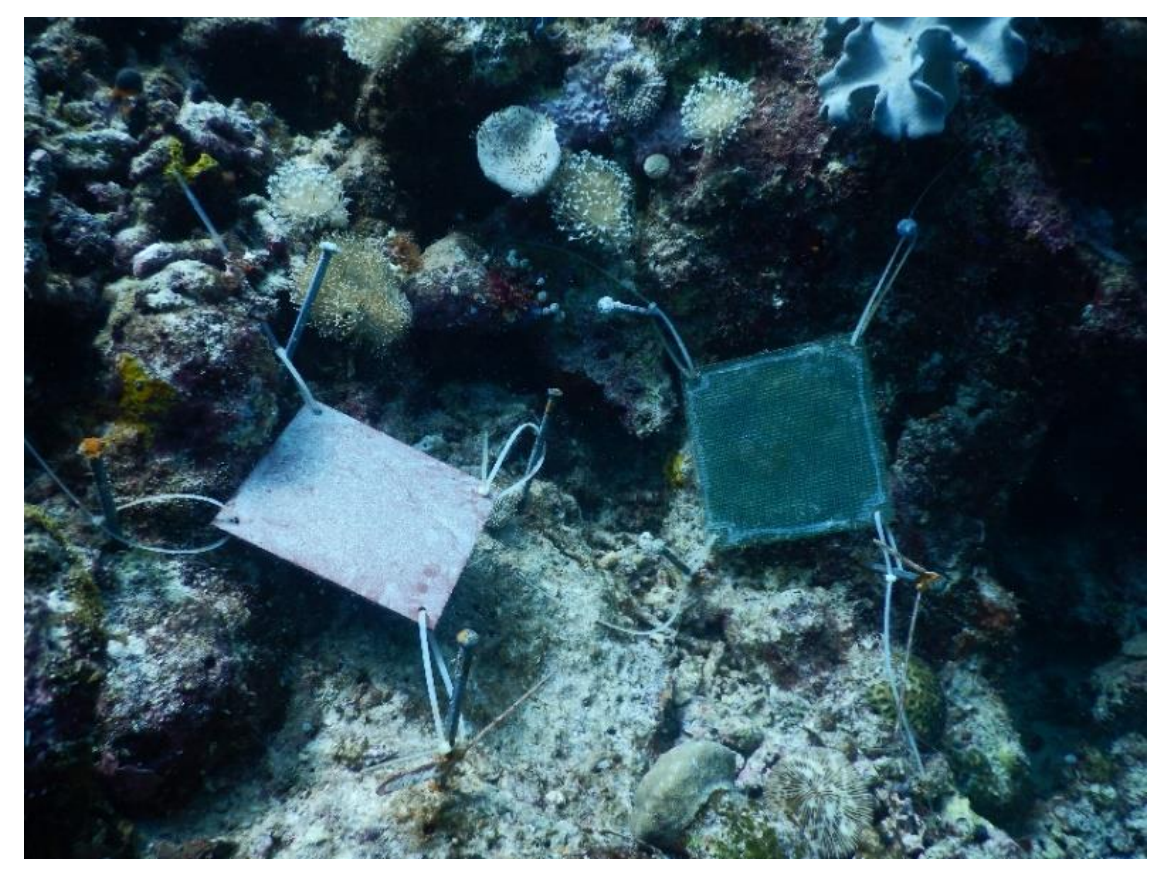

Figure 5.2. Example images of shade treatments showing $95 \%$ (left) and 70\% (right) light reduction treatments suspended above individual Cliona aff. viridis n. sp. A individuals.

Sponge size and colouration were monitored through the use of in situ images. Photos were taken of each sponge with adjacent scale bar and colour chart prior to treatment on day 0 and immediately after treatment on day 25. Images were subsequently analysed with the software 
package ImageJ to assess any changes in sponge size before and after treatment, and tissue colour changes judged by eye in relation to the colour chart.

\section{Transplant experiment}

Ten individuals of $C$. aff. viridis n. sp. A were removed from $10 \mathrm{~m}$ depth at Pak Kasim's using a hammer and chisel. Sponges were removed in a manner that incorporated both sponge material and at least $3 \mathrm{~cm}$ of calcium carbonate beneath the sponge tissue. Sponges were stored in flow through temperature controlled $\left(28^{\circ} \mathrm{C}\right)$ aquaria for three hours before relocation back to Pak Kasim's and Sampela reef, five sponges at each site. The transplanted sponges were attached to the reef at each site at $10 \mathrm{~m}$ intervals, using marine epoxy. The intention was to perform 25 days of chlorophyll fluorometry measurements parallel to the shading experiment. However, a high incidence of sponge mortality due to a combination of starfish predation and transplant dislodgement meant that these measurements had to be abandoned.

\subsubsection{PAR assessment}

In situ PAR measurements were taken for two distinct purposes: 1) to quantify the average daily PAR reaching reef benthos at Pak Kasim's and Sampela; and 2) to quantify the average daily PAR reaching the surfaces of the individual treatment sponges, when both shaded and unshaded. Individual sponge PAR levels were measured to assess not only the effect of treatment but also differences in PAR reaching sponges due to shading by reef topography and sponge orientation.

Average daily reef PAR was quantified using three separate $24 \mathrm{hr}$ deployments of an ODYSSEY PAR logger (Dataflow Systems, Christchurch NZ) at $10 \mathrm{~m}$ depth, at both sites, set to record every minute and data averaged over daylight hours. Average PAR levels for individual sponges were measured using an external PAR sensor on the PAM. PAR measurements were taken once from the middle of the sponge surface and then immediately after in the water column at the same depth. This was repeated once for each sponge at $12 \mathrm{pm}$ pre-treatment and for each sponge at $8 \mathrm{am}, 12 \mathrm{pm}$ and $4 \mathrm{pm}$ during the treatment period (on non-cloudy days). PAR was calculated as a percentage of ambient light levels in the water column. 


\subsubsection{Statistical analysis}

All statistical analyses were performed within the SPSS (version 23) statistical analysis package. Any data that did not meet the assumptions of variance, normality or sphericity for the relevant analysis were square root, fourth root or log-transformed.

Differences in ambient PAR between sites and between sponge treatment groups were tested using a One-Way Analysis of Variance (ANOVA) with Tukey's post hoc test where necessary. Differences in sponge size between days 0 and 25 were tested using a paired T-test.

Differences in $\mathrm{rETR}_{\max }, \mathrm{E}_{\mathrm{k}}, \alpha, \Phi_{\mathrm{PSII}}, \mathrm{F}_{0}$ and average $\mathrm{qP}$ among the different treatment groups over time were tested using a Repeated Measures ANOVA, with time and treatment as fixed factors, and with post hoc Bonferroni adjusted pairwise tests. Differences in RLCs and qP across time were tested using three general linear models (GLMs) for days 0, 25 and 39 (recovery), where rETR and $\mathrm{qP}$ were the dependent variables, treatment a fixed factor and PAR as a covariate.

\subsubsection{Molecular identification of symbiont cladal composition}

Tissue samples of $C$. aff. viridis sp. A were obtained from six individuals at $10 \mathrm{~m}$ depth on Pak Kasim's reef, preserved in $96 \%$ ethanol and transported to Wellington for analysis. DNA was extracted using a Qiagen extraction kit and PCR amplifications of the entire ITS region were carried using the primers S-DINO (forward) and LO (reverse) as outlined by Pawlowski et al. (2001). PCR products were separated by horizontal gel electrophoresis and gel fragments containing the desired PCR products were cut out and purified using a freeze-squeeze methodology. Sequencing was completed in both directions by a third party service (Macrogen, South Korea) and symbiont clades identified using a BLAST search in GenBank. 


\subsection{Results}

\subsubsection{PAR and treatments}

Average daily PAR at $10 \mathrm{~m}$ depth during the experimental period was $116 \mu \mathrm{mol}$ photons $\mathrm{m}^{-2} \mathrm{~s}^{-1}$ $( \pm 20 \mathrm{SE})$ at Sampela and $188 \mu \mathrm{mol}$ photons $\mathrm{m}^{-2} \mathrm{~s}^{-1}( \pm 29 \mathrm{SE})$ at Pak Kasim's, an almost $60 \%$ difference and justifying the use of the $70 \%$ light reduction treatment. At Pak Kasim's, midday water column PAR at $10 \mathrm{~m}$ depth was $216 \mu \mathrm{mol}$ photons $\mathrm{m}^{-2} \mathrm{~s}^{-1}( \pm 7 \mathrm{SE})$. Shading by reef topography and differences in sponge orientation meant that sponge surface PAR (pre-treatment) was less, at $170 \mu \mathrm{mol}$ photons $\mathrm{m}^{-2} \mathrm{~s}^{-1}( \pm 18 \mathrm{SE})$, but there were no significant differences in PAR on the unshaded sponge surface between treatment groups. Following application of treatments, the average amount of PAR reaching each treatment group across a day (from 8 am, $12 \mathrm{pm}$ and 4 pm readings) was $87 \mu$ mol photons $\mathrm{m}^{-2} \mathrm{~s}^{-1}( \pm 24 \mathrm{SE})$ for controls, $80 \mu \mathrm{mol}$ photons $\mathrm{m}^{-2} \mathrm{~s}^{-1}( \pm 20$ SE) for procedural controls, $25 \mu \mathrm{mol}$ photons $\mathrm{m}^{-2} \mathrm{~s}^{-1}$ ( $\pm 6 \mathrm{SE}$ ) for $70 \%$ treatments and $3 \mu \mathrm{mol}$ photons $\mathrm{m}^{-2} \mathrm{~s}^{-1}( \pm 1 \mathrm{SE})$ for $95 \%$ treatments, representing $52.1 \%$ ( $\left.\pm 9.1 \mathrm{SE}\right), 52.2 \%$ ( $\pm 6.7 \mathrm{SE}$ ), $15.1 \%( \pm 2.1 \mathrm{SE})$ and $2.1 \%( \pm 0.9 \mathrm{SE})$ of the available PAR in the water column, respectively. These differences were significant (one-way ANOVA, $\mathrm{F}_{(3,56)}=29.066, \mathrm{p}<0.001$ ), with post hoc tests revealing differences between the 95\% treatments and all other treatments $(\mathrm{p}<0.001)$, between the $70 \%$ treatments and all other the treatments $(\mathrm{p}<0.001$ for $95 \%$ treatments, $\mathrm{p}=0.02$ for controls, and $\mathrm{p}=0.08$ for procedural controls), and no differences between the controls and procedural controls. 


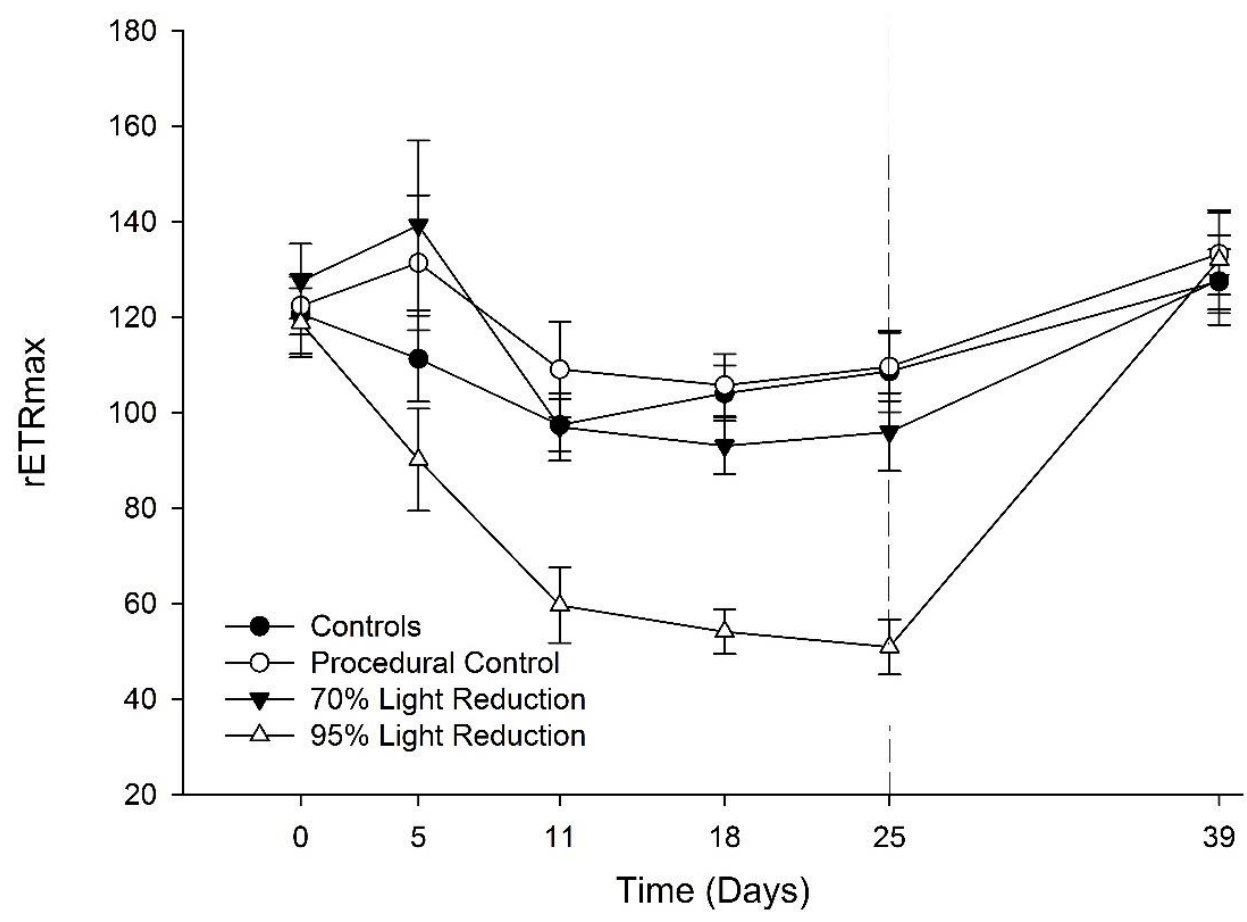

Figure 5.3. Mean rETRmax of controls (filled circles), procedural controls (open circles), 70\% light reduction (filled triangle), and 95\% light reduction (open triangle) treatments over time ( $\mathrm{n}=5$ for each). Standard errors are shown and the vertical dashed line represents the time when shades were removed.

\subsubsection{Sponge photophysiology}

There was a significant difference in $\mathrm{rETR}_{\max }$ across time (Huyn-Feldt, $\mathrm{F}_{(5,80)}=44.366, \mathrm{p}<$ 0.001 ), and interaction with time and treatment (Huyn-Feldt, $\mathrm{F}_{(15,80)}=6.983, \mathrm{p}<0.001$ ) (Fig. 5.3). Pairwise comparisons show that, by day 11 , average $\mathrm{rETR}_{\max }$ across all treatments and controls was significantly lower than at days 0 and 5 , or after recovery $(\mathrm{p}<0.001, \mathrm{p}=0.02 \& \mathrm{p}<$ 0.001 , respectively), a trend that continued on days 18 and 25 ( $\mathrm{p}<0.001$ for all). However, after the recovery period, the average $\mathrm{rETR}_{\max }$ was not significantly different from that found at days 0 and 5. Differences were primarily caused by a drop in the $\mathrm{rETR}_{\max }$ for the $95 \%$ treatment group; by day $11 \mathrm{rETR}_{\max }$ was significantly lower than for the controls $(\mathrm{p}=0.010)$, procedural controls $(\mathrm{p}=0.001)$ and $70 \%$ treatment $(\mathrm{p}=0.011)$, and this trend continued on days 18 and 25 ( $\mathrm{p}<0.001$ for all). There were no other significant differences in $\mathrm{rETR}_{\max }$ between any of the other treatment groups on any of the measured days, and after recovery no differences existed between any of the treatments. When examining differences across time within treatment groups, controls and procedural controls had a lower $\mathrm{rETR}_{\max }$ on day 18 than after recovery $(\mathrm{p}=0.05 \&$ 0.016 , respectively). However, the main differences occurred for the 70 and $95 \%$ treatments; by 
day $11, \mathrm{rETR}_{\max }$ was significantly lower in these groups than it was on day 0 within the same groups ( $\mathrm{p}=0.018 \& \mathrm{p}<0.001$, respectively). On day $25, \mathrm{rETR}_{\max }$ was at its lowest for the $70 \%$ and $95 \%$ treatments, and significantly lower than in the same treatments on days $0(\mathrm{p}<0.001$ for both), 5 ( $\mathrm{p}=0.003 \& \mathrm{p}<0.001$, respectively) and after recovery $(\mathrm{p}=0.011 \& \mathrm{p}<0.001$, respectively). After the recovery period, $\mathrm{rETR}_{\max }$ was not significantly different from that of day 0 within each group.

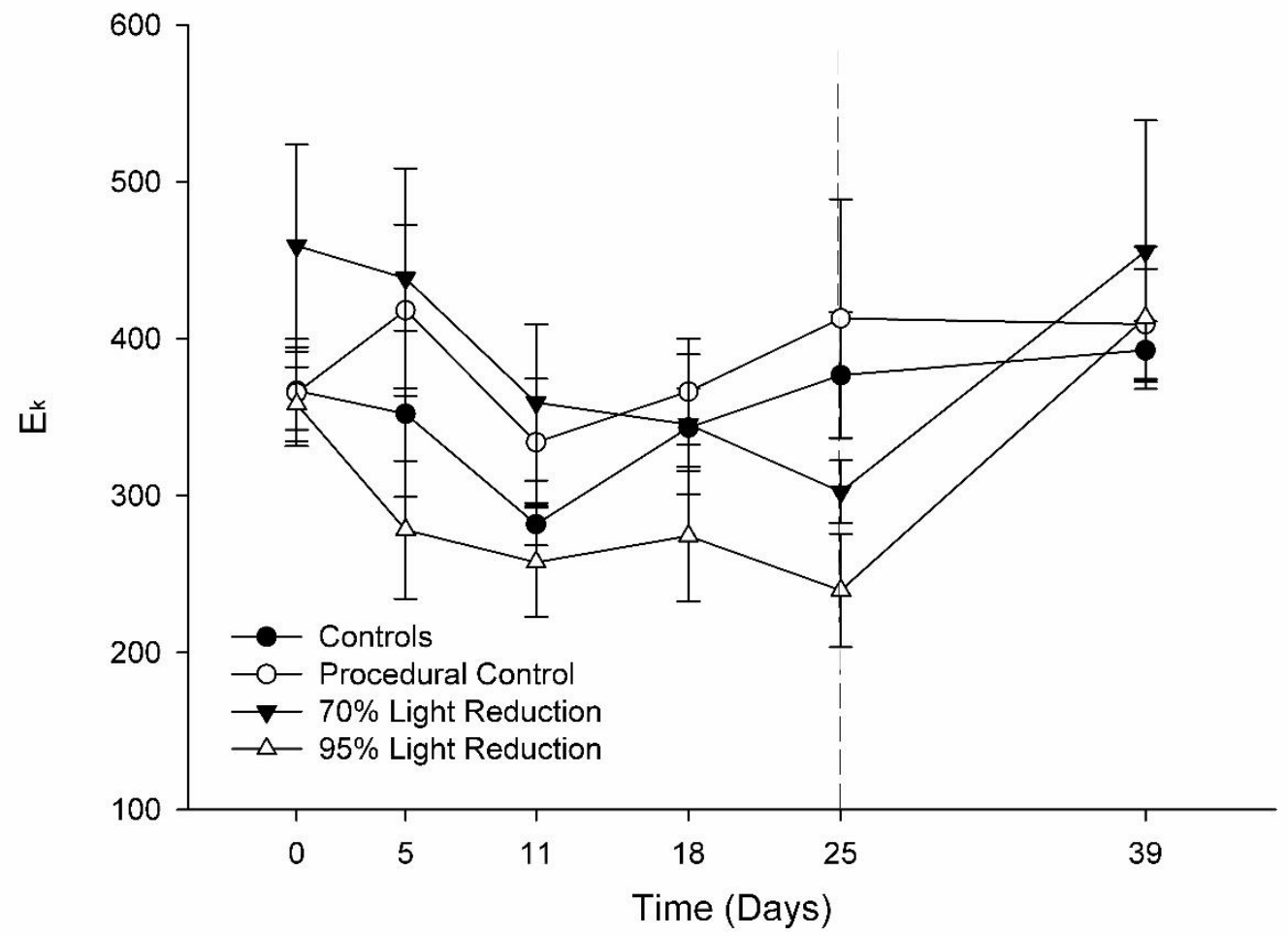

Figure 5.4. Mean $\mathrm{E}_{\mathrm{k}}$ of controls (filled circles), procedural controls (open circles), $70 \%$ light reduction (filled triangle) and 95\% light reduction (open triangle) treatments over time ( $\mathrm{n}=5$ for each). Standard errors are shown and the vertical dashed line represents the time when shades were removed.

There was a significant difference in $\mathrm{E}_{\mathrm{k}}$ across time (Huyn-Feldt, $\mathrm{F}_{(5,80)}=5.917, \mathrm{p}<0.001$ ) but no significant interaction with time and treatment (Fig. 5.4). Mean $\mathrm{E}_{\mathrm{k}}$ on day 11 (308.3 \pm 18.6) was significant lower $(\mathrm{p}=0.009)$ than on day $0(387.6 \pm 20.2)$ Mean $\mathrm{E}_{\mathrm{k}}$ was also significantly lower on days 11 and $18(332.4 \pm 18.5)$ than after the recovery period $(417.9 \pm 25.7 ; p=0.003 \&$ 0.005 , respectively). On day $25, \mathrm{E}_{\mathrm{k}}$ appeared lower in the 70 and $95 \%$ treatment groups compared to both control groups (Fig. 5.4) and lower than within the same treatments on day 0 and after recovery. However, the lack of significant interaction between time and treatment fails 
to significantly demonstrate this, probably due to the large amounts of within-treatment variation in $E_{k}$.

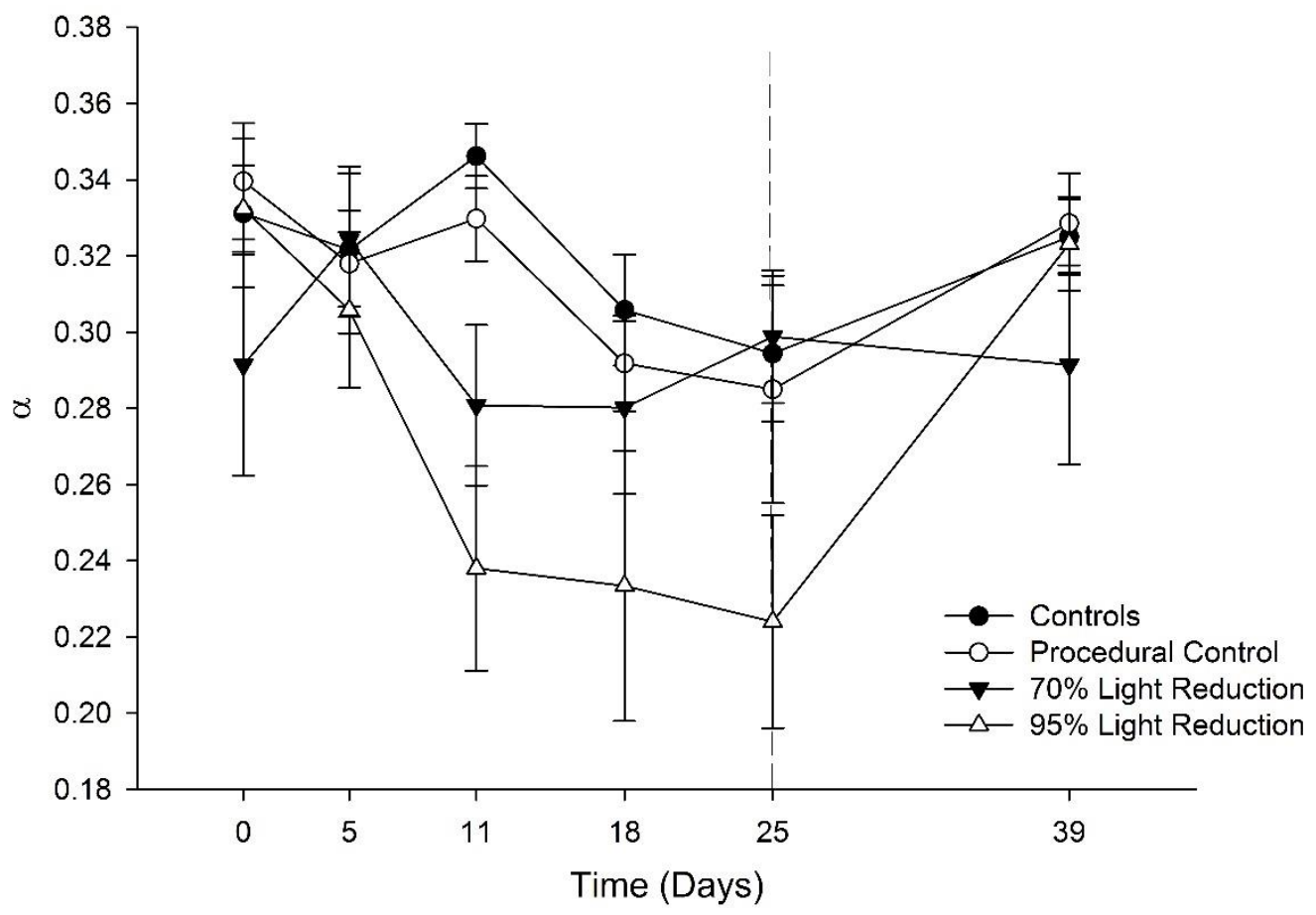

Figure 5.5. Mean $\alpha$ of controls (filled circles), procedural controls (open circles), $70 \%$ light reduction (filled triangle), and 95\% light reduction (open triangle) treatments over time ( $\mathrm{n}=5$ for each). Standard errors are shown and the vertical dashed line represents the time when shades were removed.

Light-limited photosynthetic efficiency $(\alpha)$ (Fig. 5.5) changed significantly with time (HuynFeldt, $\left.\mathrm{F}_{(5,80)}=6.294, \mathrm{p}<0.001\right) ; \alpha$ at day 25 was significantly lower than at days 0 and $5(\mathrm{p}=$ $0.41 \& 0.34$ respectively), but was not significantly different from any other day, including after the recovery period $(\mathrm{p}=0.062)$. Changes in $\alpha$ also occurred in an interaction between time and treatment (Huyn-Feldt, $\mathrm{F}_{(15,80)}=2.074, \mathrm{p}=0.020$ ) (Fig. 5.5). By day 11, $\alpha$ was significantly lower in the $95 \%$ treatment group than the controls and procedural controls $(\mathrm{p}=0.05 \& 0.017)$, however after day 11 no significant differences between treatments existed. Within treatment groups, the only change in $\alpha$ across time was in the $95 \%$ group, which by day 11 was significantly lower than at day 0 and after recovery ( $\mathrm{p}=0.001$ for both), and remained so at days $18(\mathrm{p}=0.039 \& 0.018$, respectively) and $25(\mathrm{p}=0.016$ for both). 
Effective quantum yield $\left(\Phi_{\text {PSII }}\right)$ across all treatment groups did not change significantly over time, however a significant interaction between time and treatment existed (Huyn-Feldt, $\mathrm{F}_{(15,80)}=$ $2.004, \mathrm{p}=0.025)$. Pairwise comparisons showed that this interaction was driven by changes in the $\Phi_{\text {PSII }}$ of the $70 \%$ treatments (Fig. 5.6); $\Phi_{\text {PSII }}$ was significantly greater at day 18 than at day 0 and or after recovery $(\mathrm{p}=0.017 \& 0.016$, respectively), and at day 25 was higher than after recovery $(\mathrm{p}=0.048)$, but not significantly higher than at day $0(\mathrm{p}=0.055)$.

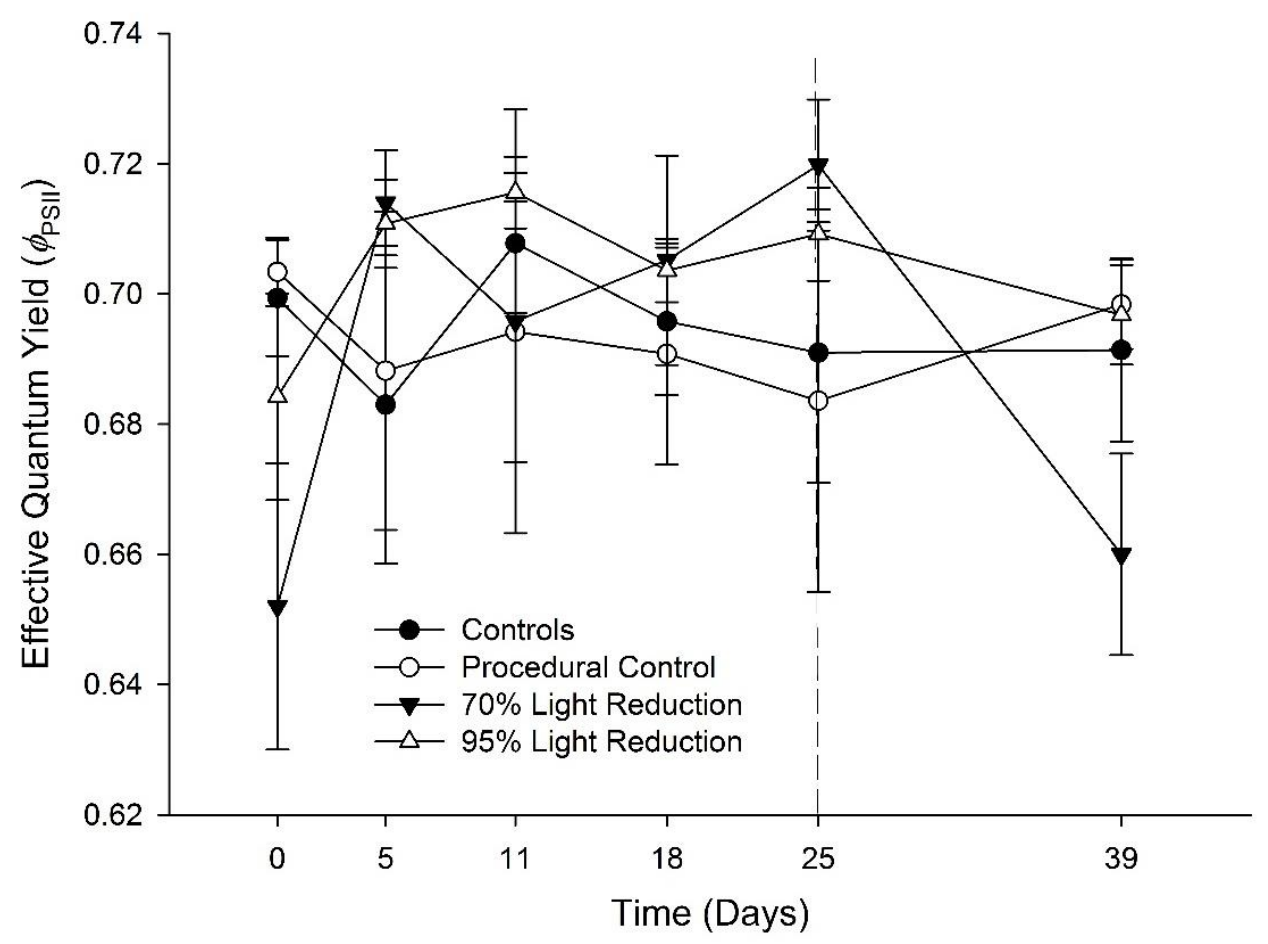

Figure 5.6. Mean $\Phi_{\mathrm{PSII}}$ of controls (filled circles), procedural controls (open circles), $70 \%$ light reduction (filled triangle), and 95\% light reduction (open triangle) treatments over time ( $\mathrm{n}=5$ for each). Standard errors are shown and the vertical dashed line represents the time when shades were removed.

$\mathrm{F}_{0}$ declined significantly across time (Huyn-Feldt, $\left.\mathrm{F}_{(5,80)}=36.511, \mathrm{p}<0.001\right)$ but there was no significant interaction with time and treatment (Fig. 5.7). 


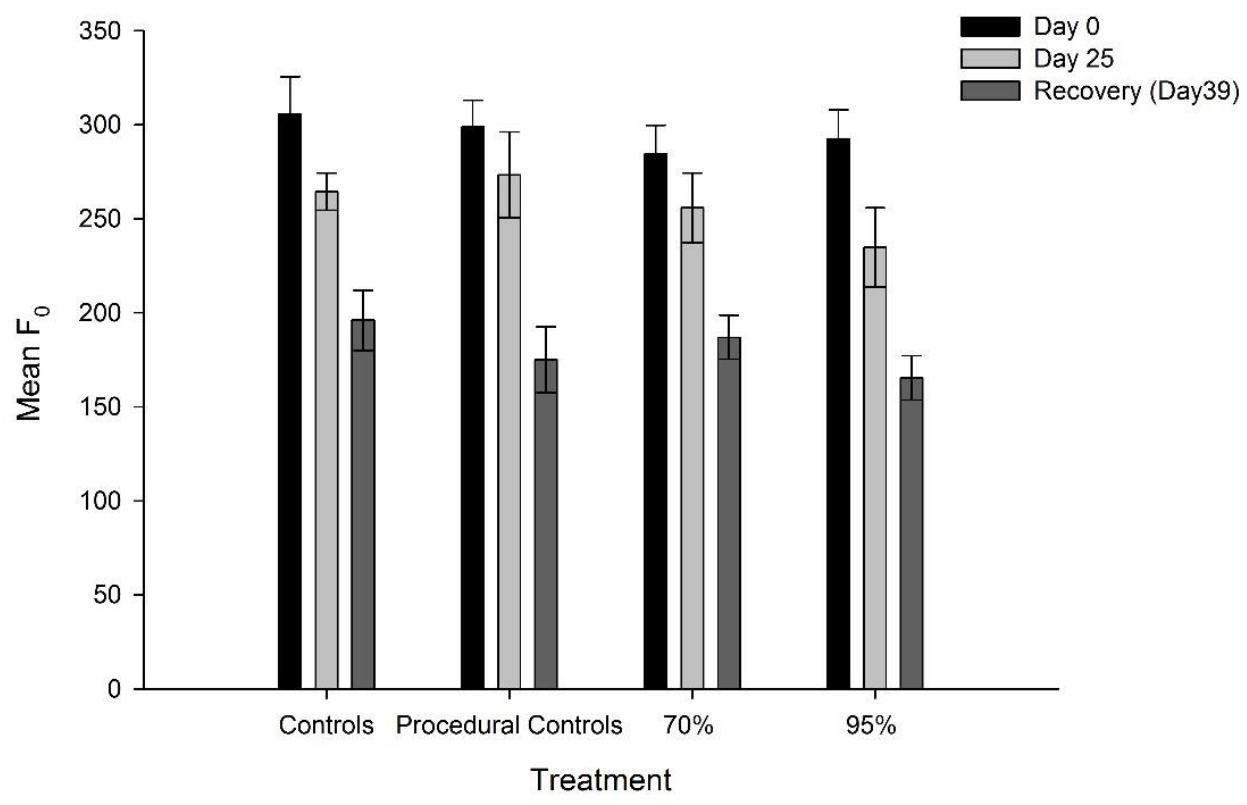

Figure 5.7. Mean F0 across time in different treatment groups $(n=5$ for each). Standard errors shown.

Mean qP changed significantly with time (Huyn-Feldt, $\mathrm{F}_{(2,32)}=113.071, \mathrm{p}<0.001$ ) and there was an interaction with treatment (Huyn-Feldt, $\mathrm{F}_{(2,32)}=2.686, \mathrm{p}<0.001$ ). Mean $\mathrm{qP}$ dropped significantly from day 0 to day 25 in the $70 \%$ and $95 \%$ treatment groups ( $\mathrm{p}<0.001$ for both), and increased again after 14 days of recovery for the treatment groups $(70 \%: \mathrm{p}=0.001 ; 95 \%: \mathrm{p}<$ $0.001)$ and controls $(\mathrm{p}=0.024)$ (Table 5.1).

Table 5.1. Mean $\mathrm{qP}$ and standard error for all controls and treatments at days 0 and 25, and after 14 days recovery.

\begin{tabular}{lccc}
\hline Treatment & & Mean qP & \\
& Day 0 & Day 25 & 14 days Recovery \\
\hline Control & $0.48 \pm 0.02$ & $0.44 \pm 0.04$ & $0.51 \pm 0.03$ \\
Procedural control & $0.49 \pm 0.01$ & $0.44 \pm 0.03$ & $0.50 \pm 0.02$ \\
$70 \%$ light reduction treatment & $0.51 \pm 0.02$ & $0.39 \pm 0.03$ & $0.49 \pm 0.02$ \\
$95 \%$ light reduction treatment & $0.48 \pm 0.03$ & $0.22 \pm 0.02$ & $0.50 \pm 0.02$ \\
\hline
\end{tabular}


Overall, RLCs and qP (Fig. 5.8) were not significantly different at day 0 or after recovery, but by day 25 there were significant differences $\left(\mathrm{GLM}, \mathrm{F}_{(3,175)}=23.665, \mathrm{p}<0.001 \& \mathrm{GLM}, \mathrm{F}_{(3,155)}=\right.$ 43.592, p $<0.001$, respectively). At day 25, pairwise comparisons showed significantly shallower RLCs and qP for the $95 \%$ treatment in relation to the $70 \%$ treatments and both controls $(\mathrm{p}<0.001$ for all).

\subsubsection{Sponge size}

Sponge surface area for all controls and treatments was not significantly different between days 0 and 25 (Table 5.2), and no necrosis was observed in any sponge. $60 \%$ of sponges within the $95 \%$ reduction group were notably paler on day 25 than within the same group on day 0 . No other group displayed obvious paling.

Table 5.2. Mean sponge size and standard error for all controls and treatments at days 0 and 25 .

\begin{tabular}{lcc}
\hline Treatment & \multicolumn{2}{c}{ Sponge Size } \\
& Day 0 & Day 25 \\
\hline Control & $18.4 \pm 5$ & $17.5 \pm 2.9$ \\
Procedural control & $20 \pm 9.1$ & $20 \pm 10.4$ \\
$70 \%$ light reduction treatment & $15.4 \pm 4.8$ & $17 \pm 5.3$ \\
$95 \%$ light reduction treatment & $17.8 \pm 2.2$ & $15.4 \pm 4.5$ \\
\hline
\end{tabular}

\subsubsection{Symbiodinium cladal composition}

Symbiodinium of clades A, C and G were found in the six $C$. aff. viridis n. sp. A individuals. A combination of clade $\mathrm{G}$ and A occurred in three individuals, two sponges contained only clade $\mathrm{C}$ and one sponge contained only clade $\mathrm{G}$. 
A
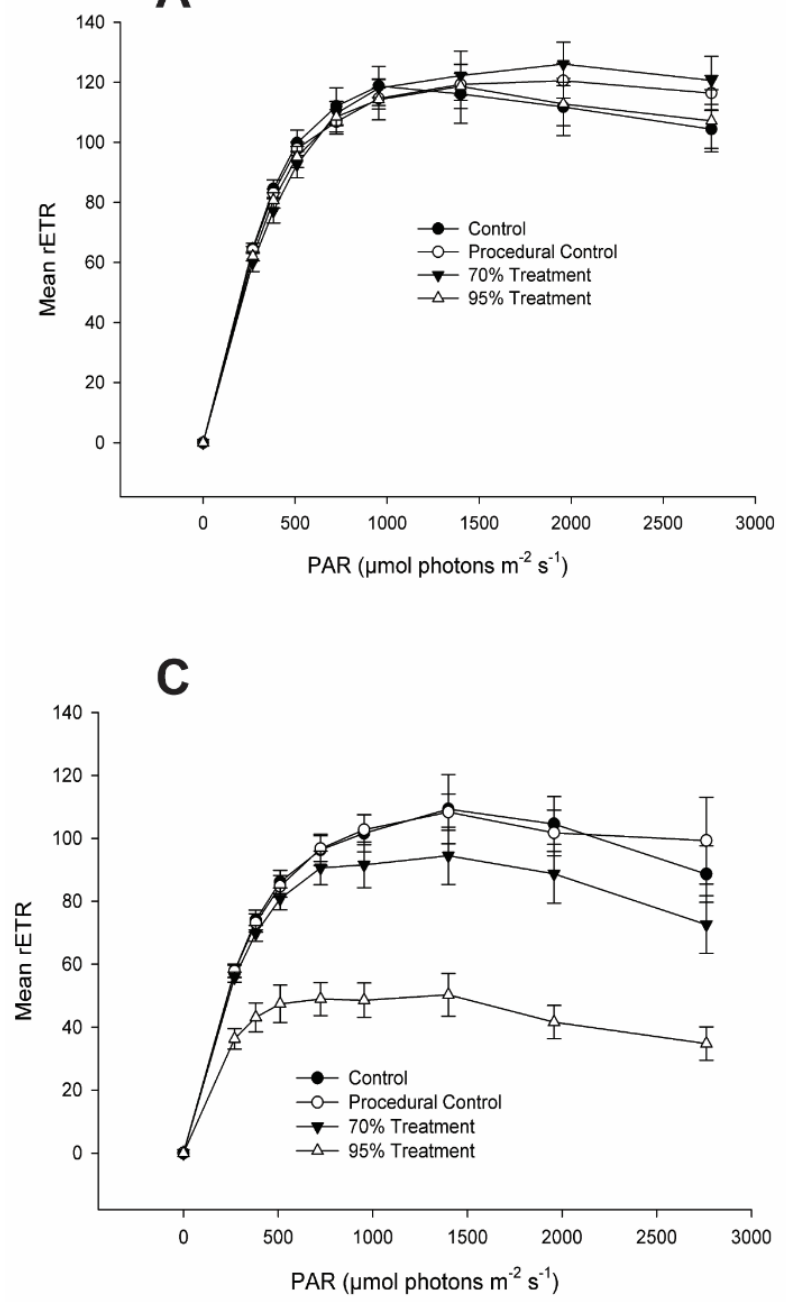

E

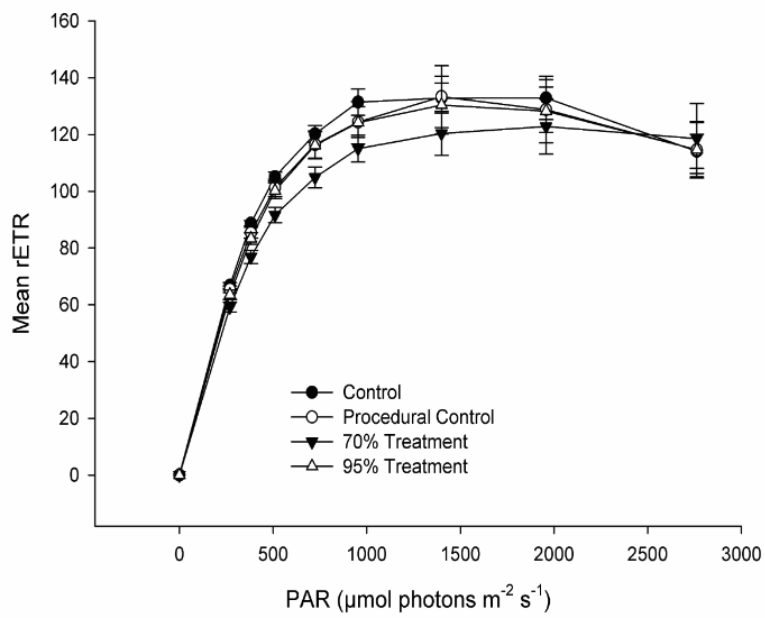

B
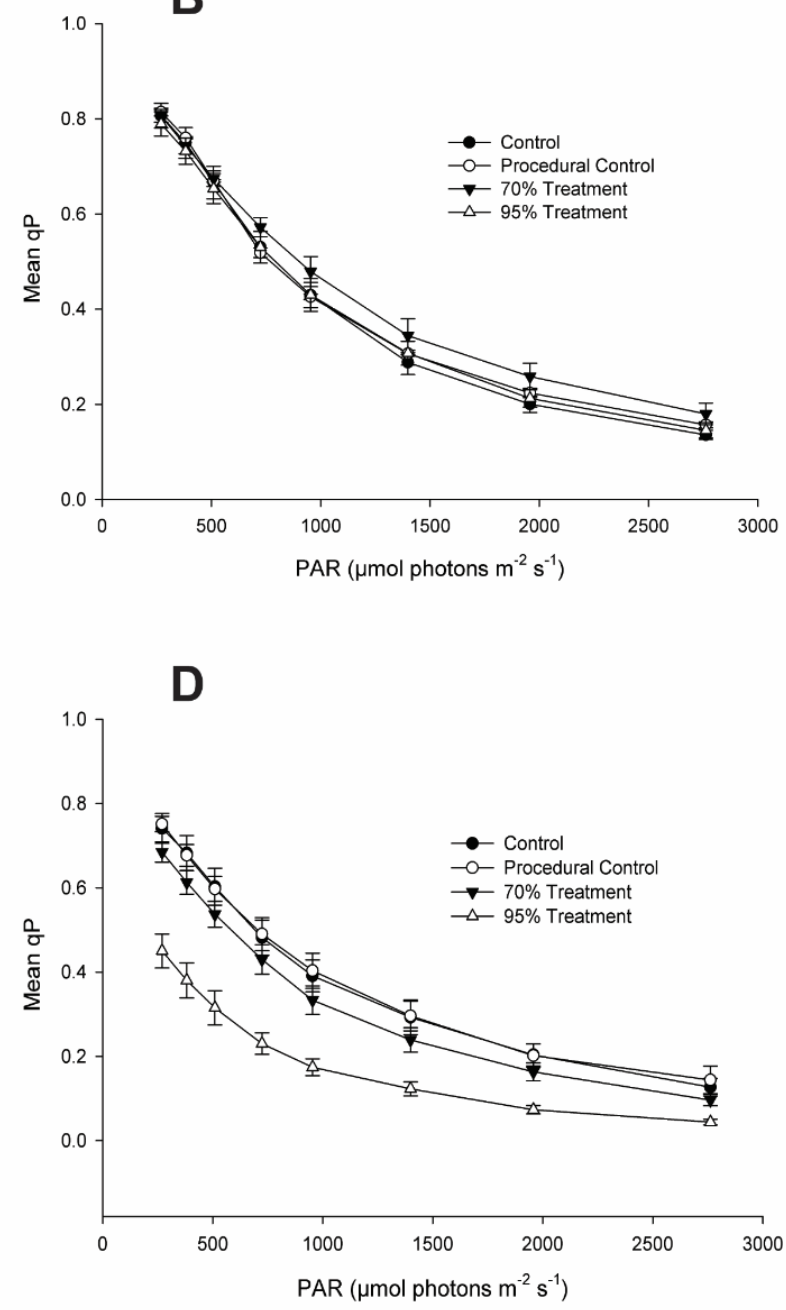

$\mathbf{F}$

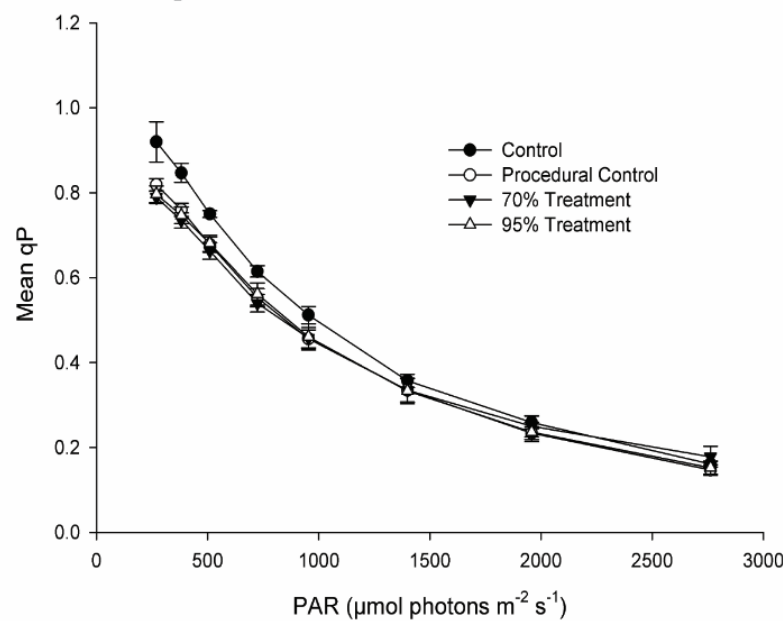

Figure 5.8. Mean rETR (RLCs) and mean qP against PAR at day 0 (A\&B) and day 25 (C\&D), and after 14 days of recovery (E\&F). Controls (filled circles), procedural controls (open circles), 70\% light reduction (filled triangle) and 95\% light reduction (open triangle) $(\mathrm{n}=5$ for each) Standard errors shown. 


\subsection{Discussion}

In the context of reef degradation and stressor resilience, research on bioeroding sponges has primarily focused on resilience to global stressors such as increased water temperature and ocean acidification (e.g. Schönberg \& Suwa 2007; Wisshak et al. 2012; 2013). Regional and local stressors (with the exception of eutrophication, e.g. Ward-Paige et al. 2005) have been largely overlooked. This is the first study to specifically focus on bioeroding sponge acclimation to light limitation on turbid reefs using PAM flourometry. I demonstrate that $C$. aff. viridis $\mathrm{n}$. $\mathrm{sp}$. A is capable of rapidly photoacclimating to extreme changes in ambient light availability and furthermore, is capable of surviving for short periods in near darkness without any visible signs of necrosis. This resilience to a regionally common form of reef stress is important given that bioeroding sponges of the $C$. viridis spp. complex are frequently associated with abundance increases on degraded reefs (Rützler 2002a; López-Victoria \& Zea 2005; Ward-Paige et al. 2005), indicating that zooxanthellate bioeroding sponges may be able to exploit coral declines on turbid reefs.

\subsubsection{Photoacclimation of C. aff. viridis n. sp. A}

Pertinent characteristics of Symbiodinium PSII in C. aff. viridis n. sp. A demonstrated altered states in relation to shading, that are consistent with photoacclimation. The most significant of which is the decline in $\mathrm{rETR}_{\max }$ and subsequent recovery. Numerous studies have shown a positive correlation between ETR $_{\max }$ and light availability in Symbiodinium (e.g. Steindler et al. 2001; Hennige et al. 2008a; Ziegler et al. 2015). In high light environments, high ETR $_{\max }$ allows Symbiodinium to capitalise on the elevated light availability by increasing photosynthetic rate (Ralph \& Gademann 2005). However, reduced ETR $_{\max }$ in low light environments appears paradoxical to the increases in photosynthetic 'units' that are usually associated with low light acclimation (Falkowski 1980; Richardson et al. 1983; Ramus 1990). This is thought to be due to increased light attenuation due to the accumulation of pigments, resulting in less light reaching the reaction centres and saturating photosynthesis (Falkowski \& Raven 2013). Reductions in ETR $_{\max }$ in the $95 \%$ treatment could also be a function of an extreme decrease in Symbiodinium density; in coral hosts $\mathrm{ETR}_{\max }$ is up to $84 \%$ lower in bleached tissues in comparison to healthy parts of the same colony (Fine et al. 2004). Although the pale appearance of $60 \%$ of the sponges at the end of the $95 \%$ treatment would support this hypothesis, the observation of bleaching in $C$. 
aff. viridis n. sp. A does not necessarily imply complete or even partial expulsion of symbionts, as is found in scleractinians (e.g. Fitt et al. 2000). Cliona orientalis relocates Symbiodinium deeper into sponge tissue at night or when experiencing light stress, giving a "bleached" appearance (Schönberg \& Suwa 2007; Fang et al. 2016) and this same diurnal movement has also been observed in $C$. aff. viridis n. sp. A (J. Marlow pers. obs.). The absence of any significant difference in the initial $\mathrm{F}_{0}$ value between the treatments and controls at day 25 would support this "bleaching" interpretation, as an initial $\mathrm{F}_{0}$ is proportional to PSII reaction centre density (Ryan et al. 2009). Therefore, the reduction in $\mathrm{ETR}_{\max }$ in shaded sponges is unlikely to be a consequence of a reduction in Symbiodnium density, but a function of photoacclimation.

Light reduction did not significantly alter one of the most reliable indicators of photoacclimation, minimum saturation irradiance $\left(E_{k}\right)$. $E_{k}$ is located on the RLC at the transition from the light limited to the light saturated region (Sakshaug et al. 1997) and is related to quenching; Qp dominates below $E_{k}$ and NPQ dominates above (Henley 1993; Ralph \& Gademann 2005). Symbiodinium cells acclimatised to low ambient PAR are usually characterised by low $\mathrm{E}_{\mathrm{k}}$ (Chalker et al. 1983) and reductions in $\mathrm{E}_{\mathrm{k}}$ reflect changes in the effective absorption cross section of PSII (Kolber \& Falkowski 1993; Rodolfo-Metalpa et al. 2008), as has been demonstrated in shaded seagrass (Collier et al. 2009) and sponges (Biggerstaff et al. 2015). $\mathrm{E}_{\mathrm{k}}$ is constantly changing in relation to irradiance, only occasionally matching instantaneous irradiance and is hence highly variable (Sakshaug et al. 1997; Ralph \& Gademann 2005). While this study found no significant difference between $\mathrm{E}_{\mathrm{k}}$ in any of the treatments, $\mathrm{E}_{\mathrm{k}}$ clearly declined in the shaded treatments, but variation was high and it is expected that more replication would have demonstrated this statistically. As $\mathrm{E}_{\mathrm{k}}$ is an accurate measurement of photoacclimation, derived values are considered indicative of the ambient light levels to which an organism is photoacclimated. However, average control $E_{k}$ values of $338 \mu \mathrm{mol}$ photons $\mathrm{m}^{-2} \mathrm{~s}^{-1}$ were substantially higher than ambient midday levels of $216 \mu \mathrm{mol}$ photons $\mathrm{m}^{-2} \mathrm{~s}^{-1}$. This is potentially due to calibration error in the PAR sensor.

Another strong indication of photoacclimation that can be derived from the RLCs is photosynthetic efficiency in the light-limited region $(\alpha)$. High $\alpha$ values are usually associated with photosynthetic organisms that are low-light acclimated, as they are more effective at rapidly utilising low irradiances (e.g. Hennige et al. 2008a). I found that $\alpha$ showed a marked decline in 
the $95 \%$ treatment over time but recovered rapidly to pre-shading levels after 14 days of recovery. In contrast, the $70 \%$ treatment showed no discernible difference over the course of the experiment. Neither reactions are typical for shade-adapted Symbiodinium and were unexpected. It is possible that the RLC sampling methodology had insufficient resolution to adequately estimate $\alpha$ in the shaded sponges, as estimates of $\alpha$ are strongly influenced by sampling frequency in the light-limited region of the RLC (Jassby \& Platt 1976; Ralph \& Gademann 2005). However, the very clear decline in $\alpha$ demonstrated by Figure 5.3 suggests that this is not the case and no alternative explanation is forthcoming.

The drop and subsequent recovery of photochemical quenching in the shade treatments is consistent with other studies that have demonstrated correlations between in situ light history and qP in aquatic phytoplankton (Harrison et al. 2015), seagrass (Ralph \& Gademann 2005) and the sponge L. herbacea (Biggerstaff et al. 2015). The association between qP capacity and in situ light conditions is a reflection of the photochemical operating efficiency of PSII and hence photosynthetic organisms that display higher qP demonstrate a higher PSII efficiency in high light (Hennige et al. 2008a; Harrison et al. 2015). The decrease in qP over the first 25 days and subsequent significant increase over the next 14 days in the control sponges corresponds with the observed trend in rETR $_{\max }$ and $\alpha$. This is likely due to the increase and subsequent decrease in water column turbidity that was observed over this time and further demonstrates the photoacclimatory capabilities of this sponge. This confounding effect no doubt also contributed to the lack of significant difference in the overall shape of the qP plot between the $70 \%$ treatment and controls at day 25 .

\subsubsection{Symbiodinium clades}

The discovery of clades $\mathrm{A}, \mathrm{C}$ and $\mathrm{G}$ in individuals of $C$. viridis n. sp. A is consistent with findings from elsewhere in the Indo-Pacific (Schönberg \& Loh 2005; Granados et al. 2008; Hill et al. 2011). Clade C has only previously been found in the Indo-Pacific Cliona caesia, clade $\mathrm{G}$ has been found in C. orientalis and the Caribbean sponges Cliona caribbaea and Cliona varians and clade $\mathrm{A}$ has only been found one Indo-Pacific sponge, Cliona jullieni, but also four Caribbean species (Schönberg \& Loh 2005; Granados et al. 2008; Hill et al. 2011). To date 10 clionaid species have had their Symbiodnium symbionts identified and of the eight sponge species that are represented by more than one individual $63 \%$ are associated with only one clade 
of Symbiodinium and the remaining 37\% are associated with two (Schönberg \& Loh 2005; Granados et al. 2008; Hill et al. 2011). The association of $C$. aff. viridis n. sp. A with three different clades is therefore a first for bioroding sponges but unsurprising given that this is common among cnidarian hosts (Baker \& Romanski 2007). The existence of different clades within individuals of $C$. aff. viridis n. sp. A could have introduced some variation into the results as different clades of Symbiodnium are known to have different photoacclimation strategies (Hennige et al. 2008b). The capacity to host different and multiple clades, also suggests an ability for these sponges to photoacclimate through horizontal acquisition of other more suitable clades. This is unlikely to have occurred over the short period of my study but could represent a longer term (months) acclimatory mechanism as has been suggested for scleractinian corals (Cohen \& Dubinsky 2015).

\subsubsection{Reliance upon symbionts}

A variety of sponges harbour Symbiodinium (Garson et al. 1998; Carlos et al. 1999), however the association is primarily associated with clionaid sponges (Sarà \& Liaci 1964; Rützler 1990; Granados et al. 2008; Hill et al. 2011). In these sponges, heightened light availability and Symbiodinium density has been associated with increases in bioerosion rates, growth and competitive ability (Hill 1996; Schönberg 2006). Despite the apparent benefits of the symbiosis in some species, very few studies have addressed the mechanisms that underpin the relationship, or the level to which the sponge depends on Symbiodinium for survival. It was long assumed that, as in scleractinians (e.g. Rädecker et al. 2015), photosynthate is translocated from Symbiodinium to host in return for protection and inorganic nutrients. Weisz et al. (2010) found strong evidence for transferal of carbon from symbiont to host in C. varians, but were unable to detect any reciprocal transfer of nitrogen. Furthermore, heterotrophic uptake of particulate and dissolved organic carbon by $C$. orientalis is $39 \%$ lower than the sponge's metabolic carbon demand (Fang et al. 2016), further demonstrating the sponge's apparent reliance on symbiontderived nutrition.

My study found that $C$. aff. viridis n. sp. A was able to photoacclimate to conditions of moderate to severe reductions in light availability. However, photoacclimation in Symbiodinium does not necessarily mean that the energetic needs of the sponge are met under the reduced light conditions. For instance, a comparable shading experiment by Biggerstaff et al. (2015) found that 
the predominantly phototrophic sponge Lamellodysidea herbacea was able to photoacclimate and survive a similar period of near-darkness, but not without incurring significant partial mortality. There were no observations of necrosis in shaded $C$. aff. viridis n. sp. A, however $60 \%$ of the $95 \%$ treatment sponges were noticeably paler at day 25 of the experiment. As mentioned above, the observation of tissue paling in $C$. aff. viridis n. sp. A does not necessarily imply complete or even partial expulsion of symbionts. Nevertheless, it is indicative of a stressed sponge and likely to result in a significant decrease in photo-autotrophically supplied carbon. One possible explanation for differences in levels of necrosis between $C$. aff. viridis n. sp. A and L. herbacea is that the former is potentially a more capable heterotroph. If this hypothesis is valid, then $C$. aff. viridis n. sp. A is potentially able to survive, at least in the short term, in similar conditions without incurring necrosis due to a combination of photoacclimation and heterotrophically-acquired carbon. Increased feeding rates and CHAR (percentage contribution of heterotrophically-acquired carbon to daily animal respiration) has been observed in bleached corals (e.g. Grottolli et al. 2006) and is thought to support long-term bleaching resilience. However, this appears not to be the case in the closely related $C$. orientalis; heterotrophic carbon uptake has been shown to remain unchanged between day and night, in experimentally bleached individuals, and after 20 days of complete darkness (Fang et al. 2014; 2016; 2017a). In fact, Fang et al. (2017a) suggest that, in the absence of photo-autotrophic energy, Symbiodinium cells are sustained through heterotrophy at the expense of the $C$. orientalis host, i.e. a shift from mutualism to parasitism. If heterotrophic compensation is as insufficient in $C$. aff. viridis n. sp. A, my research suggests that this species is unlikely to survive and recover beyond short periods of extreme turbidity (akin to the $95 \%$ treatment).

\subsubsection{Implications for survival on Sampela reef and other turbid Southeast Asian reefs}

Reefs in Southeast Asia are increasingly threatened by anthropogenic terrestrial processes such as intensive deforestation and coastal urbanisation that are leading to substantial loads of sediment entering coastal waters (Spalding et al. 2001; Baum et al. 2015). Suspended sediment, particularly the finer particles, decreases light availability for photosynthetic taxa, resulting in compressed depth distribution zones, and reduced growth and survival (Fabricius 2005; Erftemeijer et al. 2012). For example, in Singapore, sediment input through land reclamation activities has resulted in such dramatic reductions in light availability that reefs below 6-8 m are considered coral dead zones (Dikou \& van Woesik 2006; Todd et al. 2010). The capacity to 
photoacclimate to changing light conditions is therefore vital to guarantee survival and possible proliferation of zooxanthellate sponges on degraded turbid reefs.

Photoacclimation in $70 \%$ and $95 \%$ shading treatments of $C$. aff. viridis n. sp. A demonstrated the sponge's ability to acclimate to a light regime associated with highly turbid reefs such as Sampela and beyond. Light conditions at $10 \mathrm{~m}$ depth on the Sampela reef are similar to the $70 \%$ treatment and this is considered a highly-degraded reef (Crabbe et al. 2004; Haapkylä et al. 2007), where the turbidity regime has resulted in significantly reduced coral growth rates and diversity (Crabbe \& Smith 2002, 2005; Hennige et al. 2008a). This reef has a high abundance of the low-light and sediment tolerant L. herbacea (Powell et al. 2014; Biggerstaff et al. 2015; 2017), but $C$. aff. viridis n. sp. A is absent despite this studies' evidence suggesting that it can cope with the light regime. As previously mentioned, photoacclimation does not necessarily guarantee that Symbiodinium cells are able to transfer similar quantities of photonsynthate to their host in light-limited environments. Therefore, to fully understand the functioning of the light-limited holobiont it is important to include concurrent analysis of symbiont-host nutrient translocation, host respiration and heterotrophic uptake (see Weisz et al. 2010; Fang et al. 2017a).

Another possible explanation for the sponge's absence at Sampela is that the timescale at which turbidity changes on the reef is out of sync with the timescale over which photoacclimation occurs (Anthony \& Hoegh-Guldberg 2003). Photoacclimation in C. aff. viridis n. sp. A appeared to take approximately 11 days, however changing currents and tides can significantly alter the turbidity regime at Sampela over a matter of hours (J. Marlow pers. obs.). Under these timescales, photoacclimation would fail to enhance gross productivity, as downward- and upward-regulation of photosynthesis would compensate over longer timescales (current data; Fabricius 2005; Anthony \& Hoegh-Guldberg 2003).

The absence of $C$. aff. viridis n. sp. A on Sampela reef could also be a product of the direct impacts (rather than indirect shading) of the high concentration of suspended sediment (Bell et al. 2015). As an organism that likely relies on filter-feeding to provide at least some of its nutritional intake, $C$. aff. viridis n. sp. A is potentially vulnerable to clogging by fine sediments, as is the case in other tropical sponges (Bannister et al. 2012). With only minor selective control over filtering intake (Reiswig 1971a), the clogging of a sponge's inhalent canals and aquiferous 
system can cause reductions in feeding efficiency (Gerrodette \& Flechsig 1979). Active responses to high suspended sediment loads include the reduction or cessation of pumping (Reiswig 1971b; Leys et al. 1999), and metabolically active mechanisms such as mucus production or flow reversal (Bannister et al. 2012; Bell et al. 2015; Biggerstaff et al. 2017). However, sediment tolerance in bioeroding sponges varies between species (Carballo et al. 1994) and the limitations of any tolerance is currently unknown in $C$. aff. viridis n. sp. A. Therefore, although this experiment has shown that $C$. aff. viridis n. sp. A can photoacclimate to compensate for reduced light availability associated with turbidity, it remains to be seen how the sponge copes with the actual direct impact of the same suspended sediment. Any conclusions about the persistence of $C$. aff. viridis n. sp. A and other zooxanthellate sponges on turbid reefs are consequently limited.

\subsubsection{Conclusions}

Symbiodinium of $C$. aff. viridis n. sp. A are capable of substantially and rapidly altering its photophysiology in response to conditions of significantly reduced light availability, and reversing these changes once light conditions are restored. Given that the sponge's Symbiodinium composition is predominantly made up of Clade G, it is possible to cautiously extrapolate these results to other zooxanthellate clionaids, as many either contain Clade G or are dominated by it (Hill et al. 2011). The absence of $C$. aff. viridis n. sp. A at Sampela appears unlikely to be largely due to light limitation but possibly related to the other potential impacts of high sediment loading. Finally, while results from the $95 \%$ treatment demonstrate that $C$. aff. viridis $\mathrm{n}$. $\mathrm{sp}$. A is capable of photoacclimation in response to extreme reductions of light availability, observations of bleaching suggest that this may not be sustainable over prolonged periods. 


\section{Chapter 6: Factors controlling the erosion rate of a Spheciospongia cf. vagabunda}

\subsection{Abstract}

Coral reefs are increasingly threatened by anthropogenic disturbances and consequently coral cover and complexity are declining globally. However, bioeroding sponges, which are the principal agents of internal bioerosion on many coral reefs, are increasing in abundance on some degraded reefs, which is tipping them towards net carbonate erosion. The aim of this chapter was to identify the environmental factors that drive the erosion rates of the common Indonesian bioeroding sponge Spheciospongia cf. vagabunda. Sponge explants were attached to experimental calcareous substrates and deployed across seven sites characterised by different environmental conditions in the UNESCO Wakatobi Biosphere Reserve in Indonesia. Average bioerosion rates were $12.0 \mathrm{~kg} \mathrm{~m}^{-2}$ sponge tissue $\mathrm{yr}^{-1}( \pm 0.87 \mathrm{SE})$, and were negatively correlated with depth of settled sediment $\left(\mathrm{r}^{2}=-0.717, \mathrm{p}<0.01\right)$ and a showed weak positive correlation with water movement $\left(\mathrm{r}^{2}=0.485, \mathrm{p}=0.012\right)$. My results suggest that although bioeroding sponges may generally benefit from coral reef degradation, bioerosion rates may be reduced on reefs that are impacted by high sedimentation, which is a common regional stressor in the Southeast Asian Indo-Pacific. 


\subsection{Introduction}

Coral reefs are highly diverse ecosystems that globally provide critical ecosystem goods and services, such as food, tourism opportunities, fishing-derived income and shoreline protection for hundreds of millions of people (Veron et al. 2009; de Groot et al. 2012). However, these ecosystems are increasingly threatened by anthropogenic activities that have already led to a $50 \%$ decline in coral cover in the world's most biodiverse reef region, the Indo-Pacific (Bruno \& Selig 2007). On coral reefs, which are traditionally characterised by intense spatial competition, declines in the cover of scleractinian corals can potentially benefit other benthic taxa (Norström et al. 2009). Bioeroding sponges are one potential 'winner', with a number of studies reporting increased abundance on degraded reefs (Lopez-Victoria \& Zea 2004; Schönberg \& Ortiz 2009; Carballo et al. 2013). Although bioeroding sponge infestation levels can differ relative to other boring taxa depending on environmental conditions (Tribollet et al. 2002; Tribollet \& Golubic 2005), they are often the principle internal bioerosion agents on coral reefs (Risk et al. 1995). These sponges are capable of eroding substantial quantities of calcareous substrates; up to $20 \mathrm{~kg}$ $\mathrm{m}^{-2}$ sponge tissue $\mathrm{yr}^{-1}$ in the case of Cliona orientalis (Schönberg 2002) and up to $30 \mathrm{~kg} \mathrm{~m}^{-2}$ sponge tissue $\mathrm{yr}^{-1}$ for Cliona albimarginata (Calcinai et al. 2007). While these rates are greater than the calcification rates of many scleractinian corals (e.g. De'ath et al. 2009), the relative difference in abundance between these two groups results in net reef growth on healthy reefs. However, changes in environmental conditions that result in coral cover declines without causing parallel declines in the abundance of bioeroding sponges may tip reefs towards a state of net erosion, as appears to be the case on some reefs in the Caribbean and eastern tropical Pacific (Glynn 1997; Perry et al. 2008; Nava \& Carballo 2008). This shift from net accretion to net erosion results in a reduction in the topographic complexity of the reef, reducing the availability of habitat for other reef fauna and the provision of ecosystem services, such as shoreline protection (Sheppard et al. 2005; Pratchett et al. 2008).

Given the proliferation of bioeroding sponges on numerous degraded reefs and the implications this has for ecological functioning and ecosystem services, it is important to understand the rate at which sponges are eroding reefs and the factors that influence these rates. In this context, one of the most studied influences on erosion rates is nutrient availability. As many bioeroding sponges are heterotrophic (or at least partly), they are reliant on particulate and dissolved organic 
carbon to meet energetic demands (Mueller et al. 2014). Nutrient availability, often measured using chlorophyll $a$ concentration $(\operatorname{chl} a)$ as a proxy, has been shown to correlate with bioerosion rates that are typically higher on polluted eutrophic reefs than healthy reefs (e.g. Rose \& Risk 1985; Holmes et al. 2000; Holmes et al. 2009). The erosion rates of some species that harbour endosymbiotic Symbiodinium are also dependent upon light availability, with reduced bioerosion in light limited conditions (Hill 1996; Schönberg 2006). Furthermore, the density and minerology of the substrate can also influence sponge erosion, with higher erosion rates occurring in denser substrates (e.g. Schönberg 2002; Calcinai et al. 2007). Although no direct relationship has been found between sediment and sponge bioerosion rates, sediment can clog the filtering apparatus of sponges with subsequent effects on sponge ecology and physiology (see Bell et al. 2015 for review). Earlier studies have found that sedimentation can limit the abundance of specific bioeroding sponge species (Chaves-Fonnegra et al. 2007) and favour substrate infestation by microborers rather than sponge macroborers (Mallela \& Perry 2007).

In this Chapter I focused on the erosion rates of a Spheciospongia cf. vagabunda, which is a common species across the Indonesian archipelago (J. Marlow pers. obs.). In the Wakatobi UNESCO Biosphere Reserve S. cf. vagabunda is common on steep reef walls, forming large (up to $1.5 \mathrm{~m}^{2}$ ) encrusting mats with conical oscula that rise up to $10 \mathrm{~cm}$ above the sponge surface (see Chapters $2 \& 3$ ). The objective of this Chapter was to compare the bioerosion rates of $S$. cf. vagabunda into experimental blocks across sites experiencing known variation in environmental conditions. Understanding how these different environmental factors influence erosion rates in this species provides an increased understanding of how reef degradation will influence sponge bioerosion and the reefs of the future. 


\subsection{Methods}

\subsubsection{Study area}

This Chapter's research was conducted within the UNESCO Wakatobi Biosphere Reserve (Wakatobi) in southeast Sulawesi, Indonesia. Erosion rates of $S$. cf. vagabunda were measured at the seven sites around the Islands of Hoga and Kaledupa that were chosen to represent a range of environmental conditions and levels of reef degradation (Fig. 6.1). These sites constituted the "core" sites in Chapter 3; three steep-wall reefs; Buoy 1 and 3, and Ridge 1; three sloping reefs: Kaledupa 1, Kaledupa Double Spur and Pak Kasim's; and Sampela 1, which is highly sedimented and considered to be highly degraded (McMellor \& Smith 2010). Sites Buoy 1, Buoy 3, Kaledupa 1, Kaledupa Double Spur, Pak Kasim's, Ridge 1 and Sampela 1 are abbreviated in results and figures to $\mathrm{B} 1, \mathrm{~B} 3, \mathrm{~K} 1, \mathrm{KDS}, \mathrm{PK}, \mathrm{R} 1 \& \mathrm{~S} 1$ respectively.

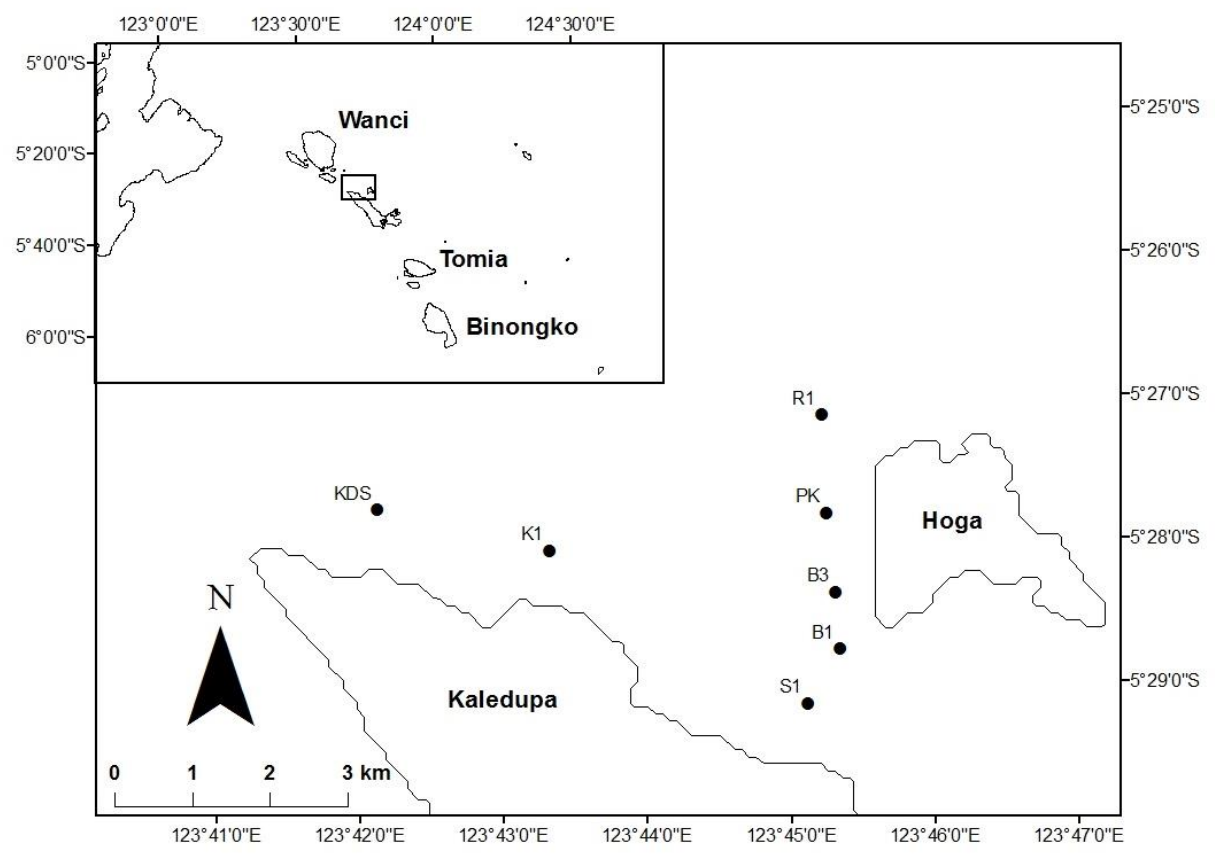

Figure 6.1. Map of Wakatobi region in southeast Sulawesi (top left) and the main study sites around the Islands of Hoga and Kaledupa.

\subsubsection{Bioerosion rates}

Sponge bioerosion rates were assessed using a modification of the methodology described by Holmes et al. (2009). This methodology uses the deployment of experimental blocks, half as treatment blocks with sponge explants attached and half as controls without sponges. Erosion 
rates were determined by weight loss in the treatment blocks over the one year period of deployment whilst controlling for weight loss by factors such as chemical erosion or grazing.

Experimental calcareous (limestone) blocks $\left(10 \times 10 \times 10 \mathrm{~cm}^{3}\right)$ were obtained from a mine on the local corraline island of Wanci (as per Chapter 4; Fig. 6.2A). Each block was thoroughly cleaned before drying to constant weight at $150{ }^{\circ} \mathrm{C}$ and then the volume was measured using water displacement. Blocks were then immersed in seawater for 48 hours before deployment. Deployment took place in July and August 2014 at each of the seven sites; ten blocks were attached to the bedrock at $10 \mathrm{~m}$ depth at $15 \mathrm{~m}$ intervals using marine epoxy, five controls and five with sponge explants of $S$. cf. vagabunda. The sponge cores were $3.5 \mathrm{~cm}$ in diameter and 2.5 $\mathrm{cm}$ deep and were attached using cable ties to the vertical side of each block. These sponge cores were haphazardly selected from 35 sponges at $10 \mathrm{~m}$ depth on Buoy 3, kept in laboratory aquaria for three hours and then transported to each of the seven sites (Fig. 6.2B). To assess the ecological relevance of using the calcareous blocks, five additional blocks of the recently dead Porites lutea were also deployed to Buoy 3 with attached sponge explants. P. lutea was chosen as it is a major reef building species in the Wakatobi, especially on reefs that have been degraded by previous bleaching events (J. Marlow pers. obs.). Unfortunately there was not enough recently dead $P$. lutea available to be used as the main treatment substrate, hence the use of calcareous blocks.

In July and August 2015 all blocks were retrieved (Fig. 6.2C), the remnants of any sponge graft removed and then immersed in household bleach. After 48 hours in bleach each block was removed, gently scrubbed with a wire brush to remove any epi- or endobionts, rinsed in fresh water and re-dried to constant weight. From visual inspection of blocks there was evidently a high amount of sponge bioerosion (Fig. 6.2E), however it was impossible to disentangle this from the weight loss due to extremely high external grazing pressure. Given this, an alternative methodology was developed to assess weight loss of treatment blocks independent to external weight loss due to grazing. The excavation region (including all erosion chambers) of each treatment block was hollowed-out using a fine chisel, retaining and weighing the non-eroded infrastructure (Fig. 6.2F). The volume of the excavated region was measured using a silicone mould and the mass of eroded calcium carbonate was then calculated by subtracting the weight of the non-eroded structure from the mass of the entire chamber (calculated from the mould volume and individual block density recorded pre-deployment). Rates were calculated in terms 
of $\mathrm{kg} \mathrm{m}^{-2}$ sponge tissue $\mathrm{yr}^{-1}$ based upon the final surface area of the sponge (measured using ImageJ software; Fig 6.2D).
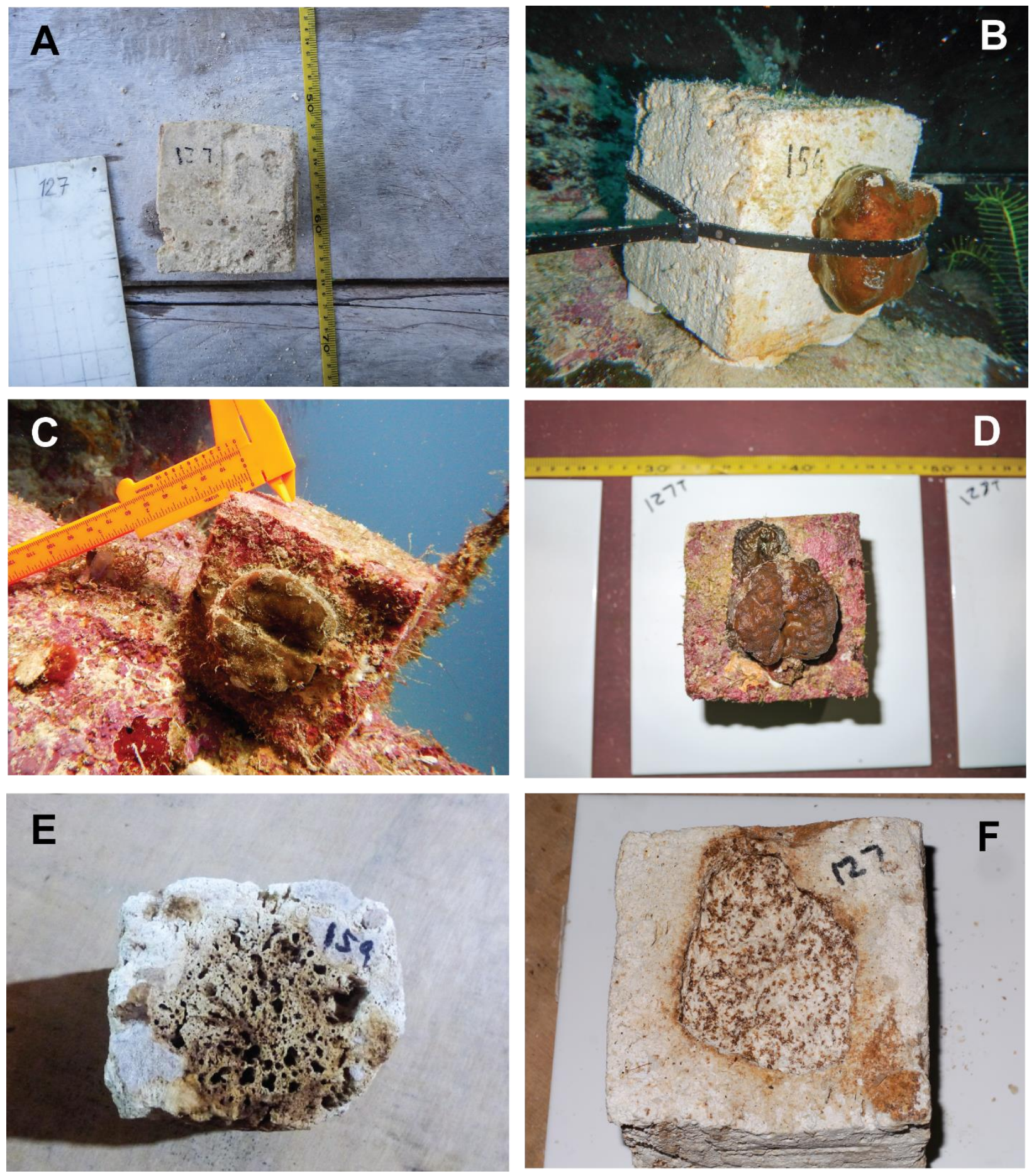

Figure 6.2. Example images of treatment calcareous blocks in 2014; pre-deployment (A), and immediately after deployment in (B), and in 2015; on retrieving from the reef (C), measuring graft surface area (D), after $48 \mathrm{hrs}$ in bleach (E), and after excavation of erosion zone (F). 


\subsubsection{Environmental variables}

Environmental data was the same as data collected for Chapter 3:

Throughout March-August 2014 and May-June 2015 an XR-420 CTD (RBR, Ottawa) data logger was deployed at the seven sites on randomly selected dates to measure turbidity and chl $a$. The CTD was set to record every minute with no averaging. Each deployment took place for a minimum of 24 hours, with a minimum of three separate deployments per site. This data collection methodology was identical (including same equipment and sites) to a previous study by Powell (2014) in 2010. Given this, the data was combined to create average values for each environmental parameter for each site. Averages were based on each 24 hour deployment with minutes considered as subsamples within each 24 hour period.

Depth of accumulated settled sediment was used as a proxy for sedimentation; at each site two $30 \mathrm{~m}$ transects were haphazardly deployed at $10 \mathrm{~m}$ depth and depth of settled sediment was measured on abiotic horizontal and inclined surfaces at $3 \mathrm{~m}$ intervals using callipers $(n=20)$.

Between May and August 2015 average current velocity was quantified for each site, in the form proportional water movement, using plaster of paris "clods" (Doty 1971). Clods were deployed on randomly selected dates for three 24 hour periods at each site during this period. Clods were prepared in $5 \mathrm{~cm}$ diameter hemispherical casts with stainless steel nails through the centre and dry weighed pre deployment. Deployment consisted of gently nailing three clods at right angles to the substrate at each site at both 10 and $5 \mathrm{~m}$ depth. After $24 \mathrm{hrs}$ all clods were recovered and the dry weight measurements repeated. For each of the three 24 hour deployments three control clods were placed on the reef within a weighted 40 ltr perforated bucket. This allowed limited water exchange, exposing the control clods to the same water temperature and salinity (which also affect clod dissolution) but excluded the water currents experienced by the freely deployed clods (Jokiel \& Morrisey 1993). Percentage dry-weight loss of clods (subtracting mean control percentage weight loss) was used to determine relative differences in water movement between sites.

\subsubsection{Statistical analysis}

All statistical analyses were performed within the SPSS (version 23) statistical analytical package. Differences in environmental parameters and erosion rates between sites were tested 
using a one-way analysis of variance (ANOVA) with relevant post-hoc tests. Tukey's post-hoc tests were used to identity individual site differences in environmental parameters and Gabriel's post-hoc test was chosen for erosion rates because it allows for unequal sample sizes. This was necessary due to differences in sponge explant survival between sites; only sites with three or more surviving explants were included in the analysis. If any data failed to meet the necessary assumptions of equal variance for the ANOVA (even after square-root or natural log transformation) then non-parametric Kruskal-Wallis tests were used with post-hoc Bonferroni adjusted pairwise comparisons between sites. Associations between environmental conditions and bioerosion rates were examined through Pearson's Correlation Analysis or Spearman's Rank when non-parametric testing was appropriate. Differences between the erosion rates of $S$. cf. vagabunda into the calcareous treatment blocks and into the P. lutea blocks at B3 were analysed using a one-way ANOVA. 


\subsection{Results}

\subsubsection{Site environmental characteristics}

The mean values for each environmental variable at each site are presented in Table 6.1. Depth of settled sediment varied between sites (Kruskal Wallis, $\mathrm{H}_{(6)}=35.398, \mathrm{p}<0.001$ ). The highest average depth of settled sediment occurred at $\mathrm{S} 1(2.94 \mathrm{~mm} \pm 0.28 \mathrm{SE})$ and pairwise comprisons showed that this was significantly higher than at all other sites. The lowest average depth of settled sediment occurred at $\mathrm{K} 1(0.25 \mathrm{~mm} \pm 0.12 \mathrm{SE})$, which was significantly lower than at B3 and (Table 6.1). Water movement was significantly different between the sites (ANOVA, $\mathrm{F}_{(6,75)}=$ $16.675, \mathrm{p}<0.001)$ with significantly higher movement at KDS $(24.42 \%$ clod weight loss \pm 1.81 $\mathrm{SE})$ compared to any other site and significantly lower movement at B1 (8.36\% clod weight loss $\pm 0.84 \mathrm{SE})$ and $\mathrm{B} 3(8.79 \%$ clod weight loss $\pm 0.75 \mathrm{SE}$ ) compared to K1, KDS and R1 (Table 6.1). Significant differences in chl $a$ (Kruskal Wallis, $\mathrm{H}_{(6)}=19.807, \mathrm{p}=0.003$ ) were detected between sites, however no significant individual inter-site differences were found in the pairwise comparisons. This is likely due to the conservativeness of so many Bonferroni corrections, however the greatest differences were between K1 and PK and S1 ( $\mathrm{p}=0.06$ and 0.054 respectively). There were no significant differences in turbidity (Kruskal Wallis, $\mathrm{H}_{(6)}=3.350, \mathrm{p}$ $=0.764)$ between the sites.

Table 6.1. Environmental characteristics of each site. Standard errors shown.

\begin{tabular}{|c|c|c|c|c|c|c|c|c|}
\hline \multirow[t]{2}{*}{ Variable } & \multirow[t]{2}{*}{ Unit } & \multicolumn{7}{|c|}{ Site } \\
\hline & & Buoy 1 & Buoy 3 & $\begin{array}{c}\text { Kaledupa } \\
1\end{array}$ & $\begin{array}{c}\text { Kal edupa } \\
\text { Double } \\
\text { Spur }\end{array}$ & $\begin{array}{c}\text { Pak } \\
\text { Kasim's }\end{array}$ & Ridge 1 & $\begin{array}{c}\text { Sampela } \\
1\end{array}$ \\
\hline $\begin{array}{l}\text { Settled } \\
\text { Sediment }\end{array}$ & $\mathrm{mm}$ & $\begin{array}{l}0.78 \\
( \pm 0.29)\end{array}$ & $\begin{array}{l}1.95 \\
( \pm 0.33)\end{array}$ & $\begin{array}{l}0.25 \\
( \pm 0.13)\end{array}$ & $\begin{array}{l}0.5 \\
( \pm 0.09)\end{array}$ & $\begin{array}{l}1.06 \\
( \pm 0.11)\end{array}$ & $\begin{array}{l}0.85 \\
( \pm 0.2)\end{array}$ & $\begin{array}{l}2.94 \\
( \pm 0.38)\end{array}$ \\
\hline $\begin{array}{l}\text { Water } \\
\text { Movement }\end{array}$ & $\begin{array}{l}\% \text { weight } \\
\text { loss }\end{array}$ & $\begin{array}{l}8.36 \\
( \pm 0.84)\end{array}$ & $\begin{array}{l}8.79 \\
( \pm 0.75)\end{array}$ & $\begin{array}{l}18.73 \\
( \pm 0.67)\end{array}$ & $\begin{array}{l}24.42 \\
( \pm 1.81)\end{array}$ & $\begin{array}{l}12.78 \\
( \pm 2.60)\end{array}$ & $\begin{array}{l}16.93 \\
( \pm 1.62)\end{array}$ & $\begin{array}{l}13.88 \\
( \pm 0.81)\end{array}$ \\
\hline Turbidity & NTU & $\begin{array}{l}2.66 \\
( \pm 1.22)\end{array}$ & $\begin{array}{l}2.06 \\
( \pm 0.7)\end{array}$ & $\begin{array}{l}1.69 \\
( \pm 0.5)\end{array}$ & $\begin{array}{l}2.07 \\
( \pm 0.4)\end{array}$ & $\begin{array}{l}1.75 \\
( \pm 0.2)\end{array}$ & $\begin{array}{l}1.32 \\
( \pm 0.6)\end{array}$ & $\begin{array}{l}4.10 \\
( \pm 1.04)\end{array}$ \\
\hline $\begin{array}{l}\text { Chlorophyll } \\
\alpha\end{array}$ & $\mu \mathrm{g} 1^{-1}$ & $\begin{array}{l}0.36 \\
( \pm 0.12)\end{array}$ & $\begin{array}{l}0.36 \\
( \pm 0.02)\end{array}$ & $\begin{array}{l}0.12 \\
( \pm 0.1)\end{array}$ & $\begin{array}{l}0.31 \\
( \pm 0.08)\end{array}$ & $\begin{array}{l}0.94 \\
( \pm 0.14)\end{array}$ & $\begin{array}{l}0.33 \\
( \pm 0.03)\end{array}$ & $\begin{array}{l}2.54 \\
( \pm 1.00)\end{array}$ \\
\hline
\end{tabular}




\subsubsection{Erosion rates}

Sponge explant survival varied between sites (Fig. 6.3) and Sampela 1 was excluded from the analysis as only one sponge explant remained by 2015. All other sites had at least three surviving explants. The mean erosion rate of $S$. cf. vagabunda across all sites was $12.0 \mathrm{~kg} \mathrm{~m}^{-2}$ sponge tissue $\mathrm{yr}^{-1}( \pm 0.9 \mathrm{SE})$ with significant differences between sites (ANOVA, $\left.\mathrm{F}_{(5,20)}=6.725, \mathrm{p}=0.001\right)$. The lowest average erosion rates occurred at B3 (6.2 $\mathrm{kg} \mathrm{m}^{-2}$ sponge tissue $\left.\mathrm{yr}^{-1} \pm 0.9 \mathrm{SE}\right)$, which was significantly lower than at K1, KDS and PK ( $\mathrm{p}=0.002,0.003$ and 0.014, respectively) (Fig. 6.3). The highest erosion rates occurred at $\mathrm{K} 1\left(16.5 \mathrm{~kg} \mathrm{~m}^{-2}\right.$ sponge tissue $\left.\mathrm{yr}^{-1} \pm 1.3 \mathrm{SE}\right)$ but rates were not significantly different from at any other site other than B3.

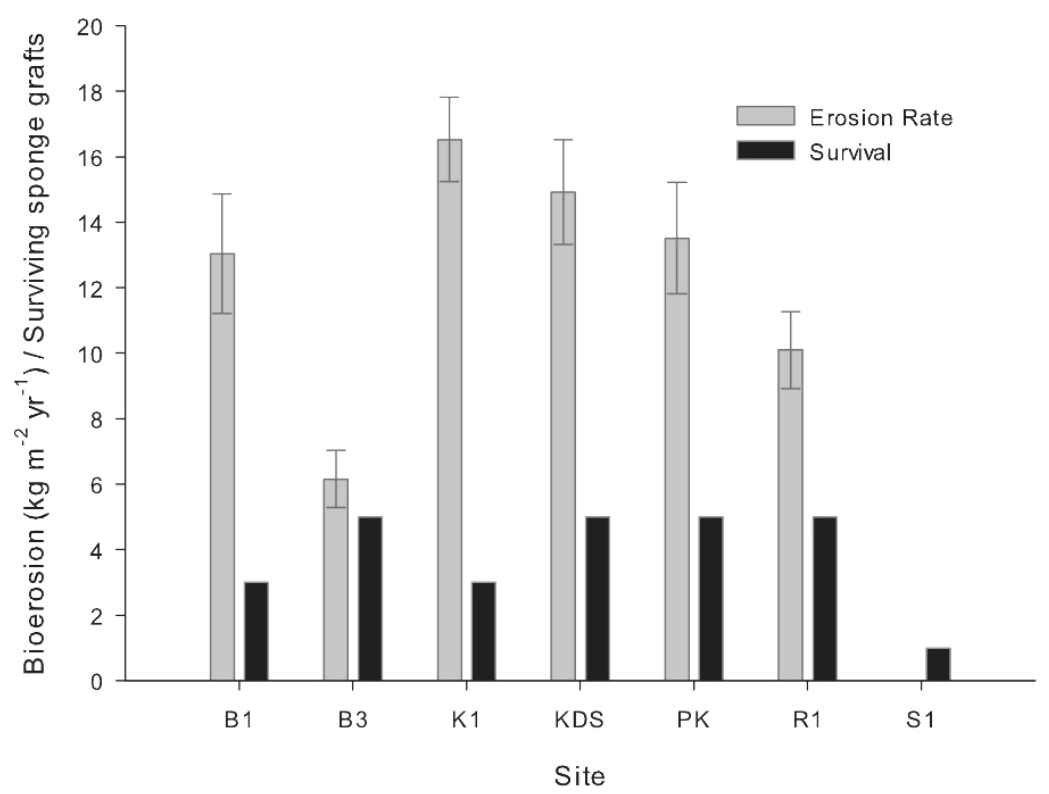

Figure 6.3. Mean bioerosion rates of Spheciospongia cf. vagabunda and number of surviving individual grafts across the study sites. Standard error shown.

Inter-site differences can be partially attributed to variation in environmental characteristics that existed in between sites. The erosion rates of $S$. cf. vagabunda were negatively correlated with depth of settled sediment (Pearson's, $\mathrm{r}^{2}=-0.717, \mathrm{p}<0.001$ ) and positively correlated with water movement (Pearson's, $\mathrm{r}^{2}=0.485, \mathrm{p}=0.012$ ) (Fig. 6.4). There were no significant correlations with chl $a$ (Pearson's, $\left.\mathrm{r}^{2}=0.019, \mathrm{p}=0.925\right)$ or turbidity (Pearson's, $\mathrm{r}^{2}=-0.234, \mathrm{p}=0.249$ ). 
All sponges survived on the five blocks of $P$. lutea. The erosion rates into these blocks (average of $5.1 \mathrm{~kg} \mathrm{~m}^{-2}$ sponge tissue $\mathrm{yr}^{-1} \pm 1.4 \mathrm{SE}$ ) was not significantly different (ANOVA, $\mathrm{F}_{(1,8)}=0.374$, $\mathrm{p}=0.558)$ from those into the limestone treatment substrate at the same site (B3, as above).
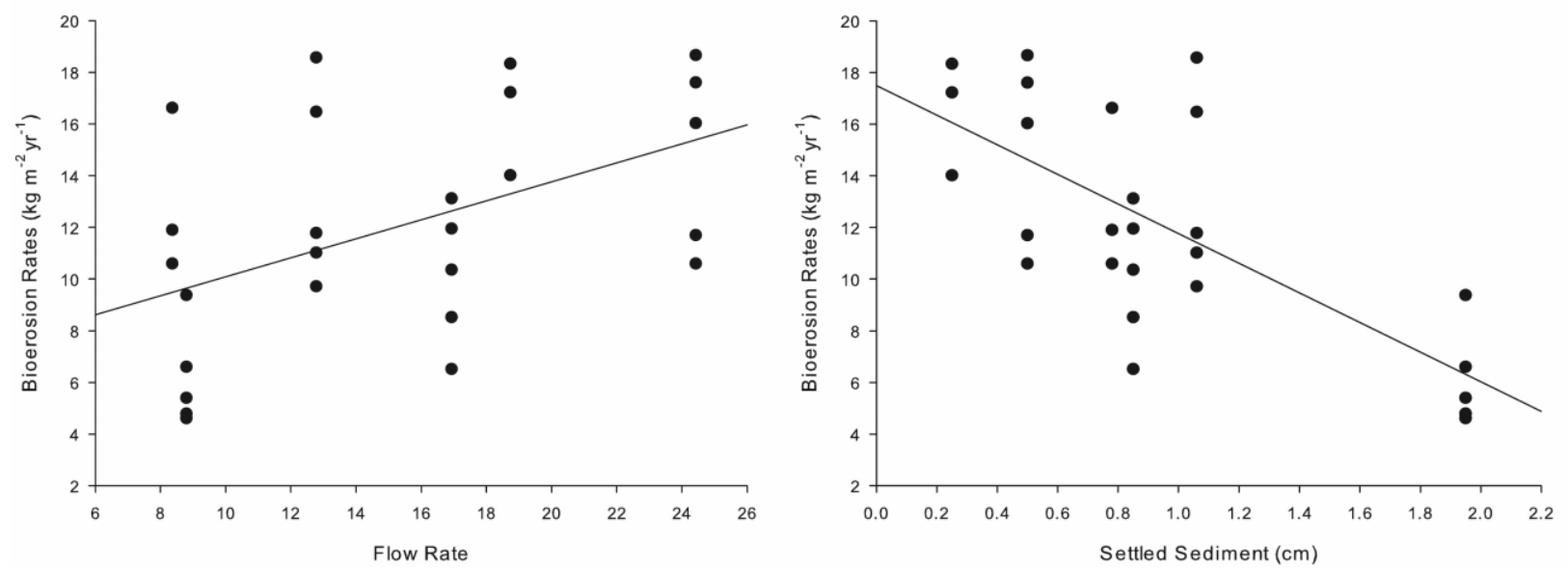

Figure 6.4. Pearson's correlations between erosion rates of Spheciospongia cf. vagabunda and water movement $\left(r^{2}=0.485, p=0.012\right.$, left $)$ and settled sediment $\left(r^{2}=-0.717, p<0.001\right.$, right $)$. 


\subsection{Discussion}

This is the first study of the bioerosion rates of a S. cf. vagabunda, or any other Spheciospongia sp. Bioerosion rates are similar to those found in other clionaid species; e.g. $3.4-17.6 \mathrm{~kg} \mathrm{~m}^{-2}$ sponge tissue $\mathrm{yr}^{-1}$ for $C$. orientalis and $2.9-29.5 \mathrm{~kg} \mathrm{~m}^{-2}$ sponge tissue $\mathrm{yr}^{-1}$ for $C$. albimarginata, depending on substrate density (Schönberg 2002; Calcinai et al. 2007; Holmes et al. 2009). The variation in these rates in relation to the measured environmental factors provides insight into how anthropogenically mediated changes in environmental conditions could affect carbonate budgets on future degraded reefs.

\subsubsection{Factors affecting erosion rates}

The correlation between high water flow and high erosion rates in S. cf. vagabunda was weak. However, it is consistent with Rützler (1975) who suggested that strong water movement stimulated bioerosion in experimental grafts of Pione lampa. High water flow is likely to be especially important for heterotrophic boring sponges such as $S$. cf. vagabunda as it increases food availability (e.g. Duckworth et al. 2004), which increases sponge bioerosion rates (e.g. Rose \& Risk 1985). This is particularly important in oligotrophic environments such as those in this study. Bioerosion rates did not correlate with chl $a$ concentration, which initially appears contradictory to many studies that have found erosion rates to increase across gradients of eutrophication (e.g. Rose \& Risk 1985; Edinger et al. 2000). However, with the exception of Sampela 1 (which was not included in the erosion analysis as all but one grafts died), chl $a$ concentrations were low and uniform across treatment sites. Holmes et al. (2000) found similar results elsewhere in Indonesian, showing that while sponge erosion rates correlated with chl $a$ concentration across polluted Javan reefs, this was not the case across less polluted Ambon reefs. On these less polluted reefs, factors such as water movement that increase food availability may be more important.

The inverse correlation between bioerosion rates of $S$. cf. vagabunda and depth of settled sediment and the survival of only one sponge explant at the highly sedimented Sampela reef indicates a negative influence of excessive sediment on this species. Some other studies have found a detrimental effect of sediment on bioeroding sponges. Abundance declines or the absence of bioeroding sponges have been attributed to excessive sedimentation in other studies (e.g. Edinger et al. 2000; Nava \& Carballo 2013). However, bioeroding sponges are generally 
quite sediment tolerant (Schönberg 2016). For example, both Hutchings et al. (2005) and Osorno et al. (2005) attributed high levels of sponge bioerosion at inshore sites on the GBR to high sediment deposition at these sites. Spheciospongia spp. in particular are thought to be sediment tolerant and often are capable of attaching to substrates buried in sediment up to $10 \mathrm{~cm}$ deep, surviving due to their fistular projections above the sediment surface (Schönberg 2016).This is also the case for previous descriptions of $S$. cf. vagabunda, which in other locations is often found buried in sediments (e.g. Bergquist 1965; Kelly-Borges \& Bergquist 1988; Sutcliffe et el. 2010). In the Wakatobi, buried fistulated $S$. cf. vagabunda have not been observed and the observed negative impacts of sediment on erosion rates and survival of this species are clearly in conflict with these previous descriptions of sediment tolerance. However, as discussed in Chapter 2, previous descriptions of the species are highly varied and likely represent a species complex rather than a single species. S. cf. vagabunda in the Wakatobi closely resembles those described by Kelly (1986) and Kelly-Borges \& Bergquist (1988) as "encrusting...form gently sloping mounds" and is potentially a less sediment tolerant reef-dwelling member of the complex. A sediment mediated reduction in bioerosion rate in $S$. cf. vagabunda could be due to the metabolic cost of active responses to sedimentation. Wakatobi $S$. cf. vagabunda in more sedimented environments often have mucus threads across their surface and have a more lamella-digitate surface, presumably allowing the body of the sponge to protrude above the sediment layer (as observed by Kelly-Borges \& Bergquist 1988). Responses to sediment such as these can have a high metabolic cost (Bannister et al. 2012) and could mean the diversion of energy away from other activities such as bioerosion. However, considering the literature's description of $S$. vagabunda as a sediment tolerant species and the snapshot collection of sediment data, this correlation should be viewed with some caution. In an effort to address this, I undertook an ex situ study into the impacts of settled sediment on the erosion rates of $S$. cf. vagabunda in 2016. Unfortunately data was highly variable and could not be used to prove or disprove the hypothesis that sedimentation constitutes a stressor for $S$. cf. vagabunda (more details in Appendix 2).

\subsubsection{Carbonate budget}

Caution is needed when interpreting the ecological relevance of this species' bioerosion rates in relation to local carbonate budgets. Firstly, the methodology of using sponge explants can overestimate rates as boring sponges can display disproportionately high erosion activity during 
the initial phases of colonisation (Rützler 1975). The use of limestone calcareous blocks was another potential source of error given the number of studies that have shown a strong link between substrate type and sponge bioerosion rates (e.g. Schönberg 2002; Calcinai et al. 2007; Hernández-Ballesteros et al. 2013). However, similar rates of bioerosion into the calcareous blocks and into $P$. lutea suggest that the measured rates are representative of those that could be expected in a regionally common form of calcareous substrate. Assuming these rates are ecologically accurate, they approach that of the calcification rates reported from massive Porites in the GBR of $\sim 15 \mathrm{~kg} \mathrm{~m}^{-2}$ coral $\mathrm{yr}^{-1}$ (De'ath et al. 2009). This suggests that if the abundance of $S$. cf. vagabunda were to increase as scleractinian corals decline, then there would be significant negative consequences for a reefs carbonate budget. However, while S. cf. vagabunda is a common relative to other bioeroding sponge species in the Wakatobi, its actual abundance is low in comparison to calcifying benthic taxa. Data from Chapter 3 shows that it covers just $0.6 \%$ of total reef area and $2.9 \%$ of available dead substrate, equating to average erosion rates of $71.6 \mathrm{~g}$ $\mathrm{m}^{-2}$ of reef $\mathrm{yr}^{-1}$. It has been suggested that high abundances of bioeroding sponges could tip a reefs carbonate budget towards net erosion (Glynn 1997; Nava \& Carballo 2008). This appears to be currently unlikely in the Wakatobi where hard coral cover is still around 20\% (Chapter 3; McMellor \& Smith 2010). However for those reefs that are currently around $10 \%$ coral cover (Sampela 1 and Kaledupa 1), which in the Caribbean is considered to be indicative of reefs likely to have a neutral carbonate budget (Perry et al. 2013), increases in the abundance of this sponge (and others of similar erosive capabilities), could have serious consequences for reef framework.

\subsubsection{Conclusions}

In conclusion, bioeroding sponges generally benefit from reef degradation (e.g. Schönberg \& Ortiz 2009; Carballo et al. 2013). In South-East Asia, a common cause of reef degradation is watershed-based pollution and its associated high levels of sedimentation and turbidity (Burke et al. 2011). The negative correlation between the depth of settled sediment and sponge bioerosion found in this study, suggest that these sponges are not resilient to all conditions that are adverse for corals. Excessive sedimentation in Southeast Asia may limit the potential additional damage of increased abundance of these sponges on the region's degraded reefs. 


\section{Chapter 7: General discussion}

\subsection{Summary of key findings}

The overall aim of my thesis was to increase our understanding of the ecology of the bioeroding sponge assemblage on coral reefs within the Southeast Asian Indo-Pacific. Specifically, to gain an insight into how anthropogenically derived disturbances would affect the abundance and functioning of these sponges.

To address my aims, it was first important that I was able to identify the main species of the Wakatobi bioeroding sponge assemblage. Working at the species level is critical to understanding the impacts of reef degradation as many of the factors that contribute towards adult distribution of bioeroding sponges, e.g. larval recruitment, stress resilience, spatial competitiveness and food availability, differ between species (Chapters 3 \& 4; Vicente 1978; Uriz et al. 1998; Holmes et al. 2000; Nava et al. 2014). This was only the second study within Indonesia to specifically address bioeroding sponge taxonomy and the first to employ phylogenetics. The assemblage of eight main species differed entirely in composition from the only other study in the region (Calcinai et al. 2005), despite a geographic separation of under 800 $\mathrm{km}$. My findings have furthered the distribution of three known species to Indonesian waters and identified two new species, which I have confirmed phylogenetically. I was able to use these species identifications to show that although the availability of suitable dead substrate appeared to drive overall bioeroding sponge abundance, inter-species differences in environmental preferences and tolerances were important contributing factors to differences in assemblage composition (Chapter 3). This was highlighted by the generally low bioeroding sponge abundance and species richness at Sampela (despite a high availability of suitable substrate) but the persistence of two apparently sediment tolerant species, Cliothosa cf. aurivilli and Cliona aff. viridis n. sp. B. In my fourth Chapter I used a two year deployment of experimental substrates to show that bioeroding sponges are able to rapidly recruit to newly available calcareous substrates, countering the view that longer timescales are required (Kiene \& Hutchings 1994; Pari et al. 1998; 2002; Tribollet et al. 2002). Recruitment rates, dispersal abilities and the relative importance of substrate cues for settlement also differed between species. In Chapter five I determined that the absence of a zooxanthellate species, Cliona aff. viridis n. sp. A, at the turbid and sedimented Sampela reef was unlikely to be due to light-limitation. Using a shading 
experiment and PAM flourometry I demonstrated that $C$. aff. viridis n. sp. A is capable of photoacclimating during prolonged periods of moderate to extreme reductions in light availability and rapidly recovering when returned to normal light levels. In my final research chapter I used a common Wakatobi species, Spheciospongia cf. vagabunda, to investigate environmental drivers of erosion rates, finding a stimulatory effect of water flow and a suppressive effect of settled sediment.

\subsection{Global and local reef threats and bioerosion}

At the global scale, the biggest threat to the survival of coral reefs is man-made climate change and associated ocean warming and acidification (Hughes et al. 2003; Done \& Jones 2006; Hoegh-Guldberg et al. 2007; De'ath et al. 2009; Hoegh-Guldberg \& Bruno 2010; Eakin et al. 2016). This has predominantly (and most dramatically) manifested as large scale bleaching events (Eakin et al. 2016; Heron et al. 2016; Hughes et al. 2017) but ocean acidification is already reducing coral calcification rates (e.g De'ath et al. 2009). The consensus is that climate change is likely to be largely beneficial for bioeroding sponges; ocean acidification has been found to increase bioerosion rates (Wisshak et al. 2012; Fang et al. 2013; Stubler et al. 2014), elevated temperatures has limited impact on bioerosion rates (Wisshak et al. 2013; Stubler et al. 2015), and bioeroding sponge abundance has increased after coral bleaching events (Sheppard et al. 2002; Schönberg \& Ortiz 2009; Carballo et al. 2013). Although my thesis was primarily focused on localised reef degradation, abundance and recruitment data clearly indicate that bioeroding sponges are closely tied to the availability of dead calcareous substrate, which is likely to increase after bleaching events and subsequent coral mortality. Bioeroding sponge species that are particularly likely to be successful are those that either invest considerable

resources in regular reproductive output, are highly spatially competitive or have high growth rates. Previous reports have found zooxanthellate bioeroding sponges to be among those that proliferate after bleaching events (e.g. Cliona orientalis; Schönberg \& Ortiz 2009). However, a recent observation of a mass bleaching of Cliona varians in the Caribbean (Hill et al. 2016) indicated that bioeroding sponges may be more sensitive to thermal events than previously thought (Vicente 1990). A similar event in the Wakatobi in 2016 (Fig. 7.1) demonstrated that $C$. aff. viridis n. sp. A was rapidly able to recover from bleaching with minimal partial mortality. Whether these sponges could recover the lost tissue and invade bleached coral substrates before 
other benthic taxa is unknown, although growth rates are high in many zooxanthellate encrusting bioeroding sponges (e.g. González-Rivero et al. 2013; López-Victoria et al. 2006). Also unknown is how bleaching would affect reproduction in these sponges. Gametogenesis is arrested in bleached corals (Szmant \& Gassman 1990) and a similar physiological response in bioeroding sponges would likely constrain the sponge's ability to occupy bleached substrates through larval settlement.
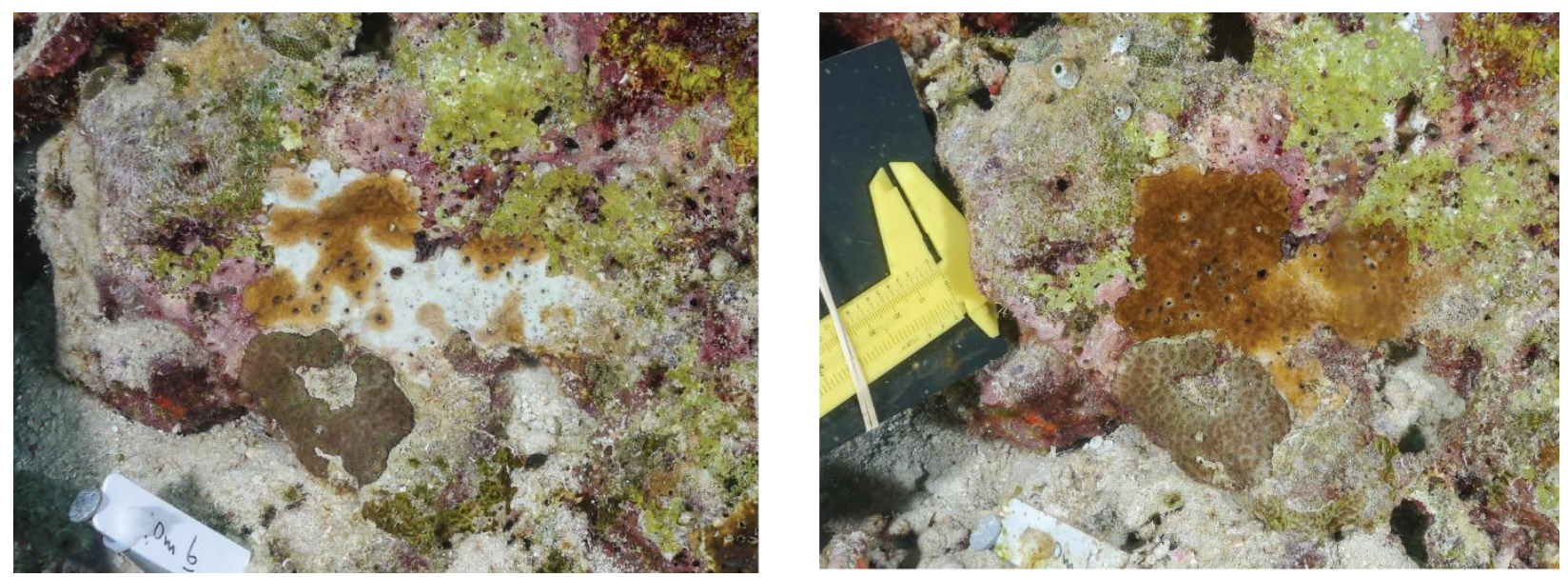

Figure 7.1. Partially bleached Cliona aff. viridis n. sp. A in July 2016 (left image) and after recovery six weeks later (right image).

Ninety-five percent of coral reefs in Indonesia and the wider Southeast Asian region are at risk from local threats, predominantly fishing pressure (destructive fishing and overfishing) and watershed-based pollution (excessive levels of sedimentation, turbidity, eutrophication and pollutants) (Burke et al. 2011). These stressors are commonly implicated in regime shifts on coral reefs (Szmant 2002; Mora 2008; Fung et al. 2011) and have sometimes been associated with shifts to sponge dominance (Ward-Paige et al. 2005; Knapp et al. 2013; Powell et al. 2014). In Southeast Asia, watershed-based pollution threatens 45\% of reefs (Burke et al. 2011) and using the Sampela reef as a model site, my thesis primarily focused on how this threat will affect sponge bioerosion. The low bioeroding sponge abundance, species richness and survival of sponge grafts at Sampela indicate that some aspects of either excessive sedimentation, turbidity, nutrient enrichment or some unmeasured variable do not provide favourable conditions for bioeroding sponges. The evidence from elsewhere in Indonesia (Holmes et al. 2000), the eastern Pacific (Nava et al. 2014) and from the Caribbean (Ward-Paige et al. 2005; Chaves-Fonnegra et 
al. 2007) suggest that nutrient enrichment is actually likely to promote bioeroding sponge abundance and erosion rates through increased food supply. Therefore the impacts of either sedimentation or turbidity, which are often associated with nutrient enrichment (Edinger et al. 1998; 2000), appear to exceed any benefits derived from increased food supply at Sampela. The presence of $C$. aff. viridis n. sp. B at Sampela and the ability of $C$. aff. viridis n. sp. A to photoacclimate to light levels significantly below those found at Sampela, suggests that photosynthetic bioeroding sponges are not light-limited on turbid reefs, at least in the short term. In fact, nutrient enrichment on these reefs might compensate for any reductions in photosynthetically derived nutrients. It consequently seems likely that on reefs degraded by watershed-based pollution, occupation and erosion of available dead substrate is primarily restrained by sedimentation. This could be attributed to either adult mortality through the clogging of the aquiferous system (Gerrodette \& Flechsig 1979), smothering (Illan \& Abelson 1995) or abrasion (Nava \& Carballo 2013) or by settled sediment hindering settlement of larvae (Maldonaldo et al. 2008). The low survival of S. cf. vagabunda grafts at Sampela and the negative correlation between depth of settled sediment and erosion rates in the species, further supports the negative impact that sedimentation can have on some bioeroding sponge species. Nevertheless the abundance and recruitment rates of both $C l$. cf. aurivillii and $C$. aff. viridis $\mathrm{n}$. sp. B demonstrate that some species are resilient to high levels of sedimentation and turbidity. Similar findings have been found in the GBR where Siphonodictyon mucosum, a sediment specialist, increased in abundance on reef flats after a coral bleaching event (Schönberg \& Ortiz 2009). Nava et al. (2014) also found distinct differences in bioeroding sponge assemblage composition between reefs associated with differing levels of chl $\alpha, \delta^{13} \mathrm{C}, \delta^{15} \mathrm{~N}$, turbidity and sedimentation. Therefore watershed-based reef degradation is likely to result in increased bioeroding sponge abundance but only limited to those sediment tolerant species. The impact this will have on the reef will largely depend on the erosion rates of those tolerant species.

While overfishing has been associated with regime shifts to macroalgal dominance on Caribbean reefs (Hughes 1994; Jackson et al. 2001), there is less evidence for involvement of overfishing in other regime shifts. In the Wakatobi widespread use of non-selective fish fences, more traditional line and speargun fishing, and destructive blast and cyanide fishing (Clifton et al. 2010) has led to significant declines in reef fish abundance (Curtis-Quick 2013). The consequence of reef fish abundance declines for bioeroding sponges is currently unclear but any impacts are likely to be 
due to changes in the abundance of herbivorous grazers or spongivorous fish. Presently, there is very little information about bioeroding sponge mortality, either indirectly due to grazing pressure or directly by spongivorous fish, however both have been observed in the Wakatobi (J. Marlow pers. obs.). The only study to specifically study spongivory on bioeroding sponges ( $C$. varians) found high rates of mortality inflicted by Angelfish (Hill \& Hill 2002), which have also been identified as prominent spongivores in the Wakatobi (Powell et al. 2015). There is more evidence for the role of grazers in influencing sponge bioerosion but the conclusions are mixed. Risk \& Sammarco (1982) measured bioerosion in Acropora inside and outside of damselfish territories and found erosion was highest inside territories. As damselfish aggressively exclude other reef fish from their territories, the authors attribute the difference in erosion to reduced bioeroder mortality by fish predators or grazers. Therefore a reduction in spongivorous fish or herbivorous grazers through over-fishing might result in a similar increase in bioerosion. However, a reduction in herbivorous grazers is also likely to result in increased macroalgae cover, which negatively correlates with the bioeroding sponge abundance and is a known spatial competitor (Wismer et al. 2009; Cebrian 2010; González-Rivero et al. 2012; Ramsby et al. 2017). Furthermore, there is evidence that grazing by parrotfish in the region between neighbouring corals and bioeroding sponges can facilitate the spread of the bioeroding sponge (Márquez \& Zea 2012). Therefore it is currently unclear the degree to which overfishing will affect sponge bioerosion on coral reefs. A more foreseeable association between sponge erosion and fishing practices is in relation to destructive fishing methods such as blast fishing. Blast fishing is illegal but widespread in Indonesia (Erdmann 2000), reducing branching coral to fields of rubble and capable of splitting-open large massive corals (Alcala \& Gomez 1987). It produces larges areas of dead calcareous substrates suitable for colonisation by other taxa (Fox et al. 2003), such as bioeroding sponge. Blast fishing also potentially acts as a form of asexual dispersal for bioeroding sponges, as has been observed from other physical forms of reef disturbance (López-Victoria \& Zea 2004)

\subsection{Carbonate consequences of increased sponge bioerosion}

The geomorphic status of coral reefs is a function of both calcium carbonate production (corals and coralline algae) and erosion (physical, chemical and biological) (Perry et al. 2008). A positive balance between these two is associated with healthy reefs but disturbance events that change the relative abundance of either coral accretors or eroders can tip this to a negative 
erosional state (Eakin 2001). The best current examples of this are in the Caribbean and Eastern Tropical Pacific. Historically (Holocene), reef carbonate budgets in the Caribbean have been positive by approximately 10-17 $\mathrm{kg} \mathrm{CaCO}_{3} \mathrm{~m}^{-2}$ year ${ }^{-1}$ (Vecsei 2001). However, recent surveys across four Caribbean nations by Perry et al. (2013) found current carbonate production ranged from -1.77 to $9.51 \mathrm{~kg} \mathrm{CaCO}_{3} \mathrm{~m}^{-2}$ year ${ }^{-1} ; 21 \%$ of reefs had a negative budgets and a further $26 \%$ had positive budgets below $1 \mathrm{~kg} \mathrm{CaCO}_{3} \mathrm{~m}^{-2}$ year ${ }^{-1}$. These authors attributed this to significant declines in coral cover across the region and suggest that $10 \%$ coral cover is the tipping point below which net-erosion occurs. If a similar relationship occurs in the Indo-Pacific, reefs at Kaledupa and Sampela (Table 3.1) are likely to be approaching "accretionary stasis" (Perry et al. 2008), with further reductions in coral cover or increases in bioerosion tipping the balance towards net-erosion. This is particularly the case if there are large increases in the abundance of highly erosive species such as S. cf. vagabunda. A prolonged period of net-erosion is likely to have serious consequences for the stability and maintenance of reef framework. For example, a mass coral mortality in Galapagos Islands during the early 1980s and a subsequent population explosion of echinoid bioeroders resulted in a carbonate deficit of 10 to $30 \mathrm{Kg} \mathrm{CaCO}_{3} \mathrm{~m}^{-2} \mathrm{year}^{-1}$ (Glynn 1988). The perseverance of the bioeroder population without any coral recovery over the past 35 years has resulted in virtually total reef frame loss in the central and southern islands (Glynn 1994; Reaka-Kudla et al. 1996; Glynn \& Manzello 2015). The loss or reduction of reef framework is likely to have serious ecological and economic consequences. The three dimensional complexity afforded by intact coral growth forms and framework on healthy reefs facilitates the high diversity and abundance of other reef taxa by providing a range of habitats and refuges from predators and environmental stressors (Bruno \& Bertness 2001; Willis et al. 2005). Reef rugosity and both height and variety of coral growth forms correlate strongly with reef fish diversity and abundance (Gratwicke \& Speight 2004). Many of the fish that inhabit these refuges are commercially or ecologically important (Beukers \& Jones 1997; Lee 2006; Graham et al. 2007). Additionally, a complex reef framework enhances coastal protection through the dissipation of wave energy (Lugo-Fernandez et al. 1998), which is of growing importance given predicted sea level rises. Therefore a state of net-erosion as a consequence of reduced coral accretion and increased sponge erosion is likely to have significant consequences for reef biodiversity, productivity and local socio-economics (Pratchett et al. 2008; Alvarez-Filip et al. 2009). One good example of this potential trajectory is the Seychelles. The reefs around these islands suffered a 90\% coral mortality in the 1998 mass bleaching event (Sheppard 2003), 
and by 2005 were a drastically altered ecosystem; benthic composition had shifted from a highly complex coral-dominated state to a low complexity rubble and algal-dominated state (Graham et al. 2006). The associated reef fish assemblage saw a local extinction of four species and a critical drop in abundance of six other species. Graham et al. (2006) found that the shift in species richness on these reefs was not a product of the reduction in coral cover but due to changes in complexity in habitat. In this regard, endolithic bioeroders often have a disproportion erosional effect on reef complexity as many preferentially occupy and erode the base of coral branches (Carballo et al. 2008b). Bioeroding sponges are therefore considered, among other bioeroders, to be key contributors to the flattening of reef framework and the reduction in habitat complexity (Glynn \& Colgan 1992; Alvarez-Filip et al. 2011). In an increasingly acidic ocean, with decreased calcification rates (Orr et al. 2005), this is likely to be exacerbated by increased rates of sponge bioerosion (see Schönberg et al. 2017 for review).

\subsection{Indonesian sponge bioerosion in a global context}

Unfortunately, direct comparisons of bioeroding sponge space occupation and abundance patterns between Wakatobi and other regions are more problematic because of differences in survey methodologies. Other surveys have used \% occurrence within rubble/coral (e.g. Carballo et al. 2013; Nava \& Carballo 2013), numerical abundance or sponge size (e.g. Ward-Paige et al. 2005), but few have used percentage cover (e.g. Schönberg 2015a), which is surprising given the methods prevalence in coral studies (e.g. Edmunds \& Elahi 2007; Green et al. 2008; Cleary et al. 2014). The most recent and analogous study to address the abundance of bioeroding sponges using percent cover has been in the GBR (Schönberg 2015a), which found that bioeroding sponges currently occupy $11.1 \%$ of suitable substrate, which is comparable to current occupation rates of bioeroding sponges in the Wakatobi (8.9\% of suitable substrate). Bioeroding sponge cover on the GBR increased from $9.8 \%$ in $1997 / 1998$ to $14.8 \%$ in 2003/2004 following bleaching events in 1998 and 2002 (Schönberg \& Ortiz 2009) but abundance has since plateaued in some species (Schönberg 2015a; Ramsby et al. 2017). Conversely around the Caribbean island of Grand Cayman average cover (non-substrate standardized) of bioeroding sponges is $1.24 \%$ (Murphy et al. 2016), under half that of the Wakatobi (3.1\%). While recent studies have demonstrated high bioeroding sponge cover in some parts of the Caribbean, the highest abundances appear to be concomitant with eutrophication (e.g. Rose \& Risk 1985; Ward-Paige et al. 2005; Chaves-Fonnegra et al. 2007). Furthermore, recent declines in bioeroding sponge 
abundance to very low levels in some parts of the Caribbean have been associated with reductions in nutrient input (Ruzicka et al. 2010: 2013). Outside of eutrophic environments, Indo-Pacific reefs (e.g. the GBR, Wakatobi) may support higher abundances of bioeroding sponges on degraded reefs as the majority of these reefs are yet to experience large shifts to macro-algal dominance (Bruno et al. 2009), which is known to be an important bioeroding sponge competitor on Caribbean reefs (Wismer et al. 2009; Cebrian 2010; González-Rivero et al. 2012).

\subsection{Implications for monitoring and management}

The 1998 El Niño and the subsequent global coral bleaching catalysed coral reef monitoring programmes around the world (Houk \& Woesik 2013). However, the focus of these monitoring programmes remains largely coral-cover-centric, and it has been argued that a more questionorientated approach that encompasses more functional groups is required (Bellwood et al. 2004; Hughes et al. 2010). Given the proliferation of bioeroding sponges on certain degraded reefs (e.g. Schönberg \& Ortiz 2009; Carballo et al. 2013) and the consequences this can have for carbonate budgets (Glynn 1997; Perry et al. 2008; Nava \& Carballo 2008), it might be assumed that bioeroding sponges are regularly included in monitoring efforts. Unfortunately, with the exception of some instances in the Caribbean (Gilliam 2007; Lang et al. 2010), bioeroding sponges (and sponges more generally) have been largely excluded from long term monitoring efforts. This is presumably due to their cryptic habitat and the specialist knowledge that is required for species identification. However, the line intercept method described by Schönberg (2015a), and used in Chapter 3, could be readily incorporated into existing monitoring programmes. Direct incorporation may not be possible in all cases, as programmes that use point intercept (e.g. Reef Check) might lack the resolution to detect bioeroding sponges. However, many current monitoring programmes could incorporate bioeroding sponges with minimal changes to their current methodologies. Larger methodological changes would be required to incorporate assessments of carbonate budget into reef monitoring programmes (see Perry et al. 2012). Realistically however, without measuring carbonate accretion or bioerosion by other bioeroders, the monitoring of bioeroding sponge abundance or erosion rates alone is meaningless in the context of understanding reef carbonate changes. 
Reef management is generally a localised process that aims to maintain biodiversity, sustain fisheries production and simultaneously allow resource extraction by the local populace (McClanahan et al. 2006; Christie \& White 2007). An increase in reef sponge bioerosion has the potential to negatively affect both total reef biodiversity and fisheries production, as well as coastal protection and is therefore an important factor to be considered in reef management strategies. Fortunately, as the abundance of bioeroding sponges is tightly linked to the availability of suitable calcareous substrates (this thesis; Chaves-Fonnegra et al. 2007, Carballo et al. 2008a, Schönberg \& Ortiz 2009, Schönberg 2015a), controlling their spread likely falls into the broad aims of most current reef management goals, i.e. maintaining or increasing coral cover. Some authors have argued that little can be done at the local scale to arrest coral declines from large-scale stressors such as climate change (Edwards \& Gomez 2007). However, there is evidence that well managed long-term marine protected areas (MPAs) are capable of increasing resilience to global stressors through the maintenance of functional groups, accumulation of herbivorous fish, trophic cascades, and subsequently increasing coral recruitment (Hughes et al. 2007; Mumby et al. 2007; Mellin et al. 2016). Therefore on Southeast Asian coral reefs, the implementation of no take zones or "coral-friendly" and fishing regulations (Mumby \& Steneck 2008) are likely to indirectly slow the proliferation of bioeroding sponges through the maintenance of coral cover.

Unfortunately, the funding for coastal zone management in Indonesia and other developing countries in the Region is sadly lacking, and many MPA or National Parks are better described as "paper parks". The Wakatobi is prime example of this and where available, data suggest that the annual funds allocated to the park represent just $1 \%$ of the estimated US\$2.7 million required for effective management (Clifton et al. 2010). The lack of appropriate funding means that enforcement of the no-take-zones (NTZs) (3.4\% of the park's area) is constrained in all but the areas that are supported by local tourism operators (Clifton 2013). Even in these areas the NTZs are so small they are unlikely to offer any real protection to target species (Stacey et al. 2016). In the unenforced NTZs, compliance is minimal and reflects the insufficient consultation, education and participation of the Bajau fishers in the process of park zoning. Although now settled, the historical nomadism of Bajau means they are unlikely participants in local fisheries management as in the past fishers have simply moved on to new fishing grounds when catches decline (Satria \& Masuda 2004). Further hindering the participation of the Bajau is that they do not perceive 
time as linear, therefore have little perception of causality, i.e. that short-term restrictions in fishing activities could be outweighed by the long term benefits (Clifton \& Majors 2012). The management and enforcement of sufficiently sized MPAs or fishing regulations in the Wakatobi and other similar regions is consequently unlikely to reverse or even slow declines in coral health or halt increases in other spatially competitive taxa such as bioeroding sponges. Local management of reefs in the Wakatobi, and others like it in the region, needs appropriate funding, scientific input and local stakeholder participation from the outset if conservation goals are to be met.

\subsection{Limitations}

From the outset, this thesis focused on the conspicuous bioeroding sponge species of the Wakatobi, i.e. those that could be observed by the naked eye. After spicule confirmation of observable macro-morphological differences in sponge species (Chapter 2), both abundance surveys and recruitment analysis relied upon visual identification of sponges. Schönberg (2015a), recommended the use of line intercepts and visual identification as they were the least spatially biased and provided the most statistical efficiency. However, the use of rubble surveys (e.g. Holmes et al. 2000), which are able to detect species with no observable surface presence, detected almost twice as many species as the line intercepts. Therefore focusing on only those species that are externally observable is likely to have underestimated the full extent of the bioeroding sponge assemblage composition and both levels of abundance and recruitment. Nevertheless, the inclusion of inconspicuous species into Chapters 3 and 4 would not have been possible in the field (as spicule identification is required). Perhaps more importantly, this thesis aims to address the impacts of habitat degradation on bioeroding sponges and a focus on the larger, more aggressive species (in terms of both erosion and spatial competition) is more appropriate. In this context, disregarding inconspicuous species is appropriate as they are generally less aggressive (Carballo et al. 2008a; Schönberg 2015a).

With exception of March-April 2014, all biological and environmental data was collected in short summer field seasons. The Wakatobi experiences seasonal changes in rainfall and prevailing wind direction; a dry season in April to October, when the prevailing wind is from the east, and a rainy season from November to March when the prevailing wind is from the west. Therefore the collection of data during only the dry season provided only a snapshot view and 
could have failed to account for intra-annual variation in environmental and biological variables. Consequently, it's presently unknown how much seasonal variation occurs in the assemblage dynamics of bioeroding sponges in the Wakatobi. Evidence from elsewhere is mixed; sponge assemblage composition on reefs in the Mexican Pacific change with seasonal differences in wind, swell and sediments (Carballo 2006; Carballo et al. 2008b), conversely a study from the Caribbean found that the sponge assemblage remained relatively constant over the course of 16 years (Hughes 1996). Most likely a bigger source of error is the collection of environmental data during only these periods with seasonal changes in wind and rain likely affecting turbidity, chlorophyll $\alpha$ concentrations and water flow.

\subsection{Future direction of research}

Reef degradation in the Indo-Pacific is likely to continue due to stressors originating both locally and globally, and therefore research into the resilience and functioning of bioeroding sponges needs operate at these two levels.

This thesis highlighted the inter-species differences in sediment tolerance in bioeroding sponge species, but there is very little available information on the mechanisms that govern these differences (see Bell et al. 2015 for review) and is an important area of future research. Extensive research into sediment tolerance has been conducted in corals, with differences in passive and active response capacity determining abundances in highly sedimented habitats (Lasker 1980; Rogers 1990; Riegl 1995; Gleason 1998; Bongaerts et al. 2012). There is evidence of passive clearing of limited amounts of sediment in C. orientalis (Schönberg 2015b), but no studies have directly studied active clearing mechanisms in these sponges. Species composition data from Sampela suggest that $\alpha$ growth forms may be better equipped to inhabit highly sedimented environments, perhaps due to the sieve-like villi formations on the inhalant papillae. These morphological structures may aid sediment clearing or prevent sediment inhalation. In fact sponges were often found under a considerable depth of settled sediment suggesting that they are capable of pumping interstitial water (Illan \& Abelson 1995). Although permanent burial is unlikely a long term option for zooxanthellate species such as $C$. aff. viridis n. sp. B (which is common at Sampela) and some form of active sediment clearing mechanisms is likely required. One aspect of passive sediment clearance that has received no attention is the role that nonsponge reef taxa can have. Time-lapse cameras deployed facing S. cf. vagabunda at B3 and B1 
showed extensive surface feeding by Holothurians (Synaptula spp.) and reef fish (predominantly Ctenochaetus spp.), which reduced surface sediment (Electronic Supplementary Material). Whether these organisms are active spongivores or feeding on either surface biofilm or sponge mucus (potentially produced due to sedimentation; Biggerstaff et al. (2017)) and the importance of this feeding as a sediment clearance mechanism is an interesting area of future research. Finally, my data also suggest that moderate sedimentation inhibits erosion rates in $S$. cf. vagabunda, possibly through diversion of metabolic activity to morphological changes. For those bioeroding sponge species that are able to tolerate sedimented environments through active sediment rejection mechanisms, it is important that we understand how these responses effect erosion rates

My study and others have demonstrated that zooxanthellate bioeroding sponges are able to photoacclimate and survive during prolonged periods of extremely reduced or elevated light availability (Steindler et al. 2001; Pineda et al. 2016; Fang et al. 2017a). However, reduced erosion rates and unchanged heterotophic feeding in shaded $C$. orientalis indicate that low light acclimated Symbiodnium are not necessarily providing the same nutritional content to their hosts as in higher light environments (Schönberg 2006; Fang et al. 2017a). Future research into photoacclimation could benefit from integrating not only PAM fluorometry, respiration assessments and measurements of organic carbon uptake, but also the use of stable isotopes to trace changes in translocated carbon.

At the global scale, the warming event in the Caribbean in 2015 was the first documented mass bleaching of bioeroding sponges (Hill et al. 2016) and a similar bleaching event and subsequent recovery in $C$. viridis n. sp. A was observed in the Wakatobi in 2016 (Fig 7.1). These observations are contrary to the previously held belief that the Cliona-Symbiodinium symbiosis was generally more thermally tolerant than in Cnidarian hosts (Vicente 1990; Schönberg \& Loh 2005). It is critically important that we understand not just the thermal tolerance of these sponges but also the capacity to recover from bleaching and the physiological mechanisms that allow this. In particular, future research should focus on the ability for these sponges to regulate Symbiodinium cladal composition in relation to thermal stress. While some clionaid species appear to be only associated with one clade of Symbiodinium, e.g. Clade G in C. orientalis and C. varians (Schönberg \& Loh 2005; Granados et al. 2008; Hill et al. 2011), my thesis has shown that $C$. aff. viridis n. sp. A is able to form symbioses with three separate clades and host multiple 
clades within the same individual sponge. The ability to host different clades of Symbiodinium is important for term long term survival on thermally stressed reefs, as different clades are known to differ in their thermal tolerance (Rowan 2004; Tchernov et al. 2004). If zooxanthellate bioeroding sponges are able to shuffle the relative abundance of these clades or acquire more thermally tolerant Symbiodinium from the environment, then this would constitute a distinct adaptive advantage.

\subsection{Concluding remarks}

To conclude, bioeroding sponges within the Wakatabi are taxonomically and morphologically diverse and found to varying degrees in all reef environments. Bioeroding sponge adult abundance is primarily a function of the availability of dead calcareous substrate but speciesspecific differences in recruitment and stressor resilience further structure populations. Overall, reef degradation in the region is expected to stimulate abundance increases. However, the exact trajectory is expected to be dependent upon the nature of the disturbance and the biology of individual species. The consequences of increasing sponge bioerosion, coinciding with reductions in calcium carbonate accretion rates is likely to have substantial ecological and economic consequences for Southeast Asian reefs and coastal communities. To avoid the worst of these consequences, local monitoring needs to include assessments of carbonate budgets to best inform local management. Reef management at these scales needs to include increasing numbers of enforced MPAs and fishing regulations that prioritise the preservation of functional groups to enhance reef resilience. Unfortunately, the biggest drivers of bioerosion sponge abundance and erosion and continuing declines in coral reef carbonate budgets is likely to be climate change. Unless large reductions are made in atmospheric $\mathrm{CO}_{2}$, even the most vigorous coral reef management and conservation is unlikely to avoid largescale coral mortalities and dismantling of calcareous framework. 


\section{References}

Acker KL and Risk MJ (1985) Substrate destruction and sediment production by the boring sponge Cliona caribbaea on Grand Cayman Island. J Sediment Petrol 55:705-711

Aerts LA and van Soest R (1997) Quantification of sponge/coral interactions in a physically stressed reef community, NE Colombia. Mar Ecol Prog Ser 148:125-134

Aerts LA (2000) Dynamics behind standoff interactions in three reef sponge species and the coral Montastraea cavernosa. Mar Ecol 21:191-204

Alcala AC and Gomez ED (1987) Dynamiting coral reefs for fish: a resource-destructive fishing method. In: Salvat B (ed) Human impacts on coral reefs: facts and recommendations. Antenne Museum EPHE, French Polynesia, p 52-60

Alve E (1999) Colonization of new habitats by benthic foraminifera: A review. Earth Sci Rev 46:167-185

Alvarez-Filip L, Dulvy NK, Gill JA, Cote IM, Watkinson AR (2009) Flattening of Caribbean coral reefs: Region-wide declines in architectural complexity. Proc Biol Sci 276:3019-3025

Alvarez-Filip L, Gill JA, Dulvy NK, Perry AL, Watkinson AR, Côté IM (2011) Drivers of region-wide declines in architectural complexity on Caribbean reefs. Coral Reefs 30:10511060

Amir I (1992) A comparison of sponge fauna of exposed and sheltered reef flats in eastern Indonesia. Mar Res Indonesia 28:1-12

Anderson M, Gorley R, Clarke K (2007) PERMANOVA for PRIMER: Guide to software and statistical methods. PRIMER-E, Plymouth

Annandale N (1915) Indian boring sponges of the family Clionidae. Rec Indian Mus 11:1-24

Anthony KR and Fabricius KE (2000) Shifting roles of heterotrophy and autotrophy in coral energetics under varying turbidity. J Exp Mar Bio Ecol 252:221-253

Anthony KR and Hoegh-Guldberg O (2003) Kinetics of photoacclimation in corals. Oecologia $134: 23-31$

Arnold SN and Steneck RS (2011) Settling into an increasingly hostile world: The rapidly closing "recruitment window" for corals. PLoS One 6:e28681 
Aronson RB and Precht WF (2001) White-band disease and the changing face of Caribbean coral reefs. Hydrobiologia 460:25-38

Aronson R, Precht W, Toscano M, Koltes K (2002) The 1998 bleaching event and its aftermath on a coral reef in Belize. Mar Biol 141:435-447

Ateweberhan M, Feary DA, Keshavmurthy S, Chen A, Schleyer MH, Sheppard CRC (2013) Climate change impacts on coral reefs: synergies with local effects, possibilities for acclimation, and management implications. Mar Pollut Bull 74:526-539

Bak R, Lambrechts D, Joenje M, Nieuwland G, Van Veghel M (1996) Long-term changes on coral reefs in booming populations of a competitive colonial ascidian. Mar Ecol Prog Ser 133:303-306

Baker AC and Romanski AM (2007) Multiple symbiotic partnerships are common in scleractinian corals, but not in octocorals: Comment on Goulet (2006). Mar Ecol Prog Ser $335: 237-42$

Ban SS, Graham NA, Connolly SR (2014) Evidence for multiple stressor interactions and effects on coral reefs. Glob Change Biol 20:681-697

Bannister R, Battershill C, De Nys R (2012) Suspended sediment grain size and mineralogy across the continental shelf of the Great Barrier Reef: Impacts on the physiology of a coral reef sponge. Cont Shelf Res 32:86-95

Bartley R, Bainbridge ZT, Lewis SE, Kroon FJ, Wilkinson SN, Brodie JE, Silburn DM (2014) Relating sediment impacts on coral reefs to watershed sources, processes and management: A review. Sci Total Environ 468:1138-1153

Barucca M, Azzini F, Bavestrello G, Biscotti MA, Calcinai B, Canapa A, Cerrano C, Olmo E (2007) The systematic position of some boring sponges (Demospongiae, Hadromerida) studied by molecular analysis. Mar Biol 151:529-535

Baum G, Januar HI, Ferse SC, Kunzmann A (2015) Local and regional impacts of pollution on coral reefs along the Thousand Islands north of the megacity Jakarta, Indonesia. PloS one 10:e0138271.

Bautista-Guerrero E, Carballo JL, Maldonado M (2010) Reproductive cycle of the coral-excavating sponge Thoosa mismalolli (Clionaidae) from Mexican Pacific coral reefs. Invertebr Biol 129:285-296 
Bautista-Guerrero E, Carballo JL, Maldonado M (2014) Abundance and reproductive patterns of the excavating sponge Cliona vermifera: A threat to pacific coral reefs? Coral Reefs 33:259266

Bautista-Guerrero E, Carballo JL, Aguilar-Camacho JM, Sifuentes-Romero I (2016) Molecular and morphological differentiation of sympatric larvae of coral excavating sponges of genus Thoosa. Zoomorphology 135:159-165

Bavestrello G, Bonito M, Sarà M (1993) Influence of depth on the size of sponge spicules. Sci Mar 57:415-420

Beer S and Ilan M (1998) In situ measurements of photosynthetic irradiance responses of two Red Sea sponges growing under dim light conditions. Mar Biol 131:613-617

Beer S, Ilan M, Eshel A, Weil A, Brickner I (1998) Use of pulse amplitude modulated (PAM) fluorometry for in situ measurements of photosynthesis in two Red Sea faviid corals. Mar Biol 131:607-612

Bell JJ, Barnes DK (2000) The distribution and prevalence of sponges in relation to environmental gradients within a temperate sea lough: Vertical cliff surfaces. Divers Distrib 6:283-303

Bell JJ and Smith D (2004) Ecology of sponge assemblages (Porifera) in the Wakatobi region, south-east Sulawesi, Indonesia: Richness and abundance. J Mar Biol Assoc UK 84:581-591

Bell JJ (2008) The functional roles of marine sponges. Estuar Coast Shelf Sci 79:341-353

Bell JJ, Berman J, Jones T, Hepburn LJ (2010) Variability in the spatial association patterns of sponge assemblages in response to environmental heterogeneity. Mar Biol 157:2503-2509

Bell JJ, Davy SK, Jones T, Taylor MW, Webster NS (2013) Could some coral reefs become sponge reefs as our climate changes? Glob Change Biol 19:2613-2624

Bell JJ, McGrath E, Biggerstaff A, Bates T, Bennett H, Marlow J, Shaffer M (2015) Sediment impacts on marine sponges. Mar Pollut Bull 94:5-13

Bellwood DR, Hoey AS, Choat JH (2003) Limited functional redundancy in high diversity systems: resilience and ecosystem function on coral reefs. Ecol Lett 6:281-285

Bellwood DR, Hughes TP, Folke C, Nyström M (2004) Confronting the coral reef crisis. Nature 429:827-833 
Bergman KM (1983) The distribution and ecological significance of the boring sponge Cliona viridis on the Great Barrier Reef, Australia. MSc Thesis, MacMaster University, Hamilton

Bergquist PR (1965) The sponges of Micronesia, part I. The Palau archipelago. Pac Sci 19:123204

Beukers JS and Jones GP (1998) Habitat complexity modifies the impact of piscivores on a coral reef fish population. Oecologia 114:50-59

Biggerstaff A, Smith DJ, Jompa J, Bell JJ (2015) Photoacclimation supports environmental tolerance of a sponge to turbid low-light conditions. Coral Reefs 34:1049-1061

Biggerstaff A, Smith DJ, Jompa J, Bell JJ (2017) Metabolic responses of a phototrophic sponge to sedimentation supports transitions to sponge-dominated reefs. Sci Rep 7:2725

Biggs BC (2013) Harnessing natural recovery processes to improve restoration outcomes: An experimental assessment of sponge-mediated coral reef restoration. PloS One 8:e64945

Birkeland C (1977) The importance of rate of biomass accumulation in early successional stages of benthic communities to the survival of coral recruits. Proc 3rd Int Coral Reef Symp 1:1521

Bongaerts P, Hoeksema B, Hay K, Hoegh-Guldberg O (2012) Mushroom corals overcome live burial through pulsed inflation. Coral Reefs 31:399-399

Borchiellini C, Chombard C, Lafay B, Boury-Esnault N (2000) Molecular systematics of sponges (Porifera). Hydrobiologia 420:15-27

Bouchet P and Duarte CM (2006) The exploration of marine biodiversity scientific and technological challenges. Fundación BBVA 33

Briggs JC (2005) The marine East Indies: diversity and speciation. J Biogeogr 32:1517-1522

Bruno JF and Bertness MD (2001) Habitat modification and facilitation in benthic marine communities. Mar Community Ecol 413:201-218

Bruno JF and Selig ER (2007) Regional decline of coral cover in the Indo-Pacific: Timing, extent, and subregional comparisons. PLoS One 2:e711

Bruno JF, Sweatman H, Precht WF, Selig ER, Schutte VG (2009) Assessing evidence of phase shifts from coral to macroalgal dominance on coral reefs. Ecology 90:1478-1484 
Brunton FR and Dixon OA (1994) Siliceous sponge-microbe biotic associations and their recurrence through the Phanerozoic as reef mound constructors. Palaios 9:370-387

Burke LM, Reytar K, Spalding M, Perry A (2011) Reefs at risk revisited. World Resources Institute Washington, DC

Burnham KP and Anderson DR (2004) Multimodel inference understanding AIC and BIC in model selection. Sociol Methods Res 33:261-304

Caballero H, Busutil L, García Y, Alcolado PM (2009) Variación espacial en comunidades de esponjas de la costa oriental de Bahía de Cochinos, Cuba. Rev Cienc Mar Cost 1:95-109

Calcinai B, Cerrano C, Sarà M, Bavestrello G (2000) Boring sponges (Porifera, Demospongiae) from the Indian Ocean. Ital J Zool 67:203-219

Calcinai B, Arillo A, Cerrano C, Bavestrello G (2003) Taxonomy-related differences in the excavating micro-patterns of boring sponges. J Mar Biol Assoc UK 83:37-39

Calcinai B, Bavestrello G, Cerrano C (2004) Bioerosion micro-patterns as diagnostic characteristics in boring sponges. Boll Mus Ist Biol Univ Genova 68:229-238

Calcinai B, Bavestrello G, Cerrano C (2005) Excavating sponge species from the Indo-Pacific Ocean. Zool Stud 44:5-18

Calcinai B, Azzini F, Bavestrello G, Cerrano C, Pansini M, Thung D (2006) Boring sponges from the Ha Long Bay, Tonkin Gulf, Vietnam. Zool Stud 45:201

Calcinai B, Azzini F, Bavestrello G, Gaggero L, Cerrano C (2007) Excavating rates and boring pattern of Cliona albimarginata (Porifera: Clionaidae) in different substrata. In Custodio MR, Lobo-Hajdu G, Hajdu E, Muricy G (eds) Porifera Research: Biodiversity, Innovation \& Sustainability. Museo Nacional, Rio de Janeiro, p 203-210

Calcinai B, Cerrano C, Iwasaki N, Bavestrello G (2008) Sponges boring into precious corals: An overview with description of a new species of Alectona (Demospongiae, Alectonidae) and a worldwide identification key for the genus. Mar Ecol 29:273-279

Caley MJ, Carr MH, Hixon MA, Hughes TP, Jones GP, Menge BA (1996) Recruitment and the local dynamics of open marine populations. Annu Rev Ecol Syst 27: 477-500

Callahan MK (2005) Distribution of clionid sponges in the Florida Keys National Marine Sanctuary (FKNMS), 2001-2003. MSc thesis, University of South Florida, Tampa, USA. Available at http://scholarcommons.usf.edu/etd/2803/ (last accessed on 17 June 2017) 
Carballo JL, Sanchez-Moyano J, Garcia-Gomez J (1994) Taxonomic and ecological remarks on boring sponges (Clionidae) from the Straits of Gibraltar (Southern Spain): Tentative bioindicators? Zool J Linn Soc 112:407-424

Carballo JL, Naranjo S, García-Gómez J (1996) Use of marine sponges as stress indicators in marine ecosystems at Algeciras Bay (southern Iberian Peninsula). Mar Ecol Prog Ser $135: 109-122$

Carballo JL (2006) Effect of natural sedimentation on the structure of tropical rocky sponge assemblages. Ecoscience 13:119-130

Carballo JL, Bautista-Guerrero E, Leyte-Morales GE (2008a) Boring sponges and the modelling of coral reefs in the east Pacific Ocean. Mar Ecol Prog Ser 356:113-122

Carballo JL, Vega C, Cruz-Barraza JA, Yanez B, Nava H, Avila E, Wilson M (2008b) Short-and long-term patterns of sponge diversity on a rocky tropical coast: Evidence of large-scale structuring factors. Mar Ecol 29:216-236

Carballo JL, Bautista E, Nava H, Cruz-Barraza JA, Chávez JA (2013) Boring sponges, an increasing threat for coral reefs affected by bleaching events. Ecol Evol 3:872-886

Carlos AA, Baillie BK, Kawachi M, Maruyama T (1999) Phylogenetic position of Symbiodinium (Dinophyceae) isolates from tridacnids (Bivalvia), cardiids (Bivalvia), a sponge (Borifera), a soft coral (Anthozoa), and a free-living strain. J Phycol 35:1054-1062

Carter, HJ (1879) Contributions to our knowledge of the Spongida. Ann Mag Nat Hist 3: 284304, 343-360

Carter H (1882) Some sponges from the West Indies and Acapulco in the Liverpool free museum described, with general and classificatory remarks. J Nat Hist 9:266-301

Cebrian E (2010) Grazing on coral reefs facilitates growth of the excavating sponge Cliona orientalis (Clionaidae, Hadromerida). Mar Ecol 31:533-538

Chadwick NE and Morrow KM (2011) Competition among sessile organisms on coral reefs. In: Dubinsky $\mathrm{Z}$ and Stambler $\mathrm{N}$ (eds) Coral reefs: An eco system in transition. Springer, Dordrecht, p 347-371

Chalker B, Dunlap W, Oliver J (1983) Bathymetric adaptations of reef-building corals at Davies Reef, Great Barrier Reef, Australia. II. Light saturation curves for photosynthesis and respiration. J Exp Mar Biol Ecol 73:37-56 
Chaves-Fonnegra A and Zea S (2007) Observations on reef coral undermining by the Caribbean excavating sponge Cliona delitrix (Demospongiae, Hadromerida). In: Custódio MR, LôboHajdu G, Hajdu E, Muricy G (eds) Porifera research. Biodiversity, innovation and sustainability. Série Livros 28. Museu Nacional, Rio de Janeiro, p 247-254

Chaves-Fonnegra A, Zea S, Gómez ML (2007) Abundance of the excavating sponge Cliona delitrix in relation to sewage discharge at San Andrés Island, SW Caribbean, Colombia. Bol Invest Mar Cost 36:63-78

Chaves-Fonnegra A and Zea S (2011) Coral colonization by the encrusting excavating Caribbean sponge Cliona delitrix. Mar Ecol 32:162-173

Chaves-Fonnegra A, Feldheim KA, Secord J, Lopez JV (2015) Population structure and dispersal of the coral-excavating sponge Cliona delitrix. Mol Ecol 24:1447-1466

Chaves-Fonnegra A, Maldonado M, Blackwelder P, Lopez JV (2016) Asynchronous reproduction and multi-spawning in the coral-excavating sponge Cliona delitrix. J Mar Biol Assoc UK 96:515-28

Cheal A, MacNeil MA, Cripps E, Emslie M, Jonker M, Schaffelke B, Sweatman H (2010) Coral-macroalgal phase shifts or reef resilience: Links with diversity and functional roles of herbivorous fishes on the Great Barrier Reef. Coral Reefs 29:1005-1015

Christie P and White AT (2007) Best practices for improved governance of coral reef marine protected areas. Coral Reefs 26:1047-1056

Clarke KR (1993) Non-parametric multivariate analyses of changes in community structure. Aust J Ecol 18:117-117

Clarke KR and Gorley RN (2006) PRIMER v6: User Manual/Tutorial. PRIMER-E, Plymouth

Clarke KR, Somerfield PJ, Chapman MG (2006) On resemblance measures for ecological studies, including taxonomic dissimilarities and a zero-adjusted Bray-Curtis coefficient for denuded assemblages. J Exp Mar Biol Ecol 330:55-80

Cleary DF, Polónia AR, Renema W, Hoeksema BW, Wolstenholme J, Tuti Y, de Voogd NJ (2014) Coral reefs next to a major conurbation: a study of temporal change (1985-2011) in coral cover and composition in the reefs of Jakarta, Indonesia. Mar Ecol Prog Ser 501:89-98

Clifton J, Unsworth RK, Smith DJ (2010) Marine research and conservation in the Coral Triangle: the Wakatobi National Park. Nova Science Publishers, New York 
Clifton J and Majors C (2012) Culture, conservation and conflict: perspectives on marine protection amongst the Bajau of south-east Asia. Soc Nat Resour 25:716-725

Clifton J (2013) Compensation, conservation and communities: an analysis of direct payments initiatives in an Indonesian marine protected area. Environ Conserve 40: 287-295

Cobb WR (1969) Penetration of calcium carbonate substrates by the boring sponge, Cliona. Am Zool 9:783-790

Cohen I and Dubinsky Z (2015) Long term photoacclimation responses of the coral Stylophora pistillata to reciprocal deep to shallow transplantation: photosynthesis and calcification. Front Mar Sci 2:45

Collier CJ, Lavery PS, Ralph PJ, Masini RJ (2009) Shade-induced response and recovery of the seagrass Posidonia sinuosa. J Exp Mar Biol Ecol 370:89-103

Connell JH, Hughes TP, Wallace CC, Tanner JE, Harms KE, Kerr AM (2004) A long-term study of competition and diversity of corals. Ecol Monogr 74:179-210

Crabbe JM and Smith DJ (2002) Comparison of two reef sites in the Wakatobi Marine National Park (SE Sulawesi, Indonesia) using digital image analysis. Coral Reefs 21:242-244

Crabbe JM, Karaviotis S, Smith DJ (2004) Preliminary comparison of three coral reef site s in the Wakatobi Marine National Park (SE Sulawesi, Indonesia): estimated recruitment dates compared with Discovery Bay, Jamaica. Bull Mar Sci 74:469-476

Crabbe JM and Smith DJ (2005) Sediment impacts on growth rates of Acropora and Porites corals from fringing reefs of Sulawesi, Indonesia. Coral Reefs 24:437-441

Cruz-Barraza JA, Carballo JL, Bautista-Guerrero E, Nava H (2011) New species of excavating sponges (Porifera: Demospongiae) on coral reefs from the Mexican pacific ocean. J Mar Biol Assoc UK 91:999-1013

Cullen LC, Pretty J, Smith D, Pilgrim SE (2007) Links between local ecological knowledge and wealth in indigenous communities of Indonesia: Implications for conservation of marine resources. Int J Interdiscip Soc Sci 2:289-299

Cullen LC (2010) Marine resource dependence and natural resource use patterns in a small IndoPacific island community: implications for management. In Clifton J, Unsworth RKF, Smith DJ (eds) Marine research and conservation in the Coral Triangle: the Wakatobi National Park. Nova Publishers, New York, p 71-92 
Curtis-Quick JA (2013) Drivers of change of reef fish assemblages within the coral triangle. PhD Thesis, University of Essex, Colchester

d'Orbigny A (1850) Prodrome de Paléontologie stratigraphique universelle des animaux mollusques et rayonnés faisant suite au cours élémentaire de Paléontologie et de Géologie stratigraphiques. Masson, Paris

de Caralt S, Otjens H, Uriz MJ, Wijffels RH (2007) Cultivation of sponge larvae: Settlement, survival, and growth of juveniles. Mar Biotechnol 9:592-605

de Goeij JM, van Oevelen D, Vermeij MJ, Osinga R, Middelburg JJ, de Goeij AF, Admiraal W (2013) Surviving in a marine desert: The sponge loop retains resources within coral reefs. Science 342:108-110

de Groot R, Brander L, van der Ploeg S, Costanza R, Bernard F, Braat L, Christie M, Crossman N, Ghermandi A, Hein L, Hussain S, Kumar P, McVittie A, Portela R, Rodriguez LC, ten Brink P, van Beukering P (2012) Global estimates of the value of ecosystems and their services in monetary units. Ecosyst Serv 1:50-61

de Laubenfels MW (1936) A discussion of the sponge fauna of the Dry Tortugas in particular and the West Indies in general: With material for a revision of the families and orders of the Porifera. Carnegie institution of Washington, Washington

de Laubenfels MW (1954) The sponges of the west-central pacific. Oregon State College press, Oregon

de Voogd NJ, Becking LE, Hoeksema BW, van Soest R (2004) Sponge interactions with spatial competitors in the Spermonde Archipelago. Boll Mus Ist Biol Univ Genova 68:253-261

de Voogd NJ, Cleary DF, Hoeksema BW, Noor A, van Soest RWM (2006) Sponge beta diversity in the Spermonde Archipelago, SW Sulawesi, Indonesia. Mar Ecol Prog Ser 309:131-142

De'ath G, Lough JM, Fabricius KE (2009) Declining coral calcification on the Great Barrier Reef. Science 323:116-119

De'ath $\mathrm{G}$ and Fabricius K (2010) Water quality as a regional driver of coral biodiversity and macroalgae on the Great Barrier Reef. Ecol Appl 20:840-850

De'ath G, Fabricius KE, Sweatman H, Puotinen M (2012) The 27-year decline of coral cover on the Great Barrier Reef and its causes. Proc Natl Acad Sci USA 109:17995-17999 
DeCarlo TM, Cohen AL, Wong GT, Davis KA, Lohmann P, Soong K (2017) Mass coral mortality under local amplification of $2{ }^{\circ} \mathrm{C}$ ocean warming. Sci Rep 7:44586

Dendy A (1887) XVI. The sponge-fauna of Madras. A report on a collection of sponges obtained in the neighbourhood of Madras by Edgar Thurston, esq. J Nat Hist 20:153-165

Dendy A (1905) Report on the sponges collected by Professor Herdman at Ceylon, in 1902. In: Herdman, WA (ed) Report to the Government of Ceylon on the Pearl Oyster Fisheries of the Gulf of Manaar. Royal Society, London

Dendy A (1922) Report on the Sigmatotetraxonida collected by H.M.S. 'Sealark' in the Indian Ocean. In: Gardner JS (ed) Reports of the Percy Sladen Trust Expedition to the Indian Ocean in 1905, Volume 7. Transactions of the Linnean Society of London, London

Diaz MC and Rützler K (2001) Sponges: An essential component of Caribbean coral reefs. Bull Mar Sci 69:535-546

Dikou A and van Woesik R (2006) Survival under chronic stress from sediment load: Spatial patterns of hard coral communities in the southern islands of Singapore. Mar Pollut Bull $52: 7-21$

Done TJ and Jones R (2006) Tropical coastal ecosystems and climate change prediction: Global and local risks. Coast Estuar Stud 61:5-32

Donner SD, Skirving WJ, Little CM, Oppenheimer M, Hoegh-Guldberg O (2005) Global assessment of coral bleaching and required rates of adaptation under climate change. Glob Change Biol 11:2251-2265

Doty MS (1971) Measurement of water movement in reference to benthic algal growth. Bot Mar $14: 32-35$

Driscoll EG (1967) Attached epifauna - substrate relations. Limnol Oceanogr 12:633-41

Duckworth AR, Battershill CN, Schiel DR (2004) Effects of depth and water flow on growth, survival and bioactivity of two temperate sponges cultured in different seasons. Aquaculture $242: 237-250$

Duckworth AR and Peterson BJ (2013) Effects of seawater temperature and $\mathrm{pH}$ on the boring rates of the sponge Cliona celata in scallop shells. Mar Biol 160:27-35

Dunstan P and Johnson C (1998) Spatio-temporal variation in coral recruitment at different scales on Heron Reef, southern Great Barrier Reef. Coral Reefs 17:71-81 
Eakin CM (2001) A tale of two ENSO events: Carbonate budgets and the influence of two warming disturbances and intervening variability, Uva Island, Panama. Bull Mar Sci 69:171-186

Eakin CM, Morgan JA, Heron SF, Smith TB, Liu G, Alvarez-Filip L, Baca B, Bartels E, Bastidas C, Bouchon C (2010) Caribbean corals in crisis: Record thermal stress, bleaching, and mortality in 2005. PloS One 5:e13969

Eakin C, Liu G, Gomez A, De la Cour J, Heron S, Skirving W, Geiger E, Tirak K, Strong A (2016) Global coral bleaching 2014-2017: Status and an appeal for observations. Reef Encounter 31:20-26

Edinger EN and Risk MJ (1996) Sponge borehole size as a relative measure of bioerosion and paleoproductivity. Lethaia 29:275-286

Edinger EN, Limmon GV, Jompa J, Widjatmoko W, Heikoop JM, Risk MJ (1998) Reef degradation and coral biodiversity in Indonesia: effects of land-based pollution, destructive fishing practices and changes over time. Mar Pollut Bull 36:617-630

Edinger EN, Limmon GV, Jompa J, Widjatmoko W, Heikoop JM, Risk MJ (2000) Normal coral growth rates on dying reefs: Are coral growth rates good indicators of reef health? Mar Pollut Bull 40:404-425

Edmunds PJ and Elahi R (2007) The demographics of a 15-year decline in cover of the Caribbean reef coral Montastrea annularis. Ecol Monogr 77:3-18

Edwards AJ and Gomez ED (2007) Reef restoration concepts and guidelines: Making sensible management choices in the face of uncertainty. Coral Reef Targeted Research \& Capacity Building for Management Programme, St Lucia

Einbinder S, Mass T, Brokovich E, Dubinsky Z, Erez J, Tchernov D (2009) Changes in morphology and diet of the coral Stylophora pistillata along a depth gradient. Mar Ecol Prog Ser 381:167-174

Elmer F (2016) Factors affecting coral recruitment and calcium carbonate accretion rates on a Central Pacific coral reef. $\mathrm{PhD}$ thesis, Victoria University of Wellington, Wellington http://researcharchive.vuw.ac.nz/xmlui/handle/10063/6148 (last accessed 31 May 2017)

Endean R (1976) Destruction and recovery of coral reef communities. In: Jones OA and Endean R (eds) Biology and Geology of Coral Reefs, Vol 3, Biology 2. Academic, New York, p 215-254 
English SS, Wilkinson CC, Baker VV (1994) Survey manual for tropical marine resources. Line intercept transect. Australian Institute of Marine Science, Townsville

Enochs IC and Manzello DP (2012) Species richness of motile cryptofauna across a gradient of reef framework erosion. Coral Reefs 31:653-661

Enochs IC, Manzello DP, Carlton RD, Graham DM, Ruzicka R, Colella MA (2015) Ocean acidification enhances the bioerosion of a common coral reef sponge: implications for the persistence of the Florida Reef Tract. Bull Mar Sci 91:271-290

Erdmann MV (2000) Destructive fishing practices in Indonesian seas. In: Sheppard C (ed) Seas at the millennium: an environmental evaluation. Pergamon, Amsterdam, p 392-393

Erftemeijer PL, Riegl B, Hoeksema BW, Todd PA (2012) Environmental impacts of dredging and other sediment disturbances on corals: A review. Mar Pollut Bull 64:1737-1765

Escobar D, Zea S, Sánchez JA (2012) Phylogenetic relationships among the Caribbean members of the Cliona viridis complex (Porifera, Demospongiae, Hadromerida) using nuclear and mitochondrial DNA sequences. Mol Phylogenet Evol 64:271-284

Fabricius KE (2005) Effects of terrestrial runoff on the ecology of corals and coral reefs: Review and synthesis. Mar Pollut Bull 50:125-146

Fairfull S and Harriott V (1999) Succession, space and coral recruitment in a subtropical fouling community. Mar Freshwater Res 50:235-242

Falkowski, PG (1980) Light-shade adaptation in marine phytoplankton. In Falkowski PG (ed) Primary productivity in the sea. Springer, New York, p 99-117

Falkowski PG and Dubinsky Z (1981) Light-shade adaptation of Stylophora pistillata, a hermatypic coral from the Gulf of Eilat. Nature 289:172-174

Falkowski PG and Raven JA (2013) Aquatic photosynthesis. Princeton University Press, NJ

Fang JKH, Mello-Athayde MA, Schönberg CHL, Kline DI, Hoegh-Guldberg O, Dove S (2013) Sponge biomass and bioerosion rates increase under ocean warming and acidification. Glob Change Biol 19:3581-3591

Fang JKH, Schönberg CHL, Mello-Athayde MA, Hoegh-Guldberg O, Dove S (2014) Effects of ocean warming and acidification on the energy budget of an excavating sponge. Glob Change Biol 20:1043-1054

Fang JKH, Schönberg CHL, Hoegh-Guldberg O, Dove S (2016) Day-night ecophysiology of the photosymbiotic bioeroding sponge Cliona orientalis Thiele, 1900. Mar Biol 163:1-12 
Fang JKH, Schönberg CHL, Hoegh-Guldberg O, Dove S (2017a) Symbiotic plasticity of Symbiodinium in a common excavating sponge. Mar Biol 164:104

Fang JKH, Mason RA, Schönberg CHL, Hoegh-Guldberg O, Dove S (2017b) Studying interactions between excavating sponges and massive corals by the use of hybrid cores. Mar Ecol 38:e12393

Field S, Glassom D, Bythell J (2007) Effects of artificial settlement plate materials and methods of deployment on the sessile epibenthic community development in a tropical environment. Coral Reefs 26:279-289

Fine M, Steindler L, Loya Y (2004) Endolithic algae photoacclimate to increased irradiance during coral bleaching. Mar Freshwater Res 55:115-121

Fitt WK, McFarland F, Warner ME, Chilcoat GC (2000) Seasonal patterns of tissue biomass and densities of symbiotic dinoflagellates in reef corals and relation to coral bleaching. Limnol Oceanogr 45:677-685

Foster NL, Box SJ, Mumby PJ (2008) Competitive effects of macroalgae on the fecundity of the reef-building coral Montastraea annularis. Mar Ecol Prog Ser 367:143-152

Fox HE, Pet JS, Dahuri R, Caldwell RL (2003) Recovery in rubble fields: Long-term impacts of blast fishing. Mar Pollut Bull 46:1024-1031

Frieler K, Meinshausen M, Golly A, Mengel M, Lebek K, Donner SD, Hoegh-Guldberg O (2013) Limiting global warming to $2{ }^{\circ} \mathrm{C}$ is unlikely to save most coral reefs. Nat Clim Change 3:165-70

Fromont J, Craig R, Rawlinson L, Alder J (2005) Excavating sponges that are destructive to farmed pearl oysters in western and northern Australia. Aquacult Res 36:150-162

Fung T, Seymour RM, Johnson CR (2011) Alternative stable states and phase shifts in coral reefs under anthropogenic stress. Ecology 92:967-982

Gardner TA, Cote IM, Gill JA, Grant A, Watkinson AR (2003) Long-term region-wide declines in Caribbean corals. Science 301:958-960

Garson M, Flowers AE, Webb RI, Charan RD, McCaffrey EJ (1998) A sponge/dinoflagellate association in the haplosclerid sponge Haliclona sp.: Cellular origin of cytotoxic alkaloids by Percoll density gradient fractionation. Cell Tissue Res 293:365-373

Gerrodette T and Flechsig A (1979) Sediment-induced reduction in the pumping rate of the tropical sponge Verongia lacunosa. Mar Biol 55:103-110 
Gilliam D, Dodge R, Spieler R, Jordan L, Goergen E (2010) Marine biological monitoring in Broward County, Florida: Year 9 Annual Report. Prepared for the BC Board of County Commissioners, BC Natural Resources Planning and Management Division, Fort Lauderdale, FL

Glassom D, Zakai D, Chadwick-Furman N (2004) Coral recruitment: A spatio-temporal analysis along the coastline of Eilat, northern Red Sea. Mar Biol 144:641-651

Glynn PW (1984) Widespread coral mortality and the 1982-83 El Niño warming event. Environ Conserv 11:133-146

Glynn PW (1988) El Niño warming, coral mortality and reef framework destruction by echinoid bioerosion in the eastern Pacific. Galaxea 7:129-160

Glynn PW and Colgan MW (1992) Sporadic disturbances in fluctuating coral reef environments: El Niño and coral reef development in the eastern Pacific. Am Zool 32:707-718

Glynn PW (1994) State of coral reefs in the Galápagos Islands: Natural vs anthropogenic impacts. Mar Pollut Bull 29:131-140

Glynn PW (1997) Bioerosion and coral-reef growth. In: Birkeland C (ed) Life and death of coral reefs. Chapman \& Hall, New York, p 69-98

Glynn PW and Manzello DP (2015) Bioerosion and coral reef growth: A dynamic balance. In: Birkeland C (ed) Coral reefs in the Anthropocene. Springer, Netherlands, p 67-97

Gleason DF (1998) Sedimentation and distributions of green and brown morphs of the Caribbean coral Porites astreoides Lamarck. J Exp Mar Biol Ecol 230:73-89

Golbuu Y, Van Woesik R, Richmond RH, Harrison P, Fabricius KE (2011) River discharge reduces reef coral diversity in Palau. Mar Pollut Bull 62:824-831

González-Rivero M, Yakob L, Mumby PJ (2011) The role of sponge competition on coral reef alternative steady states. Ecol Modell 222:1847-18 53.

González-Rivero M, Ferrari R, Schönberg CH, Mumby PJ (2012) Impacts of macroalgal competition and parrotfish predation on the growth of a common bioeroding sponge. Mar Ecol Prog Ser 444:133-142

González-Rivero M, Ereskovsky AV, Schönberg CH, Ferrari R, Fromont J, Mumby PJ (2013) Life-history traits of a common Caribbean coral-excavating sponge, Cliona tenuis (Porifera: Hadromerida). J Nat Hist 47:2815-2834 
Goreau T, McClanahan T, Hayes R, Strong A (2000) Conservation of coral reefs after the 1998 global bleaching event. Conserv Biol 14:5-15

Granados C, Camargo C, Zea S, Sánchez J (2008) Phylogenetic relationships among zooxanthellae (Symbiodinium) associated to excavating sponges (Cliona spp.) reveal an unexpected lineage in the Caribbean. Mol Phylogenet Evol 49:554-560

Graham NA, Wilson SK, Jennings S, Polunin NV, Bijoux JP, Robinson J (2006) Dynamic fragility of oceanic coral reef ecosystems. Proc Natl Acad Sci USA 103:8425-8429

Graham NA, Wilson SK, Jennings S, Polunin NV, Robinson J, Bijoux JP, Daw TM (2007) Lag effects in the impacts of mass coral bleaching on coral reef fish, fisheries, and ecosystems. Conserv Biol 21:1291-1300

Graham NA and Nash KL (2012) The importance of structural complexity in coral reef ecosystems. Coral Reefs 32:315-26

Gratwicke B and Speight M (2005) The relationship between fish species richness, abundance and habitat complexity in a range of shallow tropical marine habitats. J Fish Biol 66:650667

Green DH, Edmunds PJ, Carpenter RC (2008) Increasing relative abundance of Porites astreoides on Caribbean reefs mediated by an overall decline in coral cover. Mar Ecol Prog Ser 359: 1-10

Grottoli AG, Rodrigues LJ, Palardy JE (2006) Heterotrophic plasticity and resilience in bleached corals. Nature 440:1186-1189

Haapkylä J, Seymour AS, Trebilco J, Smith D (2007) Coral disease prevalence and coral health in the Wakatobi Marine Park, south-east Sulawesi, Indonesia. J Mar Biol Assoc UK 87:403414

Hallmann EF (1912) Report on the sponges obtained by the F.I.S. 'Endeavour' on the Coasts of New South Wales, Victoria, South Australia, Queensland, and Tasmania, 1909-10. Part 1. Zoological Results of the Fishing Experiments carried out by F.I.S. 'Endeavour', 1909-1914 2:117-300

Hallock P (1988) The role of nutrient availability in bioerosion: Consequences to carbonate buildups. Palaeogeogr Palaeoclimatol Palaeoecol 63:275-291 
Hancock A (1849) On the excavating powers of certain sponges belonging to the genus Cliona; with descriptions of several new species, and an allied generic form. Ann Mag Nat Hist $3: 321-348$

Harrison JW, Silsbe GM, Smith RE (2015) Photophysiology and its response to visible and ultraviolet radiation in freshwater phytoplankton from contrasting light regimes. J Plankton Res 37:472-488

Harrington L, Fabricius K, De'Ath G, Negri A (2004) Recognition and selection of settlement substrata determine post-settlement survival in corals. Ecology 85:3428-3437

Hartman WD (1958) Natural history of the marine sponges of southern New England. Bull Peabody Mus Hist 12:1-150

Henley WJ (1993) Measurement and interpretation of photosynthetic light-response curves in algae in the context of photoinhibition and diel changes. J Phycol 29:729-739

Hennige SJ, Smith DJ, Perkins R, Consalvey M, Paterson DM, Suggett DJ (2008a) Photoacclimation, growth and distribution of massive coral species in clear and turbid waters. Mar Ecol Prog Ser 369:77-88

Hennige SJ, Suggett DJ, Warner ME, McDougall K, Smith DJ (2008b) Unravelling coral photoacclimation: Symbiodinium strategy and host modification. Proc 11th Int Coral Reef Symp 1:132-136

Hennige SJ, Smith DJ, Walsh S, McGinley MP, Warner ME, Suggett DJ (2010) Acclimation and adaptation of scleractinian coral communities along environmental gradients within an Indonesian reef system. J Exp Mar Biol Ecol 391:143-152

Hernández-Ballesteros LM, Elizalde-Rendón EM, Carballo JL, Carricart-Ganivet JP (2013) Sponge bioerosion on reef-building corals: Dependent on the environment or on skeletal density? J Exp Mar Biol Ecol 441:23-27

Heron SF, Maynard JA, van Hooidonk R, Eakin CM (2016) Warming trends and bleaching stress of the world's coral reefs 1985-2012. Sci Rep 6:38402

Herrera-Escalante T, López-Pérez R, Leyte-Morales G (2005) Bioerosion caused by the sea urchin Diadema mexicanum (Echinodermata: Echinoidea) at Bahíasde Huatulco, Western Mexico. Rev Biol Trop 53:263-273

Hill M (1996) Symbiotic zooxanthellae enhance boring and growth rates of the tropical sponge Anthosigmella varians forma varians. Mar Biol 125:649-654 
Hill M and Wilcox T (1998) Unusual mode of symbiont repopulation after bleaching in Anthosigmella varians: Acquisition of different zooxanthellae strains. Symbiosis 25:279289

Hill M (1999) Morphological and genetic examination of phenotypic variability in the tropical sponge Anthosigmella varians. Mem Queensland Mus 44:239-248

Hill M and Hill AL (2002) Morphological plasticity in the tropical sponge Anthosigmella varians: Responses to predators and wave energy. Biol Bull 202:86-95

Hill M, Allenby A, Ramsby B, Schönberg C, Hill A (2011) Symbiodinium diversity among host Clionaid sponges from Caribbean and Pacific reefs: Evidence of heteroplasmy and putative host-specific symbiont lineages. Mol Phylogenet Evol 59:81-88

Hill M, Walter C, Bartels E (2016) A mass bleaching event involving clionaid sponges. Coral Reefs 35:153-153

Hoegh-Guldberg O (1999) Climate change, coral bleaching and the future of the world's coral reefs. Mar Freshwater Res 50:839-866

Hoegh-Guldberg O, Mumby PJ, Hooten AJ, Steneck RS, Greenfield P, Gomez E, Harvell CD, Sale PF, Edwards AJ, Caldeira K, Knowlton N, Eakin CM, Inglesias-Prieto R, Muthiga N, Bradbury RH, Dubi A, Hatziolos ME (2007) Coral reefs under rapid climate change and ocean acidification. Science 318:1737-1742

Hoegh-Guldberg O and Bruno JF (2010) The impact of climate change on the world's marine ecosystems. Science 328:1523-1528

Hoey AS, Pratchett MS, Cvitanovic C (2011) High macroalgal cover and low coral recruitment undermines the potential resilience of the world's southernmost coral reef assemblages. PLoS One 6:e25824

Hofman CC and Kielman M (1992) The excavating sponges of the Santa-Marta area, Colombia, with description of a new species. Bijdragen tot de Dierkunde 61: 205-217

Holmes KE, Edinger EN, Limmon GV, Risk MJ (2000) Bioerosion of live massive corals and branching coral rubble on Indonesian coral reefs. Mar Pollut Bull 40:606-617

Holmes G, Ortiz JC, Schönberg CH (2009) Bioerosion rates of the sponge Cliona orientalis Thiele, 1900: spatial variation over short distances. Facies 55:203-11 
Hooper JN and Krasochin V (1989) Redescription of the burrowing sponge Zyzzya massalis (Dendy) from the Seychelles and Houtman-Abrolhos Islands. The Beagle, Records of the Museums and Art Galleries of the Northern Territory 6:133-140

Hooper JN, Kennedy J, van Soest RWM (2000) Annotated checklist of sponges (Porifera) of the South China Sea region. Raff Bull Zool Suppl 8:125-207

Houk P and Van Woesik R (2013) Progress and perspectives on question-driven coral-reef monitoring. Bioscience 63:297-303

Hubbard DK, Miller AI, Scaturo D (1990) Production and cycling of calcium carbonate in a shelf-edge reef system (St. Croix, US Virgin Islands): applications to the nature of reef systems in the fossil record. J Sediment Res 60:335-360

Hughes TP (1994) Catastrophes, phase shifts, and large-scale degradation of a Caribbean coral reef. Science 265:1547-1551

Hughes TP (1996) Demographic approaches to community dynamics: A coral reef example. Ecology 77:2256-2260

Hughes TP, Baird AH, Bellwood DR, Card M, Connolly SR, Folke C, Grosberg R, HoeghGuldberg O, Jackson JB, Kleypas J, Lough JM, Marshall P, Nyström M, Palumbi SR, Pandolfi SR, Rosen B, Roughgarden J (2003) Climate change, human impacts, and the resilience of coral reefs. Science 301:929-933

Hughes TP, Rodrigues MJ, Bellwood DR, Ceccarelli D, Hoegh-Guldberg O, McCook L, Moltschaniwskyj N, Pratchett MS, Steneck RS, Willis B (2007) Phase shifts, herbivory, and the resilience of coral reefs to climate change. Curr Biol 17:360-365

Hughes TP, Graham NA, Jackson JB, Mumby PJ, Steneck RS (2010) Rising to the challenge of sustaining coral reef resilience. Trends Ecol Evol 25:633-642

Hughes TP, Kerry JT, Álvarez-Noriega M, Álvarez-Romero JG, Anderson KD, Baird AH, Babcock RC, Beger M, Bellwood DR, Berkelmans R (2017) Global warming and recurrent mass bleaching of corals. Nature 543:373-377

Hutchings P (1986) Biological destruction of coral reefs. Coral Reefs 4:239-252

Hutchings P, Peyrot-Clausade M, Osorno A (2005) Influence of land runoff on rates and agents of bioerosion of coral substrates. Mar Pollut Bull 51:438-447

Ilan M and Abelson A (1995) The life of a sponge in a sandy lagoon. Biol Bull 189:363-369 
IPCC (2007) Climate Change 2007: Synthesis Report. Contribution of working groups I, II and III to the Fourth Assessment Report of the International Governmental Panel on Climate Change. Valencia, Spain. p 26-73

Jackson JB, Kirby MX, Berger WH, Bjorndal KA, Botsford LW, Bourque BJ, Bradbury RH, Cooke R, Erlandson J, Estes JA, Hughes TP, Kidwell S, Lange CB, Lenihan HS, Pandolfi JM, Peterson CH, Steneck RS, Tegner MJ, Warner RR (2001) Historical overfishing and the recent collapse of coastal ecosystems. Science 293:629-637

Jackson D, Leys SP, Hinman VF, Woods R, Lavin MF, Degnan BM (2002) Ecological regulation of development: Induction of marine invertebrate metamorphosis. Int J Dev Biol 46:679-686

Jackson JBC, Donovan M, Cramer K, Lam V (2014) Status and trends of Caribbean coral reefs 1970-2012. Global Coral Reef Monitoring Network, International Union for the Conservation of Nature Global Marine and Polar Program, Washington, DC

Jassby AD and Platt $\mathrm{T}$ (1976) Mathematical formulation of the relationship between photosynthesis and light for phytoplankton. Limnol Oceanogr 21:540-547

Jokiel PL and Morrissey JI (1993) Water motion on coral reefs-evaluation of the clod card technique. Mar Ecol Prog Ser 93:175

Karawaiew W (1896) Über ein neues radiolar aus Villafranca. Zool Anz 19:501

Kayal M, Vercelloni J, De Loma TL, Bosserelle P, Chancerelle Y, Geoffroy S, Stievenart C, Michonneau F, Penin L, Planes S (2012) Predator crown-of-thorns starfish (Acanthaster planci) outbreak, mass mortality of corals, and cascading effects on reef fish and benthic communities. PloS One 7:e47363

Kelly M (1986) Systematics and ecology of the sponges of Motupore Island, Papua New Guinea. MSc thesis, University of Auckland, Auckland. https://researchspace.auckland.ac.nz/handle/2292/5966 (last accessed 31 May 2017)

Kelly-Borges M and Bergquist PR (1988) Sponges from Motupore Island, Papua New Guinea. Indo-Malayan Zool 5:121-159

Kelly-Borges M, Bergquist PR, Bergquist PL (1991) Phylogenetic relationships within the order Hadromerida (Porifera, Demospongiae, Tetractinomorpha) as indicated by ribosomal RNA sequence comparisons. Biochem Syst Ecol 19:117-125 
Kelly-Borges M and Vacelet J (1998) Sponges of the New Caledonian lagoon: Class Demospongiae, order Hadromerida. In: Levi C (ed) Sponges of the New Caledonian Lagoon. Orstom Editions, Paris, p 87-93

Kennedy EV, Perry CT, Halloran PR, Fine M, Carricart-Ganivet JP, Iglesias-Prieto R, Form A, Wisshak M, Schönberg CHL, Mumby PJ (2013) Avoiding coral structural collapse requires local and global action. Curr Biol 23:912-918

Kiene W and Hutchings P (1994) Bioerosion experiments at Lizard Island, Great Barrier Reef. Coral Reefs 13:91-98

Kieschnick O (1896) Silicispongiae von Ternate nach den sammlungen von herrn Prof. Dr. W. Kükenthal. Zool Anz 19:526-534

Kieschnick O (1898) Kieselschwämme Von Amboina. Denkschriften der Medizinischen und Naturwissenschaftlichen Gesellschaft Jena 8: 545-582

Kirkpatrick R (1900) Description of sponges from Funafuti. J Nat Hist 6:345-362

Kobluk DR and Risk MJ (1977) Algal borings and framboidal pyrite in Upper Ordovician brachiopods. Lethaia 10:135-143

Kolber Z and Falkowski PG (1993) Use of active fluorescence to estimate phytoplankton photosynthesis in situ. Limnol Oceanogr 38:1646-1665

Knapp IS, Williams GJ, Carballo JL, Cruz-Barraza JA, Gardner JP, Bell JJ (2013) Restriction of sponges to an atoll lagoon as a result of reduced environmental quality. Mar Pollut Bull 66:209-220

Knapp IS, Williams GJ, Bell JJ (2016) Temporal dynamics and persistence of sponge assemblages in a central pacific atoll lagoon. Mar Ecol 37:1147-1153

Kuffner IB, Walters LJ, Becerro MA, Paul VJ, Ritson-Williams R, Beach KS (2006) Inhibition of coral recruitment by macroalgae and cyanobacteria. Mar Ecol Prog Ser 323:107-117

Kuguru B, Mgaya Y, Öhman M, Wagner G (2004) The reef environment and competitive success in the Corallimorpharia. Mar Biol 145:875-884

Lamarck JBP De Monet Comte De $(1813,1814)$ Sur les polypiers empâtés. Suite du mémoire intitulé: Sur les Polypiers empâtés. Suite des éponges. Ann Mus Hist Nat Paris 20: 294-312 (published 1813), 370-386, 432-458 (published 1814) 
Lang J (1973) Interspecific aggression by scleractinian corals. 2. Why the race is only to the swift. Bull Mar Sci 23:260-27

Lang J (2010) AGRRA: Introduction to Benthos Transects. http://www.agrra.org/trainingtools/benthos-training/ (last accessed 15 June 2017)

Lasker HR (1980) Sediment rejection by reef corals: The roles of behavior and morphology in Montastrea cavernosa (Linnaeus). J Exp Mar Biol Ecol 47:77-87

Leal CV, De Paula TS, Lôbo-Hajdu G, Schönberg CHL, Esteves EL (2016) Morphological and molecular systematics of the "Cliona viridis complex" from south-eastern Brazil. J Mar Biol Assoc UK 96:313-322

Lee SC (2006) Habitat complexity and consumer-mediated positive feedbacks on a Caribbean coral reef. Oikos 112:442-447

Lendenfeld R von (1898) Die Clavulina der Adria. Nova Acta Acad Caes Leop-Carol German Nat Cur 69:1-251

Lessios HA, Robertson DR, Cubit JD (1984) Spread of Diadema mass mortality through the Caribbean. Science 226:335-337

Levitan DR (1991) Influence of body size and population density on fertilization success and reproductive output in a free-spawning invertebrate. Biol Bull 181:261-268

Leys SP, Mackie GO, Meech RW (1999) Impulse conduction in a sponge. J Exp Biol 202:11391150

Lindgren NG (1897) Beitrag zur Kenntniss der Spongienfauna des Malayischen Archipels und der Chinesischen Meere. Zool Anzeiger 20:486-487

López-Victoria M, Zea S, Weil E (2003) New aspects on the biology of the encrusting excavating sponges Cliona aprica, Cliona caribbaea and Cliona sp. Boll Mus Ist Biol Univ Genova 68:425-432

López-Victoria M and Zea S (2004) Storm-mediated coral colonization by an excavating Caribbean sponge. Clim Res 26:251-256

López-Victoria M and Zea S (2005) Current trends of space occupation by encrusting excavating sponges on Colombian coral reefs. Mar Ecol 26:33-41

López-Victoria M, Zea S, Weil E (2006) Competition for space between encrusting excavating Caribbean sponges and other coral reef organisms. Mar Ecol Prog Ser 312:113-121 
Loya Y, Sakai K, Yamazato K, Nakano Y, Sambali H, Van Woesik R (2001) Coral bleaching: the winners and the losers. Ecol Lett 4:122-131

Loya Y (2004) The coral reefs of Eilat-past, present and future: three decades of coral community structure studies. In: Rosenberg E and Loya Y (eds) Coral reef health and disease. Springer-Verlag, Berlin, p 1-34

Lugo-Fernández A, Roberts HH, Suhayda JN (1998) Wave transformations across a Caribbean fringing-barrier coral reef. Cont Shelf Res 18:1099-124

Lundbeck W (1910) Porifera, (Part III.) Desmacidonidae (Pars.) In: The Danish IngolfExpedition Volume 6. Bianco Luno, Copenhagen

MacDonald I and Perry C (2003) Biological degradation of coral framework in a turbid lagoon environment, Discovery Bay, North Jamaica. Coral Reefs 22:523-535

MacGeachy J (1977) Factors controlling sponge boring in Barbados reef corals. Proc 3rd Int Coral Reef Symp 2:478-483

MacIntyre HL, Kana TM, Anning T, Geider RJ (2002) Photoacclimation of photosynthesis irradiance response curves and photosynthetic pigments in microalgae and cyanobacteria. $\mathrm{J}$ Phycol 38:17-38

Magnusson SH, Fine M, Kühl M (2007) Light microclimate of endolithic phototrophs in the scleractinian corals Montipora monasteriata and Porites cylindrica. Mar Ecol Prog Ser $332: 119-128$

Maina J, De Moel H, Zinke J, Madin J, McClanahan T, Vermaat JE (2013) Human deforestation outweighs future climate change impacts of sedimentation on coral reefs. Nat Commun 4:1986

Maldonado M and Young CM (1996) Effects of physical factors on larval behavior, settlement and recruitment of four tropical demosponges. Mar Ecol Prog Ser 138:169-180

Maldonado M and Uriz MJ (1998) Microrefuge exploitation by subtidal encrusting sponges: Patterns of settlement and post-settlement survival. Mar Ecol Prog Ser 174:141-150

Maldonado M (2006) The ecology of the sponge larva. Can J Zool 84:175-194

Maldonado M and Riesgo A (2008) Reproduction in the phylum Porifera: A synoptic overview. Treb Soc Cat Biol 59:29-49 
Maldonado M, Giraud K, Carmona C (2008) Effects of sediment on the survival of asexually produced sponge recruits. Mar Biol 154:631-641

Mallela J and Perry C (2007) Calcium carbonate budgets for two coral reefs affected by different terrestrial runoff regimes, Rio Bueno, Jamaica. Coral Reefs 26:129-145

Mariani S, Uriz M, Turon X (2000) Larval bloom of the oviparous sponge Cliona viridis: Coupling of larval abundance and adult distribution. Mar Biol 137:783-790

Mariani S, Piscitelli M, Uriz M (2001) Temporal and spatial co-occurrence in spawning and larval release of Cliona viridis (Porifera: Hadromerida). J Mar Biol Assoc UK 81:565-567

Mariani S, Uriz MJ, Turon X (2005) The dynamics of sponge larvae assemblages from northwestern Mediterranean nearshore bottoms. J Plankton Res 27:249-262

Mariani S, Uriz M, Turon X, Alcoverro $T$ (2006) Dispersal strategies in sponge larvae: Integrating the life history of larvae and the hydrologic component. Oecologia 149:174-184

Marshall W (1892) Spongiologische Beiträge. In: Festschrift zur siebzigsten Wiederkehr des Geburtstages von Rudolf Leuckart. C.F. Winter'sche Verlagshandlung, Leipzig

Marquez JC and Zea S (2012) Parrotfish mediation in coral mortality and bioerosion by the encrusting, excavating sponge Cliona tenuis. Mar Ecol 33:417-426

Maxwell K and Johnson GN (2000) Chlorophyll fluorescence - a practical guide. J Exp Bot 51:659-668

McClanahan TR, Marnane MJ, Cinner JE, Kiene WE (2006) A comparison of marine protected areas and alternative approaches to coral-reef management. Curr Biol 16:1408-1413

McClanahan TR, Graham NA, Darling ES (2014) Coral reefs in a crystal ball: Predicting the future from the vulnerability of corals and reef fishes to multiple stressors. Curr Opin Environ Sustain 7:59-64

McKenna SA, Allen GR, Suryadi S (2002) A marine rapid assessment of the Raja Ampat Islands. Papua Province, Indonesia. RAP Bulletin of Biological Assessment 22. Conservation International, Washington

McManus JW and Polsenberg JF (2004) Coral-algal phase shifts on coral reefs: Ecological and environmental aspects. Prog Oceanogr 60:263-279 
McMellor S and Smith DJ (2010) Coral reefs of the Wakatobi: Abundance and biodiversity. In: Clifton J, Unsworth RKF, Smith DJ (eds) Marine research and conservation in the Coral Triangle: The Wakatobi National Park. NOVA Science Publishers, New York, p 11-26

McMurray SE, Henkel TP, Pawlik JR (2010) Demographics of increasing populations of the giant barrel sponge Xestospongia muta in the Florida Keys. Ecology 91:560-570

Mellin C, Aaron MacNeil M, Cheal AJ, Emslie MJ, Julian Caley M (2016) Marine protected areas increase resilience among coral reef communities. Ecol Lett 19:629-637

Moberg F and Folke C (1999) Ecological goods and services of coral reef ecosystems. Ecol Econ 29:215-233

Mora C (2008) A clear human footprint in the coral reefs of the Caribbean. Proc Biol Sci 275:767-773

Moran DP and Reaka ML (1988) Bioerosion and availability of shelter for benthic reef organisms. Mar Ecol Prog Ser 44:249-263

Morgan KM, Perry CT, Smithers SG, Johnson JA, Daniell JJ (2016) Evidence of extensive reef development and high coral cover in nearshore environments: Implications for understanding coral adaptation in turbid settings. Sci Rep 6:29616

Morrow C and Cárdenas P (2015) Proposal for a revised classification of the Demospongiae (Porifera). Front Zool 12:1-27

Mueller B, de Goeij JM, Vermeij MJ, Mulders Y, van der Ent E, Ribes M, van Duyl FC (2014) Natural diet of coral-excavating sponges consists mainly of dissolved organic carbon (DOC). PLoS One 9:e90152

Müller W, Zahn R, Rijavec M, Britvić S, Kurelec B, Müller I (1979) Aggregation of sponge cells: The aggregation factor as a tool to establish species. Biochem Syst Ecol 7:49-55

Mumby PJ, Harborne AR, Williams J, Kappel CV, Brumbaugh DR, Micheli F, Holmes KE, Dahlgren CP, Paris CB, Blackwell PG (2007) Trophic cascade facilitates coral recruitment in a marine reserve. Proc Natl Acad Sci USA 104:8362-8367

Mumby PJ and Steneck RS (2008) Coral reef management and conservation in light of rapidly evolving ecological paradigms. Trends Ecol Evol 23:555-563

Mumby PJ (2009) Phase shifts and the stability of macroalgal communities on Caribbean coral reefs. Coral Reefs 28:761-773 
Munday PL (2004) Habitat loss, resource specialization, and extinction on coral reefs. Glob Change Biol 10:1642-1647

Muricy G (1991) Structure des peuplements de spongiaires autour de l'égout de Cortiou (Marseille, France). Vie Milieu 41:205-221

Murphy GN, Perry CT, Chin P, McCoy C (2016) New approaches to quantifying bioerosion by endolithic sponge populations: applications to the coral reefs of Grand Cayman. Coral Reefs 35:1109-1121

Nassonov N (1883) Zur biologie und anatomie der Clione. Z Wiss Zool 39:295-308

Nava H and Carballo JL (2008) Chemical and mechanical bioerosion of boring sponges from Mexican Pacific Coral reefs. J Exp Biol 211:2827-2831

Nava H and Carballo JL (2013) Environmental factors shaping boring sponge assemblages at Mexican Pacific coral reefs. Mar Ecol 34:269-279

Nava H, Ramírez-Herrera MT, Figueroa-Camacho AG, Villegas-Sanchez BM (2014) Habitat characteristics and environmental factors related to boring sponge assemblages on coral reefs near populated coastal areas on the Mexican Eastern Pacific coast. Mar Biodiv 44:4554

Neumann AC (1966) Observations on coastal erosion in Bermuda and measurements of the boring rate of the sponge Cliona lampa. Limnol Oceanogr 11:92-108

Normile D (2016) El Niño’s warmth devastating reefs worldwide. Science 352:15-16

Norström AV, Nyström M, Lokrantz J, Folke C (2009) Alternative states on coral reefs: Beyond coral-macroalgal phase shifts. Mar Ecol Prog Ser 376:295-306

Orr JC, Fabry VJ, Aumont O, Bopp L, Doney SC, Feely RA, Gnanadesikan A, Gruber N, Ishida A, Joos F (2005) Anthropogenic ocean acidification over the twenty-first century and its impact on calcifying organisms. Nature 437:681-686

Osorno A, Peyrot-Clausade M, Hutchings PA (2005) Patterns and rates of erosion in dead Porites across the Great Barrier Reef (Australia) after 2 years and 4 years of exposure. Coral Reefs, 24:292-303

Pang RK (1973) The systematics of some Jamaican excavating sponges (Porifera). Peabody Museum of Natural History, New Heaven, CT 
Pari N, Peyrot-Clausade M, Le Campion-Alsumard T, Hutchings P, Chazottes V, Golubic S, Le Campion J, Fontaine M (1998) Bioerosion of experimental substrates on high islands and on atoll lagoons (French Polynesia) after two years of exposure. Mar Ecol Prog Ser 166:119130

Pari N, Peyrot-Clausade M, Hutchings PA (2002) Bioerosion of experimental substrates on high islands and atoll lagoons (French Polynesia) during 5 years of exposure. J Exp Mar Biol Ecol 276:109-127

Pascoe S, Doshi A, Thébaud O, Thomas CR, Schuttenberg HZ, Heron SF, Setiasih N, Tan JCH, True J, Wallmo K, Loper C, Calgaro E (2014) Estimating the potential impact of entry fees for marine parks on dive tourism in Southeast Asia. Mar Policy 47:147-152

Pawlik JR (1992) Chemical ecology of the settlement of benthic marine invertebrates. Oceanogr Mar Biol Annu Rev 30:273-335

Pawlowski JA, Holzmann M, Fahrni JF, Pochon X, Lee JJ (2001) Molecular identification of algal endosymbionts in large miliolid Foraminifera: 2. Dinoflagellates. J Eukaryot Microbiol 48:368-373

Perry CT and Bertling M (2000) Spatial and temporal patterns of macroboring within Mesozoic and Cenozoic coral reef systems. Geol Soc Lond Spec Publ 178:33-50

Perry CT, Spencer T, Kench P (2008) Carbonate budgets and reef production states: A geomorphic perspective on the ecological phase-shift concept. Coral Reefs 27:853-866

Perry CT, Edinger E, Kench P, Murphy G, Smithers S, Steneck R, Mumby P (2012) Estimating rates of biologically driven coral reef framework production and erosion: A new censusbased carbonate budget methodology and applications to the reefs of Bonaire. Coral Reefs 31:853-868

Perry CT, Murphy GN, Kench PS, Smithers SG, Edinger EN, Steneck RS, Mumby PJ (2013) Caribbean-wide decline in carbonate production threatens coral reef growth. Nat Commun 4:1402

Pet-Soede L and Erdmann MV (2003) Rapid Ecological Assessment Wakatobi National Park. WWF and The Nature Conservancy, Bali

Pineda J, Reyns NB, Starczak VR (2009) Complexity and simplification in understanding recruitment in benthic populations. Popul Ecol 51:17-32 
Pineda J, Porri F, Starczak V, Blythe J (2010) Causes of decoupling between larval supply and settlement and consequences for understanding recruitment and population connectivity. $\mathrm{J}$ Exp Mar Biol Ecol 392:9-21

Pineda MC, Strehlow B, Duckworth A, Doyle J, Jones R, Webster NS (2016) Effects of light attenuation on the sponge holobiont-implications for dredging management. Sci Rep $6: 39038$

Piscitelli M, Corriero G, Gaino E, Uriz M (2011) Reproductive cycles of the sympatric excavating sponges Cliona celata and Cliona viridis in the Mediterranean sea. Invertebr Biol 130:1-10

Pochon X, Montoya-Burgos JI, Stadelmann B, Pawlowski J (2006) Molecular phylogeny, evolutionary rates, and divergence timing of the symbiotic dinoflagellate genus Symbiodinium. Mol Phylogenet Evol 38:20-30

Pollock FJ, Lamb JB, Field SN, Heron SF, Schaffelke B, Shedrawi G, Bourne DG, Willis BL (2014) Sediment and turbidity associated with offshore dredging increase coral disease prevalence on nearby reefs. PLOS One 9:e102498

Pomponi SA (1980) Cytological mechanisms of calcium carbonate excavation by boring sponges. Int Rev Cytol 65:301-319

Powell AL, Hepburn LJ, Smith DJ, Bell JJ (2010) Patterns of sponge abundance across a gradient of habitat quality in the Wakatobi Marine National Park Indonesia. Op Mar Biol J 4:31-38

Powell AL, Smith DJ, Hepburn LJ, Jones T, Berman J, Jompa J, Bell JJ (2014) Reduced diversity and high sponge abundance on a sedimented Indo-Pacific reef system: implications for future changes in environmental quality. PloS one 9e85253

Powell A, Jones T, Smith DJ, Jompa J, Bell JJ (2015) Spongivory in the Wakatobi Marine National Park, southeast Sulawesi, Indonesia. Pac Sci 69:487-508

Porter JW and Targett NM (1988) Allelochemical interactions between sponges and corals. Biol Bull 175:230-239

Pratchett MS, Munday PL, Wilson SK, Graham NAJ, Cinner JE, Bellwood DR, Jones GP, Polunin N, McClanahan T (2008) Effects of climate-induced coral bleaching on coral-reeffishes: ecological and economic consequences. Oceanogr Mar Biol Annu Rev 46:251-296 
Pulitzer-Finali G (1983) A collection of Mediterranean Demospongiae (Porifera) with, in appendix, a list of the Demospongiae hitherto recorded from the Mediterranean Sea. Ann Mus Civ Stor Nat Giacomo Doria 84:445-621

Rädecker N, Pogoreutz C, Voolstra CR, Wiedenmann J, Wild C (2015) Nitrogen cycling in corals: The key to understanding holobiont functioning? Trends Microbiol 23:490-497

Radtke G and Campion-Alsumard TL (1996) Microbial assemblages of the bioerosional 'notch' along tropical limestone coasts. Algol Stud 83:469-482

Ralph PJ and Gademann R (2005) Rapid light curves: A powerful tool to assess photosynthetic activity. Aquat Bot 82:222-237

Ramus JA (1990) form-function analysis of photon capture for seaweeds. Hydrobiologia 204:6571

Ramsby BD, Hoogenboom MO, Whalan S, Webster NS, Thompson A (2017) A decadal analysis of bioeroding sponge cover on the inshore Great Barrier Reef. Sci Rep 7:2706

Reaka-Kudla M, Feingold JS, Glynn W (1996) Experimental studies of rapid bioerosion of coral reefs in the Galapagos Islands. Coral Reefs 15:101-107

Reis MAC and Leão ZMAN (2000) Bioerosion rate of the sponge Cliona celata (Grant 1826) from reefs in turbid waters, north Bahia, Brazil. Proc 9th Int Coral Reef Symp 1:273-278

Reiswig HM (1971a) Particle feeding in natural populations of three marine demosponges. Biol Bull 141:568-591

Reiswig H (1971b) In situ pumping activities of tropical Demospongiae. Mar Biol 9:38-50

Richardson K, Beardall J, Raven JA (1983) Adaptation of unicellular algae to irradiance: an analysis of strategies. New Phycol 93:157-91

Ridley S (1881) Coelenterata. In: Günther A (ed) Account of the zoological collections made during the survey of HMS Alert in the Straits of Magellan and on the coast of Patagonia. Proc Zool Soc Lond p 101-107

Ridley S (1884) Spongiida. Report on the zoological collections made in the Indo-Pacific Ocean during the voyage of HMS Alert (1881-82). Brit Mus Nat Hist Pub 2:366-482

Ridley S and Dendy A (1886) Preliminary Report on the Monaxonida collected by HMS. Challenger. Ann Mag Nat Hist 18: 325-351, 470-493 
Riegl B (1995) Effects of sand deposition on scleractinian and alcyonacean corals. Mar Biol 121:517-526

Risk MJ and Sammarco PW (1982) Bioerosion of corals and the influence of damselfish territoriality: A preliminary study. Oecologia 52:376-380

Risk MJ, Sammarco PW, Edinger EN (1995) Bioerosion in Acropora across the continental shelf of the Great Barrier Reef. Coral Reefs 14:79-86

Ritson-Williams R, Paul VJ, Arnold S, Steneck R (2010) Larval settlement preferences and postsettlement survival of the threatened Caribbean corals Acropora palmata and A. cervicornis. Coral Reefs 29:71-81

Roberts CM, McClean CJ, Veron JE, Hawkins JP, Allen GR, McAllister DE, Mittermeier CG, Schueler FW, Spalding M, Wells F, Vynne C, Werner TB (2002) Marine biodiversity hotspots and conservation priorities for tropical reefs. Science 295:1280-1284

Rodolfo-Metalpa R, Huot Y, Ferrier-Pages C (2008) Photosynthetic response of the Mediterranean zooxanthellate coral Cladocora caespitosa to the natural range of light and temperature. J Exp Biol 211:1579-1586

Rogers CS (1990) Responses of coral reefs and reef organisms to sedimentation. Mar Ecol Prog Ser 62:185-202

Rose CS and Risk MJ (1985) Increase in Cliona delitrix infestation of Montastrea cavernosa heads on an organically polluted portion of the Grand Cayman fringing reef. Mar Ecol 6:345-363

Rosell D and Uriz M (1991) Cliona viridis (Schmidt, 1862) and Cliona nigricans (Schmidt, 1862) (Porifera, Hadromerida): Evidence which shows they are the same species. Ophelia $33: 45-53$

Rosell D and Uriz M (1992) Do associated zooxanthellae and the nature of the substratum affect survival, attachment and growth of Cliona viridis (Porifera: Hadromerida)? An experimental approach. Mar Biol 114:503-507

Rosell D (1993) Effects of reproduction in Cliona viridis (Hadromerida) on zooxanthellae. Sci Mar 57:405-413

Rosell D and Uriz M (1997) Phylogenetic relationships within the excavating Hadromerida (Porifera), with a systematic revision. Cladistics 13:349-366 
Rosell D, Uriz M, Martin D (1999) Infestation by excavating sponges on the oyster (Ostrea edulis) populations of the Blanes littoral zone (north-western Mediterranean Sea). J Mar Biol Assoc UK 79:409-413

Rosell D and Uriz M (2002) Excavating and endolithic sponge species (Porifera) from the Mediterranean: Species descriptions and identification key. Org Divers Evol 2:55-86

Rowan R (2004) Coral bleaching: Thermal adaptation in reef coral symbionts. Nature 430:742742

Rützler K (1973) Clionid sponges from the coast of Tunisia. Bull Inst Océanogr Pêche 2:623-637

Rützler K and Rieger G (1973) Sponge burrowing: fine structure of Cliona lampa penetrating calcareous substrata. Mar Biol 21:144-162

Rützler K (1974) The burrowing sponges of Bermuda. Smithson Contrib Zool 165:1-32

Rützler K (1975) The role of burrowing sponges in bioerosion. Oecologia 19:203-216

Rützler K and Stone S (1986) Discovery and significance of Albany Hancock's microscope preparations of excavating sponges (Porifera: Hadromerida: Clionidae). Proc Biol Soc Wash 99:658-675

Rützler K (1990) Associations between Caribbean sponge and photosynthetic organisms. In Rützler K (ed) New Perspectives in Sponge Biology. Smithsonian Institution Press, Washington, DC p 455-466

Rützler K and Hooper JN (2000) Two new genera of Hadromerid sponges (Porifera, Demospongiae). Zoosystema 22:337-344

Rützler K (2002a) Impact of crustose clionid sponges on Caribbean reef corals. Acta Geol Hisp 37:61-72

Rützler K (2002b) Family Clionaidae D’Orbigny, 1851. In: Hooper JNA and van Soest (eds) Systema Porifera. Kluwer Academic/Plenum Publisher Springer, New York, p 173-185

Ruzicka R, Colella M, Semon K, Brinkhuis V, Morrison J, Kidney J, Porter J, Meyers M, Christman M, Colee J (2010) CREMP 2009 Final Report. Fish \& Wildlife Research Institute/Florida Fish \& Wildlife Conservation Commission, Saint Petersburg, FL

Ruzicka RR, Colella MA, Porter JW, Morrison JM, Kidney JA, Brinkhuis V, Lunz KS, Macaulay KA, Bartlett LA, Meyers MA, Colee J (2013) Temporal changes in benthic 
assemblages on Florida Keys reefs 11 years after the 1997/1998 El Niño. Mar Ecol Prog Ser 489:125-141

Ryan KG, Cowie RO, Liggins E, McNaughtan D, Martin A, Davy SK (2009) The short-term effect of irradiance on the photosynthetic properties of Antarctic fast-ice microalgal communities. J Phycol 45:1290-1298

Sakshaug E, Bricaud A, Dandonneau Y, Falkowski PG, Kiefer DA, Legendre L, Morel A, Parslow J, Takahashi M (1997) Parameters of photosynthesis: Definitions, theory and interpretation of results. J Plankton Res 19:1637-1670

Salinas-de-Leon P, Dryden C, Smith DJ, Bell JJ (2013) Temporal and spatial variability in coral recruitment on two Indonesian coral reefs: Consistently lower recruitment to a degraded reef. Mar Biol 160:97-105

Sammarco PW, Risk MJ, Rose C (1987) Effects of grazing and damselfish territoriality on internal bioerosion of dead corals: Indirect effects. J Exp Mar Biol Ecol 112:185-199

Sammarco PW and Risk MJ (1990) Large-scale patterns in internal bioerosion of Porites: cross continental shelf trends on the Great Barrier Reef. Mar Ecol Prog Ser 59:145-156

Sammarco PW (1996) Comments on coral reef regeneration, bioerosion, biogeography, and chemical ecology: Future directions. J Exp Mar Biol Ecol 200:135-168

Sarà M and Liaci L (1964) Symbiotic association between zooxanthellae and two marine sponges of the genus Cliona. Nature 203:321-323

Sarà M (1971) Ultrastructural aspects of the symbiosis between two species of the genus Aphanocapsa (Cyanophyceae) and Ircinia variabilis (Demospongiae). Mar Biol 11:214-221

Satria A and Matsuda Y (2004) Decentralization of fisheries management in Indonesia. Mar Policy 28:437-450

Schmidt O (1862) Die Spongien des Adriatischen Meeres. Wilhelm Engelmann, Leipzig

Schmidt O (1870) Grundzüge einer Spongien-Fauna des atlantischen Gebietes. Wilhelm Engelmann, Leipzig

Schönberg CHL (2000a) Bioeroding sponges common to the central Australian Great Barrier reef: Descriptions of three new species, two new records, and additions to two previously described species. Senckenb Marit 30:161-221 
Schönberg CHL (2000b) Sponges of the 'Cliona viridis complex'-a key for species identification. Sponges of the 'Cliona viridis complex'. Proc 9th Int Coral Reef Symp 1:295-299

Schönberg CHL (2001) Small-scale distribution of Great Barrier Reef bioeroding sponges in shallow water. Ophelia 55:39-54

Schönberg CHL and Wilkinson C (2001) Induced colonization of corals by a clionid bioeroding sponge. Coral Reefs 20:69-76

Schönberg CHL (2002) Substrate effects on the bioeroding demosponge Cliona orientalis. 1. Bioerosion rates. Mar Ecol 23:313-326

Schönberg CHL and Loh WK (2005) Molecular identity of the unique symbiotic dinoflagellates found in the bioeroding demosponge Cliona orientalis. Mar Ecol Prog Ser 299:157-166

Schönberg CHL (2006) Growth and erosion of the zooxanthellate Australian bioeroding sponge Cliona orientalis are enhanced in light. Proc 9th Int Coral Reef Symp 1:168-174

Schönberg CHL, Grass S, Heiermann AT (2006) Cliona inuscula, sp nov (Hadromerida: Clionaidae) and other bioeroding sponges that only contain tylostyles. Zootaxa 1312:1-24

Schönberg CHL and Suwa R (2007) Why bioeroding sponges may be better hosts for symbiotic dinoflagellates than many corals. In: Custódio MR, Lôbo-Hajdu G, Hajdu E, Muricy G (eds) Sér Livros Mus Nacional Rio de Janeiro 28. Porifera Research. Biodiversity, innovation and sustainability. Publ Museu Nac Rio De Janeiro, p 569-580

Schönberg CHL (2008) A history of sponge erosion: From past myths and hypotheses to recent approaches. In: Wisshak M and Tapanila L (eds) Current developments in bioerosion. Springer, Berlin, p 165-202

Schönberg CHL and Ortiz J (2009) Is sponge bioerosion increasing. Proc 11th Int Coral Reef Symp 1:527-530

Schönberg CHL and Wisshak M (2012) The perks of being endolithic. Aquat Biol 17:1-5

Schönberg CHL and Wisshak M (2014) Marine Bioerosion. In: Goffredo S and Dubinsky Z (eds) The Mediterranean Sea: Its History and Present Challenges. Springer, Dordrecht, p 449-461

Schönberg CHL (2015a) Monitoring bioeroding sponges: using rubbles, quadrat, or intercept surveys? Biol Bull 228:137-155 
Schönberg CHL (2015b) Self-cleaning surfaces in sponges. Mar Biodivers 45:623-624

Schönberg CHL (2016) Happy relationships between marine sponges and sediments - a review and some observations from Australia. J Mar Biol Assoc UK 96:493-514

Schönberg CHL, Fang JKH, Carreiro-Silva M, Tribollet A, Wisshak M (2017) Bioerosion: The other ocean acidification problem. ICES J Mar Sci 74:895-925

Schreiber U, Bilger W, Neubauer C (1994) Chlorophyll fluorescence as a nonintrusive indicator for rapid assessment of in vivo photosynthesis. In: Schulze ED and Caldwell M (eds) Ecophysiology of Photosynthesis: Springer, Berlin, p 49-70

Schreiber U (2004) Pulse-Amplitude (PAM) fluorometry and saturation pulse method. In: Papageorgiou G and Govindjee (eds) Chlorophyll Fluorescence: A Signature of Photosynthesis. Kluwer Academic Publishers, Dordrecht, p 279-319

Scoffin TP, Stearn C, Boucher D, Frydl P, Hawkins C, Hunter I, MacGeachy J (1980) Calciumcarbonate budget of a fringing-reef on the west-coast of Barbados. 2. Erosion, sediments and internal structure. Bull Mar Sci 30:475-508

Scott PJB and Risk MJ (1988) The effect of Lithophaga (Bivalvia: Mytilidae) boreholes on the strength of the coral Porites lobata. Coral Reefs 7:145-151

Sheppard CR, Spalding M, Bradshaw C, Wilson S (2002) Erosion vs recovery of coral reefs after 1998 El Niño: Chagos reefs, Indian Ocean. Ambio 31:40-48

Sheppard CR (2003) Predicted recurrences of mass coral mortality in the Indian Ocean. Nature 425:294-297

Sheppard CR, Dixon DJ, Gourlay M, Sheppard A, Payet R (2005) Coral mortality increases wave energy reaching shores protected by reef flats: examples from the Seychelles. Estuar Coast Shelf Sci 64:223-234

Small AM, Adey WH, Spoon D (1998) Are current estimates of coral reef biodiversity too low? The view through the window of a microcosm. Atoll Res Bull 450:1-20

Smyth MJ (1988) Penetrantia clionoides sp. nov. (Bryozoa), a boring bryozoan in gastropod shells from Guam. Biol Bull 174:276-86

Spalding M, Ravilious C, Green EP (2001) World atlas of coral reefs. University of California Press, Berkeley 
Stacey NE, Acciaioli G, Clifton J, Steenbergen DJ (2016) Impacts of marine protected areas on livelihoods and food Security of the Bajau as an indigenous migratory people in maritime Southeast Asia. In: Westlund L, Charles AT, Garcia SM and Sanders J (eds) Marine Protected Areas: Interactions with Fishery Livelihoods and Food Security, Food and Agriculture Organization of the United Nations (FAO), Rome p 111-124

Steindler L, Beer S, Peretzman-Shemer A, Nyberg C, Ilan M (2001) Photoadaptation of zooxanthellae in the sponge Cliona vastifica from the Red Sea, as measured in situ. Mar Biol 138:511-515

Stender Y, Jokiel PL, Rodgers KS (2014) Thirty years of coral reef change in relation to coastal construction and increased sedimentation at Pelekane Bay, Hawaii. Peerj 2:e300

Stobart B, Teleki K, Buckley R, Downing N, Callow M (2005) Coral recovery at Aldabra Atoll, Seychelles: Five years after the 1998 bleaching event. Philos Trans A Math Phys Eng Sci 363:251-255

Stubler AD, Furman BT, Peterson BJ (2014) Effects of pCO2 on the interaction between an excavating sponge, Cliona varians, and a hermatypic coral, Porites furcata. Mar Biol 161:1851-1859

Stubler AD, Furman BT, Peterson BJ (2015) Sponge erosion under acidification and warming scenarios: differential impacts on living and dead coral. Glob Change Biol 21:4006-4020

Stubler AD, Stevens AK, Peterson BJ (2016) Using community-wide recruitment and succession patterns to assess sediment stress on Jamaican coral reefs. J Exp Mar Biol Ecol 474:29-38

Sullivan BW, Faulkner DJ (1990) Chemical studies of the burrowing sponge Siphonodictyon coralliphagum. In: Rützler K (ed) New perspectives in sponge biology. Smithsonian Institution Press, Washington, p 45-50

Sutcliffe PR, Hooper JN, Pitcher CR (2010) The most common sponges on the Great Barrier Reef seabed, Australia, include species new to science (Phylum Porifera). Zootaxa 2616:1 30

Szmant A and Gassman N (1990) The effects of prolonged "bleaching" on the tissue biomass and reproduction of the reef coral Montastrea annularis. Coral Reefs 8:217-224

Szmant AM (2002) Nutrient enrichment on coral reefs: Is it a major cause of coral reef decline? Estuaries 25:743-766 
Tchernov D, Gorbunov MY, de Vargas C, Narayan Yadav S, Milligan AJ, Haggblom M, Falkowski PG (2004) Membrane lipids of symbiotic algae are diagnostic of sensitivity to thermal bleaching in corals. Proc Natl Acad Sci USA 101:13531-13535

Thiele J (1900) Kieselschwämme von Ternate. Abh Senck Naturf Ges 25:19-80

Thomas P (1968) Studies on Indian sponges - II. Two new species of siliceous sponges belonging to the genera Aka de Laubenfels and Damirina Burton. J Mar Biol Assoc India $10: 250-254$

Thomas P (1972) Boring sponges of the reefs of Gulf of Mannar and Palk Bay. Proc 1st Int Coral Reef Symp, p 333-362

Thomas P (1979) Studies on sponges of the Mozambique Channel. I: Sponges of Inhaca Island: II: Sponges of Mambone and Paradise Islands. Ann Mus R Afr Centr (Tervuren, Belg) Ser Octavo Sci Zool 227:1-73

Titlyanov E, Titlyanova T, Yamazato K, Van Woesik R (2001) Photo-acclimation of the hermatypic coral Stylophora pistillata while subjected to either starvation or food provisioning. J Exp Mar Biol Ecol 257:163-181

Todd PA, Ong X, Chou LM (2010) Impacts of pollution on marine life in Southeast Asia. Biodivers Conserv 19:1063-1082

Tomascik T, Mah AJ, Nontji A, Moosa MK (1997) The ecology of the Indonesian seas. Periplus Additions, Hong Kong

Topsent E (1888) Contribution à l'étude des Clionides. Arch Zool Exp Gén 5:1 -165

Topsent E (1891) Deuxième contribution à l'étude des Clionides. Arch Zool Exp Gén 9:555-592

Topsent, E (1897) Spongiaires de la Baie d'Amboine. (Voyage de MM. M. Bedot et C. Pictet dans 1'Archipel Malais). Rev Suisse Zool 4:421-487

Topsent E (1905) Cliothosa seurati, Clionide nouvelle des Iles Gambier. Bull Mus Nat Hist Natur 2:94-96

Topsent E (1928) Nouvelle étude sur les Cliothosa. Bull Inst Oceanogr (Monaco) 525:1-7

Trégouboff G (1942) Contribution à la connaissance des larves planctoniques d'éponges. Arch Zool Exp Gen 82: 357-399 
Tribollet A, Decherf G, Hutchings P, Peyrot-Clausade M (2002) Large-scale spatial variability in bioerosion of experimental coral substrates on the great barrier reef (Australia): Importance of microborers. Coral Reefs 21:424-432

Tribollet A and Golubic S (2005) Cross-shelf differences in the pattern and pace of bioerosion of experimental carbonate substrates exposed for 3 years on the northern Great Barrier Reef, Australia. Coral Reefs 24:422-434

Tribollet A (2008) The boring microflora in modern coral reef ecosystems: A review of its roles. In: Wisshak M and Tapanila L (eds) Current developments in bioerosion. Springer, Berlin, $\mathrm{p}$ 67-94

Tribollet A and Golubic S (2011) Reef bioerosion: Agents and processes. In: Dubinsky Z and Stambler N (eds) Coral Reefs: An Ecosystem in Transition. Springer, Dordrecht p 435-449

UNESCO (2012) Ecological science for sustainable development. Wakatobi. Available at: http://www.unesco.org/new/en/natural-sciences/environment/ecological-sciences/biospherereserves/asia-and-the-pacific/indonesia/wakatobi/ (last accessed 17 June 2017)

Uriz MJ, Turon X, Becerro M, Galera J (1996) Feeding deterrence in sponges. The role of toxicity, physical defenses, energetic contents, and life-history stage. J Exp Mar Biol Ecol 205:187-204

Uriz MJ, Maldonado M, Turon X, Marti R (1998) How do reproductive output, larval behaviour and recruitment contribute to adult spatial patterns in Mediterranean encrusting sponges? Mar Ecol Prog Ser 167:137-148

Uriz MJ, Turon X, Mariani S (2008) Ultrastructure and dispersal potential of sponge larvae: Tufted versus evenly ciliated parenchymellae. Mar Ecol 29:280-297

van Soest RWM (1989) The Indonesian sponge fauna: a status report. Neth J Sea Res 23:223230

van Soest RWM (1994) Demosponge distribution patterns. In: van Soest RWM, van Kempen ThMG, Braekman JC (eds) Sponges in time and space. Balkema, Rotterdam, p 213-224

van Soest RWM, Zea S, Kielman M (1994) New species of Zyzzya, Cornulella, Damiria, and Acheliderma (Porifera: Poecilosclerida), with a review of fistular genera of Iophonidae. Bijdragen tot de Dierkunde 64:163-92

van Soest R, Boury-Esnault N, Hooper JNA, Rützler K, de Voogd NJ, Alvarez de Glasby B, Hajdu E, Pisera AB, Manconi R, Schönberg C, Klautau M, Picton B, Kelly M, Vacelet J, 
Dohrmann M, Díaz MC, Cárdenas P, Carballo JL (2017) World Porifera database (WPD). http://www.marinespecies.org/porifera/index.php (last accessed 15 June 2017)

Vecsei A (2001) Fore-reef carbonate production: Development of a regional census-based method and first estimates. Palaeogeogr Palaeoclimatol Palaeoecol 175:185-200

Vermeij MJ, Van Moorselaar I, Engelhard S, Hörnlein C, Vonk SM, Visser PM (2010) The effects of nutrient enrichment and herbivore abundance on the ability of turf algae to overgrow coral in the Caribbean. PloS One 5:e14312

Veron J, Devantier LM, Turak E, Green AL, Kininmonth S, Stafford-Smith M, Peterson N (2009) Delineating the coral triangle. Galaxea J Coral Reef Stud 11:91-100

Vicente VP (1978) An ecological evaluation of the West Indian Demosponge Anthosigmella varians (Hadromerida: Spirastrellidae). Bull Mar Sci 28:771-779

Vicente V (1990) Response of sponges with autotrophic endosymbionts during the coralbleaching episode in Puerto Rico. Coral Reefs 8:199-202

Villanoy C, David L, Cabrera O, Atrigenio M, Siringan F, Aliño P, Villaluz M (2012) Coral reef ecosystems protect shore from high-energy waves under climate change scenarios. Clim Change 112:493-505

Wahab MA, de Nys R, Whalan S (2011) Larval behaviour and settlement cues of a brooding coral reef sponge. Coral Reefs 30:451-460

Warburton FE (1966) The behavior of sponge larvae. Ecology 47:672-674

Ward P and Risk MJ (1977) Boring pattern of the sponge Cliona vermifera in the coral Montastrea annularis. J Paleontol 51:520-526

Ward-Paige CA, Risk MJ, Sherwood OA, Jaap WC (2005) Clionid sponge surveys on the Florida reef tract suggest land-based nutrient inputs. Mar Pollut Bull 51:570-579

Weisz JB, Massaro AJ, Ramsby BD, Hill MS (2010) Zooxanthellar symbionts shape host sponge trophic status through translocation of carbon. Biol Bull 219: 189-197

West RR (1988) Temporal changes in carboniferous reef mound communities. Palaios 3:152-169

Whalan S, Ettinger-Epstein P, Battershill CN, de Nys R (2008) Larval vertical migration and hierarchical selectivity of settlement in a brooding marine sponge. Mar Ecol Prog Ser 368:145-154 
Whalan S, Webster NS, Negri AP (2012) Crustose coralline algae and a cnidarian neuropeptide trigger larval settlement in two coral reef sponges. PLoS One 7:e30386

Wielgus J, Glassom D, Chadwick NE (2006) Patterns of polychaete worm infestation of stony corals in the northern red sea and relationships to water chemistry. Bull Mar Sci 78:377-388

Wismer S, Hoey A, Bellwood DR (2009) Cross-shelf benthic community structure on the great barrier reef: Relationships between macroalgal cover and herbivore biomass. Mar Ecol Prog Ser 376:45-54

Wilkinson CR (1987) Productivity and abundance of large sponge populations on Flinders reef flats, Coral Sea. Coral Reefs 5:183-188

Wilkinson C (2008) Status of Coral Reefs of the World: 2008. Global Coral Reef Monitoring Network and Reef and Rainforest Research Centre, Australia, Townsville

Willis S, Winemiller K, Lopez-Fernandez H (2005) Habitat structural complexity and morphological diversity of fish assemblages in a neotropical floodplain river. Oecologia 142:284-295

Wilson M (2007) Macroborings and the evolution of bioerosion. In: Miller W (ed) Trace fossils: concepts, problems, prospects. Elsevier, Amsterdam, p 356-367

Wisshak M and Tapanila L (2008) Current developments in bioerosion. Springer, Berlin

Wisshak M, Schönberg CH, Form A, Freiwald A (2012) Ocean acidification accelerates reef bioerosion. PLoS One 7:e45124

Wisshak M, Schönberg CH, Form AU, Freiwald A (2013) Effects of ocean acidification and global warming on reef bioerosion - lessons from a clionaid sponge. Aquat Biol 19:111-127

Wolanski E, Martinez JA, Richmond RH (2009) Quantifying the impact of watershed urbanization on a coral reef: Maunalua Bay, Hawaii. Estuar Coast Shelf Sci 84:259-268

Wood R (1999) Reef evolution. Oxford University Press, Oxford

Wulff JL and Buss LW (1979) Do sponges help hold coral reefs together? Nature 281:474-475

Wulff JL (1984) Sponge-mediated coral reef growth and rejuvenation. Coral Reefs 3:157-163

Wulff JL (2001) Assessing and monitoring coral reef sponges: Why and how? Bull Mar Sci 69:831-846 
Wulff JL (2006) Ecological interactions of marine sponges. Can J Zool 84:146-166

Xavier J, Rachello-Dolmen P, Parra-Velandia F, Schönberg CH, Breeuwer J, van Soest R (2010) Molecular evidence of cryptic speciation in the "cosmopolitan" excavating sponge Cliona celata (Porifera, Clionaidae). Mol Phylogenet Evol 56:13-20

Zea S (1993) Recruitment of Demosponges (Porifera, Demospongiae) in rocky and coral reef habitats of Santa Marta, Colombian Caribbean. Mar Ecol 14:1-21

Zea S and Weil E (2003) Taxonomy of the Caribbean excavating sponge species complex Cliona caribbaea - C. aprica - C. langae (Porifera, Hadromerida, Clionaidae). Caribb J Sci 39:348370

Zea S and Lopez-Victoria M (2016) Cliona acephala (Porifera: Demospongiae: Clionaida), a new encrusting excavating reef sponge from the Colombian Caribbean belonging to the Cliona viridis species complex. Zootaxa 4178:583-592

Zilberberg C, Maldonado M, Solé-Cava A (2006) Assessment of the relative contribution of asexual propagation in a population of the coral-excavating sponge Cliona delitrix from the Bahamas. Coral Reefs 25:297-301

Ziegler M, Roder C, Büchel C, Voolstra CR (2015) Niche acclimatization in Red Sea corals is dependent on flexibility of host-symbiont association. Mar Ecol Prog Ser 533:149-161

Zundelevich A, Lazar B, Ilan M (2007) Chemical versus mechanical bioerosion of coral reefs by boring sponges - lessons from Pione cf. vastifica. J Exp Biol 210:91-96 


\section{Appendices}

\subsection{Appendix 1}

Results of bivariate correlations (Spearman's Rank, $r_{s}$ ) comparing the standardised abundance of individual species of bioeroding sponges with environmental factors. Only the three most dominant species are shown. Significant correlations are displayed in bold. Analyses were conducted with and without the inclusion of data for the outlier site Sampela 1.

\section{Factor}

\section{Sampela included}

$\mathbf{P}$

Depth of settled sediment

$\begin{array}{llll}\mathbf{- 0 . 2 4 8} & \mathbf{0 . 0 2 3} & \mathbf{- 0 . 3 4 3} & \mathbf{0 . 0 0 3} \\ -0.078 & 0.480 & 0.125 & 0.296 \\ \mathbf{0 . 2 6 0} & \mathbf{0 . 0 1 7} & \mathbf{0 . 6 0 1} & <\mathbf{0 . 0 0 1}\end{array}$

\section{Cliothosa cf. aurivillii \\ Cliona aff. viridis n. sp. B \\ Spheciospongia $\mathrm{cf}$. vagabunda}

Water movement

$$
0.06
$$

$-0.148$

$-\mathbf{0 . 4 3 8}$ vagabunda

Turbidity
Cliothosa cf. aurivillii

Cliona aff. viridis n. sp. B

Spheciospongia $\mathrm{cf}$. vagabunda

Chl $a$

$\begin{array}{llll}\mathbf{r}_{\mathrm{s}} & \mathbf{P} & \mathbf{r}_{\mathrm{s}} & \mathbf{P}\end{array}$




\subsection{Appendix 2}

Aim

My aim was to test the hypothesis that erosion rates in Spheciospongia cf. vagabunda are reduced by excessive sedimentation. My objective was to expose ex situ sponge grafts/blocks to a sediment regime comparable to Sampela for 45 days and infer erosion rates in comparison to non-sediment exposed sponge grafts/blocks.
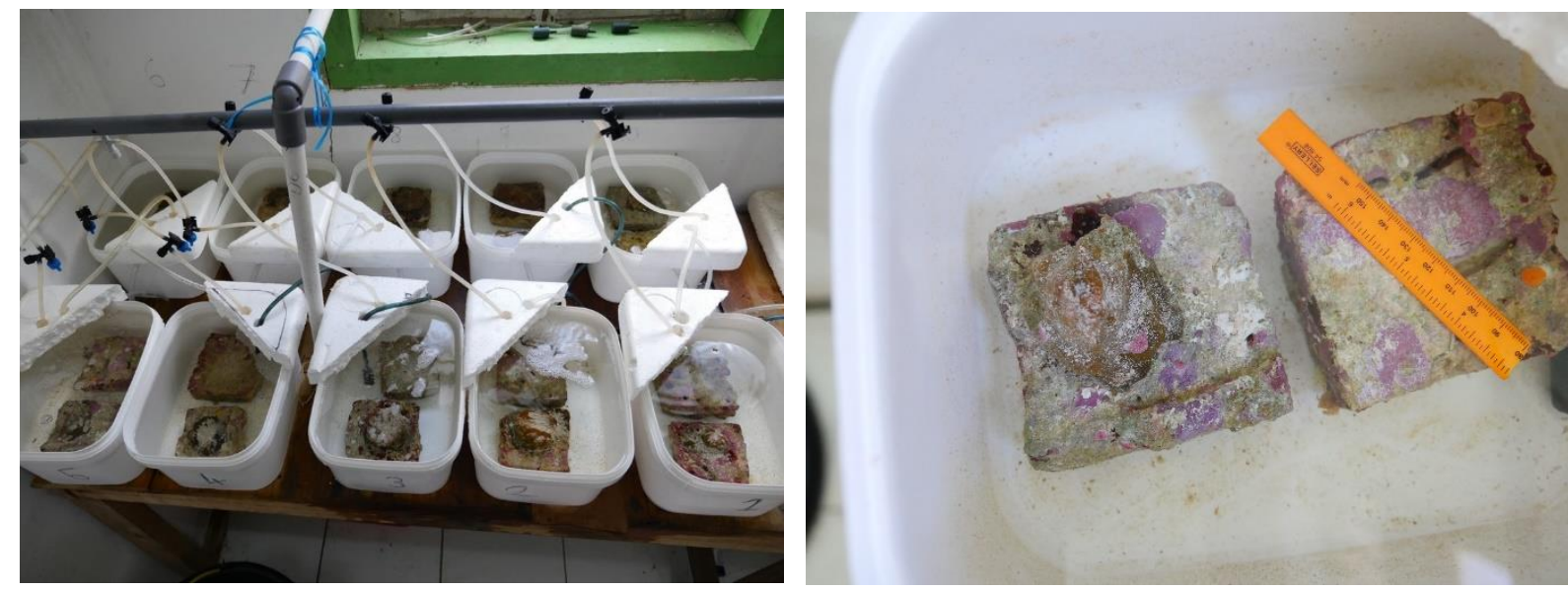

Figure 1. Ten aquaria with paired blocks (left) and example image of sponge block and control block within sediment treatment aquaria (right).

\section{Methods}

In August 201532 calcareous blocks were attached to the B3 reef at $10 \mathrm{~m}$ depth using marine epoxy. Half had attached grafts S. cf. vagabunda, half were left as controls. In May 201610 blocks with surviving grafts and 10 controls were retrieved. Each block was buoyant-weighed using digital scales (Ohaus STX422, Greifensee) in an underhanging basket immersed in an aquaria. Blocks were then placed in ten flow-through aquaria, one sponge block and one control block in each. Over the course of 45 days sediment was added daily to half the aquaria and half were left as controls (Fig.1). Sediment was collected from Sampela, rinsed in freshwater and dried for $24 \mathrm{hrs}$ at $180{ }^{\circ} \mathrm{C}$ before application in treatments. The amount of sediment added to each treatment was based on individual sponge surface area in relation to average daily sedimentation rates at Sampela (2015 sediment trap data): $3.5 \mathrm{mg} \mathrm{cm}^{-2} \mathrm{day}^{-1} ; 20 \%>250 \mu \mathrm{m}$, 
$20 \% 125-250 \mu \mathrm{m}, 40 \%$ 63-125 $\mu \mathrm{m}$ and 20\% 38-63 $\mu \mathrm{m}$. Control blocks within treatment aquaria were treated with the same amount of sediment as their reciprocal sponge block. After 45 days all blocks were reweighed using buoyant weight. Erosion rates were estimated in terms of $\mathrm{kg} \mathrm{m}^{-2}$ sponge tissue $\mathrm{yr}^{-1}$ based on surface area at the end of the experimental period and in relation to their paired control block.

\section{Results}

Seventeen of the blocks gained weight over the experimental period (average $0.52 \mathrm{~g} \pm 0.07 \mathrm{SE}$ ) and three lost weight (average $-0.47 \mathrm{~g} \pm 0.03 \mathrm{SE}$ ). Sponge blocks in the sediment treatment gained an average of $0.36 \mathrm{~g}( \pm 0.07 \mathrm{SE})$, while their reciprocal non-sponge control blocks gained an average of $0.72 \mathrm{~g}( \pm 0.16 \mathrm{SE})$. In the control aquaria sponge blocks gained an average of $0.36 \mathrm{~g}$ $( \pm 0.25 \mathrm{SE})$ and non-sponge control blocks gained an average of $0.06 \mathrm{~g}( \pm 0.23 \mathrm{SE})$. This equated to average erosion rates in the sediment treatment $S$. cf. vagabunda of $1.4 \mathrm{~kg} \mathrm{~m}^{-2}( \pm 0.6 \mathrm{SE})$ sponge tissue $\mathrm{yr}^{-1}$ based, control sponge blocks actually gained $1.151 .4 \mathrm{~kg} \mathrm{~m}^{-2}$ sponge tissue $\mathrm{yr}^{-1}$ $( \pm 0.79 \mathrm{SE})$.

\section{Discussion}

The difference in erosion rates between the treatments was in direct contrast to the results from the in situ erosion study. However, I do not believe that these are ecologically relevant results but instead a consequence of greater erosion by non-sponge endolithic bioeroders (e.g. polychaetes and molluscs) in the non-sponge blocks in the control aquaria. This hypothesis is supported by the buoyant weight data and visual observations of bioerosion (sediment production) in some of these blocks during the experimental period. Significantly greater replication and a longer experimental period would resolve this source of error. 
